\title{
WestVirginiaUniversity
}

THE RESEARCH REPOSITORY @ WVU

Graduate Theses, Dissertations, and Problem Reports

2007

\section{Propanil (3,4-DCPA)-induced alterations of macrophage function}

Irina V. Ustyugova

West Virginia University

Follow this and additional works at: https://researchrepository.wvu.edu/etd

\section{Recommended Citation}

Ustyugova, Irina V., "Propanil (3,4-DCPA)-induced alterations of macrophage function" (2007). Graduate Theses, Dissertations, and Problem Reports. 4345.

https://researchrepository.wvu.edu/etd/4345

This Dissertation is protected by copyright and/or related rights. It has been brought to you by the The Research Repository @ WVU with permission from the rights-holder(s). You are free to use this Dissertation in any way that is permitted by the copyright and related rights legislation that applies to your use. For other uses you must obtain permission from the rights-holder(s) directly, unless additional rights are indicated by a Creative Commons license in the record and/ or on the work itself. This Dissertation has been accepted for inclusion in WVU Graduate Theses, Dissertations, and Problem Reports collection by an authorized administrator of The Research Repository @ WVU.

For more information, please contact researchrepository@mail.wvu.edu. 
Propanil (3,4-DCPA)-induced alterations of macrophage function

\author{
Irina V. Ustyugova \\ Dissertation submitted to the School of Medicine \\ at West Virginia University \\ in partial fulfillment of the requirements \\ for the degree of \\ Doctor of Philosophy \\ in \\ Immunopathology and Microbial Pathogenesis
}

John B. Barnett, Ph.D., Chair

Kathleen M. Brundage, Ph.D.

Rosana Schafer, Ph.D.

Mark J. Reasor, Ph.D.

Weixin Wang, Ph.D.

Department of Microbiology, Immunology and Cell Biology

Morgantown, West Virginia

2007

Keywords: 3,4-dichloropropionanilide, propanil, macrophage, inflammatory mediators

Copyright 2007 Irina V. Ustyugova 


\section{ABSTRACT \\ Propanil (3,4-DCPA)-induced alterations of macrophage function}

\section{Irina V. Ustyugova}

The pesticide 3,4-dichloropropionanilide (propanil or alternatively, DCPA) is a postemergent herbicide predominantly used for the control of weeds on commercial rice crops worldwide. The US Environmental Protection Agency report on "Pesticides Industry Sales and Usage in 2001 " ranked propanil as the $17^{\text {th }}$ most used herbicide in the US. It is applied on the fields via groundboom sprayers or aerial equipment suppressing photosynthesis and carbon fixation of a growing plant. The primary target of herbicide exposure is personnel working in the manufacturing and application who are required to wear personal protective equipment to minimize the exposure. The common routes of this exposure are inhalational and dermal, and to a lesser extent, oral. A number of toxic side effects are induced by propanil include hemolytic anemia, methemoglobinemia, and myelotoxicity. The majority of current knowledge about propanil's toxic effects comes from animal studies. Liver and spleen were found to be the primary target organs, with many cell populations of the immune system affected, including $\mathrm{T}$ and B lymphocytes, NK cells and macrophages.

Macrophages play essential roles in both innate and adaptive immune responses. They recognize and destroy pathogens through phagocytosis and generation of reactive oxygen and nitrogen species (ROS and RNS). Macrophages can also function as antigen presenting cells in the initiation of an adaptive immune response and secrete a number of cytokines and inflammatory mediators thereby modulating the immune reaction at the inflamed site.

Previous studies have demonstrated that propanil was able to suppress interleukin (IL)$1 \beta$, IL- 6 and TNF- $\alpha$ cytokine production by LPS-activated murine macrophages. The analysis of nuclear factor $-\kappa \mathrm{B}(\mathrm{NF}-\kappa \mathrm{B})$, responsible for $\mathrm{TNF}-\alpha$ production, detected a decreased nuclear localization of NF- $\kappa \mathrm{B}$ accompanied by a reduced, but not entirely abrogated binding to DNA activity.

The first study of this dissertation demonstrated the ability of propanil to inhibit TNF- $\alpha$ production by LPS-stimulated human monocytic cells line and suppress phagocytosis of fluorescent beads and Listeria monocytogenes. The ability to directly kill this bacterium and produce ROS and RNS was also assessed. The results demonstrate that DCPA has profound effects on macrophage function, and provide insight into the potential mechanisms of immunosuppression by DCPA. The second study focused on the mechanism of dramatic suppression of an inflammatory mediator secreted by activated macrophages, prostaglandin $\mathrm{E}_{2}$ $\left(\mathrm{PGE}_{2}\right)$. Enzymatic activity and expression level of the proteins involved in $\mathrm{PGE}_{2}$ production were studied. However, the exact mechanism of propanil's action is still unknown. The third study describes a novel behavior on NF- $\kappa \mathrm{B}$, called oscillations, in continuously LPS-stimulated macrophages. Binding activity of NF- $\mathrm{KB}$ was studied by two independent methods, and a mathematical model describing the oscillatory behavior was created based on experimental data. It demonstrated that propanil exposure potentiated the NF- $\kappa \mathrm{B}$ activation process changing the oscillation behavior which could influence the transcription activity of the NF- $\kappa \mathrm{B}$-inducible genes.

Taken together our findings indicate that propanil exposure affects a number of important macrophage functions, such as phagocytosis, ROS and RNS production and inflammatory mediator's secretion. Our studies also demonstrated a potential mechanism for the inhibition of 
a number of inflammatory cytokines through changes in NF- $\kappa \mathrm{B}$ binding activity and oscillatory behavior. 


\section{DEDICATION}

I would like to dedicate this dissertation to my parents, Elena and Vladimir, who believed in me and encouraged me to pursue a career of scientist. They taught me to be persistent, honest and patient. Another person who stood by me for all these years of graduate school is Jawad, I dedicate my dissertation to him. 


\section{ACKNOWLEDGMENTS}

I gratefully acknowledge the help and support of my advisor, John Barnett, whose knowledge, experience and enthusiasm gave me strength and energy to complete this work. I thank Kathleen Brundage and Rosana Schafer for their help in daily work in the laboratory. I also would like to acknowledge Mark Reasor and Weixin Wang for their input in my research and advices throughout my graduate carrier. I would like to thank Cheryl Walton for her technical help and support she provided me over the years. Lastly, I would like to acknowledge my fellow lab members and graduate students Keith Salazar, Alexander Rowe, Tricia Lewis and Miranda Hanson. 


\section{TABLE OF CONTENTS}

$\begin{array}{ll}\text { Abstract } & 1\end{array}$

Chapter 1. Literature Review 1

I. Propanil (3,4-DCPA) 1

$\begin{array}{ll}\text { II. Macrophage differentiation and activation } & 11\end{array}$

Table 1. Tissue-specific macrophage populations 12

$\begin{array}{ll}\text { Table 2. Monocyte migration } & 13\end{array}$

Table 3. Secretory products generated by activated macrophages $\quad 14$

$\begin{array}{ll}\text { Figure 1. LPS signaling } & 16\end{array}$

Table 4. Macrophage activation 17

$\begin{array}{lr}\text { III. Inflammatory mediators } & 18\end{array}$

$\begin{array}{ll}\text { Figure 2. ROS and RNS generation } & 19\end{array}$

$\begin{array}{ll}\text { Figure 3. Prostaglandin production } & 21\end{array}$

IV. Activation of signaling pathways 23

Figure 4. NF- $\kappa$ B activation pathway 23

Figure 5. NF- $\kappa \mathrm{B}$ protein structure $\quad 24$

Figure 6. I $\mathrm{B} \alpha$ protein structure $\quad 24$

$\begin{array}{ll}\text { Summary } & 30\end{array}$

$\begin{array}{ll}\text { References } & 32\end{array}$

Appendix 1. A review of the immunotoxicity of the pesticide 3,4- 47 dichloropropionanalide

$\begin{array}{ll}\text { Abstract } & 48\end{array}$

Introduction 49 
Immunotoxicity $\quad 54$

Innate immunity $\quad 56$

Adaptive Immunity 61

Thymic atrophy and T cell function $\quad 62$

B cell toxicity and the humoral immune response $\quad 67$

Adaptive immune response to bacteria $\quad 69$

$\begin{array}{ll}\text { Future Studies and Conclusions } & 72\end{array}$

$\begin{array}{ll}\text { Acknowledgements } & 74\end{array}$

$\begin{array}{ll}\text { References } & 75\end{array}$

Table 1. Summary of the in vivo and in vitro effects of 82 propanil on natural killer cells and macrophages

Table 2. Summary of the in vivo immunotoxicity of 84 propanil on $\mathrm{T}$ cell functions of the adaptive immune system

Table 3. Summary of the in vivo immunotoxicity of 85 propanil on B cell functions of the adaptive immune system

\section{Chapter 2. 3,4-Dichloropropionaniline suppresses normal macrophage 86}

\section{function}

$\begin{array}{ll}\text { Abstract } & 87\end{array}$

$\begin{array}{ll}\text { Introduction } & 88\end{array}$

$\begin{array}{ll}\text { Materials and Methods } & 91\end{array}$

$\begin{array}{ll}\text { Results } & 98\end{array}$

Figure 1. TNF- $\alpha$ production by differentiated THP-1 cells. $\quad 100$

Figure 2. Phagocytic abilities are reduced by DCPA. 102 
Figure 3. DCPA reduces listericidal activity of macrophages. 104

Figure 4. DCPA reduces respiratory burst activity. 106

Figure 5. DCPA reduces ROS production by macrophages. 108

Figure 6. DCPA inhibits nitrite production. 110

Figure 7. DCPA inhibits iNOS protein expression. 112

$\begin{array}{ll}\text { Discussion } & 113\end{array}$

$\begin{array}{lr}\text { Acknowledgments } & 118\end{array}$

$\begin{array}{ll}\text { References } & 119\end{array}$

Chapter 3. 3,4-Dichloropropionaniline (DCPA) inhibits PGE production 128 by mouse peritoneal macrophages

$\begin{array}{lr}\text { Abstract } & 129\end{array}$

$\begin{array}{lr}\text { Introduction } & 130\end{array}$

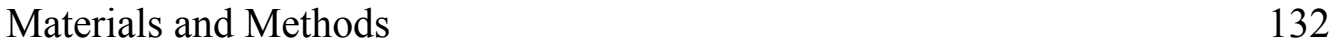

$\begin{array}{ll}\text { Results } & 136\end{array}$

Figure 1. DCPA inhibits $\mathrm{PGE}_{2}$ production in a dose dependent 137 manner.

Figure 2. CAY10404 inhibits PGE2 production and COX enzyme 139 activity.

Figure 3. DCPA does not affect in vitro COX isozymes activity. 141

Figure 4. DCPA does not affect COX-2 protein expression. 143

Figure 5. DCPA does not affect ${ }_{\mathrm{c}} \mathrm{PLA}_{2}$ protein phosphorylation. 145

Table1. Ear inflammation model. 147

$\begin{array}{ll}\text { Discussion } & 148\end{array}$

$\begin{array}{lr}\text { References } & 152\end{array}$ 
Chapter 4. Modulating Temporal Control of NF-kappaB Activation: 157

\section{Implications for Therapeutic and Assay Selection}

$\begin{array}{lr}\text { Abstract } & 158\end{array}$

$\begin{array}{ll}\text { Introduction } & 159\end{array}$

$\begin{array}{ll}\text { Materials and Methods } & 161\end{array}$

Figure 1. Schematic diagram of mathematical model developed 165

to represent the initial activation of NF- $\mathrm{BB}$.

Table 1. List of variables and parameters for NF- $\mathrm{BB}$ activation model.

Results

Figure 2. Biochemical measurement of oscillations in LPS-

170

stimulated IC-21 macrophages persists following DCPA treatment.

Figure 3. Modeling the potentiation by DCPA of the early activation of NF- $\kappa$ B in IC-21 macrophages following LPS stimulation.

Figure 4. Analysis of the NTFA and EMSA residuals to construct 176 appropriate error models.

Discussion

Figure 5. The dynamic activation of NF- $\kappa \mathrm{B}$ in macrophage compared against prior studies using fibroblasts.

$\begin{array}{lr}\text { Acknowledgements } & 183\end{array}$

$\begin{array}{ll}\text { References } & 184\end{array}$

$\begin{array}{lr}\text { Supporting Information } & 188\end{array}$

Table S1: Correlation coefficients of model parameters and initial 190 concentration of NF- $\mathrm{\kappa B}$ in cytosol.

Figure S1: Frequency of parameter values for the strength

191 parameter $\alpha$ determined via bootstrap resampling of the EMSA residuals.

Figure S2: Frequency of parameter values for the strength parameter $\alpha$ determined via bootstrap resampling of the NTFA residuals. 
References

Chapter 5. General Discussion

References

204 


\section{CHAPTER 1.}

\section{LITERATURE REVIEW}

\section{Propanil}

\section{General Usage}

Propanil (3,4-dichloropropionanilide) is a post-emergent herbicide used for the selective post-emergent control of grass-type weeds in rice, barley, oats and spring wheat crops. In the United States (US) the vast majority of propanil (99\%) is applied on rice crops and the remaining $1 \%$ is applied on other small grains. Approximately 7 million pounds of propanil are used annually to treat 2 million acres of agricultural land. The US Environmental Protection Agency (U.S. EPA) estimates that approximately $50-70 \%$ of rice crops in California and the midsouthern states (Arkansas, Louisiana, Missouri, Mississippi and Texas) are treated with propanil (U.S.EPA, 2002a). A recent EPA report on "Pesticides Industry Sales and Usage" ranked propanil as the $17^{\text {th }}$ most used herbicide in the US (U.S. EPA, 2004). Its usage is restricted to agricultural areas only. The application on the fields is conducted via groundboom sprayers or aerial equipment.

Propanil is available in different formulations with various concentrations of active ingredient ranging from $16.6-58 \%$ in emulsifiable concentrate liquid, up to $59.6-81 \%$ in a water dispersable granule. Other formulations, such as a soluble concentrate liquid and a flowable concentrate are also available. The maximum application rate for rice during a growing season is $8 \mathrm{lbs}$ of active ingredient (a.i.) per acre (A), which is applied in two 4 lbs a.i./A applications. The first application is made 15 days after planting the rice and requires an average temperature of $70^{\circ} \mathrm{F}$ to be effective. Two days later, the rice field is flushed (the temporary flood). A second treatment is applied 21-30 days later and the field is flooded again (the permanent flood) and 
stays flooded for 40-60 days. Approximately 90 days following the permanent flood, the rice is mechanically harvested (U.S. EPA, 2002a).

Small grains are also treated with propanil, however, a lower concentration of $1.4 \mathrm{lbs}$ a.i./A is used. In order to prevent residue accumulation and propanil incorporation into the grains, the use of the herbicide after $4 / 5$ leaf stage is prohibited (EPA, 2002a).

\section{Mode of action}

Propanil is a contact herbicide, applied on growing plants. It acts primarily in the leaves. Upon application it is moved from the leaves to the growing shoots, then back to other leaves. Higher plants, such as rice, can inactivate propanil by hydrolyzing it into 3,4-dichloroaniline (DCA) and propionic acid by an enzyme called acylamidase (Adachi, 1966; Ishizuka and Mitsui, 1966). Studies by Still and Kuzirian (1967) demonstrated that tissue homogenates and enzyme preparations from leaves of susceptible plants had much lower acylamidase activity than rice plants. As a result, barnyard grass exhibits an overall growth inhibition within $24 \mathrm{hr}$ after the spraying with propanil (Matsunaka, 1968).

The principal mode of propanil's action is an inhibition of photosynthesis and carbon dioxide fixation (Matsunaka, 1968). In plants photosynthesis occurs in two stages. In the first phase light-dependent reactions or photosynthetic reactions capture the energy of light and use it to make high-energy molecules. During the second phase, the light-independent reaction uses the high-energy molecules to capture carbon dioxide and make the precursors of carbohydrates. In the light reaction one molecule of the pigment chlorophyll absorbs one photon and loses one

electron. This electron starts the electron transport chain reaction that leads to the reduction of NADP (nicotinamide adenine dinucleotide phosphate) into reduced NADPH. In addition, it 
serves to create a photon gradient across the chloroplast membrane; its dissipation is used for adenosine 5'-triphosphate (ATP) synthesis, source of energy (reviewed in Calvin, 1989). Propanil inhibits the electron transport chain reaction and carbon fixation resulting in overall growth inhibition of the plant (Bartha and Pramer, 1970).

\section{Metabolism in the Environment}

The half-life of propanil in soil is 1 to 3 days where it is likely to be rapidly degraded by microorganisms. Bacteria expressing acylamidase enzyme hydrolyze propanil to DCA and propionic acid, in a manner similar to plants. Propionic acid, in turn, is metabolized by soil microorganisms to carbon dioxide and water (Bartha and Pramer, 1970). Pseudomonas strists and Fusarium solani are able to convert propanil to its metabolites in soil (Bartha and Pramer, 1970).

In water under aerobic conditions the half-life ( $(1 / 2)$ of propanil is estimated to be 2 days, and under anaerobic conditions the $t^{1} / 2$ is up to 3 days (Wauchope et al., 1992). In experiments where $50 \mathrm{ppm}$ of propanil were added to dark non-sterile water, no traces of herbicides were found $120 \mathrm{hr}$ after treatment. Pseudomonas putida and Streptococcus avium in the water sample were presumed to be as the bacteria responsible for this breakdown of the propanil (Zeyer and Kearney, 1984).

The U.S. Geological Survey National Water Quality Assessment Program (NAQWQA) reported the presence of propanil in $2.6 \%$ of the 1560 water samples from 62 agricultural streams. The maximum concentration of propanil found was $2.05 \mathrm{ppb}$. Its metabolite, DCA, was detected in 68 samples out of 219 samples obtained from creeks, bayouts and rivers in the 
states of Mississippi, Missouri, Tennessee, Arkansas and north Louisiana. DCA concentration was measured as $8.9 \mathrm{ppb}$ (EPA, 2002b).

Propanil is classified as a medium mobility compound for sand, sandy loam, and clay loam soils. Aquatic field dissipation studies demonstrated that the parent compound and its major metabolite (DCA) were associated generally with the sediment rather with the aqueous phase. Residues were detected to the top 2 inches of the sediment (U.S.EPA, 2003). These data suggest that propanil could possibly reach groundwater, but due to fast degradation by microorganisms, it does not accumulate.

However, monitoring of a groundwater contamination in the states of California, Arkansas, Missouri and Mississippi demonstrated the presence of propanil, but as expected, at lower levels than that present in surface water samples. Only 2 wells out of 124 tested in Missouri contained propanil (0.06-0.07 ppb), placing groundwater exposure at lower risk (U.S. EPA, 2002b). The amount of propanil and DCA found in surface water ranges from 6 to 72 $\mu \mathrm{g} / \mathrm{L}$. Chronic exposure to propanil over the course of a person's life time is called "a drinking water level of comparison" (DWLOC). It describes the safe level of chronic exposure to a certain contaminant. DWLOC should be higher than the environmentally occurring dose of pesticide. For adults, DWLOC is set at $86-100 \mu \mathrm{g} / \mathrm{L}$, which is higher then $6-72 \mu \mathrm{g} / \mathrm{L}$ range. For children of 1-6 years of age, DWLOC is lower, $26 \mu \mathrm{g} / \mathrm{L}$, which falls into the range of environmentally occurring exposure $(6-72 \mu \mathrm{g} / \mathrm{L})$ and raises a concern for water consumption by children of this age group (U.S. EPA, 2002b). 


\section{Routes of Exposure}

The primary target of herbicide exposure is personnel working in manufacturing and application. Occupational risk to workers was assayed by the EPA, mixers and loaders, applicators (drivers, pilots), crop advisors (scouts), hoers and irrigators are the groups primarily exposed. Personal protective equipment (PPE) is required to be worn during herbicide handling to minimize the exposure. PPE for propanil handling includes long sleeve shirt, long pants, waterproof gloves, shoes, socks and protective eye wear. Workers can be exposed to propanil residues by entering previously treated areas. For these cases a restricted-entry interval (REI) was established to minimize the exposure, and the current REI for propanil is 24 hours (U.S. EPA, 2003).

The major common routes of occupational exposure to propanil are inhalational and dermal which places propanil into category IV for acute toxicity via those two routes. Oral exposure is less common with toxicity category of III. No dermal sensitization was observed, however primary eye irritation in rabbits was detected (toxicity category II). No carcinogenic or mutagenic capabilities have been described for propanil so far. EPA has classified propanil into the category "Suggestive evidence of carcinogenic potential by all routes of exposure, but not sufficient to assess human carcinogenic potential. "(U.S. EPA, 2002a).

\section{Metabolism and Pharmocokinetics}

In the mammalian body, propanil rapidly undergoes metabolic conversion by acylamidase enzyme into 3,4-dichloroaniline (DCA) in the liver. Other metabolites of propanil are 2-hydroxypropanil and 6-hydroxypropanil (McMillan et al., 1990a). DCA can be Nhydroxylated and undergo rapid redox cycling within the erythrocytes, resulting in the oxidation 
of $\mathrm{Fe}^{2+}$ in hemoglobin to $\mathrm{Fe}^{3+}$, forming methemoglobin (MetHb). MetHb can not bind $\mathrm{O}_{2}$ and therefore the $\mathrm{O}_{2}$ carrying capacity of the blood in decreased (McMillan et al., 1990a). The resulting methemoglobinemia causes the development of hemolytic anemia, which is characterized by decreases of hemoglobin, red blood cell (RBC) count, and packed cell volume. RBC's histopathological evaluation revealed the presence of Heinz bodies and hemosiderin deposits in the spleen and kidneys (U.S. EPA, 2002b). Not only propanil but its metabolites, 2hydroxypropanil and 6-hydroxypropanil, were found to cause methemoglobinemia and hemolytic anemia (McMillan et al., 1990a; McMillan et al., 1991b).

Experimental data on acute toxicity suggested that the timing of anemic effects in Sprague-Dawley rats was dependent on a propanil dose. Rats treated with $300 \mathrm{mg} / \mathrm{kg}$ propanil demonstrated a peak in MetHb formation at 4.5 hours after treatment. Presence of MetHb was detectable for $24 \mathrm{hr}$ following exposure. A lower dose of $100 \mathrm{mg} / \mathrm{kg}$ resulted in maximum $\mathrm{MetHb}$ formation by 1.5 hours and was detectable for $12 \mathrm{hrs}$, demonstrating transient presence of propanil in the blood (McMillan et al., 1990b).

Studies on pharmacokinetics of propanil in Sprague-Dawley rats demonstrated that the majority of herbicide (78-90\%) was excreted in the urine and $2-13 \%$ in the feces. A single oral dose of $2.5 \mathrm{mg} / \mathrm{kg}$ was eliminated from the body within $24 \mathrm{hrs}$ (U.S. EPA, 2002b). The rapid elimination of propanil from the body does not raise a concern of tissue and organs accumulation.

\section{Acute and Chronic Toxicity}

Currently, a number of animal studies describing acute and chronic toxicity of propanil exposure are available. The reported $\mathrm{LD}_{50}$ value for oral propanil exposure in rats ranges from 
$1080 \mathrm{mg} / \mathrm{kg}$ and up to $2500 \mathrm{mg} / \mathrm{kg}$ (U.S. National Library of Medicine. Hazardous Substances Databank, 1995). The initial signs of distress were impaired coordination of movements, CNS depression and cyanosis of the ears and skin. Death of an animal occurred within 3-day period (Singleton and Murphy, 1973). Propanil is practically nontoxic via the dermal route, with a reported $\mathrm{LD}_{50}$ of greater than $5000 \mathrm{mg} / \mathrm{kg}$ in rabbits, but it is moderately toxic via the inhalation route, with a reported 4-hour $\mathrm{LC}_{50}$ of $1.12 \mathrm{mg} / \mathrm{L}$ (Stevens et al., 1991).

Chronic propanil exposure in a two-year rat study where animals were fed $80 \mathrm{mg} / \mathrm{kg} / \mathrm{day}$ demonstrated a decrease in overall growth and a relative increase in the weight of the spleen and liver in female rats and of the testes in males. A higher dose of $240 \mathrm{mg} / \mathrm{kg} /$ day given to mice for a 90-day period also caused increases in liver and spleen weights, cyanosis and methemoglobinemia. Histopathological analysis of liver and spleen in mice revealed incidences of necrotic lesions (Ambrose et al., 1972). A shorter 3-week study in rats with $180 \mathrm{mg} / \mathrm{kg} / \mathrm{day}$ exposure also demonstrated a reduction in feed consumption, growth, and hemoglobin levels. Altogether, these data demonstrate that spleen and liver are target organs for short- and longterm propanil exposure.

\section{Human exposure to propanil}

Limited studies on propanil toxicity demonstrated a number of symptoms caused by exposure to herbicide during its manufacturing. Factory workers who were exposed through dermal and inhalational route developed a number of symptoms, including acne, rash/skin irritation, eye irritation and cyanosis. $11(11 \%)$ of 102 workers have been hospitalized for illness related to chemical exposure and were diagnosed with methemoglobinemia (Morse et al., 1979). 
People living next to the rice crops can also be exposed to propanil as a result of drift where wind speed, direction and distance from the field are important (McClure et al., 2001). However, the levels of drifted herbicide originating from the treated fields were $10^{6}$ lower than the $\mathrm{LC}_{50}$ established in a rat inhalation model (Barnes et al., 1987). Another two-year study analyzed the blood samples from children and adults living within 125 meters of the rice field. Blood samples collected at three time intervals: preseason, prior to propanil application, 5-7 days after spraying and postseason, following harvest. Samples were analyzed for changes in the percentages of leukocytes, leukocyte cell numbers, their ability to proliferate in response to mitogen stimulation, as well as cytokine production and natural killer cell (NK) activity. None of the parameters measured in the families living adjacent to the fields were different from unexposed control families (McClure et al., 2001). These studies did not detect changes in the immune parameters of exposed people but the fact that propanil's metabolites can be detected in the body months later after the exposure raise a great concern.

The major metabolite of propanil, DCA, has been found to form hemoglobin adducts in humans (Pastorelli et al., 1998). DCA reacts with hemoglobin, producing a stable adduct which can be detected by gas chromatography-mass spectrometry (GC-MS) as an indicator of exposure (Sabbioni and Neumann, 1990; Pastorelli et al., 1995). Two agricultural workers were tested before, within 2 days and 4 months after the exposure. The detectable levels of DCAhemoglobin adducts were observed not only 2 days after exposure (36-fold increase), but 4 months later (4-fold increase) compared to background levels. Urine samples collected at 2 days after exposure varied from 1.07 to $3.5 \mathrm{nmol} / \mathrm{ml}$ of urine. No detectable levels of DCA were found in the urine at 4 months after the exposure, thus hemoglobin adduct detection are a better marker for herbicide exposure (Pastorelli et al., 1998). 
DCA is a common metabolite of several herbicides used in agriculture. Detection of DCA in the urine of non-occupationally exposed people living in a rural area of central Italy was an indicator of exposure to a panel of herbicides, including propanil. 125 people (87.1\%) out of 153 tested had DCA detected in their urine ranging from 0.01 to $6.19 \mu \mathrm{g} / \mathrm{L}$ (Turci et al., 2001). Another study of 5 non-occupationally exposed people, reported the urine levels of DCA of 0.11-0.56 $\mu \mathrm{g} / 1$ (Wittke et al., 2006). This demonstrates that even non-occupationally exposed populations carry low levels of propanil's metabolite in the body which raises a concern for people living in agricultural areas.

\section{Immunotoxicity}

The effects of propanil on a number of immune organs and responses have been studied intensively in mouse and rat models. Acute in vivo exposure of mice to $400 \mathrm{mg} / \mathrm{kg}$ of propanil causes a significant inhibition of contact hypersensitivity response (CHR), blastogenic response to T- and B-cell-specific mitogens, antibody response sheep red blood cells (SRBC), as well as mixed lymphocyte reaction (MLR). A significant reduction in the thymus weight and an elevated absolute weight and relative spleen weight were measured in animals treated with 200 and $400 \mathrm{mg} / \mathrm{kg}$ of herbicide (Barnett and Gandy, 1989). DCA at a dose of $150 \mathrm{mg} / \mathrm{kg}$ also causes a significant increase in spleen weight and cellularity, but has minimal effects on the T-cell dependent antibody response or cytotoxic T cell lymphocyte (CTL) activity. Both propanil and DCA impaired NK cell functions at doses of $100 \mathrm{mg} / \mathrm{kg}$ and $75 \mathrm{mg} / \mathrm{kg}$ respectively (Barnett et al., 1992). Overall, immunotoxicity of propanil results in suppression of T-dependent and Tindependent antibody responses, major changes in primary (thymus) and secondary (spleen) lymphoid organs, which affects many cell populations of immune system such as $\mathrm{T}$ and $\mathrm{B}$ 
lymphocytes, NK cells and macrophages. More details on the immunotoxicity of propanil are described in the review submitted to Journal of Toxicology and Environmental Health Part B (Appendix 1).

\section{Innate immunity}

The innate immune system provides the first line of defense against invading pathogens through physical barriers such as the skin and mucous membranes, chemical barriers such as enzymes and $\mathrm{pH}$, and a range of cell types including monocytes, macrophages, polymorphonuclear monocytes $(\mathrm{PMN})$, and natural killer cells $(\mathrm{NK})$. The innate immune system is responsible for not only rapidly eliminating pathogens, but also initiating adaptive immune responses through cell adhesion molecules and cytokines. Immunotoxic effects on cells of the innate immune system could therefore compromise both the ability of an organism to control initial infections and to generate an appropriate protective adaptive immune response. There are limited studies that examined the effect of propanil on NK cell function. More extensive studies have been conducted to characterize the immunotoxic effects of propanil on macrophages and on their function, as detailed below. 


\section{Macrophage differentiation and activation}

\section{Macrophage development}

Macrophage development takes place in the bone marrow and passes through the following steps: hematopoietic stem cell (HSC) $\rightarrow$ committed stem cell (granulocyte/macrophage-restricted progeny) $\rightarrow$ monoblast $\rightarrow$ pro-monocyte $\rightarrow$ monocyte (bone marrow) $\rightarrow$ monocyte (peripheral blood) $\rightarrow$ macrophage (tissue) (reviewed in Gordon and Taylor, 2005). The initial stages of hematopoeisis in the bone marrow proceeds rapidly within 1.5-3 days. The progression from HSC to committed progenitor is controlled by interleukin (IL)3, a growth factor for myeloid-restricted progeny. These IL-3-responsive progenitors will differentiate and become responsive to granulocyte/macrophage-colony stimulating factor (GM$\mathrm{CSF}$ ) and macrophage-CSF (M-CSF), giving rise to granulocyte/macrophage-restricted progeny. GM-CSF and M-CSF are the major growth factors responsible for continued proliferation and viability of macrophage precursors in the bone marrow (reviewed in Gordon and Taylor, 2005).

The blood monocyte, the next developmental stage, circulate in the blood up to 70 hours and comprise between 1-6\% of the circulating leukocytes (Whitelaw D.M., 1966). They possess chemotactic and migratory activities and express receptors for IgG Fc-domains (Fc $\gamma \mathrm{R})$ and iC3b complement (Fearon, 1983; McKenzie and Schreiber, 1998). Monocytes are able to cross the endothelial barrier using selectins, integrins and other receptors of the immunoglobulin superfamily. Upon migration into the tissues they undergo further differentiation to become multifunctional tissue macrophages. Depending on the tissue type that the macrophage resides in, the different populations are identified (Table 1). 
Table 1. Tissue-specific macrophage populations

\begin{tabular}{l|l}
\hline Tissue & Macrophage \\
\hline Bone & Osteoclast \\
Central Nervous System & Microglia \\
Intestine & Mucosa Associated Lymphoid Tissue (MALT) \\
Liver & Kupffer cell \\
Lung & Alveolar Macrophage \\
Peritoneal cavity & Peritoneal Macrophage \\
Tumor & Tumor-associated macrophage \\
\hline
\end{tabular}

Adapted from Jackson and Evans, 2000.

The renewal of tissue macrophages occurs through local proliferation of progenitor cells, with a life span between 6 and 16 days. These tissue macrophages can also be classified as resident macrophages, which are immunologically quiescent, consume low oxygen, express low levels of major histocompatibility complex (MHC) class II gene and produce little or almost no cytokines (Liu and Pope, 2004).

\section{Monocyte migration}

In the case of inflammation, monocytes are attracted to the sites of immune reaction by activated endothelial, epithelial and mesenchymal cells. This migration is accompanied by a dramatic increase in a number of monocytes along with serum levels of M-CSF and results in the final differentiation of monocytes to macrophages. The recruitment of monocytes is a multi-step process, including tethering, rolling, activation, and firm adhesion, and migration across endothelium (diapedesis) (reviewed in Worthylake and Burridge, 2001; Johnson-Ledger et al., 2000; McEver, 2002). Monocytes express leukocyte (L)-selectin, membrane glycoprotein adhesion molecule, which binds to endothelial (E)-selectin, platelet (P)-selectin and glycosylation-dependent cell adhesion molecule 1 (GlyCAM-1) on endothelial cells. The ligand for P- and E-selectin is expressed constitutively on monocytes and its ligation enhances tether 
strength and stabilizes rolling on endothelial cells under blood shear flow conditions (Ramachandran et al., 2001; Zimmerman, 2001). Firm adherence to endothelium is mediated by integrin molecules, including lymphocyte function-associated antigen-1 (LFA-1), macrophage-1 antigen (Mac-1), and very late activation antigen-1 (VLA-1). These integrins interact with intercellular adhesion molecule-1 (ICAM-1) and vascular cell adhesion molecule-1 (VCAM-1) on the endothelial cells, resulting in firm adhesion and promotes activation. Integrin ligation may also result in increased transcription and expression of cytokines, such as IL-1 $\beta$, TNF- $\alpha$ and IL-8, which may contribute to the persistent inflammation (Rossetti et al., 2002). Diapedesis, or passage of monocytes across the endothelial lining, occurs via interaction between vascular endothelial (VE)-cadherins and platelet/endothelial cell adhesion molecule-1 (PECAM), expressed on both monocytes and endothelial cells (Johnson-Ledger C., Aurrand-Lions et al., 2000). Stages of monocyte migration and the molecules involved are summarized in Table 2.

Table 2. Monocyte migration

\begin{tabular}{l|l|l}
\hline Stage & Monocyte & Endothelial cell \\
\hline Tethering & L-selectin & GlyCAM-1 \\
& PSGL-1 & E, P-selectin \\
Rolling & L-selectin & GlyCAM-1 \\
& PSGL-1 & E, P-selectin \\
Firm adhesion & LFA-1, Mac-1 & ICAM-1, 2 \\
& VLA-1 & VCAM-1 \\
Diapedesis & VE-cadherin & VE-cadherin \\
& PECAM-1 & PECAM-1 \\
\hline
\end{tabular}

Adapted from Liu and Pope, 2004.

\section{Macrophage activation}

Inflammatory macrophages, which have migrated into the tissues and encountered an infection, are also called activated macrophages. They exhibit enhanced expression of MHC II 
molecule, are able to present antigen to $\mathrm{CD}^{+} \mathrm{T}$ helper cells and have increased oxygen consumption. At the same time, activated macrophages lose their ability to proliferate. The fully activated macrophages possess high oxygen consumption through upregulation of NADPH oxidase, are able to kill facultative and intracellular parasites, lyse tumor cells and secrete a larger variety of inflammatory mediators, such as TNF- $\alpha$, IL-1, IL-6, reactive oxygen and nitrogen species. Macrophages also serve as a major source of metabolites of arachidonic acid, including prostaglandins (PGs), thromboxanes and leukotrienes; all of which are important for normal physiology and inflammation. A detailed list of macrophage products secreted in response to activation is listed in Table 3. Inflammatory mediators will be discussed in Chapter III.

Table 3. Secretory products generated by activated macrophages

\begin{tabular}{l|l}
\hline Group of products & Individual products \\
\hline Cytokines & $\begin{array}{l}\text { IL-1 } \alpha \text { and } \beta ; \text { IL-6; TNF- } \alpha \\
\text { Macrophage Inflammatory proteins (MIP-1, -2, -3) } \\
\text { Platelet Derived Growth Factor (PDGF) } \\
\text { Fibroblast Growth Factor (FGF) } \\
\text { Transforming Growth Factor- } \beta \text { (TGF- } \beta \text { ) } \\
\text { Granulocyte-Colony Stimulating Factor (G-CSF) } \\
\text { Macrophage-Colony Stimulating Factor (M-CSF) }\end{array}$ \\
\hline Complement components & $\begin{array}{l}\text { Classical Pathway: C1, 2, 3, 4, 5 } \\
\text { Alternative Pathway: factor B, D, P, I, H }\end{array}$ \\
\hline Bioactive lipids & $\begin{array}{l}\text { Prostaglandins (PGE } 2, \mathrm{PGF}_{2 \alpha} \text { ) } \\
\text { Prostacyclin } \\
\text { Tromboxanes } \\
\text { Leukotrienes (LTB }\end{array}$ \\
\hline Reactive $\mathrm{LTC}_{4}$ )
\end{tabular}

Adapted from Sasmono and Hume, 2002 


\section{Effects of propanil on cytokine production}

Propanil is known to suppress a number of immune cell types, including T and B cells. To determine the ability of propanil to alter the activation process of macrophages, IL-6 and TNF- $\alpha$ cytokine production was studied. A series of studies determined the effect of in vivo exposure to propanil on murine macrophages. Peritoneal exudate cells (PEC) were obtained 3 and 7 days after i.p. propanil exposure $(200 \mathrm{mg} / \mathrm{kg})$, re-stimulated ex vivo with lipopolysaccharide (LPS), and the culture supernatants assayed for IL-6 and TNF- $\alpha$ (Xie et al., 1997a). Both IL-6 and TNF- $\alpha$ production were inhibited at both 3 and 7 days post-exposure compared to cells from the vehicle-treated controls. Oral administration of a high dose of propanil $(400 \mathrm{mg} / \mathrm{kg})$ resulted in the inhibition of IL-6 production by PEC at 3 and 7 days postexposure; however, a lower dose (40 mg/kg) had no effect (Xie et al., 1997a). TNF- $\alpha$ production was reduced significantly 3 and 7 days post-exposure at both the $40 \mathrm{mg} / \mathrm{kg}$ and $400 \mathrm{mg} / \mathrm{kg}$ doses, demonstrating a more dramatic reduction of TNF- $\alpha$ after oral administration of propanil.

Studies of PEC exposed in vitro to propanil and simultaneously stimulated with LPS demonstrated a dose-dependent suppression of IL- 6 and TNF- $\alpha$ production after $24 \mathrm{~h}$ in culture. Doses of $33 \mu \mathrm{M}$ and $66 \mu \mathrm{M}$ propanil inhibited IL-6 production by $25 \%$ and $58 \%$, respectively (Xie et al., 1997a). TNF- $\alpha$ production was also reduced by $30 \%$ and $60 \%$ of control with the same propanil doses (Xie et al., 1997a). Furthermore, mRNA levels of both cytokines were reduced in a dose-dependent manner without affecting mRNA stability suggesting that propanil affects these cytokines at the level of transcription (Xie et al., 1997a). 


\section{Activation stimuli}

Activation of macrophages allows for an initiation of the immune response. Firstly, they initiate an innate immune response by recognizing and bacteria, pathogenic protozoa, fungi and helminthes. Recognition is mediated via pattern recognition receptors (PPR), primary toll-like

Figure 1. LPS signaling.

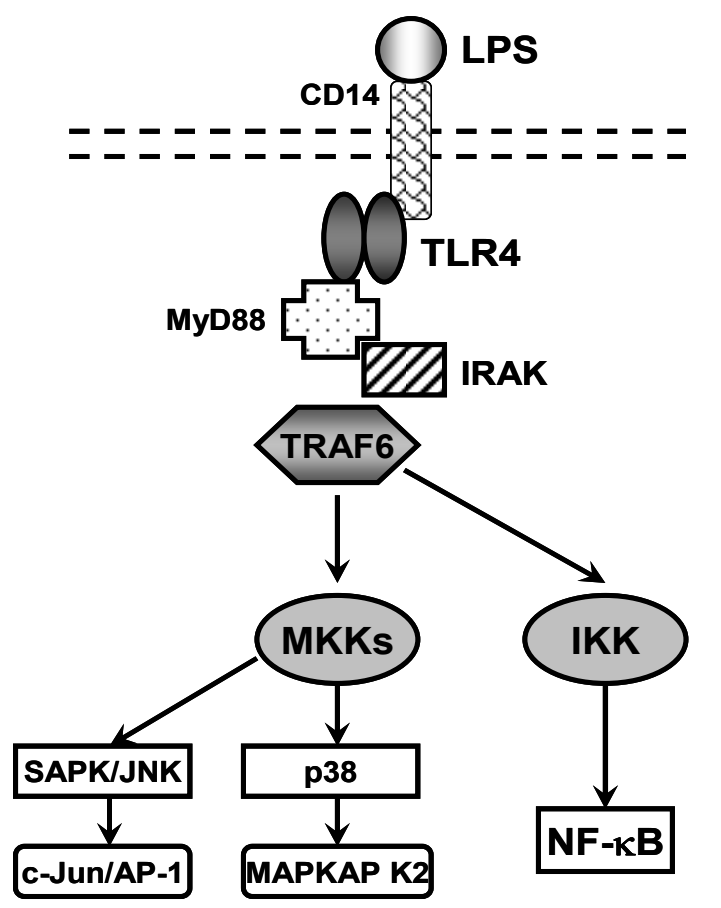

receptors (TLRs), or via the $\mathrm{Fc} \gamma$ and complement receptors $(\mathrm{CR})$.

TLRs are components of the innate immune system and structurally represented by transmembrane receptors with extracellular leucinerich domains that recognize pathogen associated molecular patterns (PAMP) (reviewed in Medzhitov, 2001). TLR-2 is critical for recognition of peptidoglycan from gram-positive organisms, where TLR-4 and surface protein CD14 recognize LPS from gram negative organisms (reviewed in Takeba

and Akira, 2004). The cytoplasmic tails of TLRs possess common toll/IL-1 receptor (TIR) domains, which are also shared with type 1 IL-1R. Upon binding to TLR, myeloid differentiation factor 88 (MyD88) is recruited to its TIR domain (Figure 1). Bound MyD88 IL-1 receptor-associated kinase (IRAK) and TNF- $\alpha$ receptor associated factor (TRAF)-6, resulting NF-kB activation. The MAP kinase pathways, such as c-Jun N-terminal kinase (JNK) and p38, can also be activated (Medzhitov, 2001).

Macrophages can also be activated by immune complexes composed of $\mathrm{IgG}$ antibodies directed against microorganisms or to auto antigens. Opsonized bacteria or particles are bound 
through Fc $\gamma$ receptors or complement receptors promoting phagocytosis, generation of ROS and RNS, and activation of the mitogen activated protein (MAP) kinase pathway. FcyRI (CD64), RIIA (CD32) and RIIIA (CD16) activation signals are mediated through immunoreceptor tyrosine-based activation motifs (ITAMs). IgG-containing immune complexes also may activate complement components resulting in soluble phase (C5a) or complement components bound to an immune complex, such as iC3b (Liu and Pope, 2004).

Macrophage activation can also be induced through receptor ligation by inflammatory cytokines, such as IFN- $\gamma$ and TNF- $\alpha$ produced by other leukocytes in the area of inflammation. IFN- $\gamma$, produced by $\mathrm{T}$ helper 1 cells, $\mathrm{NK}$ and $\mathrm{CD} 8^{+}$cells, upregulates the expression of costimulatory molecule B7 on macrophages, a ligand for CD28, providing a costimulatory signal for $\mathrm{T}$ cell activation (Harding et al., 1992). IFN- $\gamma$ also promotes phagocytosis, induces bacterial opsonization by IgG and increases Fc $\gamma$ RI receptor expression (Bosisio et al., 2002). The routes of activation, types of stimuli and receptors involved in macrophage activation are summarized in Table 4.

Table 4. Macrophage activation

\begin{tabular}{l|l|l|l}
\hline Acivation type & $\begin{array}{l}\text { Macrophage } \\
\text { receptor }\end{array}$ & Stimuli & Macrophage product \\
\hline Innate & TLRs & $\begin{array}{l}\text { Microbial } \\
\text { organisms }\end{array}$ & $\begin{array}{l}\text { TNF- } \alpha, \text { IL-1, IL-6, } \\
\text { IL-12, ROS, RNS }\end{array}$ \\
\hline Humoral & Fc $\gamma$ Rs, CRs & Immune complexes & ROS, RNS \\
\hline Cytokine receptors & IFN- $\gamma$ R, TNFR & IFN- $\gamma$, TNF- $\gamma$ & $\begin{array}{l}\text { ROS, RNS, enhances } \\
\text { TNF- } \alpha, \text { IL-1, IL-6, } \\
\text { IL-12 }\end{array}$ \\
\hline
\end{tabular}

Adapted from Liu and Pope, 2004 


\section{Inflammatory mediators}

\section{Respiratory burst}

Once macrophages have arrived at a site of infection or inflammation, they release mediators which control the accumulation and activation of other cells. Among a number of mediators produced by macrophages, reactive oxygen and nitrogen species are the major bactericidal agents. They are generated in response to phagosome formation, which is created by prominent membrane ruffles that extend around the bacteria, resulting in its engulfment. Macrophages possess preformed lysosomes, which originate from the Goldgi apparatus and contain anti-microbial proteins and peptides, such as acid hydrolases, lysozymes and proteases. This preformed lysosome fuses with the phagosome, forming a phagolysosome, which is acidified by hydrogen ion transporters and prevents bacteria from proliferating and impairs their function. Another weapon of activated macrophages are ROS, produced within minutes after exposure to bacteria. ROS are highly reactive molecules that can react with proteins, lipids and other biological molecules preventing pathogenic organisms from proliferation and destroying them.

The enzyme responsible for ROS production is NADPH oxidase. This multicomponent enzyme is located in the plasma membrane and is composed of four oxidase-specific proteins (p22 $2^{\text {phox }}, \mathrm{p} 47^{\text {phox }}, \mathrm{p} 67^{\text {phox }}$, and gp91 ${ }^{\text {phox }}$ ) and a GTPase (Rac1/2) (reviewed in Babior, 2000a). The assembly and activation of the NADPH oxidase have been shown to be preceded by an increase in intracellular $\mathrm{Ca}^{2+}$, activation of $\mathrm{IP}_{3}$-mediated signaling and protein kinase $\mathrm{C}$ (PKC) activation (Qualliotine-Mann et al., 1993). NADPH oxidase becomes activated upon translocation of cytosolic $\mathrm{p} 47^{\mathrm{phox}}, \mathrm{p} 67^{\mathrm{phox}}$ and GTPase to the phagosome, where they assemble around a membrane-bound cytochrome $b_{558}$ complex that contains $g p 91^{\text {phox }}$ and $\mathrm{p} 22^{\text {phox }}$. This 
process is tightly regulated and involves phosphorylation and numerous conformational changes, which results in reduction of extracellular molecular oxygen to superoxide $\left({ }^{\circ} \mathrm{O}_{2}^{-}\right)$using cytosolic NADPH as the electron donor (reviewed in Jones et al., 2000). The ${ }^{\circ} \mathrm{O}_{2}{ }^{-}$generated is toxic but short lived and normally converted to long lasting hydrogen peroxide $\left(\mathrm{H}_{2} \mathrm{O}_{2}\right)$ and $\mathrm{O}_{2}$. Hydrogen peroxide is a more reactive oxidant than ${ }^{\circ} \mathrm{O}_{2}{ }^{-}$and rapidly diffuses across cell membranes. It is able to oxidize cellular membranes and enzymes, causing DNA damage by the interaction with $\mathrm{Fe}^{2+}$ to form a toxic ferryl radical and inhibit membrane transport processes (Weiss and Peppin, 1986; Imlayet al., 1988). A hydroxyl radical ( $\left.{ }^{\circ} \mathrm{OH}\right)$ is also a very potent oxidant implicated in oxidation of bacterial proteins, DNA and lipids (Czapski, 1984).

Another important anti-bacterial product of activated macrophages is nitric oxide (NO). It is synthesized from L-arginine and NADPH by inducible nitric oxide synthase (iNOS). NO is

Figure 2. ROS and RNS generation.

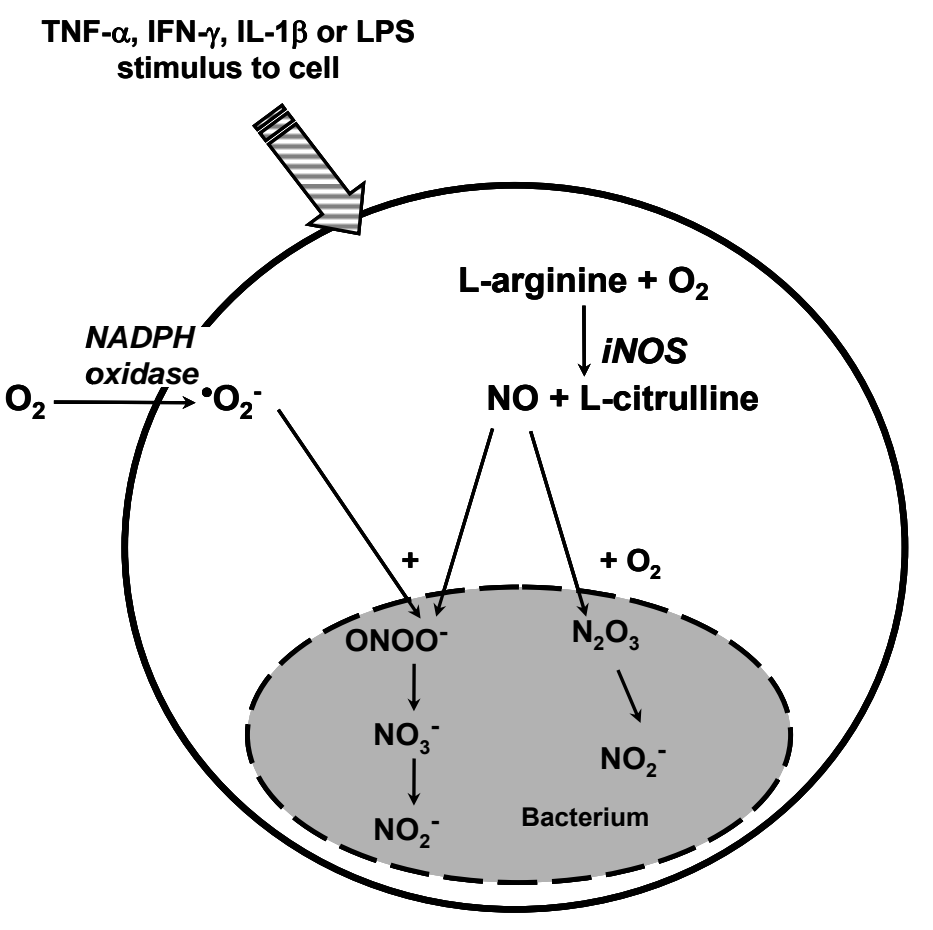

a short-lived free radical which can combine with ${ }^{\bullet} \mathrm{O}_{2}{ }^{-}$to generate very reactive peroxinitrite $\left(\mathrm{ONOO}^{-}\right)$ which in turn decomposes into additional nitrates and nitrites (Hibbs et al., 1988; Miwa et al., 1987; Stuehr and Marletta 1987). $\mathrm{NO}$ also readily reacts with $\mathrm{O}_{2}$ resulting in production of transient and unstable $\mathrm{N}_{2} \mathrm{O}_{3}$ and, ultimately, unreactive $\mathrm{NO}_{2}^{-}$ion product (Figure

2). LPS-mediated activation of the innate immune pattern recognition receptors (PRR) 
stimulates iNOS mRNA transcription within 2-4 hours, and iNOS translation within 6 hours. It is independent of elevated intracellular $\mathrm{Ca}^{2+}$ levels and can function even with low $\mathrm{Ca}^{2+}$ concentration in the cell. Once induced, iNOS in mouse macrophages can produce NO for as long as 5 days when induction stimuli and L-arginine substrate are present (Vodovotz et al., 1994). LPS activation of TLR4 leads to NF-kB activation, triggering iNOS transcription (Xie et al., 1994). IFN- $\gamma$ triggers iNOS transcription by activating the JAK/STAT pathway, leading to synthesis of the transcription factor interferon response factor 1 (IRF-1), which stimulates iNOS transcription (Kamijo et al., 1994). IFN- $\gamma$ also provides a synergistic boost to LPS induction of iNOS transcription because IRF-1 interacts with NF- $\mathrm{kB}$, altering the conformation of the iNOS promoter (Saura et al., 1999). Expression of the iNOS gene in macrophages is regulated mainly at the transcriptional level, particularly by NF- $\mathrm{BB}$, which binds to multiple sites on the iNOS gene promoter (Xie et al. 1993).

NO can inhibit bacterial DNA synthesis by multiple mechanisms, these include inhibiting bacterial ribonucleotide reductase, causing double-stranded breaks in bacterial DNA, modifying cysteine residues in bacterial proteins, oxidizing bacterial lipids, and interacting with heme iron and iron-sulfur clusters in bacterial enzymes. NO mobilizes zinc in bacteria, which suggests that DNA-binding proteins containing zinc are targets of NO (Schapiro et al., 2003). It can also increase the susceptibility of bacteria to oxidative DNA damage by blocking respiration (Woodmansee and Imlay, 2003). Peroxynitrite can oxidize bacterial lipids and produce nitrotyrosine of bacterial polypeptides, but the biological significance of these modifications is also unclear.

When generated within the phagolysosome, the ROS and RNS are antimicrobial; however, they can have other physiological and pathophysiologic functions when generated 
within the cytoplasm or released from the cell. Intracellular release of ROS seems to be important for signal transduction and results in the expression of many proinflammatory genes. The activation of NF- $\mathrm{kB}$ signaling pathway by respiratory burst components $\left(\mathrm{H}_{2} \mathrm{O}_{2}\right)$ has been demonstrated by Kaul and Forman (1996). When released from the cell, ROS may contribute to atherosclerosis, DNA mutation, malignancy, as well as apoptosis and necrosis (Babior, 2000b).

\section{Prostaglandins}

Prostaglandins (PG) are one of many products secreted by activated macrophages. Derived from arachidonic acid, they mediate a wide range of physiological functions, such as control of blood pressure, contraction of smooth muscle, and modulation of inflammation (Wilkinson, 1994). They dilate blood vessels and increase their permeability to fluid and proteins (Williams and Morley, 1973). This results in a rise in temperature and swelling of the affected area. Prostaglandins also increase the sensitivity of nerve endings to pain.

Prostaglandins are produced by the $85 \mathrm{kDa}$ enzyme cytosolic phospholipase $\mathrm{A}_{2}\left(\mathrm{cPLA}_{2}\right)$

Figure 3. Prostaglandins production.

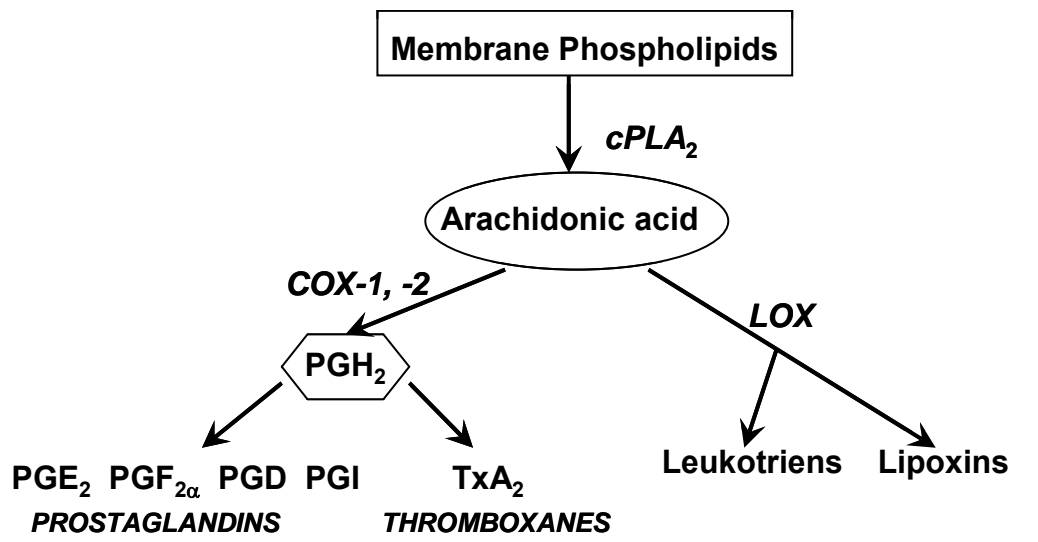

which catalyzes hydrolysis of membrane phospholipids into arachidonic acid (AA) (Clark et al., 1995). In order to become activated, $\quad \mathrm{cPLA}_{2}$ needs to be translocated from the cytosole to the membrane, where its substrate resides.

Two signals are responsible for this activation, an increase in intracellular $\mathrm{Ca}^{2+}$ and PKC- 
dependant phosphorylation of $\mathrm{cPLA}_{2}$ (Kramer and Sharp, 1997). Next, activated cPLA $\mathrm{A}_{2}$ converts membrane phospholipids to arachidonic acid, which has a short $t^{1 / 2}$ and can be metabolized by two major routes, the cyclooxygenase and lipoxygenase pathways. The cyclooxygenase (COX) pathway produces prostaglandins, prostacyclin and thromboxanes; the lipoxygenase (LOX) pathway produces leukotriens and lipoxins (Smith et al., 2000) (Figure 3). COX enzyme converts AA to prostaglandin $\mathrm{H}_{2}\left(\mathrm{PGH}_{2}\right)$, which diffuses from the $\mathrm{COX}$ protein and is converted in a tissue-specific fashion to the various prostaglandins, such as $\mathrm{PGE}_{2}, \mathrm{PGF}_{2 \alpha}, \mathrm{PGD}, \mathrm{PGI}_{2}$ and tromboxane $\left(\mathrm{TxA}_{2}\right)$ (Funk, 2001; Cao and Prescott, 2002). Cyclooxygenase enzyme exists in two isoforms, COX-1 and COX-2, which share only $60 \%$ homology at the amino acid level (Williams and Shacter, 1997). COX-1 is expressed constitutively in most tissues, and is responsible for the production of PGs that control normal physiological functions including maintenance of the gastric mucosa and platelet aggregation. COX-2 is not constitutively expressed, but is rapidly induced by inflammatory and mitogenic stimuli (Williams et al, 1999). Several transcription factors, such as AP-1, NF-IL6, NF- $\mathrm{kB}$ and NF-AT have been shown to stimulate COX-2 transcription (reviewed in Wu, 2005).

There are several strategies for inhibiting PG synthesis. Non-steroidal anti-inflammatory drugs (NSAIDs) will reduce levels of PGs by inhibiting the activity of COX isozymes. Due to the small differences in the amino acid sequences near the catalytic site, COX-1 and COX-2 can be inhibited by different NSAIDs (Gierse et al, 1996; Kurumbail et al, 1996; Meade et al, 1996). Aspirin and piroxicam inhibit both enzymes non-specifically, where as CAY10404 affects only COX-2 activity and is proven to be the most specific inhibitor with a Selectivity Index (SI) of $\left(\mathrm{COX}-1 \mathrm{IC}_{50} / \mathrm{COX}-2 \mathrm{IC}_{50}\right)>500,000$ (Parashar et al, 2005). In comparison, the SI of celecoxib, the second selective COX-2 inhibitor, is about 400 (Habeeb et al, 2000). 


\section{Activation of signaling pathways}

\section{NF-אB Activation Pathway}

A number of signaling pathways are triggered when macrophages become activated. The best characterized one is the NF- $\mathrm{B}$ signaling pathway. It can be activated by a wide variety of agents, including cytokines like TNF- $\alpha$, IL-1, IL-2, IL-12, $\mathrm{H}_{2} \mathrm{O}_{2}$, LPS, various stress conditions, environmental hazards, and many viruses. Activation of $\mathrm{NF}-\kappa \mathrm{B}$ requires phosphorylation and

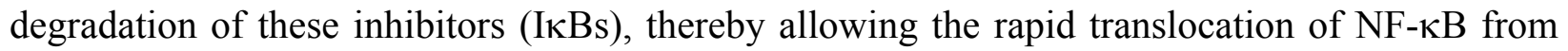
the cytoplasm to the nucleus where it binds target DNA sequences (Figure 4). Phosphorylation

Figure 4. NF-KB activation of the IאBs is regulated by a multi-subunit kinase, termed IKK pathway.

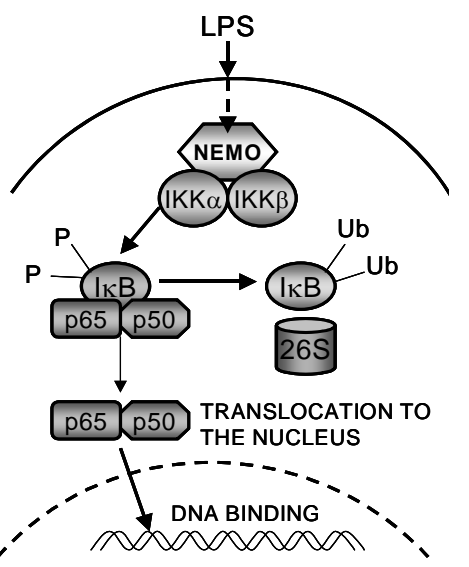

(700-900kDa), which contains two catalytic subunits, IKK $\alpha$ and IKK $\beta$, and a regulatory subunit IKK $\gamma(\mathrm{NEMO})$ (DiDonato et al., 1996; DiDonato et al., 1997; Zandi et al., 1997; Zandi et al., 1998; Li et al., 1998; Delhase and Karin, 1999; Karin, 1999a; Karin, 1999b). Even though IKK $\alpha$ and IKK $\beta$ have 52\% identity in chemical structures, phosphorylation of $\mathrm{IKK} \beta$ results in activation of IKK complex. Concurrent phosphorylation of IKK $\alpha$ is thought to be not essential for stimulation of IאB kinase activity (Li et al., 1999; Takeda et al., 1999; Tanaka et al., 1999).

\section{NF-кB Family Proteins}

Signals induced by many stimuli including LPS and other bacterial cell wall components, growth factors and cytokines result in the activation of NF- $\kappa \mathrm{B}$ signaling pathway. The term NF-

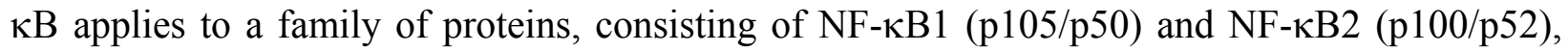


which are transcribed as precursors (p105 and p100, respectively) and then proteolytically processed to yield the DNA binding subunits (p50 and p52) (reviewed in Ghosh et al., 1998). RelA (p65) (Figure 5), cRel and RelB proteins are not proteolytically processed and contain a transcriptional activation domain (TD) in their C-termini (Attar et al., 1998). Each protein of

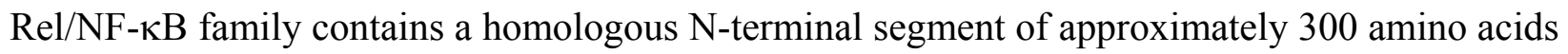

Figure 5. NF-kB proteins structure.
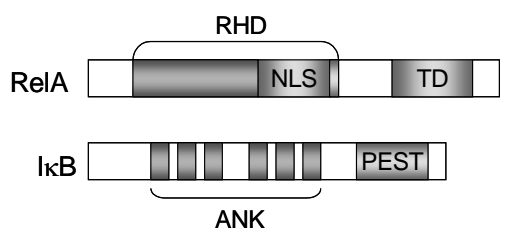

in length. This Rel homology domain (RHD) is responsible for the subunit nuclear translocation and $\mathrm{\kappa B}$ DNA binding. Formation of homo- and heterodimers that occurs between the members of the family, and this dimerization occurs through the RHD (Baeuerle, 1998; Huxford et al., 1998).

\section{Role of IאBs in the NF-кB Activation Pathway}

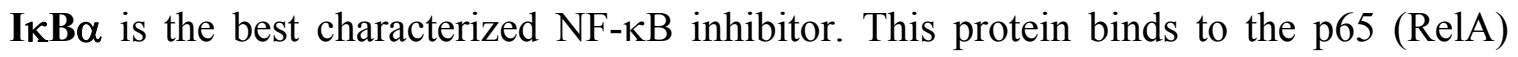

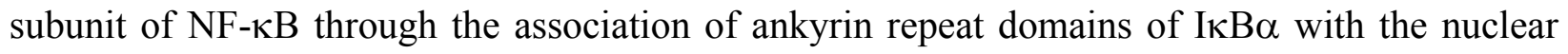
localization signal (NLS) of p65. The NLS of the p50 subunit remains exposed (Figure 6, from

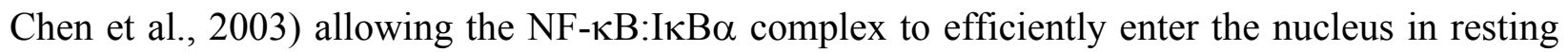

Figure 6. IKB $\alpha$ protein structure.

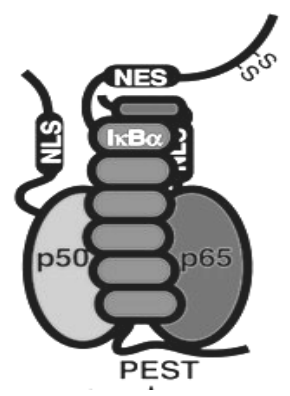

cells. However, this complex is immediately expelled as a result of a potent nuclear export sequence (NES) on I $\mathrm{KB} \alpha$ and p65. Upon stimulation with LPS, IKK phosphorylates $\mathrm{I} \kappa \mathrm{B} \alpha$ on the amino terminus at serine residues 32 and 36 (Beg et al., 1993; Chen et al., 1995). Phosphorylation of these serine residues is a necessary step for inducible $\mathrm{I} \kappa \mathrm{B} \alpha$ polyubiquitination and degradation. The principal 
al., 1996). Targeted by ubiquitin, IkB $\alpha$ undergoes rapid degradation by nonlysosomal, ATPdependent 26S proteolytic complex composed of a $700-\mathrm{kDa}$ proteosome (Palombella et al, 1994). This degradation is followed by induction of $\mathrm{I} \kappa \mathrm{B} \alpha$ mRNA through a mechanism

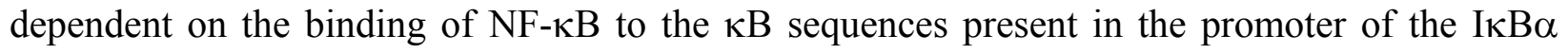
gene (Sun et al., 1993; de Martin et al., 1993). This newly synthesized IкB $\alpha$, possessing an intrinsic NLS, enters the nucleus and binds NF- $\mathrm{kB}$, thereby enhancing its dissociation from the DNA and causing re-exportation to the cytoplasm by means of NES present on IкB $\alpha$ (ArenzanaSeisdedos et al., 1997).

$\mathbf{I} \mathbf{B} \beta$, together with $I \kappa \mathrm{B} \alpha$, is a major regulator of $\mathrm{NF}-\kappa \mathrm{B}$ activity through the interaction with the same Rel proteins, RelA(p65)/p50 heterodimer as well as p65/p65 homodimer. Unlike

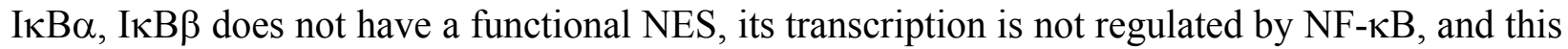

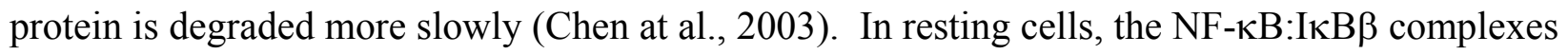
are retained in cytoplasm without shuttling in and out of the nucleus, because both NLSs of NF$\kappa \mathrm{B}$ dimers are masked by $\mathrm{I} \kappa \mathrm{B} \beta$. Unlike $\mathrm{I} \kappa \mathrm{B} \alpha, \mathrm{I} \kappa \mathrm{B} \beta$ has a unique 47 -amino acid insertion, which is bound by small Ras-like G-protein, $\kappa B-$ Ras (Fenwick et al., 2000). This $\kappa B-R a s$ is able to efficiently mask one of p65 NLS of p65/p65 homodimer or p50 NLS of p65/p50 heterodimer, thereby preventing shuttling of the complex in and out of the nucleus (Chen et al., 2003). In order to be degraded, IкB $\beta$ has to be phosphorylated on Serines 19 and 23 as well as on its Cterminal proline, glutamic acid, serine and threonine-rich (PEST) region (Weil et al., 1997). It has been demonstrated that PEST phosphorylation cooperates with $\kappa \mathrm{B}$-Ras binding and the IкB $\beta$

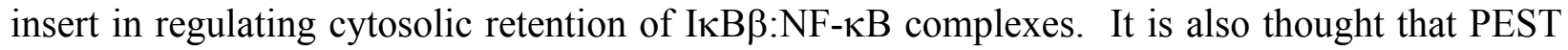
sequence must be dephosphorylated by an unknown phosphatase, which will allow the release of $\kappa B-R a s$ and consequent IкB $\beta$ degradation by $26 \mathrm{~S}$ proteosome (Chen et al., 2003). 
$\mathbf{I} \mathbf{B} \boldsymbol{\varepsilon}$, the third major IкB protein, has been found specifically associated with cRel, p65 homodimers or cRel/p65 heterodimers in cell extracts. It is able to shuttle between the cytoplasm and the nucleus. Nuclear import is mediated by its ankyrin repeat domain, but it is

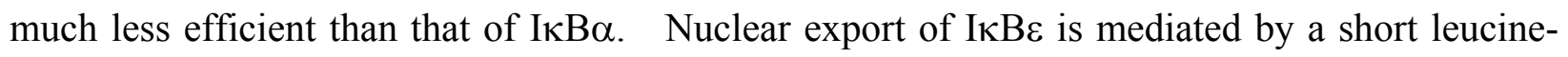
rich NES-like sequence, located at the C-terminal (Lee and Hannink, 2002). Unlike IkB $\alpha$ and

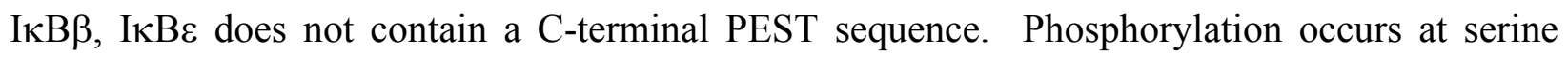
residues 18 and 22, which signals to slow degradation by proteosome (Whiteside et al., 1997; Li et al., 1997).

\section{Role of p65 phosphorylation in NF- $\kappa B$ transcriptional activity}

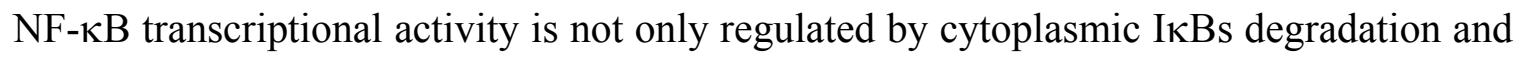
nuclear translocation, it can also be regulated by posttranslational modifications, such as phosphorylation. Upon LPS stimulation, IKK $\beta$ phosphorylates the transcriptional activation domain (TD) of p65 on Serine 536, increasing p65 transcriptional activity (Yang et al., 2003). Another kinase, protein kinase $\mathrm{A}\left(\mathrm{PKA}_{\mathrm{C}}\right)$ stimulates transcriptional activity of p65 by phosphorylating it on Serine 276 (Zhong et al., 1997). PKA ${ }_{C}$ can be found in some fractions of $\mathrm{NF}-\kappa \mathrm{B} / \mathrm{I} \kappa \mathrm{B}$ complexes and is kept inactive by IкB, which masks the ATP-binding domain of $\mathrm{PKA}_{C}$. When IкB is degraded, PKA $\mathrm{A}_{\mathrm{C}}$ becomes activated and phosphorylates Serine 276 of p65. It also promotes interaction with the transcriptional coactivator CBP/p300 (Zhong et al., 1998). 


\section{$N F-\kappa B$ oscillations}

Under continuous stimulation of the cell, I $\kappa \mathrm{B} \alpha$ goes through the degradation and

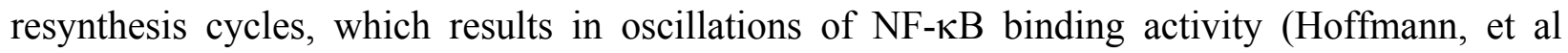
2002). These oscillations were observed in Hela cells (TNF- $\alpha$ stimulation) and macrophages (LPS stimulation). Upon activation, signal transduction leads to phosphorylation of IKK, which,

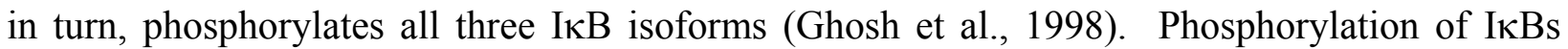
signals their ubiquitination and proteolytic degradation, which frees NF- $\kappa \mathrm{B}$ in the cytoplasm,

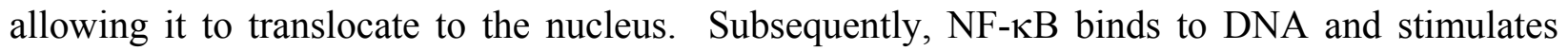
expression of $\mathrm{I} \kappa \mathrm{B} \alpha$ protein, which is NF- $\kappa \mathrm{B}$ inducible (Sun et al., 1993). However, two other isoforms, I $\mathrm{B} \beta \beta$ and $\mathrm{I} \kappa \mathrm{B} \varepsilon$, are not resynthesized as quickly as $\mathrm{I} \kappa \mathrm{B} \alpha$, and their protein levels remain low, because their transcription does not depend on NF- $\kappa$ B. Next, newly resynthesized I $\kappa \mathrm{B} \alpha$ decreases NF- $\kappa \mathrm{B}$ binding activity, by binding to it in the nucleus and removing it from DNA, which causes the first dip in oscillations (Arenzana-Seisdedos et al., 1997. At the same time, continuous stimulation of the cell results in another round of I $\kappa \mathrm{B} \alpha$ 's phosphorylation, triggering its degradation and producing another peak in oscillations (Zandi et al., 1998). However, protein levels of $\mathrm{I} \kappa \mathrm{B} \beta$ and $\mathrm{I} \kappa \mathrm{B} \varepsilon$ stay low and do not get resynthesized as fast as I $\mathrm{B} \alpha$. This leads to damping of steady oscillations as a result of the action of $\mathrm{I} \kappa \mathrm{B} \beta$ and $\mathrm{I} \kappa \mathrm{B} \varepsilon$ (Hoffmann et al., 2002).

To characterize the functional role of each I $\kappa \mathrm{B}$ isoform in NF- $\kappa \mathrm{B}$ oscillations, Hoffman and co-workers created knock-out cell lines from mouse embryonic fibroblasts containing only

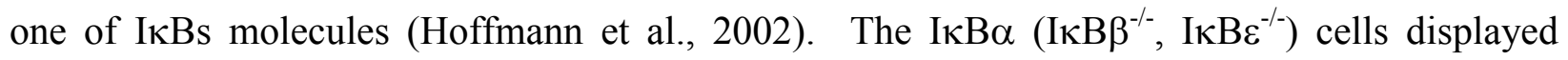
undamped continuous oscillations upon sustained TNF stimulation, where as $\mathrm{I} \kappa \mathrm{B} \beta\left(\mathrm{I} \kappa \mathrm{B} \alpha^{-/-}\right.$, 
$\left.\mathrm{I} \kappa \mathrm{B} \varepsilon^{-/ /}\right)$and $\mathrm{I} \kappa \mathrm{B} \varepsilon\left(\mathrm{I} \kappa \mathrm{B} \alpha^{-/ /} \mathrm{I} \kappa \mathrm{B} \beta^{-/}\right)$cells produced a steady increase in NF- $\kappa \mathrm{B}$ binding activity

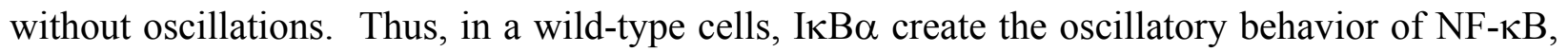

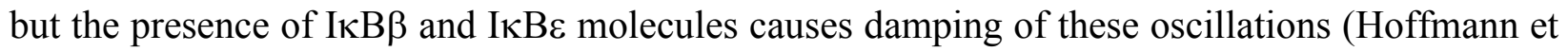
al., 2002).

The oscillations may differ in their amplitude, number and time period depending on stimuli. Short impulse (15 min TNF stimulation) will result in a single oscillation that will be short enough for the transcriptional activation of early genes, such as gene encoding chemokine IP-10 (Sarris et al., 1996). In contrast, chemokine RANTES is encoded by a late gene and requires at least 2 hours of stimulation for detectable expression of this protein (Saccani et al., 2001). Hoffmann et al. (2002) suggested that I $\mathrm{KB} \alpha$ is necessary for this differential control because it helps rapidly attenuate NF- $\mathrm{kB}$ activity in response to a short pulse of TNF. To test this hypothesis, cells lacking I $\mathrm{I} B \alpha\left(\operatorname{I\kappa B} \alpha^{-/}\right)$were pulsed with TNF for 15 min or stimulated

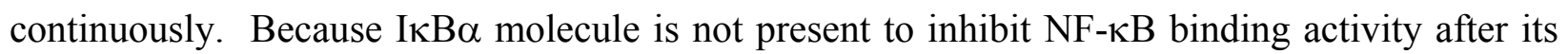
resynthesis, both types of stimulation result in sustained NF-kB activation (no oscillations) and expression of both early (IP-10) and late (RANTES) genes. This demonstrated that the presence

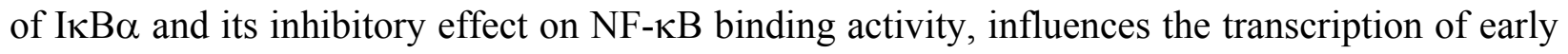
and late genes through the differences in timing of stimuli (Hoffmann et al., 2002).

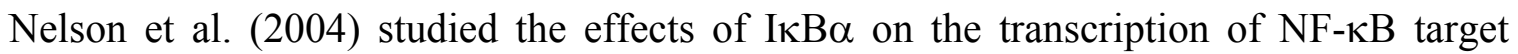
genes. They concluded that increased transcription of IкB $\alpha$, resulted in decreased frequency of oscillations, confirming the Hoffmann et al.(2002) findings. They also demonstrated that phosphorylation and dephosphorylation of p65 subunit of NF- $\mathrm{kB}$ is responsible for persistency of oscillations. Their studies also concluded that the oscillations are often asynchronous and may vary in number, period and amplitude (Nelson et al., 2004). 


\section{Effects of Propanil on signal transduction}

Propanil interferes with signal transduction cascades in activated macrophages. To study the effects of this herbicide, cell signaling cascades that result in macrophage activation were investigated. TNF- $\alpha$ synthesis is dependent on the transcription factor, nuclear factor $\kappa \mathrm{B}$ (NF$\kappa B)($ Collart et al., 1990). Upon LPS stimulation, NF- $\kappa$ B translocates into the nucleus where it binds the promoter regions of genes responsible for cytokine production. A series of studies were performed using mouse peritoneal cell line, IC-21 to determine if the reduction in cytokine production after exposure to propanil was due to effects on NF- $\kappa \mathrm{B}$ activation. Propanil was demonstrated to reduce TNF- $\alpha$ promoter activity in regions that contain NF- $\kappa$ B binding sites (Frost et al., 2001). Nuclear levels of the p65 subunit of NF- $\kappa$ B were reduced in IC-21 cells treated with $66 \mu \mathrm{M}$ or $167 \mu \mathrm{M}$ propanil and stimulated with LPS. In addition, it was demonstrated that there was decreased DNA binding of both the p65/p50 heterodimer and p50/p50 homodimers of NF- $\mathrm{B}$ after exposure to propanil (Frost et al., 2001). Overall, these results suggest that propanil may reduce cytokine production through effects on NF- $\kappa \mathrm{B}$ activation.

Another aspect of macrophage activation is the release of intracellular $\mathrm{Ca}^{2+}$-stores that initiate signal transduction cascades and the activation of transcription factors, including NF- $\kappa \mathrm{B}$ and nuclear factor of activated T cells (NFAT). A concentration of $66 \mu \mathrm{M}$ propanil completely abrogated intracellular $\mathrm{Ca}^{2+}$ release in PEC and IC-21 cells within 2 min of LPS stimulation (Xie et al., 1997b). However, binding of LPS to macrophages (Xie et al., 1997b) as well as mobility of plasma membrane lipid hydrocarbon chains were not affected by propanil (Brundage et al., 2003). 
The hydrolysis of the membrane-associated phosphatidyl-inositol-4, 5-bisphophate (PIP2) and formation of two breakdown products, inositol 1,4,5-triphosphate (IP3) and diacylglycerol (DAG) are required to release $\mathrm{Ca}^{2+}$ from the internal store. IP3 is known to directly induce intracellular $\mathrm{Ca}^{2+}$ release (Berridge and Irvine, 1984; Streb et al., 1983). Measurement of IP3 levels in propanil-treated cells demonstrated an increase in the production of this breakdown product. It did not, however, generate an increase in intracellular $\mathrm{Ca}^{2+}$ levels (Xie et al., 1997b). Overall, these data suggest that propanil inhibits $\mathrm{Ca}^{2+}$ release after IP3 generation. Thus a potential mechanism for how propanil causes a reduction in inflammatory cytokine production in macrophages is through an effect on NF- $\mathrm{kB}$ and $\mathrm{Ca}^{2+}$.

\section{Summary}

Immunotoxic effects of propanil have been studied for many years; however, the majority of reports have investigated its toxicity at the organ and cellular level. The molecular level and signal transduction mechanisms of toxicity are still unknown and require further investigation.

The present study examined effect of propanil on one of the cells of the innate immune system, macrophages. The first report tested the hypothesis that propanil inhibits the ability of activated macrophages to perform phagocytosis and kill bacteria through inhibition of the inflammatory cytokine production, TNF- $\alpha$, and through supressed generation of ROS and RNS. The second study investigated the mechanism by which propanil dramatically decreases $\mathrm{PGE}_{2}$ production in activated macrophages. It was hypothesized that propanil affects the enzymes participating in $\mathrm{PGE}_{2}$ production and their enzymatic activity. The third study described the novel behavior of NF- $\mathrm{kB}$ transcription factor, oscillations. The hypothesis of propanil's inhibition of oscillatory behavior was tested via characterization of the NF- $\mathrm{kB}$ binding activity 
using a mathematical model. Overall, this research examines the functional and signaling changes activated macrophages undergo upon treatment with propanil. The anti-inflammatory potential of propanil suggests its possible use as an antioxidant/inhibitor for therapeutic purposes. 


\section{References}

Adachi, M. (1966). Studies on selective herbicidal activity of 3,4-dichloropropionilide. I Penetration into plants and degradative detoxication. Pesticide and Technique 14, 19-21.

Aderem, A. A., Wright, S. D., Silverstein, S. C., and Cohn, Z. A. (1985). Ligated complement receptors do not activate the arachidonic acid cascade in resident peritoneal macrophages. J.Exp.Med. 161(3), 617-622.

Ambrose, A. M., Larson, P. S., Borzelleca, J. F., and Hennigar, G. R., Jr. (1972). Toxicologic studies on 3',4'-dichloropropionanilide. Toxicol.Appl.Pharmacol. 23(4), 650-659.

Aoki, T., Sano, Y., Yamamoto, T., and Inoue, J. I. (1996). The ankyrin repeats but not the PESTlike sequences are required for signal-dependent degradation of IkappaBalpha. Oncogene 12(5), 1159-1164.

Arenzana-Seisdedos, F., Turpin, P., Rodriguez, M., Thomas, D., Hay, R. T., Virelizier, J. L., and Dargemont, C. (1997). Nuclear localization of I kappa B alpha promotes active transport of NF-kappa B from the nucleus to the cytoplasm. J. Cell Sci. 110 ( Pt 3), 369-378.

Attar, R. M., Caamano, J., Carrasco, D., Iotsova, V., Ishikawa, H., Ryseck, R. P., Weih, F., and Bravo, R. (1997). Genetic approaches to study Rel/NF-kappa B/I kappa B function in mice. Semin. Cancer Biol. 8(2), 93-101.

Babior, B. M. (2000a). The NADPH oxidase of endothelial cells. Life 50(4-5), 267-269..

Babior, B. M. (2000b). Phagocytes and oxidative stress. Am.J.Med. 109(1), 33-44.

Baeuerle, P. A. (1998). IkappaB-NF-kappaB structures: at the interface of inflammation control. Cell 95(6), 729-731. 
Barnes, C. J., Lavy, T. L., and Mattice, J. D. (1987). Exposure of non-applicator personnel and adjacent areas to aerially applied propanil. Bull. Environ. Contam Toxicol. 39(1), 126133.

Barnett, J. B., and Gandy, J. (1989). Effect of acute propanil exposure on the immune response of C57B1/6 mice. Fundam. Appl. Toxicol. 12(4), 757-764.

Barnett, J. B., Gandy, J., Wilbourn, D., and Theus, S. A. (1992). Comparison of the immunotoxicity of propanil and its metabolite, 3,4-dichloroaniline, in C57Bl/6 mice. Fundam. Appl. Toxicol. 18(4), 628-631.

Bartha, R., and Pramer, D. (1967). Pesticide transformation to aniline and azo compounds in soil. Science 156(3782), 1617-1618.

Beg, A. A., Finco, T. S., Nantermet, P. V., and Baldwin, A. S., Jr. (1993). Tumor necrosis factor and interleukin-1 lead to phosphorylation and loss of I kappa B alpha: a mechanism for NF-kappa B activation. Mol. Cell Biol. 13(6), 3301-3310.

Berridge, M. J., and Irvine, R. F. (1984). Inositol trisphosphate, a novel second messenger in cellular signal transduction. Nature 312(5992), 315-321.

Bosisio, D., Polentarutti, N., Sironi, M., Bernasconi, S., Miyake, K., Webb, G. R., Martin, M. U., Mantovani, A., and Muzio, M. (2002) Stimulation of toll-like receptor 4 expression in human mononuclear phagocytes by interferon-gamma: a molecular basis for priming and synergism with bacterial lipopolysaccharide. Blood 99(9), 3427-3431.

Brundage, K. M., Barnett, J. B., and Mahaney, J. E. 2003. The amide class herbicide 3,4dichloropropionanilide (DCPA) alters the mobility of hydrocarbon chains in Tlymphocyte but not macrophage membranes. J.Toxicol.Environ.Health A 66:2253-2265. 
Cao, Y., and Prescott, S. M. (2002). Many actions of cyclooxygenase-2 in cellular dynamics and in cancer. J.Cell Physiol 190(3), 279-286.

Calvin, M. (1989) Forty years of photosynthesis and related activities. Photosynth. Res. 21: 3-16.

Chen, Y., Wu, J., and Ghosh, G. (2003). KappaB-Ras binds to the unique insert within the ankyrin repeat domain of IkappaBbeta and regulates cytoplasmic retention of IkappaBbeta x NF-kappaB complexes. J. Biol. Chem. 278(25), 23101-23106.

Chen, Z., Hagler, J., Palombella, V. J., Melandri, F., Scherer, D., Ballard, D., and Maniatis, T. (1995). Signal-induced site-specific phosphorylation targets I kappa B alpha to the ubiquitin-proteasome pathway. Genes Dev. 9(13), 1586-1597.

Clark, J. D., Schievella, A. R., Nalefski, E. A., and Lin, L. L. (1995). Cytosolic phospholipase A2. J Lipid Mediat. Cell Signal. 12(2-3), 83-117.

Collart, M. A., Baeuerle, P., and Vassalli, P. (1990). Regulation of tumor necrosis factor alpha transcription in macrophages: involvement of four kappa B-like motifs and of constitutive and inducible forms of NF-kappa B. Mol. Cell Biol. 10(4), 1498-1506.

Czapski, G. (1984). Reaction of .OH. Methods Enzymol. 105, 209-215.

de Martin, R., Vanhove, B., Cheng, Q., Hofer, E., Csizmadia, V., Winkler, H., and Bach, F. H. (1993). Cytokine-inducible expression in endothelial cells of an I kappa B alpha-like gene is regulated by NF kappa B. EMBO J. 12(7), 2773-2779.

Delhase, M., and Karin, M. (1999). The I kappa B kinase: a master regulator of NF-kappa B, innate immunity, and epidermal differentiation. Cold Spring Harb. Symp. Quant. Biol. 64, 491-503. 
DiDonato, J., Mercurio, F., Rosette, C., Wu-Li, J., Suyang, H., Ghosh, S., and Karin, M. (1996). Mapping of the inducible IkappaB phosphorylation sites that signal its ubiquitination and degradation. Mol. Cell Biol. 16(4), 1295-1304.

DiDonato, J. A., Hayakawa, M., Rothwarf, D. M., Zandi, E., and Karin, M. (1997). A cytokineresponsive IkappaB kinase that activates the transcription factor NF-kappaB. Nature 388(6642), 548-554.

Fearon, D. T. (1983). The human C3b receptor. Springer Semin.Immunopathol. 6(2-3), 159-172.

Fenwick, C., Na, S. Y., Voll, R. E., Zhong, H., Im, S. Y., Lee, J. W., and Ghosh, S. (2000). A subclass of Ras proteins that regulate the degradation of IkappaB. Science 287(5454), 869-873.

Frost, L. L., Neeley, Y. X., Schafer, R., Gibson, L. F., and Barnett, J. B. (2001). Propanil inhibits tumor necrosis factor-alpha production by reducing nuclear levels of the transcription factor nuclear factor-kappab in the macrophage cell line ic-21. Toxicol. Appl. Pharmacol. 172(3), 186-193.

Funk, C. D. (2001). Prostaglandins and leukotrienes: advances in eicosanoid biology. Science 294(5548), 1871-1875.

Ghosh, S., May, M. J., and Kopp, E. B. (1998). NF-kappa B and Rel proteins: evolutionarily conserved mediators of immune responses. Annu. Rev. Immunol. 16, 225-260.

Gierse, J. K., McDonald, J. J., Hauser, S. D., Rangwala, S. H., Koboldt, C. M., and Seibert, K. (1996). A single amino acid difference between cyclooxygenase-1 (COX-1) and -2 (COX-2) reverses the selectivity of COX-2 specific inhibitors. J Biol. Chem. 271(26), $15810-15814$. 
Gordon, S., and Taylor, P. R. (2005). Monocyte and macrophage heterogeneity. Nat.Rev.Immunol. 5(12), 953-964.

Habeeb, A. G., Praveen Rao, P. N., and Knaus, E. E. (2001). Design and synthesis of 4,5diphenyl-4-isoxazolines: novel inhibitors of cyclooxygenase-2 with analgesic and antiinflammatory activity. J Med Chem. 44(18), 2921-2927.

Harding, F. A., McArthur, J. G., Gross, J. A., Raulet, D. H., and Allison, J. P. (1992). CD28mediated signalling co-stimulates murine $\mathrm{T}$ cells and prevents induction of anergy in $\mathrm{T}$ cell clones. Nature 356(6370), 607-609.

Hibbs, J. B., Jr., Taintor, R. R., Vavrin, Z., and Rachlin, E. M. (1988). Nitric oxide: a cytotoxic activated macrophage effector molecule. Biochem. Biophys. Res. Commun. 157(1), 8794.

Hoffmann, A., Levchenko, A., Scott, M. L., and Baltimore, D. (2002). The IkappaB-NF-kappaB signaling module: temporal control and selective gene activation. Science 298(5596), 1241-1245.

Huxford, T., Huang, D. B., Malek, S., and Ghosh, G. (1998). The crystal structure of the IkappaBalpha/NF-kappaB complex reveals mechanisms of NF-kappaB inactivation. Cell 95(6), 759-770.

Imlay, J. A., Chin, S. M., and Linn, S. (1988). Toxic DNA damage by hydrogen peroxide through the Fenton reaction in vivo and in vitro. Science 240(4852), 640-642.

Ishizuka, K., and Mitsui, S. (1967). Activation or inactivation mechanisms of biological active compunds in higher plants. II. On anilide degrading enzyme. Abstr. Ann. Meeting Agr. Chem. Soc. Jap., 62. 
Jackson, P. G., and Evans, S. R. Intraperitoneal macrophages and tumor immunity: A review. J.Surg.Oncol. 75(2), 146-154. 2000.

Johnson-Leger, C., Aurrand-Lions, M., and Imhof, B. A. (2000). The parting of the endothelium: miracle, or simply a junctional affair? J.Cell Sci. 113 ( Pt 6), 921-933.

Jones, R. D., Hancock, J. T., and Morice, A. H. (2000) NADPH oxidase: a universal oxygen sensor? Free Radic.Biol.Med. 29(5), 416-424.

Kamijo, R., Harada, H., Matsuyama, T., Bosland, M., Gerecitano, J., Shapiro, D., Le, J., Koh, S. I., Kimura, T., and Green, S. J. (1994). Requirement for transcription factor IRF-1 in NO synthase induction in macrophages. Science 263(5153), 1612-1615.

Karin, M. (1999). The beginning of the end: IkappaB kinase (IKK) and NF-kappaB activation. J. Biol. Chem. 274(39), 27339-27342.

Karin, M. (1999). How NF-kappaB is activated: the role of the IkappaB kinase (IKK) complex. Oncogene 18(49), 6867-6874.

Kaul, N., and Forman, H. J. (1996). Activation of NF kappa B by the respiratory burst of macrophages. Free Radic.Biol.Med. 21(3), 401-405.

Kramer, R. M., and Sharp, J. D. (1997). Structure, function and regulation of Ca2+-sensitive cytosolic phospholipase A2 (cPLA2). FEBS Lett. 410(1), 49-53.

Kurumbail, R. G., Stevens, A. M., Gierse, J. K., McDonald, J. J., Stegeman, R. A., Pak, J. Y., Gildehaus, D., Miyashiro, J. M., Penning, T. D., Seibert, K., Isakson, P. C., and Stallings, W. C. (1996). Structural basis for selective inhibition of cyclooxygenase-2 by antiinflammatory agents. Nature 384(6610), 644-648.

Lee, S. H., and Hannink, M. (2002). Characterization of the nuclear import and export functions of Ikappa B(epsilon). J. Biol. Chem. 277(26), 23358-23366. 
Li, J., Peet, G. W., Pullen, S. S., Schembri-King, J., Warren, T. C., Marcu, K. B., Kehry, M. R., Barton, R., and Jakes, S. (1998). Recombinant IkappaB kinases alpha and beta are direct kinases of Ikappa Balpha. J. Biol. Chem. 273(46), 30736-30741.

Li, Z., and Nabel, G. J. (1997). A new member of the I kappaB protein family, I kappaB epsilon, inhibits RelA (p65)-mediated NF-kappaB transcription. Mol. Cell Biol. 17(10), 61846190.

Li, Z. W., Chu, W., Hu, Y., Delhase, M., Deerinck, T., Ellisman, M., Johnson, R., and Karin, M. (1999). The IKKbeta subunit of IkappaB kinase (IKK) is essential for nuclear factor kappaB activation and prevention of apoptosis. J. Exp. Med. 189(11), 1839-1845.

Liu, H., and Pope, R. M. (2004). Phagocytes: mechanisms of inflammation and tissue destruction. Rheum.Dis.Clin.North Am. 30(1), 19-39.

Matsunaka, S. (1968). Propanil hydrolysis: inhibition in rice plants by insecticides. Science 160(834), 1360-1361.

McClure, G. Y., Helm, R. M., Stine, K., Burks, A. W., Jones, S. M., and Gandy, J. (2001). Evaluation of immune parameters in propanil-exposed farm families. Arch. Environ. Contam Toxicol. 41(1), 104-111.

McEver, R. P. (2002). Selectins: lectins that initiate cell adhesion under flow. Curr.Opin.Cell Biol. 14(5), 581-586.

McKenzie, S. E., and Schreiber, A. D. (1998). Fc gamma receptors in phagocytes. Curr.Opin.Hematol. 5(1), 16-21.

McMillan, D. C., Freeman, J. P., and Hinson, J. A. (1990). Metabolism of the arylamide herbicide propanil. I. Microsomal metabolism and in vitro methemoglobinemia. Toxicol. Appl. Pharmacol. 103(1), 90-101. 
McMillan, D. C., Leakey, J. E., Arlotto, M. P., McMillan, J. M., and Hinson, J. A. (1990). Metabolism of the arylamide herbicide propanil. II. Effects of propanil and its derivatives on hepatic microsomal drug-metabolizing enzymes in the rat. Toxicol. Appl. Pharmacol. 103(1), 102-112.

McMillan, D. C., Bradshaw, T. P., McMillan, J. M., Hinson, J. A., and Jollow, D. J. (1991). Contribution of 3,4-dichlorophenylhydroxylamine in propanil-induced hemolytic anemia. Adv. Exp. Med. Biol. 283, 343-345.

McMillan, D. C., Bradshaw, T. P., Hinson, J. A., and Jollow, D. J. (1991). Role of metabolites in propanil-induced hemolytic anemia. Toxicol. Appl. Pharmacol. 110(1), 70-78.

McMillan, D. C., Bradshaw, T. P., McMillan, J. M., Hinson, J. A., and Jollow, D. J. (1991). Contribution of 3,4-dichlorophenylhydroxylamine in propanil-induced hemolytic anemia. Adv. Exp. Med. Biol. 283, 343-345.

Meade, E. A., Smith, W. L., and DeWitt, D. L. (1993). Differential inhibition of prostaglandin endoperoxide synthase (cyclooxygenase) isozymes by aspirin and other non-steroidal anti-inflammatory drugs. J Biol. Chem. 268(9), 6610-6614.

Medzhitov, R. (2001). Toll-like receptors and innate immunity. Nat.Rev.Immunol. 1(2), 135145.

Miwa, M., Stuehr, D. J., Marletta, M. A., Wishnok, J. S., and Tannenbaum, S. R. (1987). Nitrosation of amines by stimulated macrophages. Carcinogenesis 8(7), 955-958.

Morse, D. L., Baker, E. L., Jr., Kimbrough, R. D., and Wisseman, C. L. (1979). Propanilchloracne and methomyl toxicity in workers of a pesticide manufacturing plant. Clin.Toxicol. 15(1), 13-21. 
Nelson, D. E., Ihekwaba, A. E., Elliott, M., Johnson, J. R., Gibney, C. A., Foreman, B. E., Nelson, G., See, V., Horton, C. A., Spiller, D. G., Edwards, S. W., McDowell, H. P., Unitt, J. F., Sullivan, E., Grimley, R., Benson, N., Broomhead, D., Kell, D. B., and White, M. R. (2004). Oscillations in NF-kappaB signaling control the dynamics of gene expression. Science 306(5696), 704-708.

Palombella, V. J., Rando, O. J., Goldberg, A. L., and Maniatis, T. (1994). The ubiquitinproteasome pathway is required for processing the NF-kappa B1 precursor protein and the activation of NF-kappa B. Cell 78(5), 773-785.

Parashar, B., Latha, S. S., O'Guin, K., Butler, J., Vikram, B., and Shafit-Zagardo, B. (2005). Inhibition of human neuroblastoma cell growth by CAY10404, a highly selective Cox-2 inhibitor. J Neurooncol. 71(2), 141-148.

Pastorelli, R., Allevi, R., Romagnano, S., Meli, G., Fanelli, R., and Airoldi, L. (1995). Gas chromatography-mass spectrometry determination of ethylenethiourea hemoglobin adducts: a possible indicator of exposure to ethylene bis dithiocarbamate pesticides. Arch.Toxicol. 69(5), 306-311.

Pastorelli, R., Catnacci, G., Guanci, M., Fanelli, R., Valoti, E., Minoia, C., and Airoldi, L. (1998). 3,4-Dichloroaniline-haemoglobin adducts in humans: preliminary data on agricultural workers exposed to propanil. Biomarkers 3(3), 227-233.

Qualliotine-Mann, D., Agwu, D. E., Ellenburg, M. D., McCall, C. E., and McPhail, L. C. (1993). Phosphatidic acid and diacylglycerol synergize in a cell-free system for activation of NADPH oxidase from human neutrophils. J.Biol.Chem. 268(32), 23843-23849.

Ramachandran, V., Yago, T., Epperson, T. K., Kobzdej, M. M., Nollert, M. U., Cummings, R. D., Zhu, C., and McEver, R. P. (2001). Dimerization of a selectin and its ligand stabilizes 
cell rolling and enhances tether strength in shear flow. Proc.Natl.Acad.Sci.U.S.A 98(18), 10166-10171.

Rodriguez, M. S., Wright, J., Thompson, J., Thomas, D., Baleux, F., Virelizier, J. L., Hay, R. T., and Arenzana-Seisdedos, F. (1996). Identification of lysine residues required for signalinduced ubiquitination and degradation of I kappa B-alpha in vivo. Oncogene 12(11), 2425-2435.

Rossetti, G., Collinge, M., Bender, J. R., Molteni, R., and Pardi, R. (2002). Integrin-dependent regulation of gene expression in leukocytes. Immunol.Rev. 186, 189-207.

Sabbioni, G., and Neumann, H. G. (1990).Biomonitoring of arylamines: hemoglobin adducts of urea and carbamate pesticides. Carcinogenesis 11(1), 111-115.

Saccani, S., Pantano, S., and Natoli, G. (2001). Two waves of nuclear factor kappaB recruitment to target promoters. J.Exp.Med. 193(12), 1351-1359.

Sarris, A. H., Daliani, D., Ulmer, R., Crow, M., Broxmeyer, H. E., Pugh, W., Reiss, M., Cabanillas, F., Deisseroth, A. B., and Duvic, M. (1996). Interferon-inducible protein-10 and the pathogenesis of cutaneous T-cell lymphomas. Leuk.Lymphoma 24(1-2), 103-110.

Sasmono, R. T., and Hume, D. A. (2002). The biology of macrophages. Eds. Kaufmann, S. Gordon S. and Medzhitov, R. in The Innate Immune Response to Infection. Am.Society for Microbiology Press , 71-94.

Saura, M., Zaragoza, C., Bao, C., McMillan, A., and Lowenstein, C. J. (1999). Interaction of interferon regulatory factor-1 and nuclear factor kappaB during activation of inducible nitric oxide synthase transcription. J.Mol.Biol. 289(3), 459-471. 
Schapiro, J. M., Libby, S. J., and Fang, F. C. (2003). Inhibition of bacterial DNA replication by zinc mobilization during nitrosative stress. Proc.Natl.Acad.Sci.U.S.A 100(14), 84968501.

Scherer, D. C., Brockman, J. A., Chen, Z., Maniatis, T., and Ballard, D. W. (1995). Signalinduced degradation of I kappa B alpha requires site-specific ubiquitination. Proc. Natl. Acad. Sci. U. S. A 92(24), 11259-11263.

Singleton, S. D., and Murphy, S. D. (1973). Propanil (3,4-dichloropropionanilide)-induced methemoglobin formation in mice in relation to acylamidase activity. Toxicol.Appl.Pharmacol. 25(1), 20-29.

Smith, W. L., DeWitt, D. L., and Garavito, R. M. (2000). Cyclooxygenases: structural, cellular, and molecular biology. Annu. Rev. Biochem. 69, 145-182.

Stevens, J.T. and Summer D.D. (1991) Herbicides. In Handbook of Pesticide Toxicology. Hayes, W.J. and Laws E.R. Eds. Academic Press, New York, NY. 10-88.

Still, C. C., and Kuzirian, O. (1967). Enzyme detoxication of 3',4'-dichloropropionanilide in rice and barnyard grass, a factor in herbicide selectivity. Nature 216(5117), 799-800.

Streb, H., Irvine, R. F., Berridge, M. J., and Schulz, I. (1983). Release of Ca2+ from a nonmitochondrial intracellular store in pancreatic acinar cells by inositol-1,4,5trisphosphate. Nature 306(5938), 67-69.

Stuehr, D. J., and Marletta, M. A. (1987). Synthesis of nitrite and nitrate in murine macrophage cell lines. Cancer Res. 47(21), 5590-5594.

Sun, S. C., Ganchi, P. A., Ballard, D. W., and Greene, W. C. (1993). NF-kappa B controls expression of inhibitor I kappa B alpha: evidence for an inducible autoregulatory pathway. Science 259(5103), 1912-1915. 
Takeda, K., Takeuchi, O., Tsujimura, T., Itami, S., Adachi, O., Kawai, T., Sanjo, H., Yoshikawa, K., Terada, N., and Akira, S. (1999). Limb and skin abnormalities in mice lacking IKKalpha. Science 284(5412), 313-316.

Takeda, K., and Akira, S. (2004).TLR signaling pathways. Semin.Immunol. 16(1), 3-9.

Tanaka, M., Fuentes, M. E., Yamaguchi, K., Durnin, M. H., Dalrymple, S. A., Hardy, K. L., and Goeddel, D. V. (1999). Embryonic lethality, liver degeneration, and impaired NF-kappa B activation in IKK-beta-deficient mice. Immunity. 10(4), 421-429.

Turci, R., Barisano, A., Balducci, C., Colosio, C., and Minoia, C. (2006). Determination of dichloroanilines in human urine by gas chromatography/mass spectrometry: validation protocol and establishment of Reference Values in a population group living in central Italy. Rapid Commun.Mass Spectrom. 20(17), 2621-2625.

U.S. Environmental Protection Agency (2002a). Summary of Propanil Risk Assessment. May 20.

U.S. Environmental Protection Agency. (2002b). Memorandum. Propanil. Human Health Risk Assessment (Revised). February 28.

U.S. Environmental Protection Agency. (2003). Office of pesticide programs special review and reregistration division. Re-registration Eligibility Decision for Propanil. EPA-738-F-03002

U.S. Environmental Protection Agency. (2004). Pesticides industry sales and usage. 2000 and 2001 market estimates.

U.S. National Library of Medicine. Hazardous Substances Databank. (1995). Bethesda, MD. 1011. 
Ustyugova, I. V., Frost, L. L., Van, D. K., Brundage, K. M., Schafer, R., and Barnett, J. B. (2007). 3,4-dichloropropionaniline suppresses normal macrophage function. Toxicol.Sci. $97(2), 364-374$.

Vodovotz, Y., Kwon, N. S., Pospischil, M., Manning, J., Paik, J., and Nathan, C. (1994). Inactivation of nitric oxide synthase after prolonged incubation of mouse macrophages with IFN-gamma and bacterial lipopolysaccharide. J.Immunol. 152(8), 4110-4118.

Wauchope, R. D., Buttler, T. M., Hornsby, A. G., ugustijn-Beckers, P. W., and Burt, J. P. (1992).The SCS/ARS/CES pesticide properties database for environmental decisionmaking. Rev.Environ.Contam Toxicol. 123, 1-155.

Weil, R., Laurent-Winter, C., and Israel, A. (1997). Regulation of IkappaBbeta degradation. Similarities to and differences from IkappaBalpha. J. Biol. Chem. 272(15), 9942-9949.

Weiss, S. J., and Peppin, G. J. (1986). Collagenolytic metalloenzymes of the human neutrophil. Characteristics, regulation and potential function in vivo. Biochem. Pharmacol. 35(19), 3189-3197.

Whitelaw, D. M. (1966). The intravascular lifespan of monocytes. Blood 28(3), 455-464.

Whiteside, S. T., Epinat, J. C., Rice, N. R., and Israel, A. (1997). I kappa B epsilon, a novel member of the I kappa B family, controls RelA and cRel NF-kappa B activity. EMBO J. 16(6), 1413-1426.

Wilkinson, P. C. (1994). Cellular accumulation and inflammation. In Textbook of Immunopharmacology (M.M.Dale, J.C.Foreman, and T.D.Fan, Eds.), 3 ed., pp. 211-230. Blackwell Scientific Publications.

Williams, C. S., Mann, M., and DuBois, R. N. (1999). The role of cyclooxygenases in inflammation, cancer, and development. Oncogene 18(55), 7908-7916. 
Williams, J. A., and Shacter, E. (1997). Regulation of macrophage cytokine production by prostaglandin E2. Distinct roles of cyclooxygenase-1 and -2. J Biol. Chem. 272(41), 25693-25699.

Williams, T. J., and Morley, J. (1973). Prostaglandins as potentiators of increased vascular permeability in inflammation. Nature 246(5430), 215-217.

Wittke, K., Hajimiragha, H., Dunemann, L., and Begerow, J. (2001). Determination of dichloroanilines in human urine by GC-MS, GC-MS-MS, and GC-ECD as markers of low-level pesticide exposure. J.Chromatogr.B Biomed.Sci.Appl. 755(1-2), 215-228.

Woodmansee, A. N., and Imlay, J. A. (2003). A mechanism by which nitric oxide accelerates the rate of oxidative DNA damage in Escherichia coli. Mol.Microbiol. 49(1), 11-22.

Worthylake, R. A., and Burridge, K. (2001). Leukocyte transendothelial migration: orchestrating the underlying molecular machinery. Curr.Opin.Cell Biol. 13(5), 569-577.

$\mathrm{Wu}$, T. (2005). Cyclooxygenase-2 and prostaglandin signaling in cholangiocarcinoma. Biochim.Biophys.Acta 1755(2), 135-150.

Xie, Q. W., Whisnant, R., and Nathan, C. (1993). Promoter of the mouse gene encoding calciumindependent nitric oxide synthase confers inducibility by interferon gamma and bacterial lipopolysaccharide. J Exp. Med. 177(6), 1779-1784.

Xie, Q. W., Kashiwabara, Y., and Nathan, C. (1994). Role of transcription factor NF-kappa B/Rel in induction of nitric oxide synthase. J Biol. Chem. 269(7), 4705-4708.

Xie, Y. C., Schafer, R., and Barnett, J. B. (1997a). Inhibitory effect of 3,4-dichloropropionaniline on cytokine production by macrophages is associated with LPS-mediated signal transduction. J. Leukoc. Biol. 61(6), 745-752. 
Xie, Y. C., Schafer, R., and Barnett, J. B. (1997b). The immunomodulatory effects of the herbicide propanil on murine macrophage interleukin- 6 and tumor necrosis factor-alpha production. Toxicol. Appl. Pharmacol. 145(1), 184-191.

Yang, F., Tang, E., Guan, K., and Wang, C. Y. (2003). IKK beta plays an essential role in the phosphorylation of RelA/p65 on serine 536 induced by lipopolysaccharide. J. Immunol. 170(11), 5630-5635.

Zandi, E., Rothwarf, D. M., Delhase, M., Hayakawa, M., and Karin, M. (1997). The IkappaB kinase complex (IKK) contains two kinase subunits, IKKalpha and IKKbeta, necessary for IkappaB phosphorylation and NF-kappaB activation. Cell 91(2), 243-252.

Zandi, E., Chen, Y., and Karin, M. (1998). Direct phosphorylation of IkappaB by IKKalpha and IKKbeta: discrimination between free and NF-kappaB-bound substrate. Science 281(5381), 1360-1363.

Zeyer J., Kearney P.C., 1984. Degradation of o-nitrophenol and m-nitrophenol by Pseudomonas putida. J. Agr. Food Chem. 32, 238-242.

Zhong, H., Suyang, H., Erdjument-Bromage, H., Tempst, P., and Ghosh, S. (1997). The transcriptional activity of NF-kappaB is regulated by the IkappaB-associated PKAc subunit through a cyclic AMP-independent mechanism. Cell 89(3), 413-424.

Zhong, H., Voll, R. E., and Ghosh, S. (1998). Phosphorylation of NF-kappa B p65 by PKA stimulates transcriptional activity by promoting a novel bivalent interaction with the coactivator CBP/p300. Mol. Cell 1(5), 661-671.

Zimmerman, G. A. (2001). Two by two: the pairings of P-selectin and P-selectin glycoprotein ligand 1. Proc.Natl.Acad.Sci.U.S.A 98(18), 10023-10024. 


\section{Appendix 1}

\section{A review of the immunotoxicity of the pesticide 3,4-dichloropropionanalide}

Submitted to Journal of Toxicology and Environmental Health, Part B (2007)

Keith D. Salazar ${ }^{1,2}$, Irina V. Ustyugova ${ }^{1}$, Kathleen M. Brundage, John B. Barnett, and Rosana Schafer ${ }^{3}$.

Department of Microbiology, Immunology and Cell Biology, Robert C. Byrd Health Sciences Center, West Virginia University, Morgantown, West Virginia, 26506-9177.

Running title: Immunotoxicity of propanil

Key words: propanil, 3,4-dichloropropionanilide, pesticide, immunity, immunotoxicity, DCPA

${ }^{1}$ K.D.S. and I.V.U. contributed equally to this work.

${ }^{2}$ Present address: Keith Salazar, Ph.D. Department of Molecular Biomedical Sciences, CVM

Research Building, Box 8401, NCSU Campus, Raleigh, NC 27695.kdsalaza@ncsu.edu

${ }^{3}$ Corresponding author: Rosana Schafer, Ph.D. Department of Microbiology, Immunology and Cell Biology, Health Sciences Center North, P.O. Box 9177, West Virginia University, Morgantown, WV 26506-9177. rschafer@hsc.wvu.edu. Telephone: 304-293-3104. Fax: 304293-7823.

Contact information for authors: Telephone: 304-293-3104. Fax: 304-293-7823. 


\begin{abstract}
The pesticide 3,4-dichloropropionanilide (propanil or alternatively, DCPA) is a member of the acetanilide chemical family and is predominantly used for the control of weeds on commercial rice crops worldwide. The present report was written to provide a brief review of the general toxicity of propanil followed by a detailed summary of the immunotoxicity studies that were performed to date in mammalian in vivo and in vitro models. Propanil affects the immune system at organ, cellular, and molecular levels. Studies have demonstrated that it causes thymic atrophy and splenomegaly and decreases developing $\mathrm{T}$ and $\mathrm{B}$ cell populations in the thymus and bone marrow. Natural killer (NK) cells and macrophages are critical components of the innate immune system. NK cell cytotoxicity and the ability of macrophages to phagocytose, kill pathogenic bacteria, and produce inflammatory cytokines are suppressed by propanil. Propanil also affects the respiratory burst of macrophages, inhibiting reactive oxygen and nitrogen species production. Molecular mechanisms responsible for propanil's effects have begun to be elucidated and include alterations in NF- $\kappa \mathrm{B}$ transcription factor activity and intracellular $\mathrm{Ca}^{2+}$ signaling. Propanil exposure alters a number of functions of mature $\mathrm{T}$ lymphocytes and B lymphocytes that impacts the adaptive immune response. T cell cytotoxic activity and cytokine production are major $\mathrm{T}$ cell functions inhibited by propanil. The humoral antibody response to model antigens and intact bacteria is differentially affected after propanil exposure. How these changes in innate and adaptive immune responses impact the host response to bacterial challenge or vaccination has begun to be examined.
\end{abstract}




\section{Introduction}

The pesticide 3,4-dichloropropionanilide (propanil or alternatively, DCPA, Figure 1) is an herbicide that is predominantly used for the control of weeds on commercial rice crops. Several studies investigated the adverse effects of propanil. Propanil was demonstrated to exert significant effects on the nervous and immune systems. This report provides a brief background of the general toxic effects attributed to propanil exposure and primarily focuses on the immunotoxicity studies performed in mammalian in vivo and in vitro models. In addition, epidemiological reports examining the immunotoxic effects of propanil on professional applicators and people living in areas of propanil use are summarized. The majority of the studies reviewed here were performed in animal models. There is a continuing need for additional epidemiology studies in humans to determine if the experimental data that demonstrates immunotoxicity after exposure to herbicides has clinical relevance to humans. Vial et al. (1996) reviewed the available human data for several pesticides that demonstrated the potential for pesticides to cause immune modulation but also the divergent results reported for a number of chemicals illustrating the need for additional human studies.

\section{Background and General Toxicity}

Propanil is in the acetanilide chemical family (U.S.EPA, 2003). Approximately $99 \%$ of the propanil used in the United States is for the control of weeds on rice crops (U.S.EPA, 2003). Roughly $50-70 \%$ of all rice grown in the U.S. is treated with propanil (U.S.EPA, 2003). In the United States alone, a 2001 estimate by the Environmental Protection Agency ranked propanil as the $17^{\text {th }}$ most used pesticide in the U.S. (U.S.EPA, 2004). Although there have been numerous studies published on the effects of propanil on the immune system, the EPA recommended in 
2002 that additional studies need to be performed on the immunotoxicity of propanil. The range of propanil application extends throughout the lower southern states along the Mississippi River and in some areas of California. Propanil is restricted exclusively to commercial use and rapidly degrades in the soil and water. The half-life in the soil is 1-3 days and 2-3 days in the water (Wauchope et al., 1992). Given the lack of residential use of propanil and the short half-life, exposure to the chemical is primarily restricted to applicators and residents who live near treated farms. The preferred method of application is via ground boom sprayers and aerial methods (U.S.EPA, 2003).

The most common routes of propanil exposure include inhalation, dermal, orbital, and to a lesser extent, oral. Upon entry into the organism, propanil is rapidly metabolized in the liver by the enzyme acylamidase into the major metabolite 3,4-dichloroaniline (DCA) (Williams and Jacobson, 1966). Other metabolites of propanil include 2'-hydroxypropanil and 6'hydroxypropanil (McMillan et al., 1990a). DCA is subsequently metabolized to 6-hydroxy-3, 4dichloroaniline and N-hydroxy-3, 4-dichloroaniline. DCA can also undergo rapid redox cycling within the erythrocytes, resulting in the oxidation of $\mathrm{Fe} 2+$ in hemoglobin to $\mathrm{Fe} 3+$, forming methemoglobin. Due to the rapid metabolism of the parent compound, propanil remains at detectable concentrations in the blood of rats for approximately $48 \mathrm{hr}$ following exposure (Izmerov, 1984). A number of adverse side effects are induced after exposure to propanil including hemolytic anemia, methemoglobinemia, and myelotoxicity. In vivo studies using Sprague-Dawley rats showed that inhibition of the acylamidase activity with triorthotolyl phosphate decreased the amount of methemoglobinemia formed following a $400 \mathrm{mg}$ propanil $/ \mathrm{kg}$ body weight (mg/kg) intraperitoneal (i.p.) exposure to propanil (Singleton and Murphy, 1973). In addition, i.p. injections of the metabolite N-hydroxy-3, 4-dichloroaniline into rats were found 
to induce the same amount of hemolytic anemia as the parent compound (McMillan et al., 1991). In vitro studies analyzing the ability of propanil metabolites to oxidize hemoglobin in erythrocyte suspensions confirmed that N-hydroxy-3, 4-dichloroaniline was the most potent oxidizing metabolite (McMillan et al., 1990a). Together, these studies indicate that metabolism of the parent compound is necessary for induction of anemia.

The duration of the anemic effects differ according to the exposure concentration of propanil (McMillan et al., 1990b). Analysis of blood samples from acutely exposed SpragueDawley rats treated with a $300 \mathrm{mg} / \mathrm{kg}$ dose demonstrated that methemoglobinemia peaks at 4.5 hr post-exposure (24\%) and is detectable for up to $24 \mathrm{hr}$ (McMillan et al., 1990b). However, a lower dose of $100 \mathrm{mg} / \mathrm{kg}$ induced a peak in methemoglobin levels at $1.5 \mathrm{hr}(5 \%)$ that returned to normal levels $12 \mathrm{hr}$ following exposure (McMillan et al., 1990b). These data indicate that the anemic effect induced by propanil is brief and does not persist following the clearance of propanil from blood.

There have been animal studies to determine the overt toxicity of propanil. The reported $\mathrm{LD}_{50}$ value for oral propanil exposure is $367 \mathrm{mg} / \mathrm{kg}$ up to $2500 \mathrm{mg} / \mathrm{kg}$ in rats (US National Library of Medicine. Hazardous Substances Databank, 1995). In mice, acute toxicity occurs between 400 and $800 \mathrm{mg} / \mathrm{kg}$ (Singleton and Murphy, 1973). Propanil is practically nontoxic via the dermal route with a reported $\mathrm{LD}_{50}$ of greater than $5000 \mathrm{mg} / \mathrm{kg}$ in rabbits and is moderately toxic via the inhalation route with a reported 4 hour $\mathrm{LC}_{50}$ or $1.12 \mathrm{mg} / 1 \mathrm{in}$ rats (Stevens and Summer, 1991).

Other studies using common toxic endpoints such as mutagenicity, reproductive toxicity, and carcinogenicity have yielded negative results. Propanil was not found to be mutagenic as determined in Salmonella reversion assays (McMillan et al., 1988). The EPA determined that 
propanil is not a carcinogen in humans (U.S.EPA, 2003). Reproductive studies in rats showed that chronic oral propanil exposure does not produce any abnormalities in the fertility of the parents nor does it affect the health of the offspring (Ambrose et al., 1972). Thus, propanil is classified in the "slightly toxic" toxicity class III for oral exposures and toxicity class IV for inhalation and dermal exposures (U.S.EPA, 2003).

There is little literature available on the effects of human exposure to propanil. Propanil is applied to rice crops by aerial spraying (Barnes et al., 1987). This technique allows for the exposure of people in the area immediately surrounding the rice field to airborne particles of propanil called drift. Two studies measured the potential for dermal and mucosal exposure to propanil drift as a function of distance from the rice field (Barnes et al., 1987; Richards et al., 2001). Non-applicator personnel working in fields adjacent to propanil-treated fields were exposed to low concentrations of propanil resulting from drift after aerial application (Barnes et al., 1987). These personnel were calculated to be exposed to concentrations that were $10^{6}$ fold lower than the $\mathrm{LC}_{50}$ established in respiratory rat models (Barnes et al., 1987). Richards et al. (2001) determined the levels of propanil in and around homes adjacent to rice fields by the collection of drift on polyethylene patches and by active sampling of propanil vapor by air pumps. Air pump samples taken near the fields had no detectable propanil vapor and passive collection on polyethylene patches was highly variable. From this study it was determined that the factors most important in the drift of aerially applied propanil were wind speed, direction and distance from the field. Wind direction was correlated with deposition levels inside the homes. In conjunction with the drift study, a two-year study of immune parameters in families living adjacent to rice fields as compared to regional cohorts not exposed to aerial application of propanil was performed (McClure et al., 2001). Blood samples from both children and adults 
were taken before spraying, 5-7 days after spraying, and after harvest, and analyzed for changes in \% of blood leukocytes, leukocyte cell numbers, mitogen-induced proliferation, mitogenstimulated cytokine production and natural killer cell (NK) activity. No significant differences were found between control and group exposed to propanil in any of the immune parameters measured (Richards et al., 2001). This might be due to the low atmospheric concentration of propanil in family homes lying adjacent to the spray fields (Richards et al., 2001). Homes located approximately $125 \mathrm{~m}$ from the spray fields were found to have no more than $6.65 \mu \mathrm{g}$ of propanil per sampling section (Richards et al., 2001). These studies highlight the difficulties that arise in the determination of human exposure levels in field situations. From these studies, it may concluded that direct exposure to propanil in rice growing areas is most likely highly variable. Some exposures may occur by inhalation, although the more likely exposure route is through skin and mouth. Although the population in the vicinity of spraying appears to be unaffected, there may be a high degree of variability in the exposure of this population.

Assessment of the effects of propanil on humans demonstrates that the greatest risk of high exposure is to applicators and manufacturing workers. Propanil was demonstrated to be toxic to factory workers exposed during the production and packaging of the herbicide (Morse et al., 1979). Symptoms associated with propanil exposure included chloracne, small pupils, nausea/vomiting, blurred vision, muscle weakness, fatigue and increased salvation (Morse et al., 1979). Acne occurred in $61 \%$ of the workers in contact with propanil and was the only symptom definitively connected to propanil exposure in in vivo tests on rabbit ears. Further research demonstrated that the contaminants 3,4,3', 4'-tetrachloroazobenzene and 3,4,3', 4'tetrachloroazoxybenzene, which are found in propanil and the major metabolite DCA, are responsible for the chloracne (Kimbrough 1980). 
Pastorelli, et al., (1998) developed a gas chromatography-mass spectrometry (GC-MS) method to take advantage of the formation of adducts between DCA and hemoglobin (Hb) to measure DCA levels in agricultural workers exposed to propanil. Blood and urine was collected prior to, 2 days after, and 4 months after propanil exposure from two agricultural workers. Detectable levels of DCA-Hb adducts were detectable at both 2 days (621 and $31 \mathrm{fmol} / \mathrm{mg} \mathrm{Hb}$ ) and 4 months 65 and $57 \mathrm{fmol} / \mathrm{mg} \mathrm{Hb}$ ) post-exposure . Urine levels were only detectable at 2 days post-exposure (1.07 and $3.5 \mathrm{nmol} / \mathrm{ml}$ urine) (Pastorelli, et al., 1998). Although the study was limited to only 2 subjects it suggests that for biomonitoring over time, the measurement of DCA-hemoglobin adducts may be more sensitive. Two additional studies have used sensitive GC-MS to measure the levels of DCA in human urine (Wittke et al, 2001; Turci et al., 2006). Both studies reported levels of DCA in the urine of the general population. Since DCA is a marker for exposure to number of pesticides the exposure could not solely be attributed to propanil but the development of these more sensitive assays may now allow for closer monitoring of pesticide exposure and levels of pesticides found in humans.

\section{Immunotoxicity}

The effects of exposure to propanil on primary and secondary immune organs have been determined. Myelotoxic effects were demonstrated following propanil exposure (Blyler et al., 1994; Malerba et al., 2002;). Ex vivo colony-forming assays from the bone marrow of acutely exposed $\mathrm{C} 57 \mathrm{Bl} / 6$ mice demonstrated that the early stem cell progenitors, myeloid stem cells (CFU-S) and erythroid burst-forming units (BFU-E), are decreased in number following 200 $\mathrm{mg} / \mathrm{kg}$ i.p. propanil exposure (Blyler et al., 1994). However, the more differentiated cell types such as erythroid colony-forming units (CFU-E), granulocyte/macrophage progenitor cells 
(CFU-GM), macrophages (CFU-M), and neutrophils (CFU-G) are not reduced in number following propanil treatment (Blyler et al., 1994). Similar effects on the early erythroid stem cells are seen with human cord progenitor cells following propanil treatment (Malerba et al., 2002). In vitro exposure of human cord blood to propanil demonstrated that the CFU-E and BFU-E progenitors had $50 \%$ of their growth inhibited ( $\mathrm{IC}_{50}$ ) by $234 \mu \mathrm{M}$ and $441 \mu \mathrm{M}$ of propanil, respectively (Malerba et al., 2002). The more differentiated CFU-GM progenitors had an $\mathrm{IC}_{50}$ of greater than $500 \mu \mathrm{M}$, indicating similar susceptibility to the effects of propanil on the more immature progenitors in both humans and mice (Malerba et al., 2002). However, in humans, the metabolite DCA is far less toxic to CFU/BFU-E progenitors than its parent compound (Malerba et al., 2002).

Initial chronic and acute exposure studies found that secondary immune organs are also affected after exposure to propanil (Ambrose et al., 1972; Barnett and Gandy, 1989). Female rats exposed for 2 years to 400 ppm of propanil mixed in their feed had increased spleen weights, but the heart, kidneys, liver and testes weights were not affected (Ambrose et al., 1972). In a subchronic study, female and male rats treated for 3 months with 1000 or 3300 ppm of propanil, respectively, did not have altered organ weights except increased spleen sizes (Ambrose et al., 1972). Additionally, acutely exposed C57Bl/6 mice treated i.p. with $200 \mathrm{mg} / \mathrm{kg}$ of propanil had decreased thymus weights and increased spleen weights (Barnett and Gandy, 1989). The mechanism for thymic atrophy after propanil exposure is discussed in greater detail in the following sections. The exact cause and nature of the splenomegaly is currently unknown, however, the mature T cell and B cell populations are unchanged (Zhao et al, 1995; Salazar et al., 2005). These studies suggest that propanil may be more toxic to secondary immune organs than non-immune organs. 


\section{Innate immunity}

The innate immune system provides the first line of defense against invading pathogens through physical barriers such as skin and mucous membranes, chemical barriers such as enzymes and $\mathrm{pH}$, and a range of cell types including monocytes, macrophages, polymorphonuclear monocytes (PMN), and natural killer cells (NK). The innate immune system is responsible for not only rapidly eliminating pathogens, but also initiating adaptive immune responses through cell adhesion molecules and cytokines. Immunotoxic effects on cells of the innate immune system may therefore compromise both the ability of an organism to control initial infections and to generate an appropriate protective adaptive immune response. There are limited studies that examined the effect of propanil on NK cell function. More extensive studies were conducted to characterize the immunotoxic effects of propanil on macrophages and on macrophage function. (Table 1)

NK cells are large granular lymphocytes that contribute to innate immunity through cytokine production and as cytotoxic cells in anti-microbial and tumor immunity. Mice treated with propanil, and the major metabolite DCA, have reduced NK cell cytotoxicity (Barnett et al., 1992). Splenic NK cells from mice treated i.p. with propanil $(50,100$ or $200 \mathrm{mg} / \mathrm{kg}$ ) or molar equivalents of DCA ( 75 or $150 \mathrm{mg} / \mathrm{kg}$ ) had a concentration-dependent significant reduction in NK cell activity 7 days post-exposure (Barnett et al., 1992). A more recent study demonstrated that i.p. exposure to propanil $(50,75$, or $100 \mathrm{mg} / \mathrm{kg}$ ) suppressed NK cell activity as early as $12 \mathrm{hr}$ post-exposure in a dose-dependent manner (Pruett et al., 2000). The effect of propanil exposure on NK cell cytokine production was not reported.

Macrophages play essential roles in both innate and adaptive immune responses. Their major functions in the innate immune response are phagocytosis and killing of invading 
pathogens. Subsequently, macrophages function as antigen presenting cells in the initiation of an adaptive immune response. The production of a number of chemokines and cytokines by macrophages are important immune mediators in both innate and adaptive immune responses.

Two of the important cytokines produced by macrophages are interleukin (IL)-6 and tumor necrosis factor- $\alpha$ (TNF- $\alpha)$. A series of studies were performed to determine the effect of in vivo exposure to propanil on cytokine production by murine macrophages. Thioglycolateelicited peritoneal exudate cells (PEC) were obtained 3 and 7 days after i.p. propanil exposure (200 mg/kg), re-stimulated ex vivo with lipopolysaccharide (LPS), and the culture supernatants assayed for IL-6 and TNF- $\alpha$ (Xie et al., 1997a ${ }^{1}$ ). Both IL-6 and TNF- $\alpha$ production were inhibited at both 3 and 7 days post-exposure compared to cells from the vehicle-treated controls. Oral administration of a high dose of propanil $(400 \mathrm{mg} / \mathrm{kg})$ resulted in the inhibition of IL-6 production by PEC at 3 and 7 days post-exposure; however, a lower dose $(40 \mathrm{mg} / \mathrm{kg})$ had no effect (Xie et al., 1997a). TNF- $\alpha$ production was reduced significantly 3 and 7 days postexposure to both the $40 \mathrm{mg} / \mathrm{kg}$ and $400 \mathrm{mg} / \mathrm{kg}$ doses, demonstrating a more dramatic reduction of TNF- $\alpha$ after oral administration of propanil.

Studies of thioglycollate-elicted PEC exposed in vitro to propanil and simultaneously stimulated with LPS demonstrated a concentration-dependent suppression of IL- 6 and TNF- $\alpha$ production after $24 \mathrm{hr}$ in culture. Concentrations of $33 \mu \mathrm{M}$ and $66 \mu \mathrm{M}$ propanil inhibited IL-6 production by $25 \%$ and $58 \%$, respectively (Xie et al., 1997a). TNF- $\alpha$ production was also reduced by $30 \%$ and $60 \%$ of control with the same propanil concentrations (Xie et al., 1997a). Furthermore, mRNA levels of both cytokines were reduced in a concentration-dependent manner

\footnotetext{
${ }^{1}$ Xie et al., 1997a and Xie et al., 1997b were originally published with incorrect doses for the in vitro studies. The doses cited here are the correct doses.
} 
without affecting mRNA stability suggesting that propanil effects cytokine production at the level of transcription (Xie et al., 1997a). It was also demonstrated that in vitro exposure to propanil significantly inhibits the production of TNF- $\alpha$ by the murine macrophage cell line, IC21, and the human monocytic cell line, THP-1 (Ustyugova et al., 2007).

TNF- $\alpha$ synthesis is dependent on the transcription factor, nuclear factor $\kappa \mathrm{B}$ (NF- $\kappa \mathrm{B})$ (Collart et al., 1990). Signals induced by many stimuli including LPS and other bacterial cell

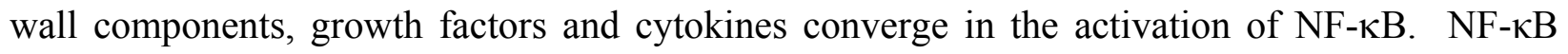
translocates into the nucleus where it binds the promoter regions of genes responsible for cytokine production. A series of studies were performed using IC-21 cells to determine if the reduction in cytokine production after exposure to propanil was due to effects on NF- $\mathrm{KB}$ activation. Propanil was demonstrated to reduce TNF- $\alpha$ promoter activity in regions that contain

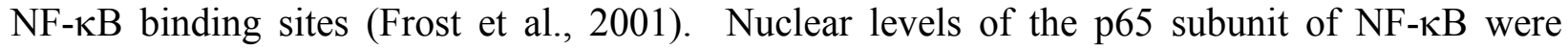
reduced in IC-21 cells treated with $66 \mu \mathrm{M}$ or $167 \mu \mathrm{M}$ propanil and stimulated with LPS. In addition, it was demonstrated that there was decreased DNA binding of both the p65/p50 heterodimer and p50/p50 homodimers of NF-kB after exposure to propanil (Frost et al., 2001). Overall, these results suggest that propanil may reduce cytokine production through effects on NF- $\mathrm{BB}$ activation.

Another aspect of macrophage activation is the release of intracellular $\mathrm{Ca}^{2+}$-stores that initiate signal transduction cascades and the activation of transcription factors, including NF- $\mathrm{KB}$ and nuclear factor of activated $\mathrm{T}$ cells (NFAT). A concentration of $66 \mathrm{M}$ propanil completely abrogated intracellular $\mathrm{Ca}^{2+}$ release in thioglycollate-elicted PEC and IC-21 cells within 2 min of LPS stimulation (Xie et al., 1997b ${ }^{1}$ ). However, binding of LPS to macrophages (Xie et al., 
1997b) as well as mobility of plasma membrane lipid hydrocarbon chains were not affected by propanil (Brundage et al., 2003).

The hydrolysis of the membrane-associated phosphatidyl-inositol-4, 5-bisphophate ( $\left.\mathrm{PIP}_{2}\right)$ and formation of two breakdown products, inositol 1,4,5-triphosphate $\left(\mathrm{IP}_{3}\right)$ and diacylglycerol (DAG) are required to release $\mathrm{Ca}^{2+}$ from the internal store. $\mathrm{IP}_{3}$ is known to directly induce intracellular $\mathrm{Ca}^{2+}$ release (Berridge and Irvine, 1984; Streb et al., 1983). Measurement of $\mathrm{IP}_{3}$ levels in propanil-treated cells demonstrated an increase in the production of this breakdown product. It did not, however, generate a rise in intracellular $\mathrm{Ca}^{2+}$ levels (Xie et al., 1997b). Overall, these data suggest that propanil inhibits $\mathrm{Ca}^{2+}$ release after IP3 generation. Thus a potential mechanism for how propanil produces a reduction in inflammatory cytokine production in macrophages is through an effect on NF- $\mathrm{KB}$ and $\mathrm{Ca}^{2+}$.

As previously mentioned, a critical function of macrophages is phagocytosis and destruction of pathogens. The production of reactive oxygen species (ROS) and reactive nitrogen species (RNS) is crucial for bactericidal activity. The effect of propanil exposure on phagocytosis and bactericidal function was determined in murine thioglycollate-elicted PEC and THP-1 cells. The ability of murine PEC and THP-1 cells to phagocytose fluorescent beads was measured after exposure to 50 or $100 \mu \mathrm{M}$ propanil (Ustyugova et al., 2007). Phagocytosis by propanil-treated PEC was reduced by 34 and $51 \%$ in the 50 and $100 \mu \mathrm{M}$ treatment groups, respectively, compared to control cells. THP-1 cell phagocytic activity was reduced by 57 and $64 \%$ in the 50 and $100 \mu \mathrm{M}$ treatment groups (Ustyugova et al., 2007). Together these data demonstrate that propanil inhibited phagocytosis by both murine and human macrophages.

After phagocytosis, an ingested pathogen is destroyed by ROS and RNS that are produced during the respiratory burst (Gwinn and Vallyathan, 2006). ROS production induced 
by LPS in vitro results in the recruitment of several of the cytosolic components to the membrane where they join with membrane-bound flavocytochrome subunits to form an active nicotinamide adenine dinucleotide phosphate (NADPH) oxidase (Bonizzi et al., 2000). Active NADPH oxidase produces hydrogen peroxide and hydroxyl radicals $\left(\mathrm{OH}^{-}\right)$that are detected intracellularly by confocal microscopy. The generation of oxygen intermediates in thioglycollate-elicted PEC and THP-1 cells treated with 25 or $100 \mu \mathrm{M}$ propanil and stimulated with LPS was determined. PEC displayed a statistically significant decrease (45\%) in ROS production in the $100 \mu \mathrm{M}$ treated group compared to controls (Ustyugova et al., 2007). THP-1 cells demonstrated a quantitative decrease in ROS generation at all concentrations of propanil, which was not statistically significant. These results suggest the production of ROS by primary macrophages was more sensitive to the effects of propanil then the THP-1 cell line.

RNS have potent anti-microbial activity and are a vital component in the elimination of invading organisms by the innate immune system. RNS are produced after ingestion of microorganisms in vivo and after in vitro stimulation with LPS, due to the induction of inducible nitric oxide synthase (iNOS) and results in the production of nitric oxide (NO). Short-lived NO reacts with ROS giving rise to a number of toxic nitrogen compounds, such as peroxynitrite (ONOO-) which in turn decompose into additional nitrates and nitrites (Hibbs et al., 1988; Miwa et al., 1987; Rao, 2000; Stuehr and Marletta, 1987). An accumulation of nitrite in the media of thioglycollate-elicited PEC treated with 25 or $100 \mu \mathrm{M}$ propanil and stimulated with LPS was determined (Ustyugova et al., 2007). Nitrite production was significantly decreased by $40 \%$ at $12 \mathrm{hr}$ after propanil-treatment $(100 \mu \mathrm{M})$ compared to ethanol-treated control cells. Cells treated with 25 or $100 \mu \mathrm{M}$ propanil for $24 \mathrm{hr}$ showed a 15 and $22 \%$ decrease in nitrate production, respectively. Propanil also decreased iNOS protein expression in PEC following LPS 
stimulation. Twenty-five and $100 \mu \mathrm{M}$ propanil inhibited iNOS levels by 10 and $14 \% 6 \mathrm{hr}$ postexposure, respectively. The largest inhibition of $29 \%$ was observed $12 \mathrm{hr}$ following $100 \mu \mathrm{M}$ propanil exposure. The longest exposure to $100 \mu \mathrm{M}$ propanil, $24 \mathrm{hr}$, decreased iNOS $12 \%$ (Ustyugova et al., 2007). The inhibition of RNS, which are important in the initial clearance of a bacterial infection, could potentially increase the susceptibility of an exposed individual to infection.

The effect of propanil on the ability of THP-1 cells and thioglycollate-elicited PEC to kill L. monocytogenes was measured as an indicator of the biological consequences of propanil exposure. Cells treated with vehicle and stimulated with interferon-gamma (IFN- $\gamma)$ and LPS, showed a significant reduction in bacterial burden after $5 \mathrm{hr}$ (Ustyugova et al., 2007). In contrast, treatment of stimulated THP-1 cells with $100 \mu \mathrm{M}$ propanil reduced the number of bacteria initially phagocytosed followed by replication of the bacteria as demonstrated by an increase in the number of colony-forming units (CFU). Stimulated PEC treated with $100 \mu \mathrm{M}$ propanil phagocytosed few bacteria and there was a quantitative increase in the number of CFU over time (Ustyugova et al., 2007). These results demonstrate that propanil produced inhibition of listeriacidal activity of macrophages and additional evidence that propanil inhibits phagocytosis.

\section{Adaptive Immunity}

Adaptive immunity is a highly specific response that results in the generation of antigenspecific lymphocytes and a memory response. The main cellular components of the adaptive response are B lymphocytes and T lymphocytes. B lymphocytes primarily function to produce and secrete antibodies, which is the basis of the humoral immune response. T lymphocytes 
perform a number of essential functions in the generation and regulation of a potent adaptive immune response. Very simplistically, $\mathrm{CD}^{+} \mathrm{T}$ cells are responsible for the activation and regulation of the humoral immune response and cell-mediated immune responses. $\mathrm{CD} 8^{+} \mathrm{T}$ cells function primarily as cytotoxic T lymphocytes (CTL) to destroy infected or transformed host cells. T-regulatory/suppressor cells function in a variety of ways to control the adaptive immune response. The following sections summarize the studies examining the effect of propanil on cellmediated and humoral immune responses (Table 2).

\section{Thymic atrophy and $T$ cell function}

The thymus is the organ responsible for $\mathrm{T}$ cell development and maturation. As mentioned above, propanil induces thymic atrophy. Thymic atrophy is present in acutely exposed mice approximately 2-4 days post-exposure (Cuff et al., 1996). Thymic weight is reduced for up to 7 days following an i.p. dose of $200 \mathrm{mg} / \mathrm{kg}$ (Barnett and Gandy, 1989). By day 7 there is an increase in thymus size and cellularity in the propanil-treated mice, however, atrophy is still significant (Cuff et al., 1996). After 14 days post-exposure, thymus size and cellularity have returned to normal (Cuff et al., 1996). Analysis of the T cell populations in the mesenteric lymph nodes and spleen 7 days post-exposure shows that $T$ cell numbers in the periphery are unaffected as a result of the thymic atrophy (Zhao et al., 1995). Failure to detect decreases in the peripheral $\mathrm{T}$ cell populations of immune organs suggests that the transient thymic atrophy is indicative of chemical stress and that acute propanil exposure does not lead to long-term changes in immune cell populations.

The decrease in thymic weight is accompanied by a loss in the total number of thymocytes, as well as an overall decline in the number of $\mathrm{T}$ cells in the various developmental 
stages of maturation (Zhao et al., 1995). Exposure to propanil at doses as low as $100 \mathrm{mg} / \mathrm{kg}$ decrease the number of all the $\mathrm{CD}^{+}$and $\mathrm{CD}^{-}$subpopulations (Zhao et al., 1995). Mice treated intraperitoneally with $200 \mathrm{mg} / \mathrm{kg}$ have the largest decrease in $\% \mathrm{CD} 4^{+} \mathrm{CD} 8^{+}$double positive (DP) thymocytes 4 days post-exposure (Cuff et al., 1996). Data indicate that DP cells are the most sensitive of the thymocyte populations (Cuff et al., 1996). The observed decrease in the immature population results in a downstream effect of decreasing the number of the more mature $\mathrm{CD}^{+}$single positive (SP) and $\mathrm{CD} 8^{+} \mathrm{SP}$ cells (de la Rosa et al., 2005; Cuff et al., 1996). In response to the sudden loss in the thymocyte populations, the recovery of the thymocyte population is generated by an increase in \% cycling DP and $\mathrm{CD} 8^{+} \mathrm{SP}$ cells 4 days post-exposure (Cuff et al., 1996). The \% cycling thymocyte subpopulations returns to normal by day 7 , indicating that recovery is initiated rapidly after exposure (Cuff et al., 1996). The rapid recovery of the thymus may explain why there are no significant changes in peripheral $\mathrm{T}$ cell populations.

The primary mechanism by which propanil induces thymic atrophy is by increasing the level of glucocorticoids (Cuff et al., 1996; de la Rosa et al., 2005). Acute i.p. propanil exposure $(50 \mathrm{mg} / \mathrm{kg}$ ) in C57Bl/6 mice elevated the levels of corticosterone in the serum to approximately $1000 \mathrm{ng} / \mathrm{ml}$ compared to approximately $60 \mathrm{ng} / \mathrm{ml}$ for control mice (de la Rosa et al., 2005). The rise in corticosterone serum levels peaks within one hr following propanil exposure and returns to baseline levels within $24 \mathrm{hr}$ (de la Rosa et al., 2005). Inhibition of the glucocorticoid receptors (GR) with the GR antagonist RU486 or removal of the adrenal glands, the primary site for glucocorticoid production, substantially abrogates thymic atrophy induced by propanil (Cuff et al., 1996; de la Rosa et al., 2005). The potent induction of glucocorticoids after propanil exposure also led to its recent use in modeling and predicting the immunotoxicity of compounds using the area under the corticosterone concentration versus time curve model (Pruett et al., 
2000; Schwab et al., 2005). This mathematical model was developed to predict the potential immunotoxic effects of a compound using the induction of corticosterone over time after exposure to a chemical stressor.

The extent of thymic atrophy induced by propanil was also increased when combined with other herbicides (de la Rosa et al., 2005). The herbicide 2,4-dichlorophenoxyacetic acid (2,4-D) did not affect the number of DP or $\mathrm{CD}^{+} \mathrm{SP}$ cells following a $150 \mathrm{mg} / \mathrm{kg}$ i.p. exposure (de la Rosa et al., 2005). However, the addition of $150 \mathrm{mg} / \mathrm{kg}$ of 2,4-D combined with a 150 $\mathrm{mg} / \mathrm{kg}$ dose of propanil induced a greater-than-additive decrease in the number of both the DP and $\mathrm{CD}^{+}$SP cell populations (de la Rosa et al., 2005). Data demonstrate the potential for other chemicals to enhance the toxicity of propanil (de la Rosa et al., 2005).

Analysis of $\mathrm{T}$ cell function after in vivo exposure to propanil indicated that $\mathrm{T}$ cells are relatively resistant to the adverse effects of propanil. As mentioned previously, propanil exposure produced splenomegaly (Ambrose et al., 1972; Barnett and Gandy, 1989). The spleen is also an important secondary lymphoid organ. Therefore, the spleen was chosen for early immunotoxic characterization studies. Mixed lymphocyte reactions (MLR) are typically used to characterize $\mathrm{CD}^{+} \mathrm{T}$ cell function. MLR of spleen cells from mice treated with an acute i.p. dose of propanil one week prior to harvest demonstrated that only at the highest dose tested (400 $\mathrm{mg} / \mathrm{kg}$ ) was there a significant decrease in the MLR (Barnett and Gandy, 1989). In vivo cell mediated immune responses were assessed using the contact hypersensitivity reaction (CHR) (Barnett and Gandy, 1989). The CHR was also decreased in animals treated with only the highest tested dose (400 mg/kg) (Barnett and Gandy, 1989). Finally, proliferation of splenocytes from mice treated in vivo with propanil was determined following ex vivo stimulation with the $\mathrm{T}$ cell mitogen, Concanavalin A (ConA). Again, only animals treated with the highest tested dose 
had significant reductions in proliferation (Barnett and Gandy, 1989). However, ConA stimulated splenocytes from animals treated i.p. with $200 \mathrm{mg} / \mathrm{kg}$ showed a significant reduction in IL-2 production (27\% of control) and IL-6 production (45\% of control) (Zhao et al., 1998 ${ }^{2}$ ). Together, the studies characterizing the $\mathrm{T}$ cell toxicity of in vivo propanil exposure indicate that several endpoints are required to establish an accurate inference of propanil's toxicity.

A number of studies have been performed using in vitro exposure of primary spleen cells or $\mathrm{T}$ cell lines to further characterize the effect of propanil on $\mathrm{T}$ lymphocyte function. Murine splenocytes exposed in vitro to propanil and stimulated with the $\mathrm{T}$ cell mitogen ConA have reduced IL-2 cytokine levels. Maximal reduction (59\% of control) of IL-2 was observed $24 \mathrm{hr}$ post-exposure at the peak of cytokine production in control splenocytes (Zhao et al., 1998). The lowest tested concentration of propanil that reduced IL-2 cytokine levels was $66 \mu \mathrm{M}$ (Zhao et al., 1998). Propanil was also found to suppress IL-2 production in the murine T cell lymphoma line, EL-4, and the human T cell lymphoma line, Jurkat (Zhao et al., 1999²; Brundage et al., 2004). Similar to primary T cells, propanil reduced IL-2 production by EL-4 cells maximally at $24 \mathrm{hr}$ post-exposure (Zhao et al., 1999). Sixty-six $\mu \mathrm{M}$ of propanil was the lowest concentration that significantly reduced IL-2 production 2 -fold (Zhao et al., 1999). In addition, $66 \mu \mathrm{M}$ of propanil inhibited transcription of IL-2 mRNA by 50\% and reduced the half-life of IL-2 mRNA from 140 to $90 \mathrm{~min}$ in EL-4 cells (Zhao et al., 1999). These studies suggest propanil acts at both the transcriptional and post-transcriptional level to affect IL-2 production by murine cells.

Interestingly, the human $\mathrm{T}$ cell line Jurkat is more sensitive to the effects of propanil than murine $\mathrm{T}$ cells. Forty-eight hr after in vitro exposure to $5 \mu \mathrm{M}$ of propanil IL-2 mRNA levels

\footnotetext{
${ }^{2}$ Zhao et al., 1998 and Zhao et al., 1999 were originally published with incorrect doses for the in vitro studies. The doses cited here are the correct doses.
} 
were reduced by $77 \%$ (Brundage et al., 2004). Propanil was also found to reduce the binding of the IL-2 transcription factor, activating-protein 1 (AP-1), to DNA suggesting a possible mechanism for propanil-induced suppression (Brundage et al., 2004). Fifty $\mu \mathrm{M}$ of propanil reduced AP-1 binding maximally (20\% of control) $1 \mathrm{hr}$ post-exposure (Brundage et al., 2004). AP-1 may have reduced binding activity due to the effects of propanil on one of the proteins of the heterodimer of AP-1. Propanil decreased both the phosphorylation of c-jun as well as the protein levels of c-jun $1 \mathrm{hr}$ post-exposure (Brundage et al., 2004). It was demonstrated that the level of c-jun mRNA was decreased early after exposure compared to control and subsequently a delayed degradation (Brundage et al., 2004). Electron-spin resonance analysis suggests that propanil increased a small population of lipid molecules that exhibited reduced hydrocarbon chain mobility near the bilayer hydrocarbon core following cell stimulation (Brundage et al., 2003). The affect of this alteration in the distribution of lipids in the membrane on IL-2 production is currently unknown (Brundage et al., 2003).

In addition to cytokine production by $\mathrm{T}$ cells, recent in vitro studies have been reported that assessed the effect of propanil exposure on Cytotoxic T Lymphocyte (CTL) function. CTL exposed to propanil in vitro during a primary MLR had proliferative capacity and CTL activity that was comparable to vehicle-treated cells (Sheil et al., 2006). Interestingly, however, when the CTL that had been exposed to propanil in the primary culture were re-stimulated in the absence of additional propanil in the culture, proliferation and CTL activity was significantly reduced (Sheil et al., 2006). Data suggest that early exposure to propanil may exert a greater ability to reduce $\mathrm{T}$ cell function during a secondary response; however, these results have not been confirmed in vivo. 
The collective studies examining the effects of propanil on $\mathrm{T}$ lymphocytes suggest that although the thymus is affected by the early induction of glucocorticoids, which results in thymic atrophy, mature $\mathrm{T}$ cell populations and their functions are relatively intact. Cytokine production was the most effected by propanil exposure and, while the exact mechanism has not been defined, transcriptional, post-transcriptional, and transcription factor activity all were altered after exposure.

\section{B cell toxicity and the humoral immune response}

As mentioned previously, propanil was found to be myelotoxic and induced splenomegaly. The bone marrow microenvironment is the site of B cell maturation prior to release into circulation. The spleen is an important site for antibody production to bacterial pathogens (Martin et al., 2001; Manz et al., 2002; Zandvoort and Timens, 2002). Approximately $40 \%$ of the lymphocytes in the spleen are B lymphocytes (Salazar et al., 2005). Together, these organs represent two important sites for evaluating the immunotoxic effects of propanil on the development and function of B cells.

$\mathrm{B}$ cell maturation proceeds in the bone marrow from the pro-B cell to pre- $\mathrm{B}$ cell and finally to the immature $\operatorname{IgM}^{+}$B cell (Rosenberg and Kincade, 1994). As discussed above, propanil had adverse effects on developing $\mathrm{T}$ cell populations in the thymus. To determine if exposure to propanil also affected developing $\mathrm{B}$ cell populations, pro-B, pre-B, and immature $\operatorname{IgM}^{+} \mathrm{B}$ cell populations were enumerated in the bone marrow after propanil treatment. Similar to the effect observed in the thymus propanil exposure decreased the number of developing B cells in the bone marrow available for maturation. In vivo i.p. propanil exposure at the lowest studied dose of $50 \mathrm{mg} / \mathrm{kg}$ decreased the number of murine pre-B cells in the bone marrow $(50 \%$ 
of control) 7 days post-exposure (de la Rosa et al., 2003). Immature $\operatorname{IgM}^{+} \mathrm{B}$ cells were also decreased in number ( $50 \%$ of control) at a dose of $150 \mathrm{mg} / \mathrm{kg} 7$ days post-exposure (de la Rosa et al., 2003). Fourteen days after propanil exposure the pre-B and immature $\operatorname{IgM}^{+} \mathrm{B}$ cell populations had returned to control levels. In addition, the transient decrease in immature B cells in the bone marrow did not result in a loss of circulating B cells as determined by an analysis of splenocyte populations (Salazar et al., 2005). Total splenic B cell numbers, as well as the circulating follicular B cell population, remained unchanged following propanil exposure (Salazar et al., 2005). Therefore, in both the thymus and the bone marrow propanil had a transient effect on the developing immature $\mathrm{T}$ and $\mathrm{B}$ cell populations that did not result in changes in the number of mature $\mathrm{T}$ cells and B cells in the periphery.

Although propanil exposure did not affect the number of B cells in the periphery, it was demonstrated to suppress some B cell functions. Exposure in vivo to $400 \mathrm{mg} / \mathrm{kg}$ of propanil suppressed splenic B cell proliferation after ex vivo stimulation with the B cell mitogen LPS (Barnett and Gandy, 1989). Analysis of the IgM antibody response to both T-independent type 2 (TI-2) and T-dependent (TD) model antigens found that these responses were more sensitive to propanil's adverse effects than B cell proliferation (Barnett and Gandy, 1989; Barnett et al., 1992). Exposure to propanil followed by immunization with sheep red blood cells (SRBC) on day 3 (post-propanil treatment) decreased the number of SRBC plaque forming cells (PFC) in a dose-dependent fashion when assayed on day 7 (Barnett and Gandy, 1989). Fifty $\mathrm{mg} / \mathrm{kg}$ of propanil was the lowest dose to significantly reduce the number of SRBC PFC ( $67 \%$ of control) (Barnett and Gandy, 1989). Higher doses of propanil, $200 \mathrm{mg} / \mathrm{kg}$, and a molar equivalent of the major metabolite, DCA, $150 \mathrm{mg} / \mathrm{kg}$, respectively, were found to decrease the number of PFC in animals immunized with DNP-Ficoll 4 days following propanil exposure (75\% of control) 
(Barnett at al., 1992). These reports suggest that propanil exerts immunotoxic effects either directly on B cells or the supporting microenvironment critical for normal B cell function.

\section{Adaptive immune response to bacteria}

In general, the collective studies on immune function demonstrated that propanil exerted suppressive effects on the immune system. Challenging the immune system with live and killed whole bacteria provides important information toward understanding the relevance of the altered immune functions described in the previous sections. Live bacterial challenge studies may be utilized to determine the significance of the effect of decreased immune cell function on clearing infections produced by common pathogens. These studies are important for assessing the risk of infection that is associated with a specific level of immunotoxicity.

The toxic effects of propanil on the cell-mediated immune response were studied using a Listeria monocytogenes infection model in C57BL/6 mice (Watson et al., 2000). Animals were exposed to propanil and at various days after exposure were challenged with live $L$. monocytogenes. Spleen cells and liver cells from the propanil-treated and L. monocytogenes challenged animals had a $50 \%$ reduction in IFN- $\gamma$ production compared to cells from control animals after ex vivo stimulation with Con A or heat-killed L. monocytogenes (Watson et al., 2000). However, analysis of spleen and liver homogenates taken directly from propanil-treated and L. monocytogenes-infected animals showed no significant difference in the levels of IL-6, IFN- $\gamma$, TNF- $\alpha$, and IL- $1 \beta$ compared to control animals only infected with $L$. monocytogenes (Watson et al., 2000). Additionally, animals treated with $200 \mathrm{mg} / \mathrm{kg}$ propanil and challenged with a $\mathrm{LD}_{50}$ of $L$. monocytogenes did not demonstrate any greater susceptibility to infection than control animals (Watson et al., 2000). This indicates that a $200 \mathrm{mg} / \mathrm{kg}$ dose produces 
immunotoxic effects on cell-mediated responses measured in vitro, but does not significantly affect the host's ability to mount an effective immune response in vivo. A limitation of this study is that $L$. monocytogenes infections are initially controlled in mice lacking an adequate cytotoxic T cell response (Bancroft et al., 1991). However, there have been no studies reported to date characterizing the effect of an acute propanil exposure on the immune response to a pathogen that predominantly requires a competent cytotoxic $\mathrm{T}$ cell response to clear the infection.

The effect of propanil exposure on the antibody response to a bacterial challenge was also characterized. The antibody response to the bacterial vaccine heat-killed Streptococcus pneumoniae (HKSP) elicits both a TI-2 and a TD antibody response. The immunodominant TI-2 antigen is the cell wall polysaccharide phosphorylcholine (PC). S. pneumoniae also has a number of TD antigens capable of stimulating an antibody response. Pneumococcal surface protein A (PspA) is a TD antigen that was well characterized in antibody response studies. C57Bl/6 mice treated i.p. with $150 \mathrm{mg} / \mathrm{kg}$ of propanil at the time of i.p. vaccination with $2 \times 10^{8}$ colony forming units (CFU) of HKSP have increased numbers of PC-specific IgM, and the predominant $\mathrm{PC}$ isotypes IgG2b and $\mathrm{IgG} 3$, splenic antibody secreting cells (ASC) compared to vehicle treated vaccinated animals (Salazar et al., 2005). Propanil increased the PC-specific antibody response 4-fold 5 days post-exposure. Propanil maximally elevated the PC-specific ASC response 4-6-fold 7 days post-exposure (Salazar et al., 2005). However, when mice were treated i.p. with $150 \mathrm{mg} / \mathrm{kg}$ of propanil on the day of HKSP vaccination, the number of PspAspecific IgM and IgG splenic ASC was unchanged from control animals 14 days post-exposure and vaccination (Salazar et al., 2005). Interestingly, if treatment with propanil was delayed until day 9 after HKSP vaccination, the number of IgM and IgG PspA-specific ASC increased 2-fold 
over vehicle-treated mice on day 14, the time of the peak PspA-specific serum antibody response (Schafer, unpublished observations). The increase in PC-specific and PspA-specific ASC following propanil exposure and HKSP vaccination affected IgM and IgG in a similar manner and did not alter either the kinetics or the predominant isotypes produced to either antigen.

The mechanism regulating the increased antibody response due to propanil exposure has not been established. However, it is clear that the ovaries play a role in mediating the antibody increase (Salazar et al., 2006). Mice that were surgically ovariectomized and treated i.p. with propanil and HKSP did not produce the 4-6-fold rise in PC-specific ASC (Salazar et al., 2006). Although the ovaries are required for the propanil-induced antibody stimulation, several lines of evidence demonstrated that the enhanced response was independent of an estrogenic mechanism (Salazar et al., 2006). In male mice, propanil exposure also induced a similar increase in PCspecific ASC but the rise was independent of the testes as demonstrated using castrated mice (Salazar et al., 2006).

The studies discussed above suggest that propanil is able to increase or decrease the antibody response to a diverse set of antigens depending on the time of propanil exposure. The initial studies characterizing the effect of propanil on the antibody response to model antigens suppressed the response when animals were exposed to propanil prior to immunization (Barnett and Gandy, 1989; Barnett et al., 1992). More recently, the S. pneumoniae studies demonstrated a several fold amplification of the antibody response when animals were exposed to propanil simultaneously or following vaccination (Salazar et al, 2005). The data illustrate that the consequences of propanil exposure vary depending on both the timing of the humoral immune response and the type of antigen presented. 
The studies examining the effect of propanil on in vivo humoral and cellular immune responses to bacteria (Watson, et al., 2000; Salazar et al., 2005) suggest that in vitro analysis of cell function is not always indicative of the effects observed on in vivo immune responses. Although the studies characterizing the toxicity of propanil on immune cell populations suggested that propanil might inhibit the response to a virulent pathogen or a bacterial vaccine, data demonstrated either no discernable change in immune effectiveness or a stimulated immune response. The requirement for the ovaries in amplifying the humoral immune response also underscores the importance of potential interactions with the endocrine system in influencing the immune system.

\section{Future Studies and Conclusions}

This review should provide the basis for future studies on understanding the mechanisms of how this commonly used pesticide affects the immune system. There are additional areas that remain to be studied to complete the profile of the immunotoxicity of propanil in mammalian systems. The first major gap that was discussed previously is the paucity of human studies to definitively quantitate both the levels of exposure in humans and the outcomes of exposure. Areas that could begin to be addressed in animal models include the effects of developmental exposure and long-term immune deficits that may result from in utero and/or neonatal exposure to propanil. There are several questions that remain as to propanil's effects on additional components of the innate immune system including complement activation and function, the expression of Toll-like receptors or potential interaction with toll-like receptors. As CTL activity and NK activity are inhibited after propanil exposure, the potential consequences of the inhibition of lytic function on anti-viral and anti-tumor immunity remain to be determined. The 
differential effect propanil has on antibody production to different antigens is also not understood. Propanil may have a direct effect on B cells, in the processing and presentation of antigens, or on signaling pathways necessary for antibody production. The demonstration that propanil can enhance the humoral response after a bacterial vaccination could potentially have implications for propanil acting as an environmental trigger for autoimmune disease, a poorly understood area in immunology. Potential routes of environmental exposure to propanil include aerosol or ingestion. There is very limited information on if propanil alters mucosal immune response in the gut or the respiratory tract.

The overall literature on propanil illustrates the diverse effects a chemical exerts on the immune system and the role that in vivo and in vitro exposure regimens play in defining the immunotoxicity of a chemical and its mechanisms of toxicity. Propanil exerts diverse effects on several components of the immune system including effector cells of both innate and adaptive immune responses. A review of the literature demonstrates that the immunotoxic effects of a chemical are quite complex and involve a number of different mechanisms underlying toxicity. To add to the complexity, exposure to propanil may result in either suppression of immune responses or enhancement depending on the exposure regimen and the particular response being evaluated. The results of the studies reviewed here serve to illustrate the usefulness of in vivo and in vitro assays in defining mechanisms underlying toxicity but also as a reminder that the results obtained in one system may not always reflect the response that will be observed in the other. Overall, for accurate risk assessment, a thorough analysis of the effects of chemical exposure on the immune system must be performed using a variety of experimental systems. 


\section{Acknowledgements}

This work was supported by the National Institutes of Health grants ES007512 (J.B.B.) ES011311 (J.B.B.), ES010953 (J.B.B.) and ES07460 (R.S.). The Flow Cytometric Core Facility is supported by the National Institutes of Health grant RR16440. The authors also acknowledge all of the present and past members of the Barnett and Schafer laboratories for their contributions to the research cited here. 


\section{References}

Ambrose, A. M., Larson, P. S., Borzelleca, J. F., and Hennigar, G. R., Jr. 1972. Toxicologic studies on 3',4'-dichloropropionanilide. Toxicol.Appl.Pharmacol. 23:650-659.

Bancroft, G. J., Schreiber, R. D., and Unanue, E. R. 1991. Natural immunity: a T-cellindependent pathway of macrophage activation, defined in the scid mouse. Immunol.Rev. 124:5-24.

Barnes, C. J., Lavy, T. L., and Mattice, J. D. 1987. Exposure of non-applicator personnel and adjacent areas to aerially applied propanil. Bull.Environ.Contam Toxicol. 39:126-133.

Barnett, J. B. and Gandy, J. 1989. Effect of acute propanil exposure on the immune response of C57B1/6 mice. Fundam.Appl.Toxicol. 12:757-764.

Barnett, J. B., Gandy, J., Wilbourn, D., and Theus, S. A. 1992. Comparison of the immunotoxicity of propanil and its metabolite, 3,4-dichloroaniline, in $\mathrm{C} 57 \mathrm{Bl} / 6$ mice. Fundam.Appl.Toxicol. 18:628-631.

Berridge, M. J., and Irvine, R. F. 1984. Inositol trisphosphate, a novel second messenger in cellular signal transduction. Nature 312:315-321.

Blyler, G., Landreth, K. S., Lillis, T., Schafer, R., Theus, S. A., Gandy, J., and Barnett, J. B. 1994. Selective myelotoxicity of propanil. Fundam.Appl.Toxicol. 22:505-510.

Bonizzi, G., Piette, J., Merville, M. P., and Bours, V. 2000. Cell type-specific role for reactive oxygen species in nuclear factor-kappaB activation by interleukin-1. Biochem. Pharmacol. 59:7-11.

Brundage, K. M., Barnett, J. B., and Mahaney, J. E. 2003. The amide class herbicide 3,4dichloropropionanilide (DCPA) alters the mobility of hydrocarbon chains in $\mathrm{T}$ lymphocyte but not macrophage membranes. J.Toxicol.Environ.Health A 66:2253-2265. 
Brundage, K. M., Schafer, R., and Barnett, J. B. 2004. Altered AP-1 (activating protein-1) activity and c-jun activation in $\mathrm{T}$ cells exposed to the amide class herbicide 3,4dichloropropionanilide (DCPA). Toxicol.Sci. 79:98-105.

Collart, M. A., Baeuerle, P., and Vassalli, P. 1990. Regulation of tumor necrosis factor alpha transcription in macrophages: involvement of four kappa B-like motifs and of constitutive and inducible forms of NF-kappa B. Mol. Cell Biol. 10:1498-1506.

Cuff, C. F., Zhao, W., Nukui, T., Schafer, R., and Barnett, J. B. 1996. 3,4Dichloropropionanilide-induced atrophy of the thymus: mechanisms of toxicity and recovery. Fundam.Appl.Toxicol. 33:83-90.

de la Rosa, P., Barnett, J. B., and Schafer, R. 2003. Loss of pre-B and $\operatorname{IgM}(+)$ B cells in the bone marrow after exposure to a mixture of herbicides. J.Toxicol.Environ.Health A 66:22992313.

de la Rosa, P., Barnett, J. B., and Schafer, R. 2005. Characterization of thymic atrophy and the mechanism of thymocyte depletion after in vivo exposure to a mixture of herbicides. J.Toxicol.Environ.Health A 68:81-98.

Frost, L. L., Neeley, Y. X., Schafer, R., Gibson, L. F., and Barnett, J. B. 2001. Propanil inhibits tumor necrosis factor-alpha production by reducing nuclearlevels of the transcription factor nuclear factor-kappaB in the macrophage cell line IC-21. Toxicol Appl Pharmacol. 172:186-193.

Gwinn, M.R. and Vallythan, V. 2006. Respiratory burst: role in signal transduction in alveolar macrophages. J.Toxicol.Environ.HealthPartB 9:27-39.

Hibbs, J. B., Jr., Taintor, R. R., Vavrin, Z., and Rachlin, E. M. 1988. Nitric oxide: a cytotoxic activated macrophage effector molecule. Biochem. Biophys. Res. Commun. 157: 87-94. 
Izmerov, N. F. 1984. Propanide. Sci.Rev.Soviet Literature Tox.Haz.Chem. 76:1-24.

Kimbrough, R. D. 1980. Human health effects of selected pesticides, chloroaniline derivatives. J.Environ.Sci.Health B 15:977-992.

Malerba, I., Castoldi, A. F., Parent-Massin, D., and Gribaldo, L. 2002. In vitro myelotoxicity of propanil and 3,4-dichloroaniline on murine and human CFU-E/BFU-E progenitors. Toxicol.Sci. 69:433-438.

Manz, R. A., Arce, S., Cassese, G., Hauser, A. E. , Hiepe, F., and Radbruch, A. 2002. Humoral immunity and long-lived plasma cells. Curr.Opin.Immunol. 14:517-521.

Martin, F., Oliver, A. M., and Kearney, J. F. 2001. Marginal zone and B1 B cells unite in the early response against T-independent blood-borne particulate antigens. Immunity 14:617629.

McClure, G. Y., Helm, R. M., Stine, K., Burks, A. W., Jones, S. M., and Gandy, J. 2001. Evaluation of immune parameters in propanil-exposed farm families. Arch.Environ.Contam. Toxicol. 41:104-111.

McMillan, D. C., Bradshaw, T. P., Hinson, J. A., and Jollow, D. J. 1991. Role of metabolites in propanil-induced hemolytic anemia. Toxicol.Appl.Pharmacol. 110:70-78.

McMillan, D. C., Freeman, J. P., and Hinson, J. A. 1990a. Metabolism of the arylamide herbicide propanil. I. Microsomal metabolism and in vitro methemoglobinemia. Toxicol.Appl.Pharmacol. 103:90-101.

McMillan, D. C., McRae, T. A., and Hinson, J. A. 1990b. Propanil-induced methemoglobinemia and hemoglobin binding in the rat. Toxicol.Appl.Pharmacol. 105:503-507.

McMillan, D. C., Shaddock, J. G., Heflich, R. H., Casciano, D. A., and Hinson, J. A. 1988. Evaluation of propanil and its N-oxidized derivatives for genotoxicity in the Salmonella 
typhimurium reversion, Chinese hamster ovary/hypoxanthine guanine phosphoribosyl transferase, and rat hepatocyte/DNA repair assays. Fundam.Appl.Toxicol. 11: 429-439.

Miwa, M., Stuehr, D. J., Marletta, M. A., Wishnok, J. S., and Tannenbaum, S. R. 1987. Nitrosation of amines by stimulated macrophages. Carcinogenesis 8:955-958.

Morse, D. L., Baker, E. L., Jr., Kimbrough, R. D., and Wisseman, C. L., III 1979. Propanilchloracne and methomyl toxicity in workers of a pesticide manufacturing plant. Clin.Toxicol. 15:13-21.

Pastorelli, R., Catenacci, G., Guanci, M., Fanelli, R., Valoti, E., Minoia, C., and Airoldi, L. 1998. 3,4-Dichloroaniline-haemoglobin adducts in humans: preliminary data on agricultural workers exposed to propanil. Biomarkers 3:227-233.

Pruett, S.B., Fan, R., Zheng, Q., Myers, L. P., and Hebert, P. 2000. Modeling and predicting selected immunological effects of a chemical stressor (3,4-dichloropropionanilide) using the area under the corticosterone concentration versus time curve. Toxicol.Sci. 58:7787.

Rao, K. M. K. 2000. Molecular mechanisms regulating iNOS expression in various cell types. J.Toxicol.Environ.HealthPartB 3:27-58.

Richards, S. M., McClure, G. Y., Lavy, T. L., Mattice, J. D., Keller, R. J., and Gandy, J. 2001. Propanil (3,4-dichloropropionanilide) particulate concentrations within and near the residences of families living adjacent to aerially sprayed rice fields. Arch.Environ.Contam. Toxicol. 41:112-116.

Rosenberg, N. and Kincade, P. W. 1994. B-lineage differentiation in normal and transformed cells and the microenvironment that supports it. Curr.Opin.Immunol. 6:203-211. 
Salazar, K. D., de la Rosa, P., Barnett, J. B., and Schafer, R. 2005. The polysaccharide antibody response after Streptococcus pneumoniae vaccination is differentially enhanced or suppressed by 3,4-dichloropropionanilide and 2,4-dichlorophenoxyacetic acid. Toxicol.Sci. 87:123-133.

Salazar, K. D., Miller, M. R., Barnett, J. B., and Schafer, R. 2006. Evidence for a novel endocrine disruptor: The pesticide propanil requires the ovaries and steroid synthesis to enhance humoral immunity. Toxicol.Sci. 93:62-74

Schwab, C. L., Fan, R., Zheng, Q., Myers, L. P., Hebert, P., and Pruett, S. B. 2000. Modeling and predicting stress-induced immunosuppression in mice using blood parameters. Toxicol.Sci. 83:101-113.

Sheil, J. M., Frankenberry, M. A., Schell, T. D., Brundage, K. M., and Barnett, J. B. 2006. Propanil exposure induces delayed but sustained abrogation of cell-mediated immunity through direct interference with cytotoxic T-lymphocyte effectors. Environ.Health Persp. 114:1059-1064.

Singleton, S. D. and Murphy, S. D. 1973. Propanil (3,4-dichloropropionanilide)-induced methemoglobin formation in mice in relation to acylamidase activity. Toxicol.Appl.Pharmacol. 25:20-29.

Stevens, J. T., and Summer, D. D. 1991. Herbicides. Handbook of pesticide toxicology. Hayes, W. J. and Laws, E. R. Eds. Academic Press, New York, NY 10-88

Streb, H., Irvine, R. F., Berridge, M. J., and Schulz, I. 1983. Release of Ca2+ from a nonmitochondrial intracellular store in pancreatic acinar cells by inositol-1,4,5trisphosphate. Nature 306:67-69. 
Stuehr, D. J., and Marletta, M. A. 1987. Synthesis of nitrite and nitrate in murine macrophages. Cancer Res. 47:5590-5594.

Turci, R., Barisano, A., Balducci, C., Colosio, C., and Minoia, C. 2006. Determination of dichloroanilines in human urine by gas chromatography/mass spectrometry: validation protocal and establishment of Reference Values in a population group living in central Italy. RapidCommun.MassSpec. 20:2621-2625.

U.S.ENVIRONMENTAL PROTECTION AGENCY OFFICE OF PESTICIDE PROGRAMS SPECIAL REVIEW AND REREGISTRATION DIVISION. 2003. Re-registration Eligibility Decision for Propanil. EPA-738-F-03-002

U.S.ENVIRONMENTAL PROTECTION AGENCY. 2004. Pesticides industry sales and usage. 2000 and 2001 market estimates.

Ustyugova, I. V., Frost, L. L., Vandyke, K., Brundage, K. M., Schafer, R., and Barnett, J. B. 2007. 3,4-Dichloropropionaniline suppresses normal macrophage function. Toxicol. Sci. $97: 364-374$.

Vial, T., Nicolas, B., and Descotes, J. 1996. Clinical immunotoxicity of pesticides. J.Toxicol.Environ.Health 48:215-229.

Watson, V. A., Barnett, J. B., and Schafer, R. 2000. In vivo cytokine production and resistance to infection after acute exposure to 3,4-dichloropropionaniline. J.Toxicol.Environ.Health A 60:391-406.

Wauchope, R. D., Burt, J. P., Augustijn Beckers, P. W. M., Hornsby, A. G., and Buttler, T. M. 1992. SCS/ARS/CES Pesticide properties database for environmental decision making. Rev.Environ.Contam.Toxicol. 123:10-12. 
Williams, C. H. and Jacobson, K. H. 1966. An acylamidase in mammalian liver hydrolyzing the herbicide 3,4-dichloropropionanilide. Toxicol Appl Pharmacol 9:495-500.

Wittke, K., Hajimiragha, H., Dunemann, L., and Begerow, J. 2001. Determination of dichloroanilines in human urine by GC-MS, GC-MS-MS, and GC-ED as markers of lowlevel pesticide exposure. JchromatographyB 755:215-228.

Xie, Y. C., Schafer, R., and Barnett, J. B. 1997a. The immunomodulatory effects of the herbicide propanil on murine macrophage interleukin-6 and tumor necrosis factor-alpha production. Toxicol.Appl.Pharmacol. 145:184-191.

Xie, Y. C., Schafer, R., and Barnett, J. B. 1997b. Inhibitory effect of 3,4-dichloro-propionaniline on cytokine production by macrophages is associated with LPS-mediated signal transduction. J.Leukoc.Biol. 61:745-752.

Zandvoort, A. and Timens, W. 2002. The dual function of the splenic marginal zone: essential for initiation of anti-TI-2 responses but also vital in the general first-line defense against blood-borne antigens. Clin.Exp.Immunol. 130:4-11.

Zhao, W., Schafer, R., and Barnett, J. B. 1998. Cytokine production by C57BL/6 mouse spleen cells is selectively reduced by exposure to propanil. J.Toxicol.Environ.Health A 55:107120.

Zhao, W., Schafer, R., and Barnett, J. B. 1999. Propanil affects transcriptional and posttranscriptional regulation of IL-2 expression in activated EL-4 cells. Toxicol.Appl.Pharmacol. 154:153-159.

Zhao, W., Schafer, R., Cuff, C. F., Gandy, J., and Barnett, J. B. 1995. Changes in primary and secondary lymphoid organ T-cell subpopulations resulting from acute in vivo exposure to propanil. J.Toxicol.Environ.Health 46:171-181. 
Table 1. Summary of the in vivo and in vitro effects of propanil on natural killer cells and macrophages

\begin{tabular}{|c|c|c|c|c|c|}
\hline Cell Origin & $\begin{array}{l}\text { Route of exposure/ } \\
\text { Length of exposure }\end{array}$ & Assessment & Result & LOAEL $^{1}$ & Reference \\
\hline Spleen & $\begin{array}{c}\text { Intraperitoneal/ } \\
7 \text { days }\end{array}$ & NK lytic activity & Decreased $(20 \%)^{2}$ & $50 \mathrm{mg} / \mathrm{kg}$ & Barnett et al., 1992 \\
\hline \multirow[t]{3}{*}{$\begin{array}{l}\text { Peritoneal } \\
\text { cavity }\end{array}$} & $\begin{array}{c}\text { Intraperitoneal/ } \\
7 \text { days }\end{array}$ & $\begin{array}{l}\text { Cytokine production } \\
\text { (LPS stimulation) }\end{array}$ & & & Xie et al., 1997a \\
\hline & & IL-6 & Decreased $(32 \%)$ & $200 \mathrm{mg} / \mathrm{kg}$ & \\
\hline & & TNF- $\alpha$ & Decreased (55\%) & $200 \mathrm{mg} / \mathrm{kg}$ & \\
\hline \multirow[t]{3}{*}{$\begin{array}{l}\text { Peritoneal } \\
\text { cavity }\end{array}$} & $\begin{array}{l}\text { Oral/ } \\
7 \text { days }\end{array}$ & $\begin{array}{l}\text { Cytokine production } \\
\text { (LPS stimulation) }\end{array}$ & & & Xie et al., 1997a \\
\hline & & IL-6 & Decreased $(35 \%)$ & $400 \mathrm{mg} / \mathrm{kg}$ & \\
\hline & & TNF- $\alpha$ & Decreased $(46 \%)$ & $40 \mathrm{mg} / \mathrm{kg}$ & \\
\hline \multirow{9}{*}{$\begin{array}{l}\text { Peritoneal } \\
\text { exudate } \\
\text { cells }\end{array}$} & In vitro/24 hours & $\begin{array}{l}\text { Cytokine production } \\
\text { (LPS stimulation) }\end{array}$ & & & Xie et al., 1997a, b ${ }^{3}$ \\
\hline & & IL-6 & Decreased $(25 \%)$ & $33 \mu \mathrm{M}$ & \\
\hline & & TNF- $\alpha$ & Decreased $(30 \%)$ & $33 \mu \mathrm{M}$ & \\
\hline & In vitro/24 hours & $\begin{array}{l}\text { mRNA levels } \\
\text { (LPS stimulation) }\end{array}$ & & & Xie et al., 1997a, b \\
\hline & & IL-6 & Decreased (50\%) & $33 \mu \mathrm{M}$ & \\
\hline & & TNF- $\alpha$ & Decreased $(50 \%)$ & $33 \mu \mathrm{M}$ & \\
\hline & In vitro/2 hours & Phagocytosis & Decreased $(33 \%)$ & $50 \mu \mathrm{M}$ & Ustyugova et al., 2007 \\
\hline & In vitro/24 minutes & $\begin{array}{l}\text { ROS production } \\
\text { (LPS stimulation) }\end{array}$ & Decreased (45\%) & $100 \mu \mathrm{M}$ & Ustyugova et al., 2007 \\
\hline & In vitro/12 hours & $\begin{array}{l}\text { RNS production } \\
\text { (LPS stimulation) }\end{array}$ & Decreased (40\%) & $100 \mu \mathrm{M}$ & Ustyugova et al., 2007 \\
\hline
\end{tabular}




\begin{tabular}{|c|c|c|c|c|c|}
\hline \multirow{3}{*}{$\begin{array}{l}\text { THP-1 } \\
\text { (Human } \\
\text { Monocytic } \\
\text { Cell line) }\end{array}$} & In vitro/12 hours & $\begin{array}{l}\text { iNOS protein levels } \\
\text { (LPS stimulation) }\end{array}$ & Decreased (29\%) & $100 \mu \mathrm{M}$ & Ustyugova et al., 2007 \\
\hline & In vitro/ 6 hours & $\begin{array}{l}\text { Cytokine production } \\
\text { (LPS stimulation) } \\
\text { TNF- } \alpha\end{array}$ & Decreased $(30 \%)$ & $50 \mu \mathrm{M}$ & Ustyugova et al., 2007 \\
\hline & In vitro/2 hours & Phagocytosis & Decreased (57\%) & $50 \mu \mathrm{M}$ & Ustyugova et al., 2007 \\
\hline \multirow{4}{*}{$\begin{array}{l}\text { IC-21 } \\
\text { (Murine } \\
\text { macrophage } \\
\text { cell line) }\end{array}$} & In vitro/24 hours & $\begin{array}{c}\text { Cytokine production } \\
\text { (LPS stimulation) } \\
\text { TNF- } \alpha\end{array}$ & Decreased $(30 \%)$ & $33 \mu \mathrm{M}$ & Frost et al., 2001 \\
\hline & In vitro/18 hours & $\begin{array}{l}\text { NF- } \kappa \text { B-dependent } \\
\text { promoter activity } \\
\text { (LPS stimulation) }\end{array}$ & Decreased $(40 \%)$ & $42.5 \mu \mathrm{M}$ & Frost et al., 2001 \\
\hline & In vitro/4 hours & 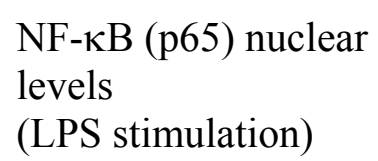 & Decreased (59\%) & $167 \mu \mathrm{M}$ & Frost et al., 2001 \\
\hline & In vitro/2 minutes & $\begin{array}{l}\text { Intracellular } \mathrm{Ca}^{2+} \\
\text { release }\end{array}$ & Decreased $(100 \%)$ & $20 \mu \mathrm{M}$ & Xie et al., 1997b \\
\hline
\end{tabular}

${ }^{1}$ LOAEL - lowest observed adverse effect level tested, $\mathrm{mg} / \mathrm{kg}=\mathrm{mg}$ propanil $/ \mathrm{kg}$ body weight, $\mathrm{m}=$ in vitro dose

${ }^{2}$ Result (\% change) - represents the \% decreased compared to the control group response

${ }^{3}$ Xie et al., 1997a and Xie et al., 1997b were originally published with incorrect doses for the in vitro studies. A correction was submitted to the journal. The doses listed in the table are the correct doses. 
Table 2. Summary of the in vivo immunotoxicity of propanil on $T$ cell functions of the adaptive immune system

\begin{tabular}{|c|c|c|c|c|c|}
\hline $\begin{array}{l}\text { Tissue/Cell } \\
\text { line }\end{array}$ & $\begin{array}{l}\text { Route of exposure/ } \\
\text { Day post-exposure }\end{array}$ & Assessment & Result & LOAEL $^{1}$ & Reference \\
\hline Thymus & $\begin{array}{l}\text { Intraperitoneal/ } \\
\text { 2-4 days }\end{array}$ & $\begin{array}{l}\text { Cell population } \\
\text { CD4-CD8- } \\
\text { CD4+CD8+ } \\
\text { CD4+CD8- } \\
\text { CD4-CD8+ }\end{array}$ & $\begin{array}{l}\text { No change } \\
\text { Decreased } \\
\text { Decreased } \\
\text { Decreased }\end{array}$ & $\begin{array}{l}100 \mathrm{mg} / \mathrm{kg} \\
100 \mathrm{mg} / \mathrm{kg} \\
200 \mathrm{mg} / \mathrm{kg}\end{array}$ & $\begin{array}{l}\text { Cuff et al., } 1996 \\
\text { de la Rosa et al., } 2005\end{array}$ \\
\hline Spleen & $\begin{array}{l}\text { Intraperitoneal/ } \\
7 \text { days }\end{array}$ & $\begin{array}{l}\text { Mixed lymphocyte } \\
\text { response }\end{array}$ & Decreased (47\%) & $400 \mathrm{mg} / \mathrm{kg}$ & Barnett and Gandy, 1989 \\
\hline Spleen & $\begin{array}{l}\text { Intraperitoneal/ } \\
7 \text { days }\end{array}$ & $\begin{array}{l}\text { Contact hypersensitivity } \\
\text { response }\end{array}$ & Decreased (55\%) & $400 \mathrm{mg} / \mathrm{kg}$ & Barnett and Gandy, 1989 \\
\hline Spleen & $\begin{array}{l}\text { Intraperitoneal/ } \\
7 \text { days }\end{array}$ & $\begin{array}{l}\text { Cytokine production } \\
\text { (ConA stimulation) } \\
\text { IL-2 } \\
\text { IL-6 }\end{array}$ & $\begin{array}{l}\text { Decreased }(27 \%) \\
\text { Decreased }(45 \%)\end{array}$ & $200 \mathrm{mg} / \mathrm{kg}$ & Zhao et al., 1998 \\
\hline Splenocytes & $\begin{array}{l}\text { In vitro/ } \\
24 \text { hours }\end{array}$ & $\begin{array}{l}\text { Cytokine production } \\
\text { (ConA stimulation) IL-2 }\end{array}$ & Decreased $(59 \%)$ & $66 \mu \mathrm{M}$ & Zhao et al., 1998 \\
\hline EL-4 & $\begin{array}{l}\text { In vitro/ } \\
24 \text { hours }\end{array}$ & $\begin{array}{l}\text { Cytokine production } \\
\text { (PMA stimulation) } \\
\quad \text { IL-2 } \\
\text { IL-2 mRNA levels } \\
\text { IL-2 mRNA half-life }\end{array}$ & $\begin{array}{l}\text { Decreased ( } 2 \text { fold }) \\
\text { Decreased }\end{array}$ & $\begin{array}{l}66 \mu \mathrm{M} \\
66 \mu \mathrm{M}\end{array}$ & Zhao et al., 1998 \\
\hline Jurkat & $\begin{array}{l}\text { In vitro/ } \\
48 \text { hours } \\
1 \text { hour } \\
1 \text { hour } \\
1 \text { hour }\end{array}$ & $\begin{array}{l}\text { IL-2 mRNA } \\
\text { AP-1 binding } \\
\text { c-jun protein } \\
\text { c-jun phosphorylation }\end{array}$ & $\begin{array}{l}\text { Decreased }(77 \%) \\
\text { Decreased }(20 \%) \\
\text { Decreased } \\
\text { Decreased }\end{array}$ & $\begin{array}{l}5 \mu \mathrm{M} \\
50 \mu \mathrm{M} \\
50 \mu \mathrm{M} \\
50 \mu \mathrm{M}\end{array}$ & Brundage et al., 2004 \\
\hline
\end{tabular}

${ }^{1}$ LOAEL - lowest observed adverse effect level tested, $\mathrm{mg} / \mathrm{kg}=\mathrm{mg}$ propanil/ $\mathrm{kg}$ body weight

${ }^{2}$ Result (\% change) - where indicated the (\%) represents the \% decreased compared to the control group response 
Table 3. Summary of the in vivo immunotoxicity of propanil on B cell functions of the adaptive immune system

\begin{tabular}{|c|c|c|c|c|c|}
\hline Tissue & $\begin{array}{l}\text { Route of exposure/ } \\
\text { Day post-exposure }\end{array}$ & Assessment & Result & LOAEL $^{1}$ & Reference \\
\hline $\begin{array}{l}\text { Bone } \\
\text { marrow }\end{array}$ & $\begin{array}{l}\text { Intraperitoneal/ } \\
7 \text { days }\end{array}$ & $\begin{array}{l}\text { Cell population } \\
\text { pro-B } \\
\text { pre-B } \\
\operatorname{IgM}^{+} \mathrm{B}\end{array}$ & $\begin{array}{l}\text { No change } \\
\text { Decreased }(50 \%)^{2} \\
\text { Decreased }(50 \%)\end{array}$ & $\begin{array}{l}50 \mathrm{mg} / \mathrm{kg} \\
50 \mathrm{mg} / \mathrm{kg}\end{array}$ & de la Rosa et al., 2003 \\
\hline Spleen & $\begin{array}{l}\text { Intraperitoneal/ } \\
7 \text { days }\end{array}$ & $\begin{array}{l}\text { Proliferation } \\
\text { (LPS stimulation) }\end{array}$ & Decreased (33\%) & $400 \mathrm{mg} / \mathrm{kg}$ & Barnett and Gandy, 1989 \\
\hline Spleen & $\begin{array}{l}\text { Intraperitoneal/ } \\
7 \text { days }\end{array}$ & $\begin{array}{l}\text { SRBC Plaque forming } \\
\text { units }\end{array}$ & Decreased (33\%) & $50 \mathrm{mg} / \mathrm{kg}$ & Barnett and Gandy, 1989 \\
\hline Spleen & $\begin{array}{l}\text { Intraperitoneal/ } \\
7 \text { days }\end{array}$ & $\begin{array}{l}\text { DNP-Ficoll Plaque } \\
\text { forming units }\end{array}$ & Decreased (75\%) & $200 \mathrm{mg} / \mathrm{kg}$ & Barnett et al., 1992 \\
\hline Spleen & $\begin{array}{l}\text { Intraperitoneal/ } \\
7 \text { days }\end{array}$ & $\begin{array}{l}\text { PC-specific antibody } \\
\text { secreting cells }\end{array}$ & Increased (4 fold) & $150 \mathrm{mg} / \mathrm{kg}$ & Salazar et al., 2005 \\
\hline
\end{tabular}

${ }^{1}$ LOAEL - lowest observed adverse effect level tested, $\mathrm{mg} / \mathrm{kg}=\mathrm{mg}$ propanil $/ \mathrm{kg}$ body weight

${ }^{2}$ Result (\% change) - where indicated the (\%) represents the \% decreased compared to the control group response 


\section{CHAPTER 2}

\section{3,4-Dichloropropionaniline suppresses normal macrophage function}

Published in Toxicol.Sci. 97(2), 364-374.

Irina V. Ustyugova*1, Laura L. Frost*1,2 ${ }^{1}$, Knox VanDyke ${ }^{\dagger}$, Kathleen M. Brundage*\$, Rosana Schafer*§, and John B. Barnett*§

*Department of Microbiology, Immunology and Cell Biology, ${ }^{\dagger}$ Department of Biochemistry and Molecular Pharmacology, ${ }^{\S}$ Center for Immunopathology and Microbial Pathogenesis, West Virginia University, Morgantown, WV 26506-9177

Running title: DCPA suppresses macrophage function

Correspondence to:

John B. Barnett, Ph.D.

Department of Microbiology, Immunology and Cell Biology

PO Box 9177

West Virginia University

Morgantown, WV 26506

jbarnett@hsc.wvu.edu 


\begin{abstract}
Macrophages are a critical part of the innate immune response and natural surveillance mechanisms. As such, proper macrophage function is crucial for engulfing bacterial pathogens through phagocytosis and destroying them by generation of reactive oxygen (ROS) and reactive nitrogen (RNS) species. The production of a number of cytokines by macrophages such as tumor necrosis factor- $\alpha(\mathrm{TNF}-\alpha)$, interleukin-1 $\beta$ and interleukin-6, plays an important role in the initiation of the acquired immune response creating an inflammatory environment favorable for fighting a bacterial infection. 3,4-Dichloropropionaniline (DCPA) suppresses several inflammatory parameters, including TNF- $\alpha$ production through a mechanism where nuclear factor- $\kappa \mathrm{B}(\mathrm{NF}-\kappa \mathrm{B}) \mathrm{DNA}$ binding is inhibited but not entirely abrogated. The goal of the present study was to evaluate the effects of DCPA on the inflammatory mediators of macrophages, including ROS and RNS in both murine peritoneal exudate cells (PEC) and the human monocytic cell line, THP-1. The ability to perform phagocytosis and directly kill Listeria monocytogenes was also assessed. The results indicate that DCPA decreases the ability of both types of macrophages to phagocytize beads and generate both types of reactive species, which was correlated with a decrement in listericidal activity. These results demonstrate that DCPA has profound effects on macrophage function, and provide insight into the potential mechanisms of immunosuppression by DCPA.
\end{abstract}

\title{
Key words
}

bactericidal, phagocytosis, Listeria monocytogenes, Dichloropropionaniline, macrophage, THP-1 cell line 


\section{Introduction}

Macrophages are critical for normal maintenance of homeostasis as well as immune regulation and tumor surveillance. Whereas phagocytosis of apoptotic cells is a normal homeostatic function of macrophages, phagocytosis and clearance of bacteria and viruses is a crucial function of innate immunity. Through cytokine and chemokine production, direct cellular contacts and antigen presentation, macrophages orchestrate the initiation of adaptive immune responses (Adams and Hamilton, 1984; Celada and Nathan, 1994; Ganz 1993). Clearly, alterations in any of the normal functions of these cells can lead to serious, even fatal consequences.

Defects in normal macrophage function contribute to chronic granulomatous disease (CGD) and result in altered immunity to bacterial and fungal pathogens. Patients with CGD develop granulomas consisting of fused monocytes and macrophages, which have engulfed bacteria but are unable to destroy them as a result of a defect in the nicotinamide adenine dinucleotide phosphate (NADPH) oxidase. Activation of NADPH oxidase is normally induced by microbial products such as bacterial lipopolysaccharide (LPS), or by cytokines such as interferon- $\gamma$, interleukin (IL)-1 $\beta$, or IL-8 (Bonizzi et al., 2000). Superoxide produced by NADPH oxidase diffuses into the bacterium and kills it by inactivating essential enzymes (Miller and Britigan, 1997; Roos et al., 1984). Superoxide can be converted to hydrogen peroxide $\left(\mathrm{H}_{2} \mathrm{O}_{2}\right)$, which can be a more reactive oxidant. $\mathrm{H}_{2} \mathrm{O}_{2}$ oxidizes cellular membranes and enzymes and causes DNA damage by interacting with $\mathrm{Fe}^{2+}$ to form the toxic ferryl radical which inhibits membrane transport processes (Forman and Torres, 2002; Imlay et al., 1988; Weiss and Peppin, 1986). Hydroxyl radicals $\left({ }^{\circ} \mathrm{OH}\right)$ are also very potent oxidants implicated in the oxidation of bacterial proteins, DNA and lipids (Ohya et al., 1998a). All these reactive oxygen intermediates 
are critical for macrophage bactericidal mechanisms against the facultative intracellular pathogen, Listeria monocytogenes (Alvarez-Dominguez et al., 2000; Ohya et al., 1998a).

Production of reactive nitrogen species (RNS) is also important for control of microbial proliferation. Nitric oxide (NO) is produced by the inducible nitric oxide synthase (iNOS or NOS2) in the presence of $\mathrm{O}_{2}$, which catalyzes enzymatic oxidation of L-arginine to L-citrulline, using NADPH-derived electrons (Marletta, 1994). Increased iNOS expression and NO production are observed at sites of infection in animal models, such as toxoplasmosis and leishmaniasis, or in human infections such as tuberculosis (Nicholson et al., 1996). NO readily reacts with $\mathrm{O}_{2}$ resulting in production of transient and unstable $\mathrm{N}_{2} \mathrm{O}_{3}$ and, ultimately, unreactive $\mathrm{NO}_{2}^{-}$ion product. Activated macrophages will also produce superoxide, which reacts with NO to form the reactive and toxic peroxynitrite $\left(\mathrm{ONOO}^{-}\right)$which in turn decomposes into additional nitrates and nitrites (Hibbs, Jr. et al., 1988; Miwa et al., 1987; Stuehr and Marletta, 1987). Expression of the iNOS gene in macrophages is regulated mainly at the transcriptional level, particularly by $\mathrm{NF}-\kappa \mathrm{B}$, which binds to multiple sites on the iNOS gene promoter (Xie et al., 1993). iNOS, similar to NADPH oxidase, in that it is stimulated by proinflammatory cytokines such as IFN- $\gamma$, TNF- $\alpha$ and IL-1 $\beta$, as well as by LPS (Fang, 1997).

Major listericidal mechanisms include the production of ROS and RNS by activated macrophages (Alvarez-Dominguez et al., 2000; Muller et al., 1999; Ohya et al., 1998b; Ouadrhiri et al., 1999). Although ROS and RNS have been identified as major anti-bacterial defense mechanisms, the details of how these agents work in activated macrophages are not completely understood. Both interferon- $\gamma($ IFN- $\gamma)$ activation of macrophages and production of tumor necrosis factor- $\alpha(\mathrm{TNF}-\alpha)$ are necessary for clearance of L. monocytogenes (Buchmeier and Schreiber, 1985; Kiderlen et al., 1984; Nakane et al., 1988; Nakane et al., 1989). Therefore, 
reductions in macrophage cytokine production, reactive oxygen and/or nitrogen species generation result in increased susceptibility to L. monocytogenes infection.

The most common routes of exposure to DCPA are thought to be inhalational and dermal during manufacturing and application and to a lesser extent oral through drinking water and food. Upon entry into the individual, propanil is rapidly metabolized in the liver by the enzyme acylamidase into the major metabolite 3,4-dichloroaniline (3,4-DCA). Both DCPA and 3,4DCA are often detected in the urine of the general population living in the agricultural areas as well as occupationally exposed people (Turci et al., 2006; Wittke et al., 2001). In nonoccupationally exposed people, the urine levels of 3,4-DCA were reported to reach a maximum level of $6.19 \mathrm{lg} / \mathrm{l}$ (Turci et al., 2006). Thus, it is apparent that the general population in areas that use DCPA carry a measurable body burden of 3,4-DCA.

The experiments reported herein were conducted in vitro, and the relationship of the in vitro concentrations used with expected body burdens found in humans is a relevant question. However, given that blood levels of a pesticide, which would be more relevant for study, may exceed the urine levels (McMullin et al., 2003), and that data on in vivo organ concentrations are unavailable, extrapolating from measured human urine levels to in vitro exposure concentrations is imprecise.

DCPA reduces several macrophage functions, including TNF- $\alpha$ and IL-6 production, $\mathrm{IP}_{3^{-}}$ mediated calcium release and nuclear NF-кB translocation (Frost et al., 2001; Xie et al., 1997a; Xie et al. 1997b). The present report was designed to determine the direct effects of DCPA on different macrophage functions. The results demonstrate that DCPA reduced phagocytic ability, ROS and RNS generation, and listericidal activity of both human and mouse macrophages. 


\section{Materials and Methods}

\section{Cell line culture and maintenance}

The human monocytic cell line THP-1 was obtained from the American Type Culture Collection (Rockville, MD). The cells were maintained in RPMI 1640 media (BioWhittaker, Walkersville, MD) supplemented with 10\% fetal bovine serum (FBS, Hyclone, Logan UT), 10mM HEPES, $100 \mathrm{U} / \mathrm{ml}$ penicillin, $100 \mu \mathrm{g} / \mathrm{ml}$ streptomycin, $2 \mathrm{mM}$ L-glutamine and $5 \times 10^{-5} \mathrm{M}$ 2-mercaptoethanol (all obtained from Sigma, St. Louis, MO) (complete media), and incubated at $37^{\circ} \mathrm{C}$ in an atmosphere of $5 \% \mathrm{CO}_{2}$.

\section{Animals}

C57Bl/6 female and male mice were purchased from Charles River Farms (Wilmington, DE). Animals were allowed to acclimate for 7 days before experimental procedures were initiated. Food and water were provided ad libitum. Experimental procedures were conducted between the ages of 7 and 12 weeks. All animal experiments were reviewed and approved by the WVU Animal Care and Use Committee.

\section{Primary macrophage harvest and preparation}

Resident and inflammatory primary macrophages (PEC, peritoneal exudate cells) were utilized. Inflammatory macrophages were elicited by injecting $1.5 \mathrm{ml}$ of aged $4 \%$ sterile thioglycollate broth intraperitoneally (i.p.) four days before macrophage harvest. To harvest the PEC, $10 \mathrm{ml}$ sterile Dulbecco's PBS (DPBS, BioWhittaker) containing $10 \mathrm{U} / \mathrm{ml}$ heparin or $100 \mu \mathrm{M}$ EDTA (Sigma) was injected into the mouse's exposed peritoneum and syringe aspirated. Resulting cell suspensions were washed twice in complete media, plated at the appropriate density in tissue culture dishes, and allowed to adhere for 3 hours at $37^{\circ} \mathrm{C}$ in $5 \% \mathrm{CO}_{2}$. Nonadherent cells were removed by the addition of two bursts of warm PBS and vacuum 
aspiration. Macrophage enrichment was monitored by nonspecific esterase staining and was $\geq$ $95 \%$. Viability was monitored by trypan blue exclusion and was routinely $\geq 95 \%$.

\section{Cell stimulation and exposure to DCPA}

PEC or THP-1 cells were simultaneously stimulated with LPS from Escherichia coli Serotype 055:B5 (Sigma) and treated with DCPA (3,4-dichloropropionanilide, 99\% purity, ChemServices, West Chester, PA) diluted in absolute ethanol (Mallinckrodt, Paris, KY) at concentrations indicated in the Results section. Control cultures received an equivalent amount of absolute ethanol only and are referred to as vehicle or $0 \mu \mathrm{M}$ DCPA. The final concentration of ethanol for all cultures was $0.10 \%$. LPS was dissolved in RPMI 1640 at $1 \mathrm{mg} / \mathrm{ml}$ and added to cultures at $1 \mu \mathrm{l}$ per ml of culture media. The possible cytotoxic effects of DCPA alone during the culture period were determined and no significant difference in viability was measure at any DCPA concentration used for this study.

\section{TNF- $\alpha$ specific enzyme-linked immunosorbent assay (ELISA)}

THP-1 cells were plated at $1.5 \times 10^{6}$ cells $/ 3 \mathrm{ml}$ in 6 well plates then differentiated by addition of $100 \mathrm{ng} / \mathrm{ml}$ of phorbol 12-myristate 13-acetate (PMA, Sigma) for 24 hours. Differentiation of the cells led to their adherence to tissue culture dishes. Monolayers were washed vigorously with PBS and cultured in complete media for 72 hours. Differentiated cell were stimulated with $1 \mu \mathrm{g} / \mathrm{ml}$ LPS (Sigma) in the presence of DCPA or vehicle and incubated for 6,12 and $24 \mathrm{hr}$ at $37^{\circ} \mathrm{C}$ in $5 \% \mathrm{CO}_{2}$. Supernatants were collected and assayed by human TNF ELISA set with detection limit of $7.8 \mathrm{pg} / \mathrm{ml}$ (cat. 555212, BD Biosciences PharMingen, San Diego, CA) according to manufacturer's instructions. The plates were then read at an optical density of $450 \mathrm{~nm}$ on a $\mu$ Quant plate reader (BioTek Instruments, Inc. Winooski, VT). 


\section{Bacteria}

Listeria monocytogenes, strain EGD, were grown overnight in $10 \mathrm{ml}$ of brain-heart infusion (BHI) broth (Difco Laboratories, Detroit, $\mathrm{MI}$ ) with aeration at $37^{\circ} \mathrm{C}$. One $\mathrm{ml}$ of this culture was inoculated into $50 \mathrm{ml}$ of sterile $\mathrm{BHI}$ broth and incubated at $37^{\circ} \mathrm{C}$ with aeration until culture reached an $\mathrm{OD}_{600}$ of approximately 0.4 (2 to 4 hours). An $\mathrm{OD}_{600}$ absorbance value of 1.000 is equivalent to $1 \times 10^{9}$ bacteria $/ \mathrm{ml}$. The culture was diluted to the appropriate number of viable L. monocytogenes.

\section{Phagocytosis}

THP-1 cells were differentiated by addition of $100 \mathrm{ng} / \mathrm{ml}$ PMA (Sigma) as described above. On the day of the phagocytosis assay, differentiated THP-1 cells or PEC (previously prepared and allowed to adhere overnight) were trypsinized, washed in PBS, seeded in $5 \mathrm{ml}$ snap-cap tubes at $1 \times 10^{6}$ cells/ml in PBS $+1 \%$ FBS. Phagocytosis assays were conducted as described with minor modifications (Antonini et al., 2000). Briefly, carboxylate-modified, 2.0 $\mu \mathrm{m}$ yellow-green FluoroSpheres (Molecular Probes, Eugene, OR) were added at a concentration of approximately 30 beads/cell. LPS, DCPA and vehicle treatments were added as indicated. Cells were incubated on a rocker in constant motion at $37^{\circ} \mathrm{C}$ in $5 \% \mathrm{CO}_{2}$ for 2 hours. Cells were pelleted by centrifugation at $500 \mathrm{~g}$, washed twice to remove any free beads and allowed to adhere to sterile cover slips placed in 6 well plates for two hours. Adherent cells were washed twice with warm PBS, fixed with 2\% paraformaldehyde for 30 minutes, stained with the fluorochrome nile red $(0.1 \mu \mathrm{g} / \mathrm{ml}$; Molecular Probes $)$ for 5 minutes and washed with PBS. Coverslips were then mounted to glass slides and stored in the dark (a maximum of 48 hours before analysis). Confocal microscopy using a Zeiss LSM 510 microscope equipped with an argon laser (Zeiss, Thornwood, NY) was performed to evaluate the cells which were scored as 
having $0,1-2,3-4, \geq 5$ beads/cell. A weighted phagocytic index was calculated by multiplying the number of cells with 0 beads by 0 ; the number of cells with $1-2$ beads/cell by 1 ; the number of cells with 3-4 beads/cell by 2; and the number of cells with 5 or more beads/cell by 4 , summing these products, and dividing by 200 (the total number of cells counted).

\section{Determination of Listericidal activity}

THP-1 or PEC $\left(5 \times 10^{5}\right.$ cells $\left./ \mathrm{ml}\right)$ were activated with $100 \mathrm{U} / \mathrm{ml}$ rhIFN- $\gamma$ (BD PharMingen) or rmIFN- $\gamma$ (BD PharMingen), respectively, for 24 hours in RPMI 1640 media containing 10\% FBS (no antibiotics). This activation did not cause adhesion of THP-1 cells, which continued to grow in loose suspension as described (Ouadrhiri et al. 1999). THP-1 cells were washed with PBS, resuspended in $1 \mathrm{ml}$ PBS containing $1 \%$ FBS and infected with $2.5 \times 10^{6}$ Listeria monocytogenes, strain EGD/ml. Activated PEC were trypsinized, washed in PBS, resuspended in PBS containing 1\% FBS, and also infected with $2.5 \times 10^{6}$ L. monocytogenes, strain EGD/ml. LPS stimulation and vehicle and DCPA treatments were initiated at the same time as initial infection. Cells were transferred to $5 \mathrm{ml}$ snap-cap tubes and incubated at $37^{\circ} \mathrm{C}$ in $5 \% \mathrm{CO}_{2}$ on a rocker for 1 hour to allow for infection. Cells were then centrifuged at $500 \mathrm{~g}$ and washed twice with PBS. The final pellet was resuspended in PBS containing $25 \mu \mathrm{g} / \mathrm{ml}$ gentamicin. Initial infection levels (1 hour) were obtained by lysing cells in $500 \mu$ of ice-cold, sterile, distilled water and plating $50 \mu \mathrm{l}$ of the lysate. Remaining treatment groups were returned to incubation conditions in the gentamicin solution. Cell lysates were prepared at 3 and 5 hours post infection. Lysates were plated on TSA plates (Trypticase Soy Agar; Difco Laboratories, Detroit, MI) using an Autoplate 4000 (Spiral Biotech, Bethesda, MD) in triplicate. Plates were incubated at $37^{\circ} \mathrm{C}$ for 24 hours, and colonies were counted using a CASBA 4 plate scanner and 
CIA-BEN colony imaging and analysis software (Spiral Biotech). Resulting L. monocytogenes colony forming units (CFU) per $1 \mathrm{ml}$ were calculated and compared across treatments.

\section{Respiratory burst}

Luminol, 5-amino-2-3dihydro-1,4 phthalazinedione (Sigma) was used to amplify chemiluminescence (CL) signals generated by activation of the NADPH-oxidase (Allen and Loose, 1976; Dahlgren and Karlsson, 1999). The CL signal generated by luminol occurs as the compound accepts an electron from free radical species as they return to ground state. To measure respiratory burst, we differentiated THP-1 cells, or harvested PEC as previously described. All cells were plated at $5 \times 10^{5}$ cells $/ \mathrm{ml}$ in $35 \mathrm{~mm}$ tissue culture dishes. Cells were washed with PBS before elicitation of the respiratory burst. In a total reaction volume of $2 \mathrm{ml}$, respiratory burst activity was elicited by addition of $100 \mu \mathrm{M}$ PMA simultaneously with PBS, 5 $\mu \mathrm{M}$ luminol, and indicated concentrations of LPS, and either ethanol or propanil. Dishes were placed in a pre-warmed luminometer (Berthold, Co., Wilbad, Germany) and CL readings were taken every minute for 20 minutes. Data shown represent CL curves generated from these readings over time to peak values. Control experiments to determine if DCPA alone quenched the CL signal showed no interference of the assay by DCPA.

\section{Intracellular ROS measurement}

THP-1 cells were plated at $2.25 \times 10^{5}$ cells per $\mathrm{ml}$ in Lab-Tek ${ }^{\circledR}$ chambered cover glass system (4 chamber; Nalge Nunc International Corp, Naperville, IL) in phenol red-free complete RPMI and differentiated by addition of PMA as described above. Cells were washed with PBS three times and incubated for $40 \mathrm{~min}$ at $37^{\circ} \mathrm{C}$ in $5 \% \mathrm{CO}_{2}$ in the dark with $5 \mu \mathrm{M} \mathrm{5}$-(and 6)chloromethyl-2',7'-dichlorodihydrofluorescein diacetate, acetyl ester $\left(\mathrm{CM}-\mathrm{H}_{2} \mathrm{DCFDA}\right.$, Invitrogen, Carlsbad, CA). CM- $\mathrm{H}_{2}$ DCFDA is a non-fluorescent dye which enters the cells by 
passive diffusion; it becomes fluorescent only when it is oxidized by ROS, particularly by hydrogen peroxide $\left(\mathrm{H}_{2} \mathrm{O}_{2}\right)$, hydroxyl radicals $\left({ }^{\circ} \mathrm{OH}\right)$, or their down stream free radical products. After incubation with the dye, cells were washed three times with PBS and Hanks' Balanced Salt Solution (HBSS, BioWhittaker) was added to the wells. Cells were treated with different doses of DCPA or vehicle control and simultaneously stimulated with $1 \mu \mathrm{g} / \mathrm{ml}$ LPS and $100 \mu \mathrm{M}$ PMA. Cultures were examined with a Zeiss Axiovert 100M microscope equipped with a laser scanning confocal attachment (model LSM 510; Zeiss) to locate the cells and analyze their images overtime at $512 \times 512$ pixel resolution. $\mathrm{CM}-\mathrm{H}_{2}$ DCFDA was excited with the 488 -nm line of an argon/krypton mixed-gas laser; emission was collected with a $505 \mathrm{~nm}$ long-pass filter. Images were collected every $2 \mathrm{~min}$ for up to $26 \mathrm{~min}$; 14 images total were taken for the course of each experiment; cells were treated and stimulated after the first scan. Pixel time was $1.76 \mu$ s with the scan time of 983.04 msec for each image taken. Plan-Neofluar $40 \times / 0.75$ objective was used to obtain the images. Fluorescence emission from 25-30 cells per experiment was analyzed by LPS 510 software, and at least 3 experiments were performed per treatment group.

\section{NO release from mouse peritoneal macrophages}

Resident PEC were harvested as previously described and cultured in $5 \mathrm{ml}$ of complete RPMI in $60 \mathrm{~mm}$ plates. The cells were stimulated with $1 \mu \mathrm{g} / \mathrm{ml}$ LPS and simultaneously treated with $0,5,25$ or $100 \mu \mathrm{M}$ DCPA and incubated for 12, 24 and 48 hours for NO induction. Each treatment was plated in duplicate and analyzed in triplicate. The supernatant of each culture was transferred to a plastic tube, centrifuged at $2000 \mathrm{rpm}$, and the supernatant was stored at $-80^{\circ} \mathrm{C}$ assayed for NO. Greiss reagent was used to measure nitrite $\left(\mathrm{NO}_{2}{ }^{-}\right)$as a stable form of NO. Briefly, $100 \mu$ test sample was mixed with $150 \mu \mathrm{l}$ of Greiss reagent $(0.1 \%$ naphthylethylenediamine chloride (Sigma) in 60\% acetic acid and 1\% sulfanilamide (Sigma) in 
$30 \%$ acetic acid) for $10 \mathrm{~min}$, and color development was assessed at $540 \mathrm{~nm}$ with a $\mu$ Quant plate reader (BioTek Instruments, Inc. Winooski, VT). A standard curve was generated with a serial dilution of sodium nitrite dissolved in culture medium.

\section{Immunoblotting}

PEC were harvested as described above and plated at $6.5 \times 10^{6}$ cells $/ 5 \mathrm{ml}$ in $60 \mathrm{~mm}$ dishes (Becton Dickinson Labware, Franklin Lakes, NJ) in complete RPMI and allowed to adhere for 3 hr at $37 \mathrm{C}^{\circ} 5 \% \mathrm{CO} 2$. Nonadherent cells were removed by addition of three bursts of warm DPBS and aspirated by pipette; $5 \mathrm{ml}$ of complete RPMI was added to the wells and cells were incubated for $1 \mathrm{hr}$ before treatments were administrated. The cells were stimulated with $1 \mu \mathrm{g} / \mathrm{ml}$ LPS and simultaneously treated with 5,25 or $100 \mu \mathrm{M}$ DCPA or ethanol, and incubated for 6,12 and 24 hours for iNOS protein detection. Whole-cell extracts were prepared using lysis buffer (Cell Signalling Technology, Beverly, MA) according to manufacturer instructions, and protein levels were quantitated using BCA protein assay kit (Pierce, Rockford, IL). 15 $\mathrm{g}$ of whole-cell lysates were separated by $8 \%$ polyacrylamide gels using SDS-PAGE, transferred to polyvinylidene fluoride membranes (Pall Corporation, Pensacola, Fl) overnight at $0.1 \mathrm{~A}$. The membranes were then blocked by incubation for 45 min with 5\% nonfat dry Carnation milk (Nestle) in Trisbuffered saline (TBS: $20 \mathrm{mM}$ Tris- $\mathrm{HCl}$, ph 7.6, $137 \mathrm{mM} \mathrm{NaCl}$ ) containing $0.1 \%$ Tween 20 (TBS-Tween), and then rinsed three times with TBS-Tween. The protein blots were cut across to incubate the upper half overnight with rabbit polyclonal IgG anti-NOS2 (Santa Cruz Biotechnology, Santa Cruz, CA; sc-650; 1:2000 dilution) and the lower half with goat polyclonal IgG anti-actin (Santa Cruz Biotechnology, Santa Cruz, CA; sc-1616; 1:1000 dilution) in TBSTween plus 5\% BSA. After incubation with the appropriate secondary antibodies (Sigma, A0545 and A5420), blots were developed using Phototope-HRP detection kit for western blots 
(Cell Signaling) and visualized by exposing to X-Ray film (Kodak BioMax Light Film, Eastman Kodak Company, Rochester, NY) for $15 \mathrm{sec}$ to 3 minutes. Densitometric analysis was completed with Optimas software (Media Cybernetics, Silver, MD).

\section{Statistical Analysis}

Data were analyzed using JMP (SAS, Inc, Belmont, CA) and SigmaStat (SPSS, Inc. Chicago, IL) statistical analysis software. Significance of interactions between treatment groups was assessed using an analysis of variance. For all analyses, the minimum criterion of significance was set at $p<0.05$. Each experiment was repeated at least twice with similar results. Data shown represent means of at least three experiments or representative experiments, as indicated. Error bars represent standard deviation unless otherwise noted to represent standard error, where appropriate.

\section{Results}

\section{DCPA suppresses TNF- $\alpha$ production by THP-1 cells}

The production of TNF- $\alpha$, a key inflammatory mediator produced by activated macrophages, is reduced when murine macrophages are exposed to DCPA (Xie et al., 1997b; Xie et al., 1997a). To provide a closer link to possible effects on humans, a human cell line was used throughout this study. To determine if DCPA caused a similar reduction in TNF- $\alpha$ in human cells, we measured TNF- $\alpha$ production from the human monocytic cell line, THP-1

(Figure 1). DCPA reduced TNF- $\alpha$ production from THP-1 cells at all time points tested. In a representative experiment, DCPA caused a reduction in TNF- $\alpha$ production from $2465 \pm 107$, $2279 \pm 196$, and $1998 \pm 18.68 \mathrm{pg} / \mathrm{ml}$ in the vehicle control cells to $1637 \pm 125,1321 \pm 142$, and $1202 \pm 168 \mathrm{pg} / \mathrm{ml}$ at 6,12 , and $24 \mathrm{~h}$, respectively, in the $100 \mu \mathrm{M}$ DCPA-treated cells. The 
difference in TNF- $\alpha$ levels between the 0 and both 50 and $100 \mu \mathrm{M}$ DCPA was statistically significant at all time points $(\mathrm{p}<0.001)$. A statistically significant reduction in TNF- $\alpha$ production was also observed in the $25 \mu \mathrm{M}$ DCPA-treated cells at $12 \mathrm{~h}(\mathrm{p}<0.001)$. Differences in TNF- $\alpha$ production between the 0 and 5 or $25 \mu \mathrm{M}$ concentrations were not significantly reduced at 6 and $24 \mathrm{~h}$. 


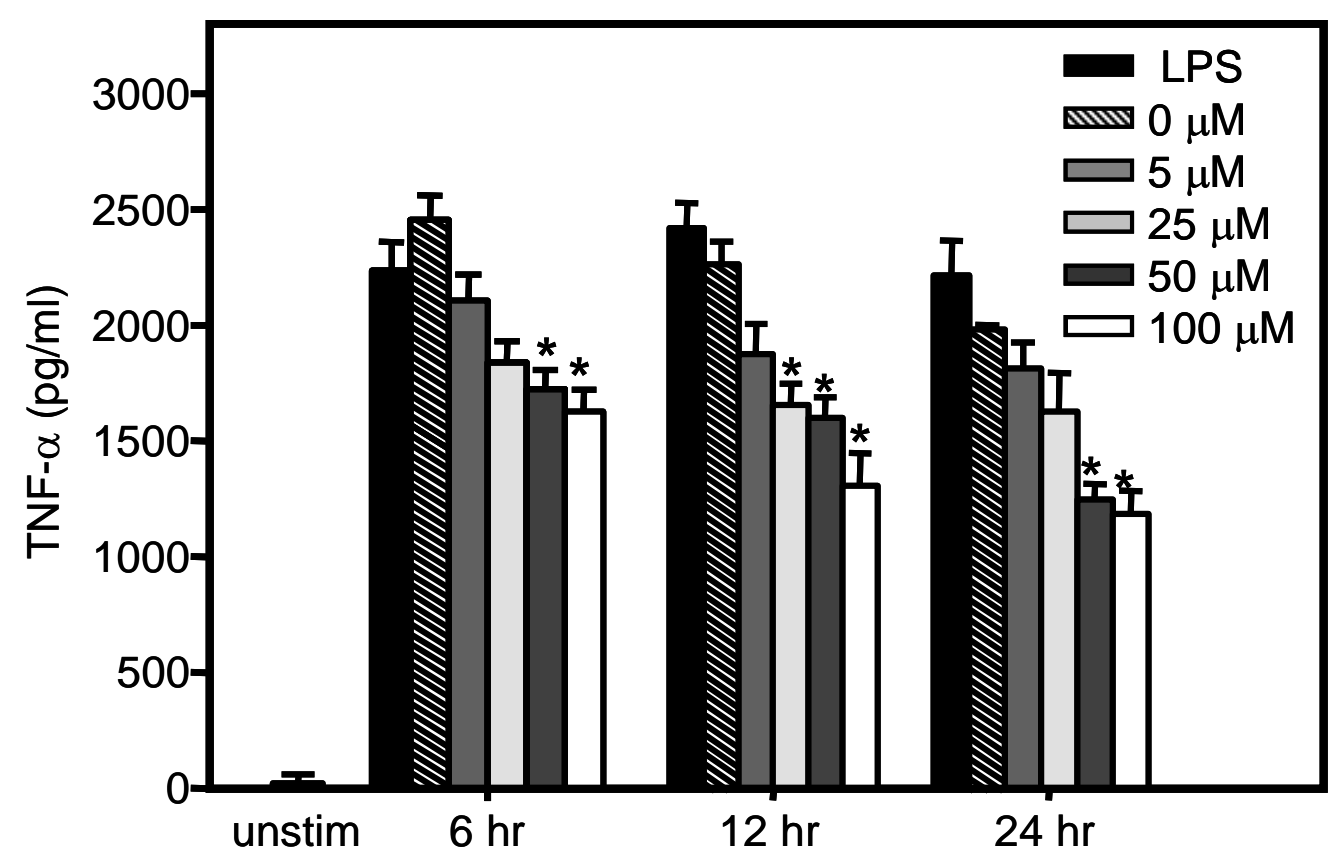

Figure 1. TNF- $\alpha$ production by differentiated THP-1 cells.

THP-1 cells were differentiated by PMA, treated with DCPA or vehicle control, stimulated with LPS, and incubated for 6,12 , and $24 \mathrm{~h}$. Supernatants were removed and assayed for TNF- $\alpha$ production by ELISA. The experiment was performed three times, and each treatment was performed and analyzed in triplicate. The mean TNF- $\alpha$ production of a representative experiment $\pm \mathrm{SD}$ is shown; * indicates significant difference from vehicle control $(\mathrm{p}<0.001)$. 


\section{In vitro exposure to DCPA reduces phagocytic capabilities}

A major function of macrophages in vivo is phagocytosis of bacteria and cellular debris. To determine if DCPA affected the ability of PMA-differentiated THP-1 cells and PEC to phagocytize fluorescent $2.0 \mu \mathrm{m}$ beads a weighted phagocytic index was measured. The weighted phagocytic index allows a quantification of the amount of phagocytosis (number of beads per cell) in addition to the number of macrophages that are capable of phagocytosis. DCPA caused significant reductions $(\mathrm{p}<0.05)$ in the ability of THP-1 and PEC cells to phagocytize beads. The weighted phagocytic index for THP-1 cells was reduced from $0.730 \pm 0.303$ in the vehicle control to $0.320 \pm 0.07$ and $0.267 \pm 0.068$ in the 50 and $100 \mu \mathrm{M}$ DCPA groups, respectively (Figure 2A). Significant differences $(\mathrm{p}<0.05)$ were also evident with the DCPA-treated PEC, from an average of $1.084 \pm 0.108$ in the vehicle control group to $0.724 \pm 0.071$ and $0.534 \pm 0.072$ in the $50 \mu \mathrm{M}$ and $100 \mu \mathrm{M}$ treatments, respectively (Figure $2 \mathrm{~B}$ ). 


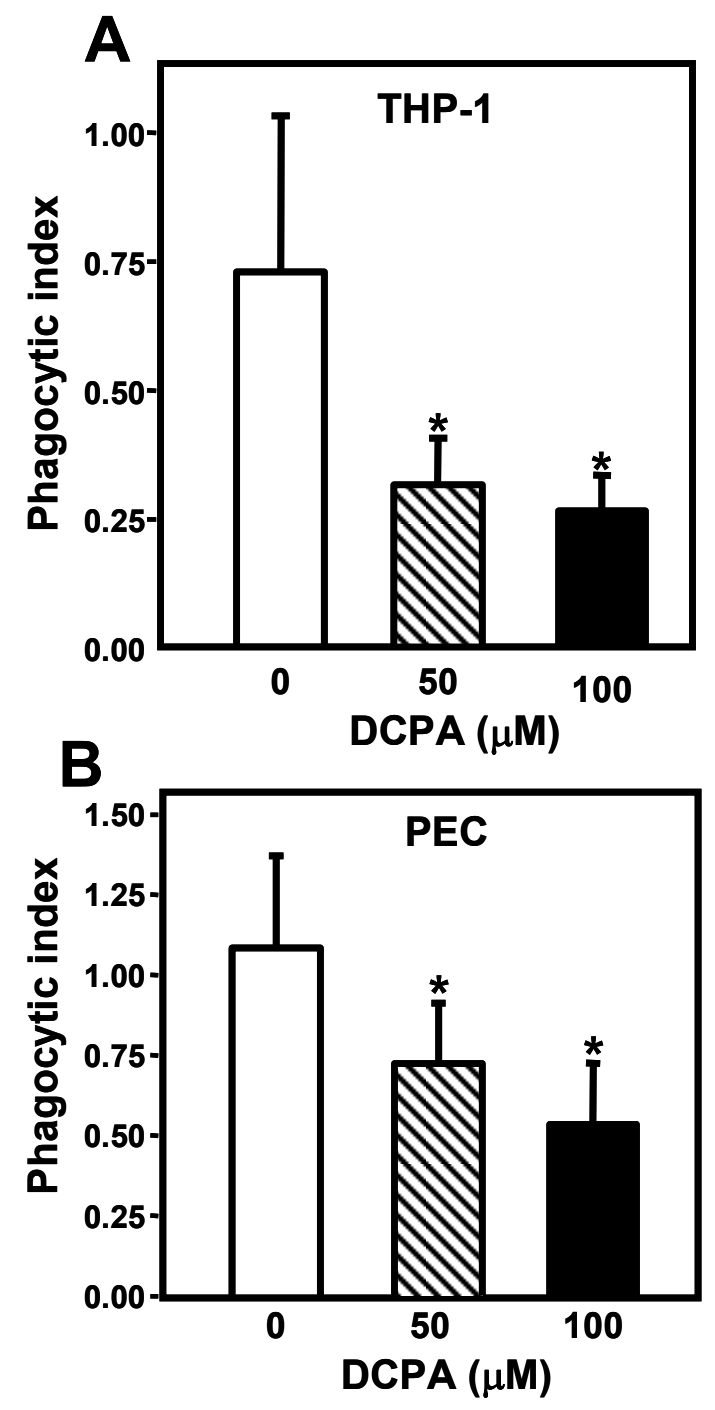

Figure 2. Phagocytic abilities are reduced by DCPA.

PMA-differentiated THP-1 (A) or PEC (B) were activated by IFN- $\gamma$ for 24 hours before addition of LPS with either vehicle or indicated concentrations of DCPA. Phagocytosis of $2 \mu \mathrm{m}$ fluorescent beads was determined by confocal microscopy. A weighted phagocytic index was calculated as described in the Materials. Experiments were performed 3 times with similar results. The mean phagocytic index $\pm \mathrm{SD}$ is shown. The asterisk indicates significant difference from vehicle control $(\mathrm{p}<0.05)$. 


\section{In vitro exposure to DCPA reduces anti-bacterial capabilities}

The effect of DCPA on the ability of THP-1 and PEC macrophages to kill L. monocytogenes was measured as an indicator of the biological consequences of DCPA exposure. IFN- $\gamma$ plus LPS stimulated macrophages that were treated with vehicle had significant bacterial reductions by 5 hours $(\mathrm{p}<0.05)$ (Figure $3 \mathrm{~A}$ and 3B). Treatment of both THP-1 cells and PEC cells with $100 \mu \mathrm{M}$ DCPA abrogated or reduced their listericidal activity (Figure 3A and 3B). Fewer bacteria were initially phagocytosed by THP-1 cells and PEC treated with 50 or $100 \mu \mathrm{M}$ DCPA than by cells treated with vehicle $(\mathrm{p}<0.05)$ (Figure $3 \mathrm{~A}$ and $3 \mathrm{~B} ; 1$ hour). THP-1 cells treated with $100 \mu \mathrm{M}$ DCPA actually showed that the bacteria continued to multiply in these cells at least until the $3 \mathrm{~h}$ time point, while vehicle treated cells showed a consistent decline in the number of intracellular bacteria. PEC cells treated with $50 \mu \mathrm{M}$ DCPA showed a steady decline in the number of intracellular bacteria. Those treated with $100 \mu \mathrm{M}$ phagocytosed a much smaller number of bacteria ( $1 \mathrm{~h}$ value) and there appeared to be a slight increase in their CFU over time. These results demonstrate that DCPA causes inhibition of listericidal activity of macrophages, and further support the effects of DCPA on phagocytosis described above. 

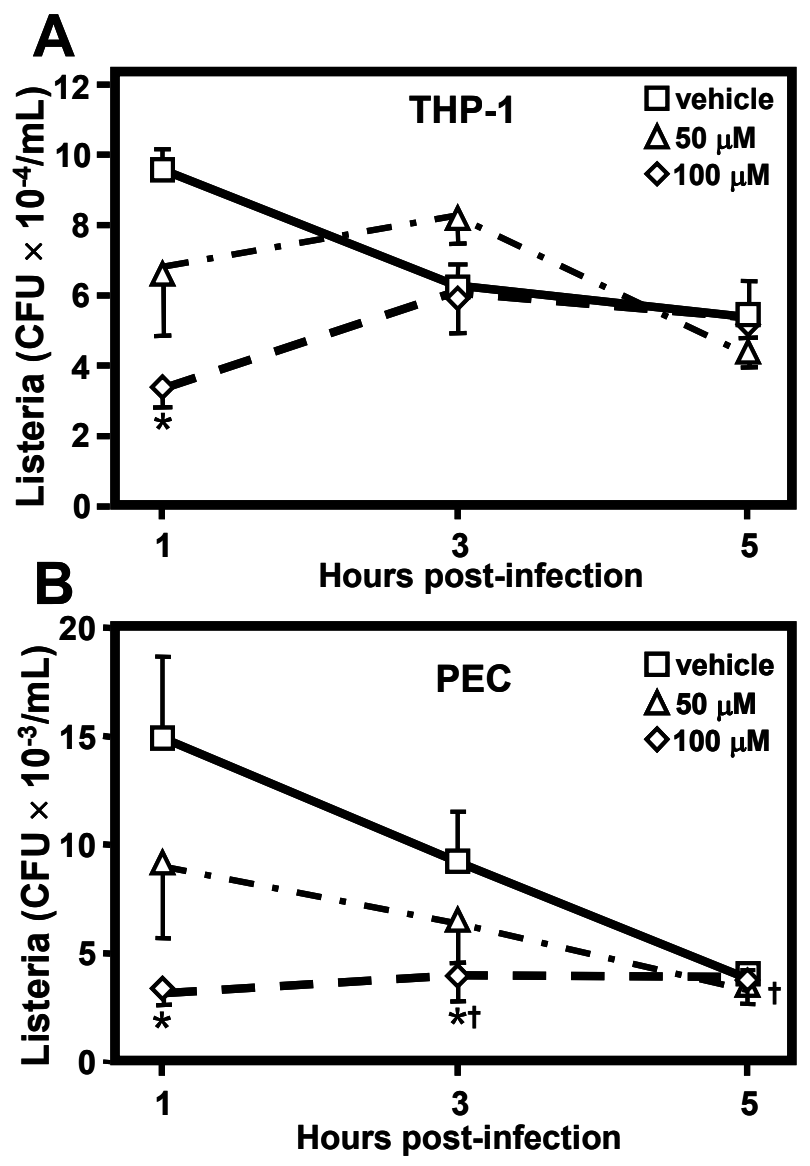

Figure 3. DCPA reduces listericidal activity of macrophages.

Mean Listeria CFU \pm SEM from IFN- $\gamma$ activated THP-1 (A) or PEC (B) following Listeria infection. The mean CFU \pm SEM of each time point is shown. The asterisk represents a significant differences at the noted time point between the vehicle control and DCPA-treated macrophages (vertical comparison) $(\mathrm{p}<0.05)$ and, contrary to convention, a dagger represents $\underline{\mathbf{n o}}$ significant difference between the $1 \mathrm{~h}$ time point and the indicated time point of the same experimental group (horizontal comparison). 


\section{DCPA exposure inhibits the generation of a respiratory burst}

Functional aspects of macrophage biology include destruction of phagocytosed organisms via generation of reactive oxidants and nitrogen species. Exposure to $100 \mu \mathrm{M}$ DCPA virtually shuts down the respiratory burst activity of both cell types, whereas $50 \mu \mathrm{M}$ DCPA had an intermediate effect on the respiratory burst (Figure 4A and 4B). The response of THP-1 cells treated with $25 \mu \mathrm{M}$ DCPA was similar to vehicle control cells (data not shown). The respiratory burst of PEC was more sensitive to the effects of DCPA, resulting in significantly different concentration-dependent decreases in integrated relative light units upon exposure to 50 and 100 $\mu \mathrm{M}$ DCPA (Figure 4B). 

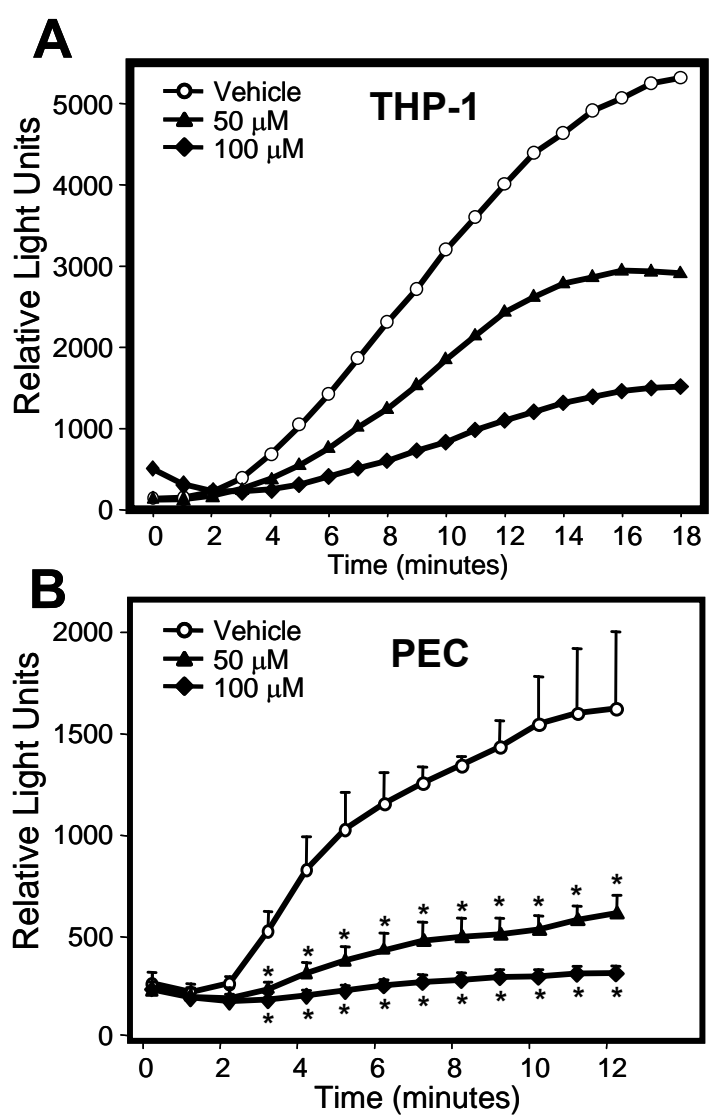

Figure 4. DCPA reduces respiratory burst activity.

Generation of respiratory burst was measured from PMA-differentiated THP-1 cells (A) and PEC (B). PMA was used to elicit the respiratory burst from cells simultaneously treated with LPS, and either vehicle or the indicated concentrations of DCPA, in the presence of luminol. Chemiluminescence was detected by a luminometer and expressed as relative light units. Experiments were performed twice in THP-1 cells and 3 times in PEC with similar results. A representative THP-1 experiment (A) is shown due to variability in the level of luminescence detected from the THP-1 cells in experiments conducted on different days. Mean relative light units \pm SD are shown for PEC (B). ANOVA results confirm differences between each treatment of PEC from the 3-minute time until the experiment was terminated $\left({ }^{*} \mathrm{p}<0.05\right)$. 


\section{Intracellular ROS production is inhibited by DCPA.}

The respiratory burst due to ROS production in phagocytic cells produced by hydrogen peroxide and hydroxyl radicals is an important function of macrophages. Figure 5A shows representative confocal image fields of PEC cells at 0, 10 and 20 min after LPS stimulation with or without DCPA. Amount of fluorescence produced by the cells during oxidation of CM$\mathrm{H}_{2}$ DCFDA dye directly corresponded to the amount of ROS generated. Figure 4B shows the increase in measured fluorescent intensity with respect to time of PEC cells treated with the vehicle. PEC cells exposed for $20 \mathrm{~min}$ to vehicle and LPS demonstrated a 2-fold increase in fluorescent intensity from $53.73 \pm 2.76$ to $103.47 \pm 15.63$, indicating an induction of ROS production (Figure 5B). PEC treated with 25 or $100 \mu \mathrm{M}$ DCPA showed a significant decrease in ROS generation over the $26 \mathrm{~m}$ assayed $(\mathrm{P}<0.05)$. Further, $5 \mu \mathrm{M}$ DCPA treated cells also demonstrated a decrease in ROS generation for the 26 min (data not shown). Altogether, these data confirm the luminol CL data, providing more specific characterization of the respiratory burst in the presence of DCPA. THP-1 cells show a decrease in ROS generation (fluorescent intensity) at all concentrations of DCPA; however, none of these decreases were significantly different (data not shown). The lack of significance for the $100 \mu \mathrm{M}$ treated THP-1 cells may be due to a high variance in the data as there is a constant decrease in fluorescence intensity during the initial 14 min of the experiment, however, the lack of an apparent concentration-dependent decrease at 5 and $25 \mu \mathrm{M}$ would imply that THP-1 cells are fairly resistant to DCPA with regard to ROS generation. 

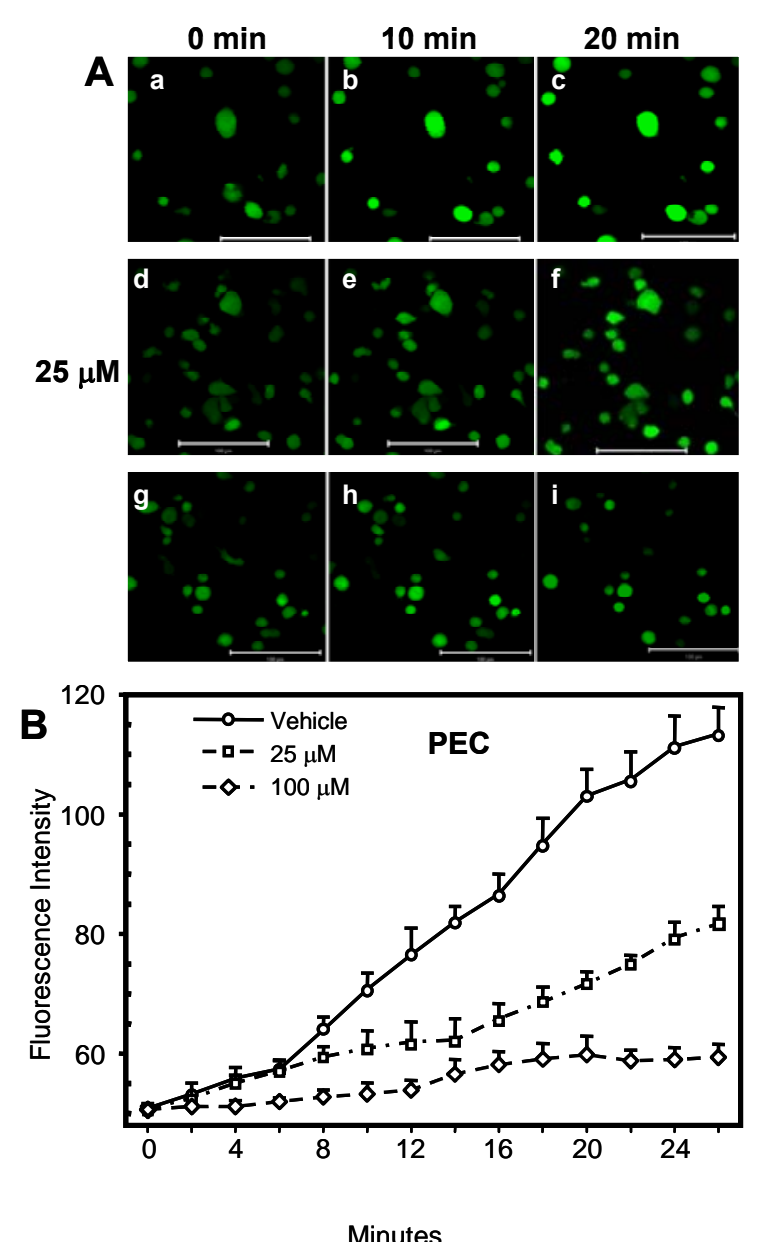

Figure 5. DCPA reduces ROS production by macrophages.

A) Generation of ROS species was measured in PEC (A-L). PMA was used to elicit a reactive oxygen species production from cells simultaneously treated with LPS, and either vehicle or the indicated concentrations of DCPA, in the presence of CM- $\mathrm{H}_{2} \mathrm{DCFDA}$ dye. ROS production was observed for 26 min and images were collected every 2 min with $0.983 \mathrm{sec}$ scan time. Images taken at 0,10 and 20 min of each treatment are shown. Images are representative of typical fields, $230.3 \times 230.3 \mu \mathrm{m}$, seen in three experiments. The magnification is $40 \mathrm{X}$. Scale bar is generated and inserted by LSM software and represents $100 \mu \mathrm{m}$. B) Time course of ROS production observed in PEC. An average of three experiments shown, fluorescent intensity \pm SD. * indicates significant difference from vehicle control $(\mathrm{p}<0.05)$. 


\section{DCPA inhibits nitrite production}

RNS are important anti-microbial factors and their production over time can be monitored by measuring nitrite accumulation in culture supernatants of activated macrophages. The production of nitrite by PEC was significantly decreased in $100 \mu \mathrm{m}$ DCPA-treated cells compared to vehicle treated control cells by $40 \%$ at $12 \mathrm{hr}(\mathrm{P}<0.05)$ (Figure 6). Cells treated with $25 \mu \mathrm{M}$ and $100 \mu \mathrm{M}$ DCPA for $24 \mathrm{~h}$ resulted in $15 \%$ and $22 \%$ decreases, respectively $(\mathrm{P}<0.01)$ in nitrate production (Figure 5). Treatment with $5 \mu \mathrm{M}$ DCPA did not decrease nitrate production at any time point (data not shown). Nitrite production by THP-1 cells was not measured because human macrophages do not produce NO when stimulated in vitro (Stuehr and Marletta, 1987). 


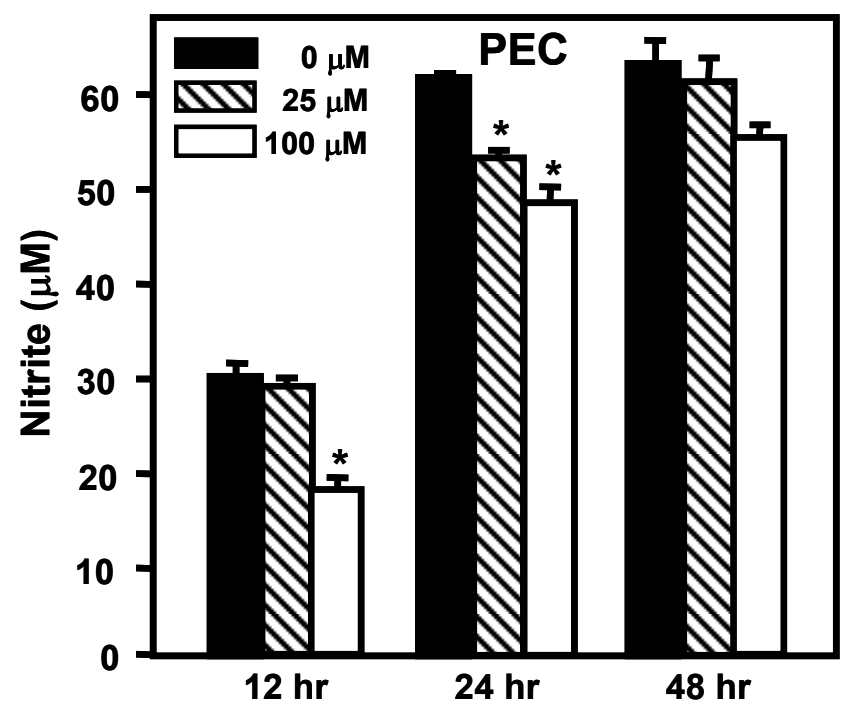

Figure 6. DCPA inhibits nitrite production.

PEC were treated with DCPA or vehicle control, stimulated with LPS and incubated for 12, 24 and 48 hours. Supernatants were removed and assayed for nitrite $\left(\mathrm{NO}_{2}{ }^{-}\right)$accumulation in the media by Griess reagent. Experiments were performed three times, each treatment was run and analyzed in triplicates. The mean nitrite production of a representative experiment $\pm \mathrm{SD}$ is shown, * indicates significant difference from vehicle control $(\mathrm{p}<0.05$ at $12 \mathrm{hr} ; \mathrm{p}<0.01$ at $24 \mathrm{hr})$. 


\section{DCPA inhibits iNOS protein expression}

In activated macrophages, nitric oxide is produced by iNOS, an enzyme converting Larginine to L-citrulline. To determine whether the reduced NO production by PEC exposed to DCPA was due to the inhibition of iNOS protein expression, cellular lysates were analyzed by Western Blotting. In these experiments PEC were treated with 5, 25 or $100 \mu \mathrm{M}$ DCPA or vehicle and simultaneously stimulated with LPS for 6, 12 and $24 \mathrm{~h}$. iNOS protein expression was undetected in unstimulated PEC, however gradual induction of expression was observed over period of time as a result of LPS stimulation (Figures $6 \mathrm{~A}$ and $6 \mathrm{~B}$ ). A $6 \mathrm{~h}$ treatment resulted in detectable levels of iNOS, demonstrating $10 \%$ and $14 \%$ inhibition at 25 and $100 \mu \mathrm{M} \mathrm{DCPA}$, respectively. A $12 \mathrm{~h}$ treatment resulted in a dose-dependent decrease in iNOS protein levels demonstrating the largest decrease of $29 \%$ in $100 \mu \mathrm{M}$ DCPA treated cells and $9 \%$ in $25 \mu \mathrm{M}$ DCPA treated cells compared to vehicle-treated controls. The longest exposure to DCPA, $24 \mathrm{~h}$, demonstrated a $12 \%$ decrease at $100 \mu \mathrm{M}$ DCPA. The lowest concentration of DCPA, $5 \mu \mathrm{M}$, did not decrease expression in comparison to control-treated cells. 

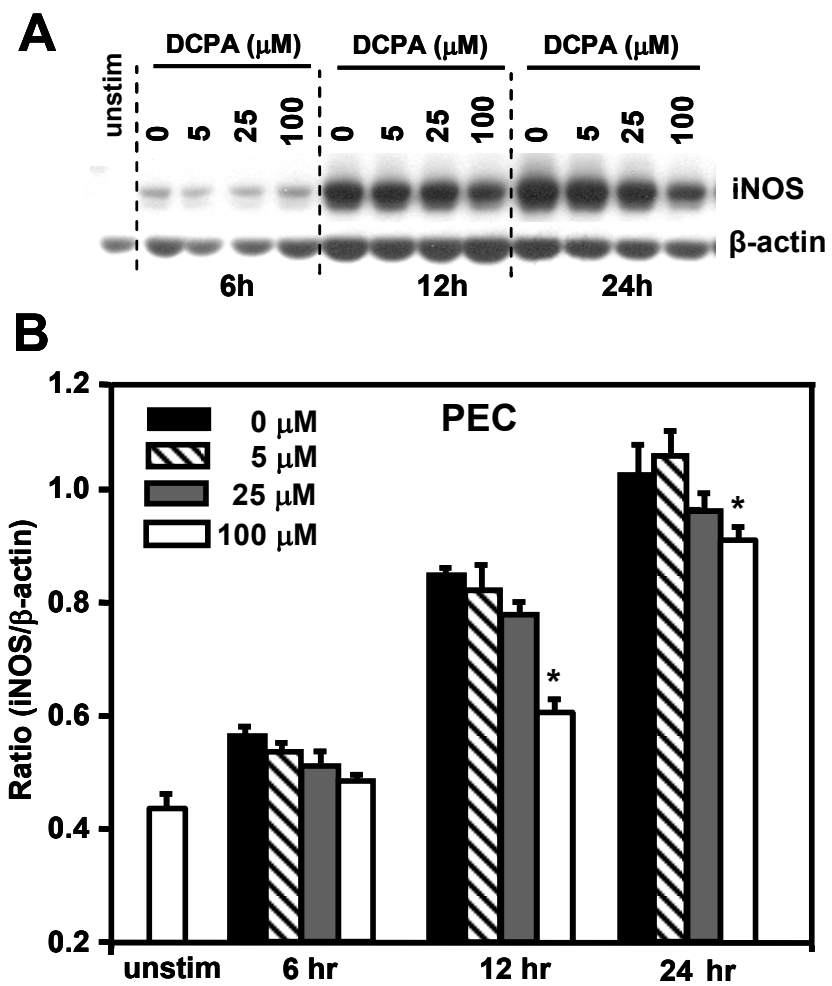

Figure 7. DCPA inhibits iNOS protein expression.

PEC were treated with DCPA or vehicle control, stimulated with LPS and incubated for 6, 12 and 24 hours. A) The protein levels of iNOS and $\beta$-actin in whole-cell lysates were analyzed by Western Blotting. B) Ratio of relative band density between iNOS and $\beta$-actin was calculated. Values are means $\pm \mathrm{SD}$ of three independent experiments. 


\section{Discussion}

Appropriate macrophage function is critical for normal immune functions and homeostasis, as macrophages participate in various aspects of innate and adaptive immunity as well as tumor surveillance. The present report demonstrates that DCPA decreased TNF- $\alpha$ production from the human THP-1 cell line, similar to results shown previously in murine cells (Frost et al. 2001; Xie et al. 1997a). DCPA also caused reductions in phagocytic ability, ROS and RNS production, and listericidal activity in both the THP-1 cell line and primary murine PEC. The nuclear factor primarily responsible for activating TNF- $\alpha$ transcription is NF- $\kappa \mathrm{B}$. Previous work has demonstrated that DCPA causes reductions in nuclear levels of NF- $\kappa \mathrm{B}$ in

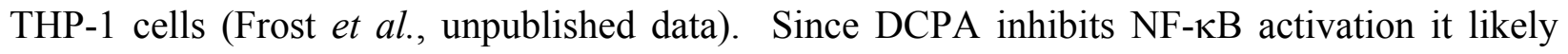
plays a role in the reduction of TNF- $\alpha$ and investigations are underway to further elucidate the mechanism of suppression of TNF- $\alpha$ production by DCPA.

The THP-1 cell line is a human monocytic cell line that has been extensively characterized (Tsuchiya et al., 1980, Tsuchiya et al., 1982). These cells have been shown to mobilize NF- $\kappa$ B into the nucleus upon stimulation with LPS and produce cytokines typical of activated human macrophages (Steer et al., 2000; Gatanaga et al., 1991). Further differentiation of the cells with PMA leads to a mature, differentiated macrophage phenotype (Tsuchiya et al., 1982). We wanted to demonstrate the effects of propanil in both murine and human models. Primary PEC were used for murine studies because we had previously established the effects of propanil on cytokine production, and other immune parameters with these cells (Xie et al., 1997a, Xie et al., 1997b, Frost et al., 2001). THP-1 cells were chosen for a human model due to the existing body of literature regarding their monocytic phenotype, and characterizing their cytokine response, respiratory burst activity, and phagocytic abilities (Condino-Neto et al, 1998; 
Delbosc et al., 2002; Gatanaga et al., 1991; Steer et al., 2000; Tsuchiya et al., 1980). The use of THP-1 cells also did not impose the restrictions of utilizing primary human monocytes.

DCPA has also been shown to ablate the $\mathrm{IP}_{3}$-mediated calcium release in macrophages despite the generation of $\mathrm{IP}_{3}$ equivalent to control cells (Xie et al. 1997b). An extensive body of literature has established a critical role for calcium $\left(\mathrm{Ca}^{2+}\right)$ in various aspects of the generation of a respiratory burst in macrophages and neutrophils (Dahlgren et al., 1992; Dusi et al., 1993; Foyouzi-Youssefi et al., 1997; Geiszt et al., 1999; Movitz et al., 1997). Calcium has specifically been implicated to play a role in the translocation of the $\mathrm{p} 47^{\text {phox }}$ cytosolic component of the NADPH oxidase to the membrane-bound cytochrome b portion (Zhou et al., 1997). Recently, Granfeldt et al. (2002) further evaluated the differential activation of plasma membrane- and granule-localized NADPH oxidase, showing that intracellular NADPH oxidase activity could be activated by an increase in intracellular $\mathrm{Ca}^{2+}$ via the capacitative $\mathrm{Ca}^{2+}$ entry, whereas plasma membrane-localized NADPH oxidase activity required the capacitative $\mathrm{Ca}^{2+}$ influx in addition to other signaling events. The results demonstrating reductions in respiratory burst activity have been generated using luminol, which can cross the plasma membrane (Dahlgren and Karlsson, 1999), as the chemiluminescent detector, therefore the measurements may reflect a decrease in activity of either intracellular or plasma membrane-localized NADPH oxidase activity, or both. This decrease in NADPH oxidase activity is potentially a result of the altered calcium dynamics induced by DCPA.

The effects of DCPA on respiratory burst activity may also affect the listericidal capability of macrophages. Contributions of the various phagocyte oxidase (phox) proteins to the listericidal capacity of macrophages have been investigated using mice with targeted gene deletions (Dinauer et al., 1997; Endres et al., 1997; Shiloh et al., 1999). These studies 
demonstrated that macrophages harvested from gp91 ${ }^{\text {phox-// }}$ mice were substantially defective in their ability to kill L. monocytogenes (Shiloh et al., 1999). Dinauer et al. (1997), also using gp9 $1^{\text {phox-/ }}$ mice, suggested that neutrophils and ROS controlled early in vivo Listeria infection. Macrophages and RNS production were suggested to be important in later stages of infection.

The CM- $\mathrm{H}_{2}$ DCFDA fluorescent method demonstrated that within 2-3 min of LPS and PMA stimulation hydrogen peroxide and hydroxyl radical were produced. DCPA treatment inhibited their production and that can potentially decrease the ability of macrophages to fight $L$. monocytogenes and other bacterial infections. Previous studies by Watson et al. (Watson et al., 2000) demonstrated that exposure to DCPA 2 or 7 days prior to L. monocytogenes infection did not affect bacterial colonization of the spleens and livers at 3 days post-infection when compared to control mice. However, it is not known if exposure to DCPA at the time of infection would have an immediate effect on the ability of macrophages to control early bacterial replication and thus increase susceptibility of the host. Myers et al (Myers et al., 2003) demonstrated that reactive oxygen species were absolutely required for L. monocytogenes clearance by activated macrophages. In their model, gp91 ${ }^{\text {phox-/- }}$ mice defective in NADPH oxidase were unable to generate superoxide, resulting in bacterial escape from the phagolysosome and proliferation in the cytoplasm (Myers et al., 2003). A critical factor implicated in the escape of Listeria from the phagolysosome is lysteriolysin O (LLO), a sulfhydryl-activated pore-forming hemolysin secreted by $L$. monocytogenes. It has been reported that mutants lacking LLO remained in vacuoles without proliferating (Gaillard et al., 1987; Portnoy et al., 1988). Myers et al (Myers et al., 2003) suggest that ROS could inactivate LLO, thereby preventing the escape of Listeria into the cytosol. The present report studies the initial events in the course bacterial infection, which does not contradict with previously published report by Watson et al (2000). 
THP-1 cells generally were less sensitive that primary mouse cells. There are known changes in this cell line from normal blood monocytes that may explain this difference includes the lack of functional p53 resulting in impaired signal transduction (Traore et al., 2005). THP-1 cells also failed to respond to chemokine stimulation to polymerize actin and demonstrate cell polarization (Vaddi and Newton, 1994). NADPH oxidase activity and superoxide production in THP-1 cells were also diminished compared to primary blood monocytes (Almeida et al., 2005).

Examination of $\mathrm{NO}_{2}$ accumulation in the media allowed for direct RNS detection upon LPS stimulation of primary mouse cells. A decrease in nitrite production can be explained by down regulation of iNOS enzyme, resulting in low levels of nitric oxide production. Studies on LPS-activated macrophages demonstrated that the iNOS gene has two consensus sequences for binding of NF-кB. Upon LPS activation, the heterodimer p65/p50 has been reported to be responsible for NF-kB binding to the iNOS promoter (Na et al., 1999; Spink et al., 1995; Xie et al., 1994; Kim et al., 1997). DCPA exposure caused a decrease in NF-kB binding and its transcriptional activity (Frost et al., 2001) and could explain a decrease in NO production through inhibition of iNOS gene expression. A study by Ohya et al. (1998a) observed an induction of iNOS mRNA transcription and gene expression followed by accumulation of nitrite in culture media as a result of L. monocytogenes infection.

DCPA also decreases phagocytosis. Interestingly, phagocytosis in macrophages is regulated, to some extent by activation of the signaling proteins syk and PI-3K (Aderem and Underhill, 1999). Activation of PI-3K leads to the downstream activation of PKC, Akt and NF$\kappa \mathrm{B}$. The Internalin B (Inl B) protein of L. monocytogenes, which mediates internalization of the bacterium, also requires activation of PI-3K (Ireton et al., 1996). InlB ultimately leads to NF-אB activation via PI-3K and Akt (Mansell et al., 2001). DCPA alters NF-אB activation (Frost et al., 
2001) and further studies have demonstrated that DCPA also affects Akt activity (Barnett et al., unpublished data). Studies examining the effects of DCPA on the upstream mediator PI-3K are ongoing. It is possible that the signaling alterations induced by DCPA exposure affect several pathways that culminate in the observed reductions in phagocytosis.

The data herein demonstrate the profound effects of DCPA on macrophage function. DCPA exposure results in decreased TNF- $\alpha$ production, phagocytosis, ROS and RNS production and listericidal activity. Additionally, the effect of DCPA on the respiratory burst suggests the potential use of DCPA as an inhibitor/antioxidant. Future laboratory experiments are aimed at furthering our understanding of respiratory burst regulation and redox signaling in cells using DCPA. 


\section{Acknowledgements}

This work support by a grant from the National Institute of Environmental Health Sciences (ES07512)

${ }^{1}$ Contributed equally to this work.

${ }^{2}$ Current address: Department of Natural Sciences and Engineering Technology, Point Park University, Pittsburgh, PA 15222 


\section{References}

Adams, D. O., and Hamilton, T. A. (1984). The cell biology of macrophage activation. Annu. Rev. Immunol. 2, 283-318.

Aderem, A., and Underhill, D. M. (1999). Mechanisms of phagocytosis in macrophages. Annu. Rev. Immunol. 17, 593-623.

Allen, R. C., and Loose, L. D. (1976). Phagocytic activation of a luminol-dependent chemiluminescence in rabbit alveolar and peritoneal macrophages. Biochem. Biophys. Res. Commun. 69(1), 245-252.

Almeida, A. C., Rehder, J., Severino, S. D., Martins-Filho, J., Newburger, P. E., and CondinoNeto, A. (2005). The effect of IFN-gamma and TNF-alpha on the NADPH oxidase system of human colostrum macrophages, blood monocytes, and THP-1 cells. J Interferon Cytokine Res. 25(9), 540-546.

Alvarez-Dominguez, C., Carrasco-Marin, E., Lopez-Mato, P., and Leyva-Cobian, F. (2000). The contribution of both oxygen and nitrogen intermediates to the intracellular killing mechanisms of C1q-opsonized Listeria monocytogenes by the macrophage-like IC-21 cell line. Immunology 101(1), 83-89.

Antonini, J. M., Yang, H. M., Ma, J. Y., Roberts, J. R., Barger, M. W., Butterworth, L., Charron, T. G., and Castranova, V. (2000). Subchronic silica exposure enhances respiratory defense mechanisms and the pulmonary clearance of Listeria monocytogenes in rats. Inhal. Toxicol. 12(11), 1017-1036.

Bonizzi, G., Piette, J., Merville, M. P., and Bours, V. (2000). Cell type-specific role for reactive oxygen species in nuclear factor-kappaB activation by interleukin-1. Biochem. Pharmacol. 59(1), 7-11. 
Buchmeier, N. A., and Schreiber, R. D. (1985). Requirement of endogenous interferon-gamma production for resolution of Listeria monocytogenes infection. Proc. Natl. Acad. Sci. U. S. A $82(21), 7404-7408$.

Celada, A., and Nathan, C. (1994). Macrophage activation revisited. Immunol. Today 15(3), 100-102.

Condino-Neto, A., Whitney, C., and Newburger, P. E. (1998). Dexamethasone but not indomethacin inhibits human phagocyte nicotinamide adenine dinucleotide phosphate oxidase activity by down-regulating expression of genes encoding oxidase components. $\mathrm{J}$ Immunol. 161(9), 4960-4967.

Dahlgren, C., Johansson, A., Lundqvist, H., Bjerrum, O. W., and Borregaard, N. (1992). Activation of the oxygen-radical-generating system in granules of intact human neutrophils by a calcium ionophore (ionomycin). Biochim. Biophys. Acta 1137(2), 182188.

Dahlgren, C., and Karlsson, A. (1999). Respiratory burst in human neutrophils. J Immunol. Methods 232(1-2), 3-14.

Delbosc, S., Morena, M., Djouad, F., Ledoucen, C., Descomps, B., and Cristol, J. P. (2002). Statins, 3-hydroxy-3-methylglutaryl coenzyme A reductase inhibitors, are able to reduce superoxide anion production by NADPH oxidase in THP-1-derived monocytes. J Cardiovasc. Pharmacol. 40(4), 611-617.

Dinauer, M. C., Deck, M. B., and Unanue, E. R. (1997). Mice lacking reduced nicotinamide adenine dinucleotide phosphate oxidase activity show increased susceptibility to early infection with Listeria monocytogenes. J Immunol. 158(12), 5581-5583. 
Dusi, S., Della, B., V, Grzeskowiak, M., and Rossi, F. (1993). Relationship between phosphorylation and translocation to the plasma membrane of $\mathrm{p} 47 \mathrm{phox}$ and $\mathrm{p} 67 \mathrm{phox}$ and activation of the NADPH oxidase in normal and $\mathrm{Ca}(2+)$-depleted human neutrophils. Biochem. J 290 ( Pt 1), 173-178.

Endres, R., Luz, A., Schulze, H., Neubauer, H., Futterer, A., Holland, S. M., Wagner, H., and Pfeffer, K. (1997). Listeriosis in p47(phox-/-) and TRp55-/- mice: protection despite absence of ROI and susceptibility despite presence of RNI. Immunity. 7(3), 419-432.

Environmental Protection Agency (2002). Propanil. Human Risk Assessment (Revised). Memorandum. February.

Environmental Protection Agency (2004). Pesticides industry sales and usage. 2000 and 2001 market estimates. May.

Fang, F. C. (1997). Perspectives series: host/pathogen interactions. Mechanisms of nitric oxiderelated antimicrobial activity. J Clin. Invest 99(12), 2818-2825.

Forman, H. J., and Torres, M. (2002). Reactive Oxygen Species and Cell Signaling: Respiratory Burst in Macrophage Signaling. Am. J. Respir. Crit. Care Med. 166(12), 4S-8.

Foyouzi-Youssefi, R., Petersson, F., Lew, D. P., Krause, K. H., and Nusse, O. (1997). Chemoattractant-induced respiratory burst: increases in cytosolic $\mathrm{Ca} 2+$ concentrations are essential and synergize with a kinetically distinct second signal. Biochem. J 322 ( Pt 3), 709-718.

Frost, L. W., Neeley, Y. X., Schafer, R., Gibson, L. F., and Barnett, J. B. (2001). Propanil inhibits Tumor Necrosis Factor-alpha production by reducing nuclear levels of the transcription factor NF-kB in the macrophage cell line IC-21. Toxicol. Appl. Pharmacol. 172(3), 186-193. 
Gaillard, J. L., Berche, P., Mounier, J., Richard, S., and Sansonetti, P. (1987). In vitro model of penetration and intracellular growth of Listeria monocytogenes in the human enterocytelike cell line Caco-2. Infect. Immun. 55(11), 2822-2829.

Ganz, T. (1993). Macrophage function. New Horiz. 1(1), 23-27.

Gatanaga, T., Hwang, C. D., Gatanaga, M., Cappuccini, F., Yamamoto, R. S., and Granger, G. A. (1991). The regulation of TNF receptor mRNA synthesis, membrane expression, and release by PMA- and LPS-stimulated human monocytic THP-1 cells in vitro. Cell Immunol. 138(1), 1-10.

Geiszt, M., Szeberenyi, J. B., Kaldi, K., and Ligeti, E. (1999). Role of different Ca2+ sources in the superoxide production of human neutrophil granulocytes. Free Radic. Biol. Med. 26(9-10), 1092-1099.

Granfeldt, D., Samuelsson, M., and Karlsson, A. (2002). Capacitative Ca2+ influx and activation of the neutrophil respiratory burst. Different regulation of plasma membrane- and granule-localized NADPH-oxidase. J. Leukoc. Biol. 71(4), 611-617.

Hibbs, J. B., Jr., Taintor, R. R., Vavrin, Z., and Rachlin, E. M. (1988). Nitric oxide: a cytotoxic activated macrophage effector molecule. Biochem. Biophys. Res. Commun. 157(1), 8794.

Imlay, J. A., Chin, S. M., and Linn, S. (1988). Toxic DNA damage by hydrogen peroxide through the Fenton reaction in vivo and in vitro. Science. 240(4852), 640-642.

Ireton, K., Payrastre, B., Chap, H., Ogawa, W., Sakaue, H., Kasuga, M., and Cossart, P. (1996). A role for phosphoinositide 3-kinase in bacterial invasion. Science 274(5288), 780-782. 
Kiderlen, A. F., Kaufmann, S. H., and Lohmann-Matthes, M. L. (1984). Protection of mice against the intracellular bacterium Listeria monocytogenes by recombinant immune interferon. Eur. J Immunol. 14(10), 964-967.

Kim, Y. M., Lee, B. S., Yi, K. Y., and Paik, S. G. (1997). Upstream NF-kappaB site is required for the maximal expression of mouse inducible nitric oxide synthase gene in interferongamma plus lipopolysaccharide-induced RAW 264.7 macrophages. Biochem. Biophys. Res. Commun. 236(3), 655-660.

Mansell, A., Reinicke, A., Worrall, D. M., and O'Neill, L. A. (2001). The serine protease inhibitor antithrombin III inhibits LPS-mediated NF-kappaB activation by TLR-4. FEBS Lett. 508(3), 313-317.

Marletta, M. A. (1994). Nitric oxide synthase: aspects concerning structure and catalysis. Cell 78(6), 927-930.

Miller, R. A., and Britigan, B. E. (1997). Role of oxidants in microbial pathophysiology. Clin. Microbiol. Rev. 10(1), 1-18.

Miwa, M., Stuehr, D. J., Marletta, M. A., Wishnok, J. S., and Tannenbaum, S. R. (1987). Nitrosation of amines by stimulated macrophages. Carcinogenesis 8(7), 955-958.

Movitz, C., Sjolin, C., and Dahlgren, C. (1997). A rise in ionized calcium activates the neutrophil NADPH-oxidase but is not sufficient to directly translocate cytosolic p47phox or p67phox to b cytochrome containing membranes. Inflammation 21(5), 531-540.

Muller, M., Althaus, R., Frohlich, D., Frei, K., and Eugster, H. P. (1999). Reduced antilisterial activity of TNF-deficient bone marrow-derived macrophages is due to impaired superoxide production. Eur. J Immunol. 29(10), 3089-3097. 
Myers, J. T., Tsang, A. W., and Swanson, J. A. (2003). Localized reactive oxygen and nitrogen intermediates inhibit escape of Listeria monocytogenes from vacuoles in activated macrophages. J Immunol. 171(10), 5447-5453.

Na, S. Y., Kang, B. Y., Chung, S. W., Han, S. J., Ma, X., Trinchieri, G., Im, S. Y., Lee, J. W., and Kim, T. S. (1999). Retinoids inhibit interleukin-12 production in macrophages through physical associations of retinoid X receptor and NFkappaB. J Biol Chem. 274(12), 7674-7680.

Nakane, A., Minagawa, T., and Kato, K. (1988). Endogenous tumor necrosis factor (cachectin) is essential to host resistance against Listeria monocytogenes infection. Infect. Immun. 56(10), 2563-2569.

Nakane, A., Minagawa, T., Kohanawa, M., Chen, Y., Sato, H., Moriyama, M., and Tsuruoka, N. (1989). Interactions between endogenous gamma interferon and tumor necrosis factor in host resistance against primary and secondary Listeria monocytogenes infections. Infect. Immun. 57(11), 3331-3337.

Nicholson, S., Bonecini-Almeida, M. G., Lapa e Silva JR, Nathan, C., Xie, Q. W., Mumford, R., Weidner, J. R., Calaycay, J., Geng, J., Boechat, N., Linhares, C., Rom, W., and Ho, J. L. (1996). Inducible nitric oxide synthase in pulmonary alveolar macrophages from patients with tuberculosis. J Exp. Med. 183(5), 2293-2302.

Ohya, S., Tanabe, Y., Makino, M., Nomura, T., Xiong, H., Arakawa, M., and Mitsuyama, M. (1998a). The contributions of reactive oxygen intermediates and reactive nitrogen intermediates to listericidal mechanisms differ in macrophages activated pre- and postinfection. Infect. Immun. 66(9), 4043-4049. 
Ohya, S., Xiong, H., Tanabe, Y., Arakawa, M., and Mitsuyama, M. (1998b). Killing mechanism of Listeria monocytogenes in activated macrophages as determined by an improved assay system. J Med. Microbiol. 47(3), 211-215.

Ouadrhiri, Y., Scorneaux, B., Sibille, Y., and Tulkens, P. M. (1999). Mechanism of the intracellular killing and modulation of antibiotic susceptibility of Listeria monocytogenes in THP-1 macrophages activated by gamma interferon. Antimicrob. Agents Chemother. 43(5), 1242-1251.

Portnoy, D. A., Jacks, P. S., and Hinrichs, D. J. (1988). Role of hemolysin for the intracellular growth of Listeria monocytogenes. J Exp. Med. 167(4), 1459-1471.

Roos, D., Eckmann, C. M., Yazdanbakhsh, M., Hamers, M. N., and de, B. M. (1984). Excretion of superoxide by phagocytes measured with cytochrome $\mathrm{c}$ entrapped in resealed erythrocyte ghosts. J Biol. Chem. 259(3), 1770-1775.

Shiloh, M. U., MacMicking, J. D., Nicholson, S., Brause, J. E., Potter, S., Marino, M., Fang, F., Dinauer, M., and Nathan, C. (1999). Phenotype of mice and macrophages deficient in both phagocyte oxidase and inducible nitric oxide synthase. Immunity. 10(1), 29-38.

Spink, J., Cohen, J., and Evans, T. J. (1995). The cytokine responsive vascular smooth muscle cell enhancer of inducible nitric oxide synthase. Activation by nuclear factor-kappa B. J Biol. Chem. 270(49), 29541-29547.

Steer, J. H., Kroeger, K. M., Abraham, L. J., and Joyce, D. A. (2000). Glucocorticoids suppress tumor necrosis factor-alpha expression by human monocytic THP-1 cells by suppressing transactivation through adjacent NF-kappa B and c-Jun-activating transcription factor-2 binding sites in the promoter. J Biol. Chem. 275(24), 18432-18440. 
Stuehr, D. J., and Marletta, M. A. (1987). Synthesis of nitrite and nitrate in murine macrophage cell lines. Cancer Res. 47(21), 5590-5594.

Traore, K., Trush, M. A., George, M., Jr., Spannhake, E. W., Anderson, W., and Asseffa, A. (2005). Signal transduction of phorbol 12-myristate 13-acetate (PMA)-induced growth inhibition of human monocytic leukemia THP-1 cells is reactive oxygen dependent. Leuk. Res. 29(8), 863-879.

Tsuchiya, S., Yamabe, M., Yamaguchi, Y., Kobayashi, Y., Konno, T., and Tada, K. (1980). Establishment and characterization of a human acute monocytic leukemia cell line (THP1). Int J Cancer 26(2), 171-176.

Tsuchiya, S., Kobayashi, Y., Goto, Y., Okumura, H., Nakae, S., Konno, T., and Tada, K. (1982). Induction of maturation in cultured human monocytic leukemia cells by a phorbol diester. Cancer Res. 42(4), 1530-1536.

Turci, R., Barisano, A., Balducci, C., Colosio, C., and Minoia, C. (2006). Determination of dichloroanilines in human urine by gas chromatography/mass spectrometry: validation protocol and establishment of Reference Values in a population group living in central Italy. Rapid Commun. Mass Spectrom. 20(17), 2621-2625.

Vaddi, K., and Newton, R. C. (1994). Comparison of biological responses of human monocytes and THP-1 cells to chemokines of the intercrine-beta family. J Leukoc Biol. 55(6), 756762.

Watson, V. A., Barnett, J. B., and Schafer, R. (2000). In vivo cytokine production and resistance to infection after acute exposure to 3,4-dichloropropionaniline. J. Toxicol Environ. Health A 60(6), 391-406. 
Weiss, S. J., and Peppin, G. J. (1986). Collagenolytic metalloenzymes of the human neutrophil. Characteristics, regulation and potential function in vivo. Biochem. Pharmacol. 35(19), 3189-3197.

Wittke, K., Hajimiragha, H., Dunemann, L., and Begerow, J. (2001). Determination of dichloroanilines in human urine by GC-MS, GC-MS-MS, and GC-ECD as markers of low-level pesticide exposure. J Chromatogr. B Biomed. Sci. Appl. 755(1-2), 215-228.

Xie, Q. W., Kashiwabara, Y., and Nathan, C. (1994). Role of transcription factor NF-kappa B/Rel in induction of nitric oxide synthase. J Biol. Chem. 269(7), 4705-4708.

Xie, Q. W., Whisnant, R., and Nathan, C. (1993). Promoter of the mouse gene encoding calciumindependent nitric oxide synthase confers inducibility by interferon gamma and bacterial lipopolysaccharide. J Exp. Med. 177(6), 1779-1784.

Xie, Y. C., Schafer, R., and Barnett, J. B. (1997a). The immunomodulatory effects of the herbicide propanil on murine macrophage interleukin- 6 and tumor necrosis factor-alpha production. Toxicol. Appl. Pharmacol. 145(1), 184-191.

Xie, Y. C., Schafer, R., and Barnett, J. B. (1997b). Inhibitory effect of 3,4-dichloropropionaniline on cytokine production by macrophages is associated with LPS-mediated signal transduction. J. Leukoc. Biol. 61(6), 745-752.

Zhou, H., Duncan, R. F., Robison, T. W., Gao, L., and Forman, H. J. (1997). Ca(2+)-dependent p47phox translocation in hydroperoxide modulation of the alveolar macrophage respiratory burst. Am. J. Physiol 273(5 Pt 1), L1042-L1047. 


\section{CHAPTER 3}

\section{3,4-Dichloropropionaniline (DCPA) inhibits $\mathrm{PGE}_{2}$ production by mouse peritoneal macrophages}

Irina V. Ustyugova ${ }^{* \dagger}$, Kathleen M. Brundage ${ }^{* \dagger}$, Rosana Schafer ${ }^{* \dagger}$, and John B. Barnett ${ }^{* \dagger}$

*Department of Microbiology, Immunology and Cell Biology, West Virginia University, Morgantown, WV 26506-9177 and the ${ }^{\dagger}$ Center for Immunopathology and Microbial Pathogenesis, West Virginia University, Morgantown, WV 26506-9106

Running title: DCPA inhibits PGE2 production

Keywords: Prostaglandin, Rodent, Macrophages, Inflammation correspondence to:

John B. Barnett, Ph.D.

Department of Microbiology, Immunology and Cell Biology

PO Box 9177

West Virginia University

Morgantown, WV 26506

$\begin{array}{ll}\text { (T) 304-293-2649 } & \text { (F) 304-293-7823 }\end{array}$ 


\begin{abstract}
Activated macrophages produce a number of inflammatory mediators, such as tumor necrosis factor- $\alpha$ (TNF- $\alpha)$, interleukin- $1 \beta$ and interleukin-6. These mediators play an important role in the initiation of the acquired immune response creating an inflammatory environment favorable for fighting bacterial infections and attracting other cell types to the inflamed site. Prostaglandins (PGs) are another type of inflammatory mediator produced by two enzymes in response to bacterial stimuli and secreted by activated macrophages. The first enzyme, known as cytosolic phospholipase A2 ( $\left.{ }_{\mathrm{C}} \mathrm{PLA} \mathrm{A}_{2}\right)$, converts membrane phospholipids into free arachidonic acid. The second enzyme, cyclooxygenase (COX), utilizes arachidonic acid to produce endoperoxide intermediate $\left(\mathrm{PGH}_{2}\right)$, which is in turn metabolized to various prostaglandins. $\mathrm{PGE}_{2}$ is the major type of prostaglandins produced by activated macrophages. 3,4dichloropropionaniline (DCPA) is a chemical known to suppress several inflammatory cytokines, including TNF- $\alpha$, IL-6 and IL-1 $\beta$. It also suppresses the ability of macrophages to perform phagocytosis and generate reactive oxygen and nitrogen species. The goal of the present study was to evaluate the effects of DCPA on the production of $\mathrm{PGE}_{2}$ by murine peritoneal exudate cells (PEC). A dramatic decrease of PGs secretion was observed after exposure to DCPA. An induction of ${ }_{\mathrm{C}} \mathrm{PLA}_{2}$ and COX-2 enzymes was studied to investigate the mechanisms behind this inhibition. A known selective COX-2 inhibitor, CAY10404, was used to compare its effect on $\mathrm{PGE}_{2}$ secretion with DCPA. The mouse ear inflammation model also confirmed the anti-inflammatory properties of DCPA. However, examination of ${ }_{\mathrm{C}} \mathrm{PLA} 2$ protein phosphorylation, COX-2 protein induction and COX-2 enzymatic activity were not affected by DCPA suggesting a different mechanism of PGs inhibition.
\end{abstract}




\section{Introduction}

Prostaglandins (PGs) are ubiquitous compounds involved in a variety of homeostatic and pathological processes. They mediate a wide range of physiological functions, such as control of blood pressure, contraction of smooth muscle, and modulation of inflammation. During acute and chronic inflammation PGs are produced by activated macrophages among other inflammatory mediators, such as cytokines, reactive oxygen and reactive nitrogen species. The first step in PGs formation is a conversion of membrane-bound phospholipids into free arachidonic acid (AA) by $\mathrm{Ca}^{2+}$-dependent cytosolic phospholipase $\mathrm{A}_{2}\left(\mathrm{cPLA}_{2}\right)$. This enzyme is known to play a major role in the overproduction of lipid mediators during inflammation (Bonventre et al, 1997; Uozumi et al, 1997). Arachidonic acid is in turn converted into the endoperoxide intermediate $\left(\mathrm{PGH}_{2}\right)$ by two isozymes, cyclooxygenase (COX)-1 and COX-2. $\mathrm{PGH}_{2}$ diffuses from the $\mathrm{COX}$ proteins and is converted by the action of cell-specific synthases in to the various prostaglandins, such as $\mathrm{PGE}_{2}, \mathrm{PGF}_{2 \alpha}$, PGD, PGI (Smith et al, 2000). $\mathrm{PGE}_{2}$ is one of the major PGs produced. COX-1 and -2 share $60 \%$ homology at the amino acid levels; however, they have different physiological functions (reviewed in Wu T., 2005). COX-1 is expressed constitutively and is responsible for regulating normal physiological functions such as gastric acid secretion and platelet aggregation (Roth et al, 2001). COX-2 is not constitutively expressed, but is transiently induced by growth factors, cytokines and bacterial toxins. Overexpressed COX-2 is a characteristic of chronic inflammatory conditions, such as rheumatoid arthritis (Sano et al, 1992; Anderson et al, 1996) and experimental peritonitis (Hinson et al, 1996). It is induced by several transcription factors, such as AP-1, NF-IL-6, NF- $\kappa B$ and NF-AT (Smith et al, 2000). 
There are several strategies for inhibiting PGs synthesis. Inhibitors of $\mathrm{PLA}_{2}$ will limit the amount of AA available for PGs production. Non-steroidal anti-inflammatory drugs (NSAIDs) will reduce levels of PGs by inhibiting the activity of COX isozymes. Due to the small differences in the amino acid sequences near catalytic site, COX-1 and COX-2 can be inhibited by different NSAIDs (Gierse et al, 1996; Kurumbail et al, 1996; Meade et al, 1996). Aspirin inhibits both enzymes non-specifically, where as CAY10404 affects only COX-2 activity and is proven to be the most specific inhibitor with a Selectivity Index (SI) of (COX-1 $\mathrm{IC}_{50} / \mathrm{COX}-2$ $\left.\mathrm{IC}_{50}\right)>500,000$ (Parashar et al, 2005). In comparison, the SI of celecoxib, the second selective COX-2 inhibitor, is about 400 (Habeeb et al, 2000).

3,4-Dichloropropionaline (DCPA) is the aniline compound known to suppress several inflammatory mediators produced by activated macrophages. Overproduction of the inflammatory mediators is involved in many diseases, such as rheumatoid arthritis, chronic hepatitis and pulmonary fibrosis (Tilg et al, 1992; Isomaki et al, 1998; Coker et al, 1998). DCPA inhibits the production of cytokines such as tumor necrosis factor-alpha (TNF- $\alpha$ ), interleukin (IL)-1 $\beta$ and IL-6 which is accompanied by a reduction in NF- $\mathrm{kB}$ DNA binding activity (Frost et al, 2001). The reactive oxygen and reactive nitrogen species (ROS and RNS) generation is also reduced by DCPA, affecting not only nitrite production but decreasing the protein levels of inducible nitric oxide synthase (iNOS), an enzyme responsible for NO production. The ability of DCPA to suppress a number of inflammatory mediators suggests its use as an inhibitor/antioxidant (Ustyugova et al, 2007).

In this report, we demonstrate that DCPA dramatically inhibits $\mathrm{PGE}_{2}$ production by LPSstimulated macrophages without affecting COX-2 protein expression and its enzymatic activity. The degree of PGE2 inhibition by DCPA was similar to the inhibition by CAY10404, the most 
specific COX-2 inhibitor. An in vivo animal model of ear inflammation confirmed the antiinflammatory properties of the studied compound.

\section{Materials and Methods}

\section{Cell culture and maintenance}

Resident and inflammatory primary macrophages (PEC, peritoneal exudate cells) were maintained in RPMI 1640 media (BioWhittaker, Walkersville, MD) supplemented with $10 \%$ fetal bovine serum (FBS, Hyclone, Logan UT), 10mM HEPES, $100 \mathrm{U} / \mathrm{ml}$ penicillin-100 $\mu \mathrm{g} / \mathrm{ml}$ streptomycin, $2 \mathrm{mM} \mathrm{L-glutamine}$ and $5 \times 10^{-5} \mathrm{M}$ 2-mercaptoethanol (all obtained from Sigma, St. Louis, $\mathrm{MO}$ ) (complete media), and incubated at $37^{\circ} \mathrm{C}$ in an atmosphere of $5 \% \mathrm{CO}_{2}$.

\section{Animals}

C57B1/6 female and male mice were purchased from Charles River Farms (Wilmington, DE). Animals were allowed to acclimate for 7 days before experimental procedures were initiated. Food and water were provided ad libitum. Experimental procedures were conducted between the ages of 7 and 12 weeks. All animal experiments were reviewed and approved by the WVU Animal Care and Use Committee.

\section{Primary macrophage harvest and preparation}

Resident and inflammatory primary macrophages (PEC, peritoneal exudate cells) were utilized. Inflammatory macrophages were elicited by injecting $1.5 \mathrm{ml}$ of aged $4 \%$ sterile thioglycollate broth intraperitoneally (i.p.) four days before macrophage harvest. To harvest the

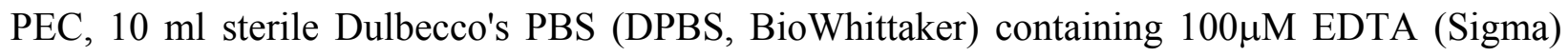
was injected into the mouse's exposed peritoneum and syringe-aspirated. Resulting cell suspensions were washed twice in complete media, plated at the appropriate density in tissue 
culture dishes, and allowed to adhere for 3 hours at $37^{\circ} \mathrm{C}$ in $5 \% \mathrm{CO}_{2}$. Nonadherent cells were removed by the addition of two bursts of warm PBS and vacuum aspiration.

\section{Cell stimulation and exposure to DCPA}

PEC were harvested as described above and plated at concentration of $6.5 \times 10^{6}$ cells $/ 5 \mathrm{ml}$ in $60 \mathrm{~mm}$ dish (Corning, Acton, MA) in complete RPMI and allowed to adhere for $3 \mathrm{hr}$ at $37 \mathrm{Co}$ $5 \% \mathrm{CO} 2$. Nonadherent cells were removed by addition of three bursts of warm DPBS and aspirated by pipette; $5 \mathrm{ml}$ of complete RPMI was added to the wells and cells were incubated for $1 \mathrm{hr}$ before treatments were administrated. The cells were stimulated with $1 \mu \mathrm{g} / \mathrm{ml}$ LPS from Escherichia coli Serotype 055:B5 (Sigma) and simultaneously treated with DCPA (3,4dichloropropionanilide, 99\% purity, ChemServices, West Chester, PA) diluted in absolute ethanol (Mallinckrodt, Paris, KY) at concentrations indicated in the Results section. Control cultures received an equivalent amount of absolute ethanol only and are referred to as vehicle or $0 \mu \mathrm{M}$ DCPA. The final concentration of ethanol for all cultures was $0.10 \%$. LPS was dissolved in RPMI 1640 at $1 \mathrm{mg} / \mathrm{ml}$ and added to cultures at $1 \mu \mathrm{l}$ per $\mathrm{ml}$ of culture media. The possible cytotoxic effects of DCPA alone during the culture period were determined and no significant difference in viability was measure at any DCPA concentration used for this study.

\section{$\mathrm{PGE}_{2}$ release from mouse peritoneal macrophages}

$\mathrm{PGE}_{2}$ secretion was measured in supernatants using Correlate-EIA Prostaglandin $\mathrm{E}_{2}$ kit (Assay Designs, Ann Harbor, MI) according to the manufacturer's protocol. Time course study has not been conducted beyond $24 \mathrm{~h}$ because no further increase in $\mathrm{PGE}_{2}$ production was observed between 24 and 48 h. CAY10404 (Cayman Chemical, Ann Arbor, MI) and Aspirin (Sigma) were diluted in absolute ethanol (100\%) (Mallinckrodt) and added directly to the cell cultures before LPS stimulation. 


\section{COX enzyme activity assay}

After removal of supernatants cells were layered with $5 \mathrm{ml}$ RPMI complete containing $30 \mu \mathrm{M}$ arachidonic acid (Cayman Chemical) and incubated for $10 \mathrm{~min}$ at $37^{\circ} \mathrm{C}$. Next, the reaction was stopped by an addition of aspirin (Sigma, $2.1 \mathrm{mM}$ ), then supernatants were immediately removed and stored at $-80^{\circ} \mathrm{C}$. Cells were then incubated with $300 \mu \mathrm{l}$ of $1 \mathrm{M}$ sodium hydroxide $(\mathrm{NaOH}$, Sigma) for $5 \mathrm{~min}$, and supernatants were removed and stored at $-20^{\circ} \mathrm{C}$ for protein analysis by BCA Protein Assay (Pierce, Rockford, IL).

\section{Mouse ear inflammation model}

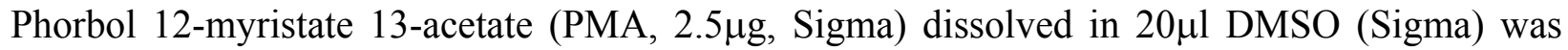
applied in $10 \mu \mathrm{l}$ volume to both inner and outer surfaces of the left ear of $\mathrm{C} 57 \mathrm{Bl} / 6$ mice. The right ear was treated with 25, 100 or $1000 \mu \mathrm{M}$ DCPA dissolved in DMSO and PMA. Four mice per treatment group were used. Mice in the control group received DMSO as a vehicle control on the left ear, and right ear was left untreated to monitor the effects of the vehicle. After $4 \mathrm{~h}$, the animals were sacrificed by cervical dislocation and circular sections ( $8 \mathrm{~mm}$ diameter) of both ears were punched out and weighed.

\section{Immunoblotting}

PEC were harvested and plated as described above, stimulated with $1 \mu \mathrm{g} / \mathrm{ml}$ LPS and simultaneously treated with $5,25,100 \mu \mathrm{M}$ DCPA or ethanol, and incubated for 6,12 and 24 hours for COX-2 protein detection. Whole-cell extracts were prepared using lysis buffer (Cell Signaling Technology, Beverly, MA) according to manufacturer instructions, and protein levels were quantified using BCA protein assay kit (Pierce, Rockford, IL). $15 \mu \mathrm{g}$ of whole-cell lysates were separated by $8 \%$ polyacrylamide gels using SDS-PAGE, transferred to polyvinylidene fluoride membranes (Pall Corporation, Pensacola, Fl) overnight at 0.1A. The membranes were 
then blocked by incubation for 45 min with 5\% nonfat dry Carnation milk (Nestlé, Glendale CA) in Tris-buffered saline (TBS: $20 \mathrm{mM}$ Tris-HCl, ph 7.6, $137 \mathrm{mM} \mathrm{NaCl}$ ) containing 0.1\% Tween 20 (TBS-Tween), and then rinsed three times with TBS-Tween. The protein blots were cut across to incubate the upper part overnight with rabbit polyclonal IgG anti-COX-2 (sc-1745) or rabbit polyclonal IgG anti-phospho cPLA 2 (sc-34391-R) from Santa Cruz Biotechnology, Santa Cruz, CA at 1:2000 dilution and the lower part with goat polyclonal IgG anti-actin (Santa Cruz Biotechnology, sc-1616; 1:1000 dilution) in TBS-Tween plus 5\% bovine serum albumin (BSA). After incubation with the appropriate secondary antibodies (Sigma, A0545 and A5420), blots were developed using Phototope-HRP detection kit for western blots (Cell Signaling Technology) and visualized by exposing to X-Ray film (Kodak BioMax Light Film, Eastman Kodak Company, Rochester, NY) for $15 \mathrm{sec}$ to 3 minutes. Densitometric analysis was completed with Optimas software (Media Cybernetics, Silver Springs, MD).

\section{Statistical Analysis}

Significance of interactions between treatment groups was assessed using an analysis of variance. For all analyses, the minimum criterion of significance was set at $p<0.05$. Each experiment was repeated at least twice with similar results. Error bars represent standard deviation unless otherwise noted to represent standard error, where appropriate. Ear inflammation model was analyzed using one-way ANOVA comparing two ears of the same animal. 


\section{Results}

\section{DCPA inhibits PGE $_{2}$ production from mouse peritoneal macrophages}

To assess effects of DCPA on LPS-induced $\mathrm{PGE}_{2}$ production in PEC, cell culture media was harvested and the amount of secreted $\mathrm{PGE}_{2}$ was measured for over $24 \mathrm{~h}$ period (Figure 1). $\mathrm{PGE}_{2}$ levels in unstimulated cultures were $891 \pm 144$ at12 hr. This low amount of $\mathrm{PGE}_{2}$ was attributed to the functional activity of constitutively expressed COX-1 enzyme. In LPSstimulated macrophages, $\mathrm{PGE}_{2}$ production was significantly higher and continually increased over time from $3592 \pm 490.73 \mathrm{pg} / \mathrm{ml}$ at $6 \mathrm{~h}$ to $11470 \pm 275.32 \mathrm{pg} / \mathrm{ml}$ at $12 \mathrm{~h}$ and reaching 13214.5 $\pm 590 \mathrm{pg} / \mathrm{ml}$ by $24 \mathrm{~h}$ post-stimulation. This large increase in $\mathrm{PGE}_{2}$ production by LPS-stimulated macrophages can be explained by a rapid induction of COX-2 enzyme. DCPA treatment had a dramatic effect on $\mathrm{PGE}_{2}$ production by LPS-stimulated macrophages reducing it in concentration-dependent manner (Figure 1). The highest concentration of DCPA used, $5 \mu \mathrm{M}$, reduced $\mathrm{PGE}_{2}$ production by $89 \%(1913.5 \pm 71.4 \mathrm{pg} / \mathrm{ml})$ and $83.9 \%(23203 \pm 123 \mathrm{pg} / \mathrm{ml})$ at 12 and $24 \mathrm{~h}$, respectively, compared to ethanol-treated control cultures produced $17713 \pm 574.1$ $\mathrm{pg} / \mathrm{ml}$ and $14323 \pm 1315 \mathrm{pg} / \mathrm{ml}$. Lower concentrations of $1,0.5$ and $0.05 \mu \mathrm{M}$ DCPA resulted in 73,60 and $22 \%$ inhibition at $12 \mathrm{~h}$ after stimulation, and $64,52,25 \%$ decrease at $24 \mathrm{~h}$ compared to ethanol-treated controls. Even $0.01 \mu \mathrm{M}$ DCPA reduced $\mathrm{PGE}_{2}$ production by $30 \%$ at $24 \mathrm{~h}$ time point (Figure 1). 


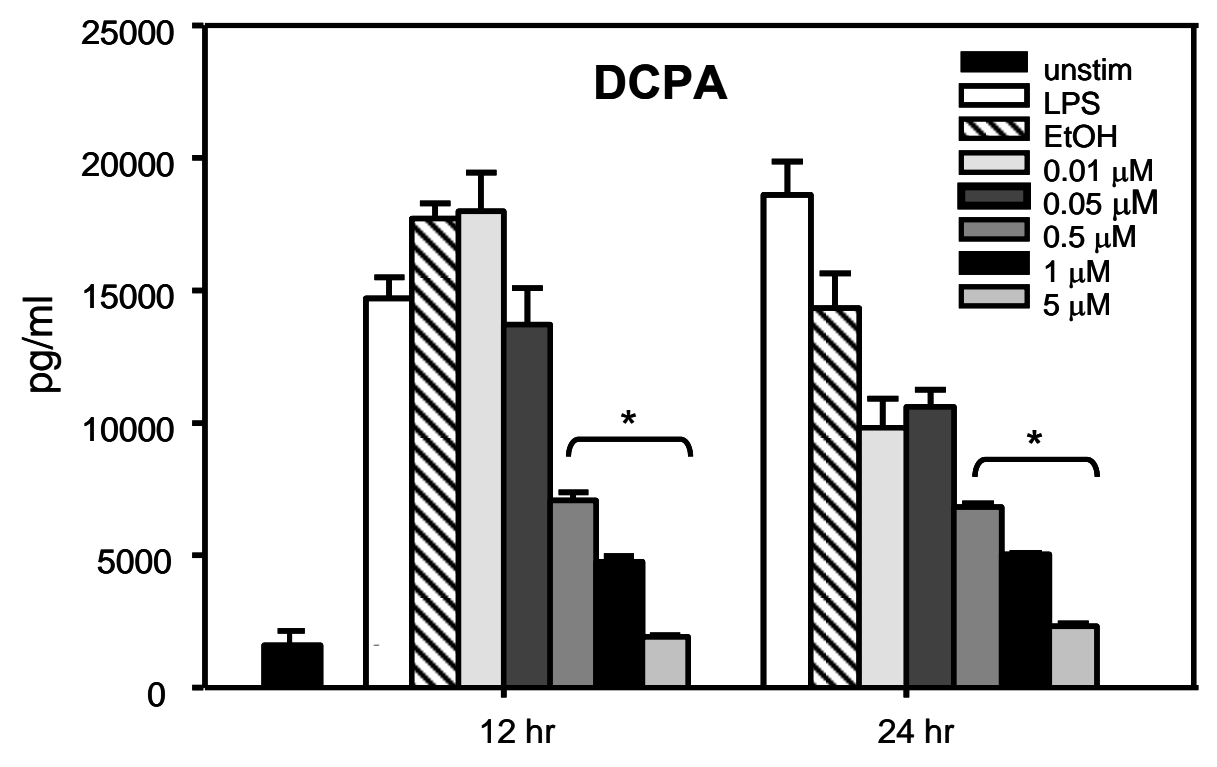

Figure 1. DCPA inhibitis $\mathrm{PGE}_{2}$ production in a dose dependent manner.

Secreted $\mathrm{PGE}_{2}(\mathrm{pg} / \mathrm{ml})$ production by LPS-stimulated PECs treated with $0.01,0.05,0.1,1,5 \mu \mathrm{M}$ DCPA for 12 and $24 \mathrm{~h}$. Experiments were performed three times, each treatment was run and analyzed in triplicates. The mean $\mathrm{PGE}_{2}$ production of a representative experiment $\pm \mathrm{SD}$ is shown, * indicates significant difference from vehicle control $(\mathrm{p}<0.01)$. 


\section{CAY10404 inhibits PGE2 production and COX enzymes activity}

To compare the ability of DCPA to inhibit $\mathrm{PGE}_{2}$ production by activated macrophages, a specific inhibitor of COX-2 was used. As shown in Figure 2a, the lowest concentration of $1 \mathrm{nM}$ CAY10404 had no effect on cell cultures which released $13428 \pm 996 \mathrm{pg} / \mathrm{ml}$ and $15047 \pm 1653$ $\mathrm{pg} / \mathrm{ml}$ PGE2 at 12 and $24 \mathrm{~h}$ post-treatment, respectively. Treatment with 0.5 and $5 \mu \mathrm{M}$ CAY 10404 resulted in $80 \%$ and $90 \%$ reduction in $\mathrm{PGE}_{2}$ at $12 \mathrm{~h}$ compared to ethanol-treated controls, respectively. At $24 \mathrm{~h}, \mathrm{PGE}_{2}$ levels were decreased by $67 \%$ and $84 \%$ for 0.5 and $5 \mu \mathrm{M}$ CAY10404 compared to ethanol-treated cultures, respectively. These results demonstrate that similar micromolar concentrations of DCPA and CAY10404 were able to inhibit $\mathrm{PGE}_{2}$ production by $70-90 \%$.

The ability of CAY10404 to inhibit COX-2 activity as a measure of $\mathrm{PGE}_{2}$ secreted over a 10-min period was tested (Figure 2b). Cells treated with CAY10404 and stimulated with LPS for 6, 12 and 24 hrs were washed, and then an exogenous source of prostaglandins, arachidonic acid, was added to the cell cultures and $\mathrm{PGE}_{2}$ secretion was measured after 10 min incubation by EIA. The largest concentration of CAY10404, $1 \mu \mathrm{M}$, inhibited COX-2 activity by $80-90 \%$ at all time-points measured (Figure 2b).

CAY10404 inhibits COX-2 through binding into an active site pocket of enzyme, preventing it from converting arachidonic acid into PGs. The next set of experiments was designed to test whether DCPA affects $\mathrm{PGE}_{2}$ production through the same mechanism. 
a.

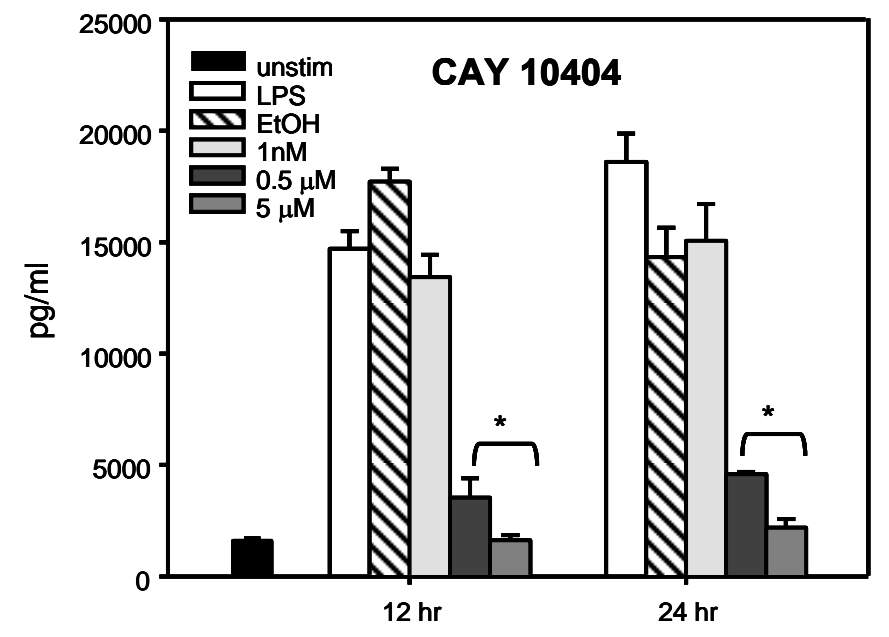

b.

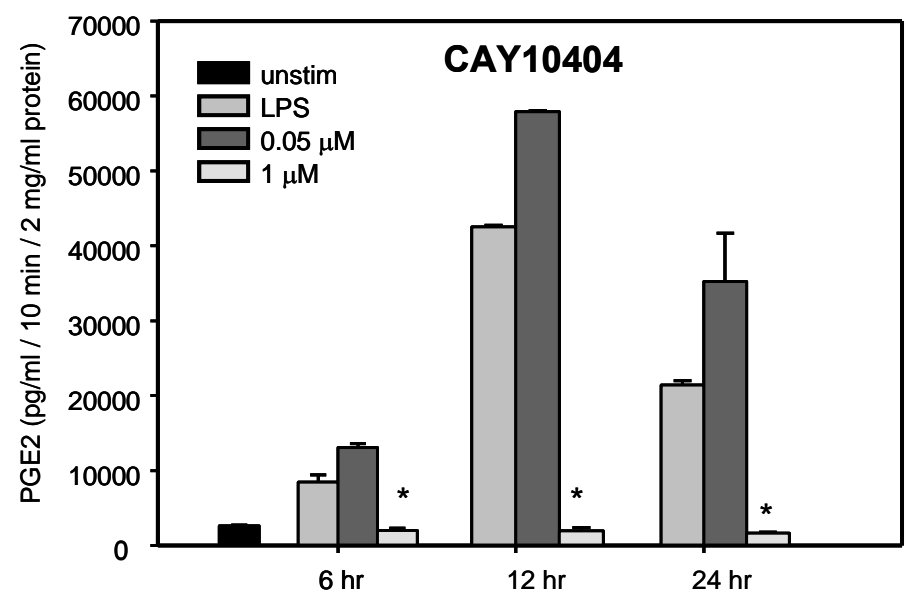

Figure 2. CAY10404 inhibits PGE2 production and COX enzyme activity.

a). Secreted $\mathrm{PGE}_{2}(\mathrm{pg} / \mathrm{ml})$ production by LPS-stimulated PEC at 12 and $24 \mathrm{~h}$. b). Secreted PGE 2 (pg/ml / $10 \mathrm{~min} / 2 \mathrm{mg} / \mathrm{ml}$ ) produced over 10-min period from exogenously added arachidonic acid by LPS-stimulated PEC at 6, 12 and $24 \mathrm{~h}$. Experiments were performed twice, each treatment was run and analyzed in duplicates. The mean $\mathrm{PGE}_{2}$ production of a representative experiment $\pm \mathrm{SD}$ is shown, * indicates significant difference from vehicle control $(\mathrm{p}<0.01)$. 


\section{DCPA does not affect in vitro COX isozymes activity in PEC}

To examine in vitro COX enzyme activity, DCPA-treated and stimulated cell cultures were supplemented with arachidonic acid, and $\mathrm{PGE}_{2}$ secreted during 10-min period was measured as described for CAY10404 experimets (Figure 3). No statistically significant difference among treatments and time points were found. 


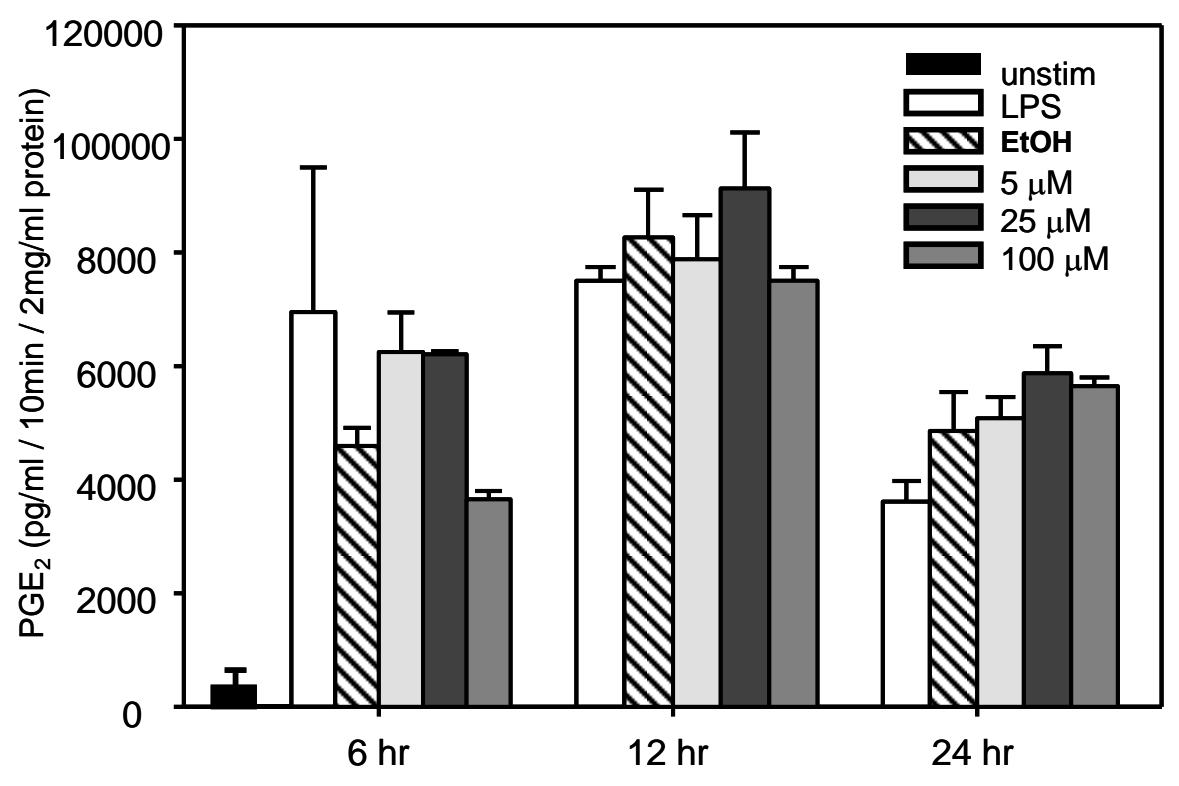

Figure 3. DCPA does not affect in vitro COX isozymes activity.

Secreted $\mathrm{PGE}_{2}(\mathrm{pg} / \mathrm{ml} / 10 \mathrm{~min} / 2 \mathrm{mg}$ protein) produced from exogenously added arachidonic acid by $\mathrm{PEC}$. The mean $\mathrm{PGE}_{2}$ production of a representative experiment $\pm \mathrm{SD}$ is shown. 


\section{DCPA does not affect COX-2 protein expression}

A dramatic decrease in $\mathrm{PGE}_{2}$ production might be explained by an impaired induction of COX-2 protein. To test this hypothesis, protein extracts from unstimulated and stimulated cells were resolved by SDS-Page and probed for COX-2 protein expression (Figure 4). As expected, unstimulated macrophages did not express any detectable levels of COX-2, while LPSstimulated macrophages expressed protein at all time points measured, reaching maximum at 12 $\mathrm{h}$ and declining by $24 \mathrm{~h}$ post-treatment. No changes among the treatment groups have been observed demonstrating that induction of COX-2 enzyme was not affected by DCPA treatment. 

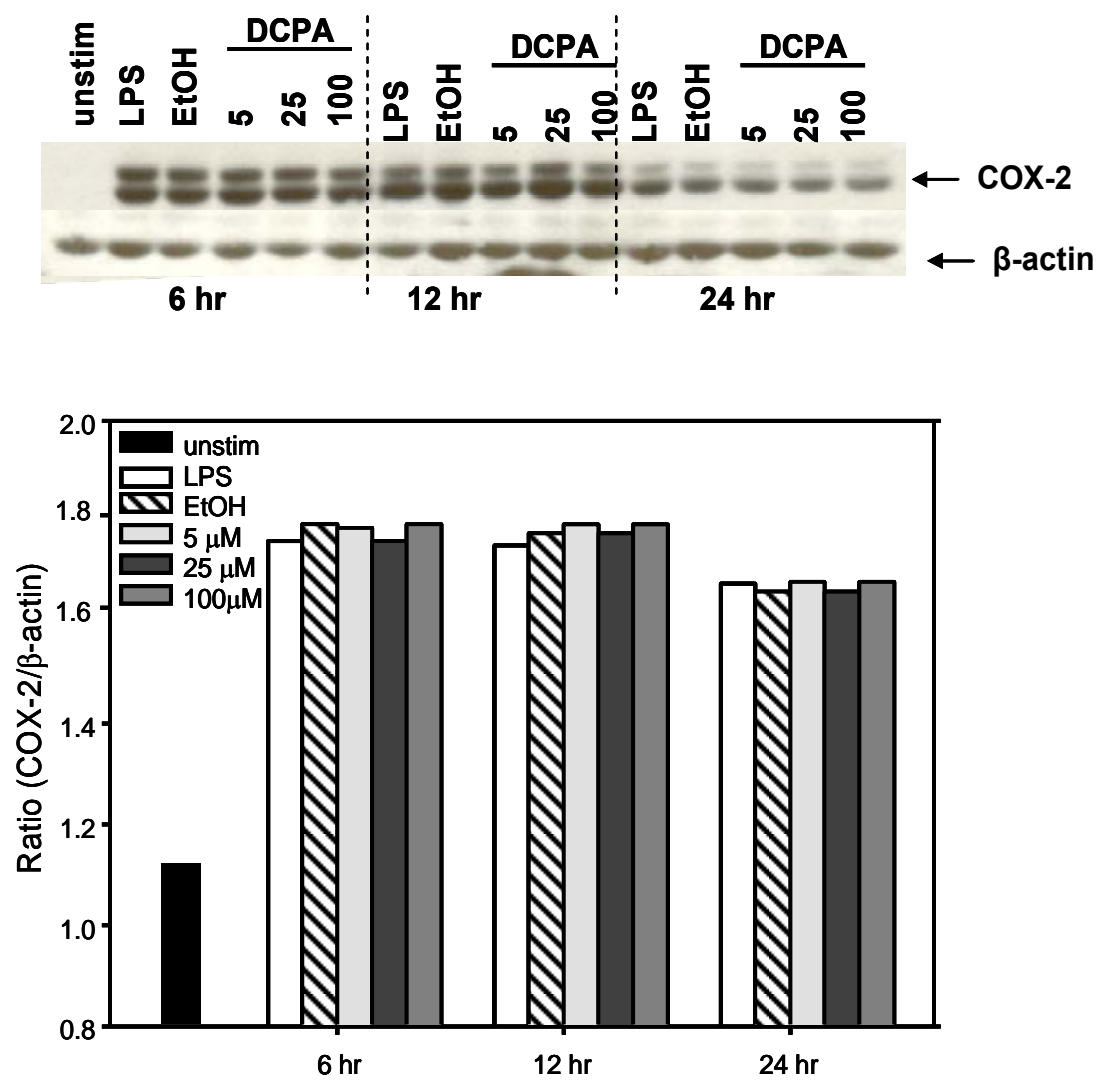

Figure 4. DCPA does not affect COX-2 protein expression.

PECs were treated with DCPA or vehicle control, stimulated with LPS and incubated for 6, 12 and 24 hours. The protein levels of COX-2 and $\beta$-actin in whole-cell lysates were analyzed by Western Blotting. 


\section{DCPA does not affect cPLA2 phosphorylation}

cPLA 2 activation is triggered by two events: an increase in intracellular $\mathrm{Ca}^{2+}$ levels and phosphorylation on Ser505 within the first $5 \mathrm{~min}$ after stimulation. To investigate whether phosphorylation of protein was affected by DCPA, whole cell lysates were subjected to SDSPage and probed for phospho-cPLA 2 expression (Figure5). To capture the initial steps of protein activation and subsequent phosphorylation, 5, 15, 30 and 45 min time-points were observed. As expected, 5 min after LPS stimulation macrophages expressed low levels of phosphorylated cPLA $_{2}$ similar to unstimulated cells. Later time-points (15, 30 and $\left.45 \mathrm{~min}\right)$ demonstrated upregulated levels of phosphorylated protein. However, no changes between treatment groups were observed. 

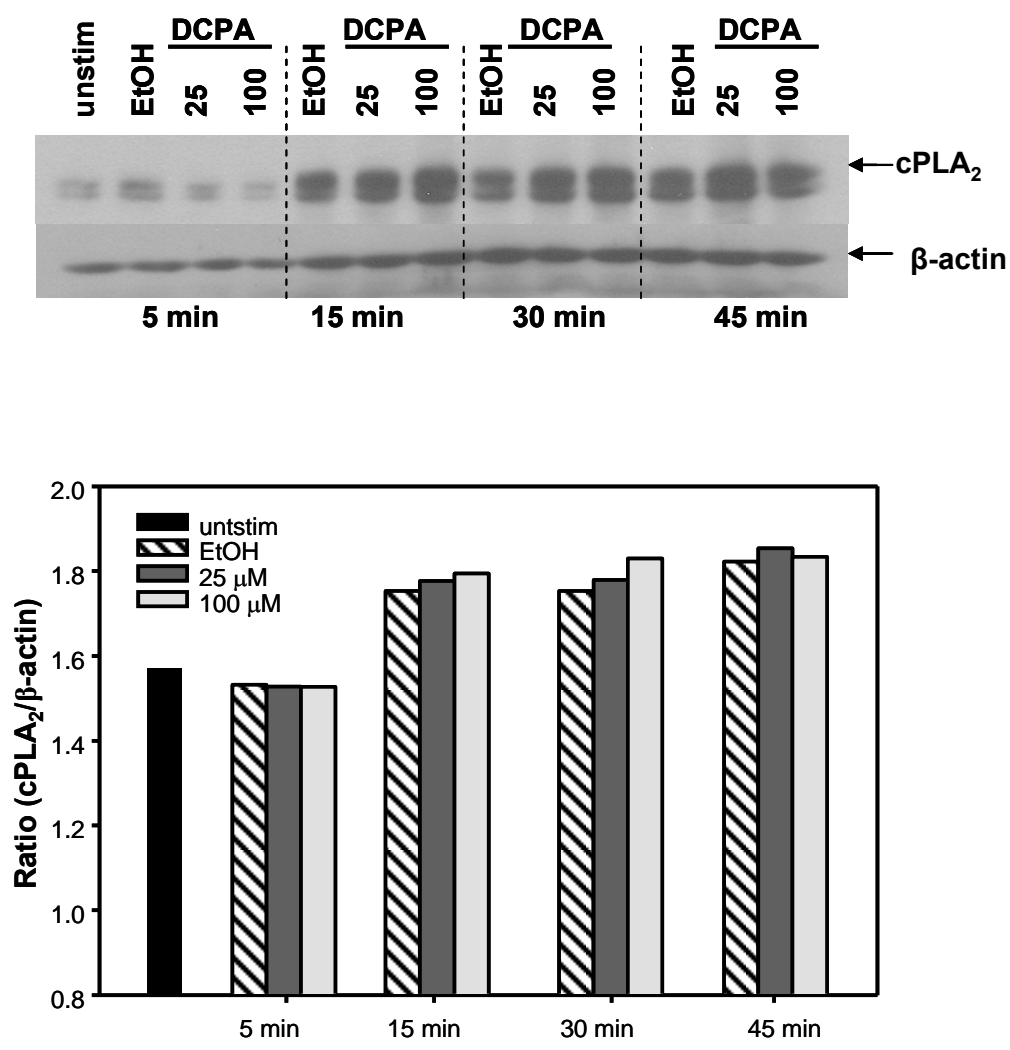

Figure 5. DCPA does not affect ${ }_{\mathrm{c}}$ PLA2 protein phosphorylation.

PECs were treated with DCPA or vehicle control, stimulated with LPS and incubated for 5, 15, 30 and 45 min. The protein levels of cPLA2and $\beta$-actin in whole-cell lysates were analyzed by Western Blotting. 


\section{Ear inflammation model}

To determine the ability of DCPA to inhibit the synthesis of inflammatory mediators in vivo, the mouse ear inflammation model has been used. In this model, inflammation was induced by PMA dissolved in DMSO (control) and applied topically to the both surfaces of the

mouse ear (Figure 6). The other ear of the same animal was treated with mixture of PMA and DCPA also dissolved in DMSO. Induction of an inflammation was demonstrated by an increased weight of the $8 \mathrm{~mm}$ ear section from $17.7 \pm 0.35 \mathrm{mg}$ in DMSO treated controls to 27.3 $\pm 1.31 \mathrm{mg}$ in PMA-treated samples. In animals treated with $25 \mu \mathrm{M}$ DCPA + PMA, the ear section weight was $25.06 \pm 1.5 \mathrm{mg}$, which was not statistically significantly different from PMAtreated samples with a weight of $25.26 \pm 1.2 \mathrm{mg}$. However, treatment with $100 \mu \mathrm{M}$ DCPA reduced the ear section weights from $32.05 \pm 1.9 \mathrm{mg}$ in PMA treated controls to $27.35 \pm 2.47 \mathrm{mg}$ in DCPA-treated $(15 \%$ decrease $)(\mathrm{p}<0.005)$. The highest concentration of DCPA tested, 1000 $\mu \mathrm{M}$ resulted in even larger reduction of the section weights from $30.05 \pm 3.9 \mathrm{mg}$ to $24.62 \pm 4.6$ $\operatorname{mg}(19 \%$ decrease $)$. 
Table 1. Ear inflammation model.

\begin{tabular}{c|l|l}
\hline $\begin{array}{c}\text { Mice per } \\
\text { treatment group }\end{array}$ & \multicolumn{1}{c|}{$\begin{array}{c}\text { Left Ear } \\
\text { Ear section weight }( \pm \mathbf{S D}), \mathbf{m g}\end{array}$} & \multicolumn{1}{c}{$\begin{array}{c}\text { Right Ear } \\
\text { Ear section weight }( \pm \mathbf{S D}), \mathbf{m g}\end{array}$} \\
\hline $\mathrm{n}=2$ & $16.2 \pm 0.98$ (untreated) & $17.75 \pm 0.35(\mathrm{DMSO})$ \\
$\mathrm{n}=4$ & $25.26 \pm 1.16(\mathrm{PMA}+\mathrm{DMSO})$ & $25.06 \pm 1.53(25 \mu \mathrm{M}$ DCPA in DMSO) \\
$\mathrm{n}=4$ & $32.05 \pm 1.93(\mathrm{PMS}+\mathrm{DMSO})$ & $27.35 \pm 2.47 *(100 \mu \mathrm{M}$ DCPA in DMSO) \\
$\mathrm{n}=4$ & $30.07 \pm 3.91(\mathrm{PMA}+\mathrm{DMSO})$ & $24.62 \pm 4.607(1 \mathrm{mM}$ DCPA in DMSO) \\
\hline
\end{tabular}

PMA-induced ear inflammation presented as ear section weights (mg) from different treatment groups ( $\mathrm{n}=4$ per group) measured $4 \mathrm{~h}$ after stimulation. The mean ear section weight of a treatment group $\pm \mathrm{SD}$ is shown, * indicates significant difference from vehicle control $(\mathrm{p}<0.05)$ (one-way ANOVA). 


\section{Discussion}

The ability of DCPA to suppress the production of inflammatory mediators, such as TNF$\alpha$ and IL-6, and the generation of ROS and RNS, has been previously described (Xie, et al, 1997a, Xie, et al, 1997b, Ustyugova et al, 2007). The present study demonstrates that DCPA dramatically inhibits $\mathrm{PGE}_{2}$ production by LPS-stimulated macrophages, without affecting COX2 protein induction or interfering with its enzymatic activity. In vivo studies of the inflammatory potential of DCPA confirms its ability to reduce the local inflammatory response in the PMAinduced mouse ear inflammation model.

Prostaglandins are considered to promote inflammation by inducing vasolidation, increasing vascular permeability and cellular migration to the site of inflammation (Dubois et al, 1998; Williams and Shacter, 1997; Williams and Morley, 1973). The present study demonstrates that DCPA dramatically inhibits $\mathrm{PGE}_{2}$ production by LPS-activated macrophages. A concentration as low as $0.01 \mu \mathrm{M}$ DCPA inhibited secreted $\mathrm{PGE}_{2}$ release by $30 \%$ at $24 \mathrm{~h}$ posttreatment. The highest dose of $5 \mu \mathrm{M}$ DCPA suppressed $\mathrm{PGE}_{2}$ production to the baseline levels of unstimulated cells, totally abrogating induced $\mathrm{PGE}_{2}$ generation. The ability of DCPA to inhibit $\mathrm{PGE}_{2}$ was compared to a highly selective COX-2 inhibitor, CAY10404. A concentration of $5 \mu \mathrm{M}$ CAY10404 completely abrogated the LPS-induced $\mathrm{PGE}_{2}$ production, through suppression of COX-2 enzyme activity. Surprisingly, the micromolar concentrations of DCPA and CAY10404 used were strikingly similar and resulted in a comparable degree of $\mathrm{PGE}_{2}$ inhibition. $0.1 \mathrm{mM}$ Aspirin, a prototypic non-specific COX-1 and COX-2 inhibitor also inhibited $\mathrm{PGE}_{2}$ production to the baseline levels.

The ability of DCPA to inhibit COX enzymatic activity was tested by supplementing cell cultures with exogenous arachidonic acid and evaluated the amount of PGE2 secreted during 10- 
min period. No significant difference among the treatment groups was observed, suggesting that the enzymatic ability of COX isozymes was not affected by DCPA. Next, the protein expression of COX-2 was examined to test whether the enzyme is properly induced by LPS stimulation. It was possible that DCPA was inhibiting COX-2 expression through a decrease in NF- $\mathrm{BB}$ binding activity, previously reported by Frost et al. (2001). Previous studies also demonstrated that DCPA treatment caused a reduction in inducible levels of iNOS protein, whose transcription is NF-kB-dependant (Ustyugova et al, 2007). COX-2 protein expression is also regulated by NF$\kappa \mathrm{B}$, including a number of other transcription factors, such as AP-1, NF-AT and NF-IL6 (Smith et al, 2000). However, the relative importance NF- $\mathrm{kB}$ and its contribution to COX-2 induction in macrophages is controversial. Some studies report a correlation between an inhibition of NF$\kappa \mathrm{B}$ activation and a decrease in the induction of COX-2 followed by treatment with antiinflammatory compounds (Won et al, 2005; Park et al, 2006). A study of cardamonin applied to LPS-stimulated macrophages demonstrated reduced iNOS protein induction through a mechanism of interfering with NF-kB DNA binding. However, the induction of COX-2 enzyme has not been affected by this compound, which parallels with the present study (Hatziierema et $a l, 2006)$.

Another enzyme known to be crucial for prostaglandin production is cytosolic phospholipase $\mathrm{A}_{2}\left(\mathrm{CPLA}_{2}\right)$ located upstream from COX isoezymes in the PGs signaling cascade. In order to become activated, cPLA 2 is directly phosphorylated by members of the mitogenactivated protein kinases (MAPK) (Lin et al, 1993), and then, upon an increase in intracellular $\mathrm{Ca}^{2+}$ levels, it is translocated to the membrane (Clark et al, 1995). These two events allow for translocation of $\mathrm{cPLA}_{2}$ from the cytosol to the membrane site to where its substrate resides (Kramer et al, 1997; Leslie 1997). No change in phosphorylation pattern of cPLA 2 was 
observed. However, an increase in intracellur $\mathrm{Ca}^{2+}$ release might be affected. It has been previously demonstrated, that $20 \mu \mathrm{M}$ DCPA completely abrogated intracellular $\mathrm{Ca}^{2+}$ release in LPS-stimulated PEC (Xie et al, 1997b), which might potentially suppress cPLA $\mathrm{A}_{2}$ activation and inhibit downstream signaling events resulting in a decrease in arachidonic acid release and subsequent reduction of prostaglandins production.

A study by Burke et al. (1999) characterized a choline derivative known to inhibit cPLA 2 reversibly. The studied compound acts by inhibiting $\mathrm{CPLA}_{2}$ enzyme at the lipid-water interface through partitioning into the bilayer and competing with membrane phospholipids for the active site of the enzyme. It is possible that DCPA interferes with the macrophage membrane by inserting into the lipid bilayer or changing its architecture. Brundage et al. (2003) studied the mobility of hydrocarbon chains in T-lymphocytes and demonstrated that DCPA alters the distribution of lipids in the membrane by increasing a small population of lipid molecules that exhibited reduced hydrocarbon chain mobility. The study of macrophage cell line, IC-21, did not produce similar data, but it is possible that the membrane of activated macrophages is affected differently, and these changes can not be captured by the methods used in the study.

The in vivo ear inflammation model tested whether DCPA was able to reduce local inflammation induced by PMA. The inflammatory response is coordinated by many cell types including macrophages, lymphocytes, leukocytes and mast cells. DCPA is known to suppress/alter $\mathrm{T}$ and $\mathrm{B}$ lymphocyte functions, which may reduce an inflammatory response or suppress inflammation. The weight reduction of the sections indicates the lower rate in infiltration of polymorphonuclear leukocytes and a decrease in vascular permeability in the treated ear, through suppression of ROS and RNS generation, cytokines, histamine and prostaglandins production (Dugas et al., 1995; Wilkinson 1994). 
The data herein demonstrate the profound ability of DCPA to suppress $\mathrm{PGE}_{2}$ production by activated peritoneal macrophages. The degree of inhibition was comparable with the newest selective inhibitors of COX-2. However, COX-2 protein expression and its enzymatic activity were not affected suggesting a different mechanism of PGs inhibition. The in vivo model of PMA-induced mouse ear inflammation provided additional evidence for the anti-inflammatory abilities of DCPA. 


\section{References}

Anderson, G. D., Hauser, S. D., McGarity, K. L., Bremer, M. E., Isakson, P. C., and Gregory, S. A. (1996). Selective inhibition of cyclooxygenase (COX)-2 reverses inflammation and expression of COX-2 and interleukin 6 in rat adjuvant arthritis. J Clin. Invest 97(11), 2672-2679.

Bonventre, J. V., Huang, Z., Taheri, M. R., O'Leary, E., Li, E., Moskowitz, M. A., and Sapirstein, A. (1997). Reduced fertility and postischaemic brain injury in mice deficient in cytosolic phospholipase A2. Nature 390(6660), 622-625.

Brundage, K. M., Barnett, J. B., and Mahaney, J. E. (2003). The amide class herbicide 3,4dichloropropionanilide (DCPA) alters the mobility of hydrocarbon chains in Tlymphocyte but not macrophage membranes. J Toxicol. Environ. Health A 66(23), 2253 2265.

Burke, J. R., Witmer, M. R., Zusi, F. C., Gregor, K. R., Davern, L. B., Padmanabha, R., Swann, R. T., Smith, D., Tredup, J. A., Micanovic, R., Manly, S. P., Villafranca, J. J., and Tramposch, K. M. (1999). Competitive, reversible inhibition of cytosolic phospholipase A2 at the lipid-water interface by choline derivatives that partially partition into the phospholipid bilayer. J Biol. Chem. 274(27), 18864-18871.

Clark, J. D., Schievella, A. R., Nalefski, E. A., and Lin, L. L. (1995). Cytosolic phospholipase A2. J Lipid Mediat. Cell Signal. 12(2-3), 83-117.

Coker, R. K., and Laurent, G. J. (1998). Pulmonary fibrosis: cytokines in the balance. Eur. Respir. J 11(6), 1218-1221. 
Dubois, R. N., Abramson, S. B., Crofford, L., Gupta, R. A., Simon, L. S., Van De Putte, L. B., and Lipsky, P. E. (1998). Cyclooxygenase in biology and disease. FASEB J 12(12), 1063-1073.

Dugas, B., Debre, P., and Moncada, S. (1995). Nitric oxide, a vital poison inside the immune and inflammatory network. Res. Immunol. 146(9), 664-670.

Frost, L. L., Neeley, Y. X., Schafer, R., Gibson, L. F., and Barnett, J. B. (2001). Propanil inhibits tumor necrosis factor-alpha production by reducing nuclear levels of the transcription factor nuclear factor-kappab in the macrophage cell line ic-21. Toxicol. Appl. Pharmacol. 172(3), 186-193.

Gierse, J. K., McDonald, J. J., Hauser, S. D., Rangwala, S. H., Koboldt, C. M., and Seibert, K. (1996). A single amino acid difference between cyclooxygenase-1 (COX-1) and -2 (COX-2) reverses the selectivity of COX-2 specific inhibitors. J Biol. Chem. 271(26), $15810-15814$.

Habeeb, A. G., Praveen Rao, P. N., and Knaus, E. E. (2001). Design and synthesis of 4,5diphenyl-4-isoxazolines: novel inhibitors of cyclooxygenase-2 with analgesic and antiinflammatory activity. J Med Chem. 44(18), 2921-2927.

Hatziieremia, S., Gray, A. I., Ferro, V. A., Paul, A., and Plevin, R. (2006). The effects of cardamonin on lipopolysaccharide-induced inflammatory protein production and MAP kinase and NFkappaB signalling pathways in monocytes/macrophages. Br. J Pharmacol. 149(2), 188-198.

Hinson, R. M., Williams, J. A., and Shacter, E. (1996). Elevated interleukin 6 is induced by prostaglandin E2 in a murine model of inflammation: possible role of cyclooxygenase- 2 . Proc. Natl. Acad. Sci. U. S. A 93(10), 4885-4890. 
Isomaki, P., and Punnonen, J. (1997). Pro- and anti-inflammatory cytokines in rheumatoid arthritis. Ann. Med 29(6), 499-507.

Kramer, R. M., and Sharp, J. D. (1997). Structure, function and regulation of Ca2+-sensitive cytosolic phospholipase A2 (cPLA2). FEBS Lett. 410(1), 49-53.

Kurumbail, R. G., Stevens, A. M., Gierse, J. K., McDonald, J. J., Stegeman, R. A., Pak, J. Y., Gildehaus, D., Miyashiro, J. M., Penning, T. D., Seibert, K., Isakson, P. C., and Stallings, W. C. (1996). Structural basis for selective inhibition of cyclooxygenase-2 by antiinflammatory agents. Nature 384(6610), 644-648.

Leslie, C. C. (1997). Properties and regulation of cytosolic phospholipase A2. J Biol. Chem. 272(27), 16709-16712.

Lin, L. L., Wartmann, M., Lin, A. Y., Knopf, J. L., Seth, A., and Davis, R. J. (1993). cPLA2 is phosphorylated and activated by MAP kinase. Cell 72(2), 269-278.

Luong, C., Miller, A., Barnett, J., et al. (1996). The structure of human cyclooxygenase2, conservation and flexibility of the NSAID binding size. Nat Struct Biol 3:927-33.

Meade, E. A., Smith, W. L., and DeWitt, D. L. (1993). Differential inhibition of prostaglandin endoperoxide synthase (cyclooxygenase) isozymes by aspirin and other non-steroidal anti-inflammatory drugs. J Biol. Chem. 268(9), 6610-6614.

Parashar, B., Latha, S. S., O'Guin, K., Butler, J., Vikram, B., and Shafit-Zagardo, B. (2005). Inhibition of human neuroblastoma cell growth by CAY10404, a highly selective Cox-2 inhibitor. J Neurooncol. 71(2), 141-148.

Park, Y. M., Won, J. H., Yun, K. J., Ryu, J. H., Han, Y. N., Choi, S. K., and Lee, K. T. (2006). Preventive effect of Ginkgo biloba extract (GBB) on the lipopolysaccharide-induced 
expressions of inducible nitric oxide synthase and cyclooxygenase-2 via suppression of nuclear factor-kappaB in RAW 264.7 cells. Biol. Pharm. Bull. 29(5), 985-990.

Roth, G. J., and Calverley, D. C. (1994). Aspirin, platelets, and thrombosis: theory and practice. Blood 83(4), 885-898.

Sano, H., Hla, T., Maier, J. A., Crofford, L. J., Case, J. P., Maciag, T., and Wilder, R. L. (1992). In vivo cyclooxygenase expression in synovial tissues of patients with rheumatoid arthritis and osteoarthritis and rats with adjuvant and streptococcal cell wall arthritis. J Clin. Invest 89(1), 97-108.

Smith, W. L., DeWitt, D. L., and Garavito, R. M. (2000). Cyclooxygenases: structural, cellular, and molecular biology. Annu. Rev. Biochem. 69, 145-182.

Smith, W. L., and Langenbach, R. (2001). Why there are two cyclooxygenase isozymes. J Clin. Invest 107(12), 1491-1495.

Tilg, H., Wilmer, A., Vogel, W., Herold, M., Nolchen, B., Judmaier, G., and Huber, C. (1992). Serum levels of cytokines in chronic liver diseases. Gastroenterology 103(1), 264-274.

Uozumi, N., Kume, K., Nagase, T., Nakatani, N., Ishii, S., Tashiro, F., Komagata, Y., Maki, K., Ikuta, K., Ouchi, Y., Miyazaki, J., and Shimizu, T. (1997). Role of cytosolic phospholipase A2 in allergic response and parturition. Nature 390(6660), 618-622.

Wilkinson, P. C. (1994). Cellular accumulation and inflammation. In Textbook of Immunopharmacology (M.M.Dale, J.C.Foreman, and T.D.Fan, Eds.), 3 ed., pp. 211-230. Blackwell Scientific Publications.

Williams, J. A., and Shacter, E. (1997). Regulation of macrophage cytokine production by prostaglandin E2. Distinct roles of cyclooxygenase-1 and -2. J Biol. Chem. 272(41), 25693-25699. 
Williams, T. J., and Morley, J. (1973). Prostaglandins as potentiators of increased vascular permeability in inflammation. Nature 246(5430), 215-217.

Won, J. H., Park, S. Y., Nam, S. G., Park, H. J., Choi, J. W., and Lee, K. T. (2005). Inhibition of lipopolysaccharide-induced expression of inducible nitric oxide and cyclooxygenase-2 by chiisanoside via suppression of nuclear factor-kappaB activation in RAW 264.7 macrophage cells. Biol. Pharm. Bull. 28(10), 1919-1924.

Wu, T. (2006). Cyclooxygenase-2 in hepatocellular carcinoma. Cancer Treat. Rev. 32(1), 28-44.

Xie, Y. C., Schafer, R., and Barnett, J. B. (1997). The immunomodulatory effects of the herbicide propanil on murine macrophage interleukin- 6 and tumor necrosis factor-alpha production. Toxicol. Appl. Pharmacol. 145(1), 184-191.

Xie, Y. C., Schafer, R., and Barnett, J. B. (1997). Inhibitory effect of 3,4-dichloro-propionaniline on cytokine production by macrophages is associated with LPS-mediated signal transduction. J Leukoc. Biol. 61(6), 745-752. 


\section{CHAPTER 4}

Modulating Temporal Control of NF-kappaB Activation: Implications for Therapeutic and Assay Selection

Submitted to Biophysical Journal (2007)

David J. Klinke $\mathrm{II}^{1,2 \psi}$, Irina V. Ustyugova ${ }^{2,3 \psi}$, Kathleen M. Brundage ${ }^{2,3}$ \& John B. Barnett ${ }^{2,3}$ ${ }^{\psi}$ equal contributions

${ }^{1}$ Department of Chemical Engineering, West Virginia University, Morgantown, WV 26506

${ }^{2}$ Department of Microbiology, Immunology, and Cell Biology, West Virginia University, Morgantown, WV 26506

${ }^{3}$ Center for Immunopathology and Microbial Pathogenesis, West Virginia University, Morgantown, WV 26506

Corresponding Author:

David J. Klinke II, Ph.D.

Department of Chemical Engineering

West Virginia University

Morgantown, WV 26506

T: 304-293-2111 x2432

david.klinke@mail.wvu.edu 


\begin{abstract}
The transcription factor $\mathrm{NF}-\kappa \mathrm{B}$ (nuclear factor $\cdot \kappa \mathrm{B}$ ) plays a central role in the inducible expression of a wide range of immune and inflammatory response genes. This cellular response is a dynamic process characterized by either oscillations or stable induction of NF- $\kappa \mathrm{B}$ nuclear binding. Changes in dynamics of binding result in the expression of distinct subsets of genes leading to different physiological outcomes. Chemical manipulation of NF- $\kappa$ B binding activity can be used to study differential gene expression and used in treatment of pathological

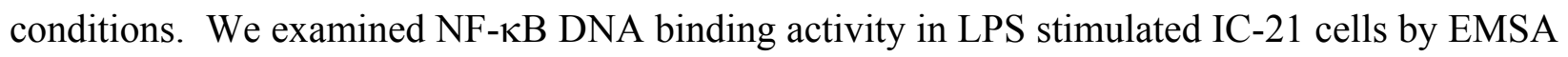
and NTFA assay. Both methods detected damped oscillatory behavior of NF- $\kappa$ B with differences in a degree of sensitivity and reproducibility. Based on experimental data, a kinetic model simulating NF- $\kappa \mathrm{B}$ activation process was developed to capture the dynamic of its regulation. The oscillatory behavior of activated NF- $\mathrm{BB}$ was manipulated using 3,4dichloropropionaniline (DCPA) in conjunction with LPS stimulation. DCPA is known to inhibit production of two of NF- $\mathrm{BB}$ inducible cytokines, IL-6 and TNF- $\alpha$, by reducing but not completely abrogating NF- $\kappa \mathrm{B}$-induced transcription. In this paper we demonstrated that DCPA treatment resulted in a potentiation of early NF- $\kappa \mathrm{B}$ activation by LPS. Results from the NTFA with lower signal-to-noise ratio than EMSA combined with in silico modeling revealed changes in NF- $\mathrm{NB}$ dynamics which have never been previously reported. Our results highlight the importance of cell type and stimuli specificity in transcription factor activity assessment, which makes assay selection important for determining network inference and drug discovery.
\end{abstract}




\section{Introduction}

NF- $\mathrm{kB}$ is a family of structurally related and evolutionarily conserved proteins related to the proto-oncogene c-rel. In mammals, the family of NF-kB proteins includes Rel (cRel), RelA

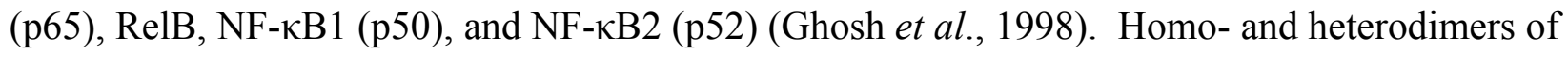
these NF- $\mathrm{kB}$ proteins combine to form active and repressive complexes of gene transcription. The $\mathrm{p} 50 / \mathrm{p} 65$ heterodimer of NF- $\mathrm{kB}$ is the most frequently studied and most abundant complex in cells (Baldwin, 1996). In resting cells, NF- $\mathrm{kB}$ is maintained inactive in the cytoplasm

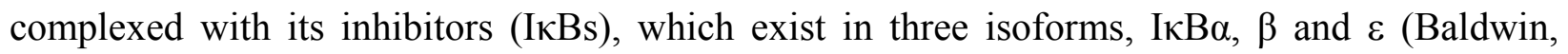
1996). Upon activation through a variety of receptor signaling pathways, including the Toll-like receptor $\left(\mathrm{TLR}^{3}\right) 4$ and Tumor Necrosis Factor (TNF) receptor family members, IкBs undergo phosphorylation, ubiquitination and proteolytic degradation (Ghosh et al., 19981; Wallach et al.,

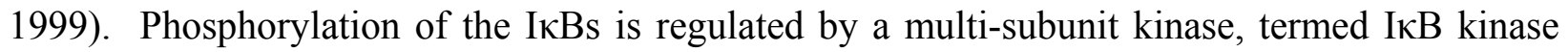
(IKK), which contains two catalytic subunits, IKK $\alpha$ and IKK $\beta$, and a regulatory subunit IKK $\gamma$ (NEMO) (Hayden et al,. 2004). Proteolytic degradation of IkBs allows for rapid translocation of

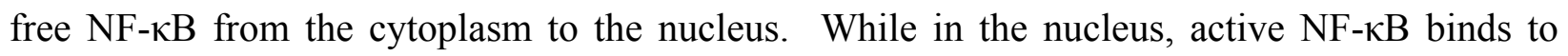
DNA and promotes the transcription of multiple genes, including the auto-inhibitor IкB $\alpha$. Newly

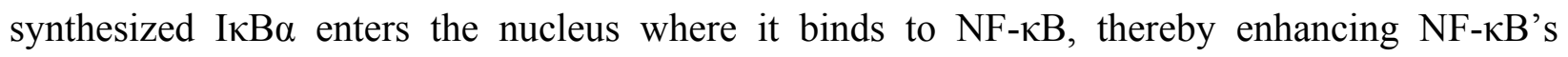
dissociation from the DNA and causing it's re-exportation to the cytoplasm where it joins the

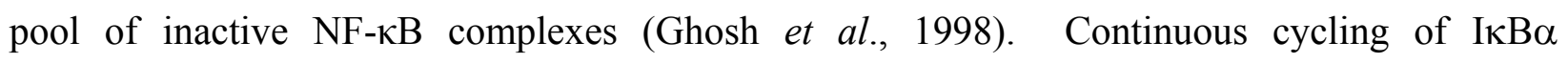
degradation and resynthesis results in oscillations in nuclear NF-kB activity (Hoffmann et al., 2002). Moreover, due to the importance of aberrant activation of NF- $\mathrm{kB}$ in a variety of diseases, over 780 compounds have been identified that modulate NF-kB activation (Gilmore et al., 2006).

\footnotetext{
${ }^{3}$ Abbreviations: TLR, Toll-like receptors; DCPA, 3,4-dichloropropionaniline; EMSA, electromobility shift assay; NTFA, non-radioactive transcription factor assay
} 
As illustrated by efforts to recapitulate temporal regulation of the NF- $\kappa \mathrm{B}$ pathway using mathematical models, e.g. Hoffmann et al. (2002), the dynamics of this process has been the subject of intense scientific scrutiny (Hoffmann and Baltimore, 2006). However, how therapeutics modulate the dynamics of the activation of NF- $\mathrm{B}$ is still unknown.

Present in all body compartments, macrophages initiate an innate immune response to bacterial pathogens through phagocytosis, thereby eliminating them by the generation of reactive oxygen (ROS) and reactive nitrogen (RNS) species (Nathan and Hibbs, 1991; Miller and Britigan, 1997). Macrophages also activate T lymphocytes by acting as a professional antigen presenting cell (APC) and secreting cytokines, such as IL-6 and TNF- $\alpha$ (Unanue, 1981). These cytokines are important early mediators of acute inflammatory responses contributing to downstream lymphocyte activation (Unanue, 1984, Adams and Hamilton, 1984). Due to their importance in immune surveillance, macrophages provide a highly relevant context for the study of NF- $\mathrm{NB}$.

DCPA effects on the immune response have been studied extensively and its ability to suppress various macrophage functions has been characterized. DCPA was demonstrated to decrease phagocytic activity of macrophages along with their ability to generate both reactive oxygen and nitrogen species (Ustyugova et al., 2007). The production of inflammatory cytokines, such as TNF- $\alpha$, IL-1 $\beta$ and IL-6 was also decreased (Xie et al., 1997a; Xie et al., 1997b). Effects of DCPA on the steady-state levels of NF- $\kappa$ B activation have been studied and demonstrated a decreased nuclear localization of NF- $\kappa \mathrm{B}$ accompanied by a reduced, but not entirely abrogated binding to DNA (Frost et al., 2001).

DNA binding of activity of transcription factor can be determined by different methods. An electromobility shift assay (EMSA) detects complexes of protein (e.g. NF- $\mathrm{B}$ ) and ${ }^{32} \mathrm{P}-$ 
labeled DNA containing transcription factor consensus sequences migrating through a nondenaturing polyacrylamide gel (Hendrickson, 1985; Revzin, 1989). DNA-protein complexes will migrate more slowly than unbound radioactive probe and thus they are visualised by discrete bands of radioactivity in the upper part of an acrylamide gel image (Fried and Crothers, 1981; Garner and Revzin, 1981). This technique is labor intensive and requires radioactivity.

A non-radioactive transcription factor assay (NTFA) combines the principle of EMSA where protein:DNA interaction is observed in enzyme-linked immunosorbent assay format (Benotmane et al., 1997; McKay et al., 1998; Renard et al., 2001). Active NF-kB is captured as it binds to its non-radioactive DNA consensus sequence that has been immobilized on a streptavidin-coated plate. The transcription factor that formed complexes with DNA is then probed with specific primary antibody (anti-p65) followed by HRP-conjugated secondary antibody and substrate detection. This method allows sampling a larger number of tests in a shorter period of time and does not require radioactive labeling.

The present study explores the initial phase of nuclear NF-kB oscillatory behavior induced in LPS-stimulated macrophages by the means of two independent methods commonly used for quantifying the binding activity of transcription factors. Immunosuppressant DCPA is used to modulate NF- $\mathrm{KB}$ activity and incorporated in the dynamic model to demonstrate the changes in transcription factor activation.

\section{Materials and Methods}

Cell culture, stimulation and DCPA treatment. The murine peritoneal macrophage cell line, IC-21, was cultured in $5 \% \mathrm{CO}_{2}$ at $37^{\circ} \mathrm{C}$ to $80 \%$ confluency in complete RPMI (cRPMI) (BioWhittaker, Walkerville, MD). cRPMI consists of RPMI 1640 supplemented with 10\% fetal 
bovine serum (Hyclone, Logan, UT), L-glutamine (2 mM), penicillin (100 U/ml), streptomycin (100 $\mu \mathrm{g} / \mathrm{ml}), 2$-mercaptoethanol $\left(5 \times 10^{-5} \mathrm{M}\right)$, and Hepes buffer $(10 \mathrm{mM})$ (all obtained from Sigma-Aldrich, St. Louis, MO). Cells were treated with 99\% pure DCPA (ChemService, Inc., West Chester, PA) and simultaneously stimulated with $1 \mu \mathrm{g} / \mathrm{ml}$ LPS phenol extracted (SigmaAldrich) for various times. Appropriate concentrations of DCPA were dissolved in $100 \%$ ethanol (Mallinckrodt Baker, Inc., Paris, KY) and added to cells at concentrations ranging from 0 to $150 \mu \mathrm{M}$. The final ethanol concentration added to all cultures was $0.1 \%$; control cultures received equal concentrations of ethanol.

Nuclear Extracts. Cells were plated at a concentration of $8 \times 10^{5}$ cells in $5 \mathrm{ml}$ of cRPMI in $60 \mathrm{~mm}$ dish and incubated overnight at $37^{\circ} \mathrm{C} 5 \% \mathrm{CO}_{2}$. Cells were then treated with either $0.1 \%$ ethanol or DCPA at concentrations of $25 \mu \mathrm{M}, 100 \mu \mathrm{M}, 150 \mu \mathrm{M}$, then simultaneously stimulated with $1 \mu \mathrm{g} / \mathrm{ml}$ LPS. Cells were washed with $2.5 \mathrm{ml}$ of ice-cold Dulbecco's phosphate buffered saline (DPBS) (BioWhittaker) and lysed by adding $200 \mu \mathrm{l}$ of a buffer consisting of 10 $\mathrm{mM}$ HEPES pH 7.9, $10 \mathrm{mM} \mathrm{KCl}, 0.1 \mathrm{mM}$ ethylenediamineteraacetic acid (EDTA), $0.1 \mathrm{mM}$ ethylene glycol-bis(2-aminoethyl ether) N, N, N', N'-tetraacetic acid (EGTA), 1 mM phenyl methyl sulfonyl fluoride (PMSF), $1 \mathrm{mM}$ dithiothreitol (DTT), and $1 \mu \mathrm{g} / \mathrm{ml}$ of the protease inhibitors leupeptin, antipain, chymostatin and pepstatin A (Sigma-Aldrich). Cells were scraped off the dishes and lysates were transferred to a microcentrifuge tubes and incubated on ice for 15 min. Next, $50 \mu \mathrm{l}$ of $10 \%$ NP-40 was added, samples were vortexed for $30 \mathrm{sec}$ and the lysates were pelleted by centrifugation for $30 \mathrm{sec}$ at $14000 \mathrm{rpm}$ at $4^{\circ} \mathrm{C}$. The supernatants (cytoplasmic extracts) were collected and saved at $-20^{\circ} \mathrm{C}$. Pellets were resuspended in $30 \mu 1$ of $20 \mathrm{mM}$ HEPES buffer containing $400 \mathrm{mM} \mathrm{NaCl}, 1 \mathrm{mM}$ EDTA, 1 mM EGTA, 1mM PMSF, 1 mM DTT and $1 \mu \mathrm{g} / \mathrm{ml}$ of the protease inhibitors (see above), vortexed and incubated for $15 \mathrm{~min}$ on ice. 
The lysates were pelleted by centrifugation at $14000 \mathrm{rpm}$ for $5 \mathrm{~min}$ at the same conditions and the supernatants containing the nuclear fraction stored at $-70^{\circ} \mathrm{C}$. A total protein concentration for nuclear extracts was determined with Coomassie Plus Protein Assay Reagent, as described by manufacturer (Pierce, Rockford, IL).

Electrophoretic mobility shift assay (EMSA). NF- $\mathrm{kB}$ consensus oligonucleotides (sc2505; Santa Cruz Biotechnology, Santa Cruz, CA) were labeled with $\gamma_{-}{ }^{32} \mathrm{P}-\mathrm{ATP}$ (PerkinElmer, Boston, MA) using Ready-To-Go ${ }^{T M}$ T4 polynucleotide kinase kit (Amersham Pharmacia Biotech Inc., Piscataway, NJ). Nuclear extracts, $5 \mu \mathrm{g}$ per sample, were incubated with 50,000 cpm of labeled probe and $1 \mu \mathrm{g} / \mathrm{ml} \mathrm{dI}: \mathrm{dC}$ for $30 \mathrm{~min}$ at room temperature in $1 \mathrm{x}$ binding buffer (5x stock: $250 \mathrm{mM} \mathrm{NaCl}, 50 \mathrm{mM}$ Tris-Cl, 50\% (v/v) glycerol, $5 \mathrm{mM}$ DTT, $2.5 \mathrm{mM}$ EDTA, adjusted to $\mathrm{pH}$ 7.6, stored at $-20^{\circ} \mathrm{C}$ ) to allow formation of band shift complexes. Next, complexes were resolved from free probe in $5 \%$ polyacrylamide gels $(1 \times$ TGE, $5 \%$ glycerol, $0.075 \%$ ammonium persulfate, $0.1 \%$ TEMED). Samples were electrophoresed at $125 \mathrm{~V}$ for $4 \mathrm{~h}$, dried on Whatman 3MM paper, and placed on PhosphoImage Screens for analysis with ImageQuant TL Software (Amersham Pharmacia Biotech Inc.). The EMSA experimental results are reported as the ratio of the intensity measured for a particular condition (i.e. time $>0$ ) relative to the intensity of nuclear NF- $\mathrm{kB}$ prior to treatment (i.e. time $=0$ ).

Transcription factor assay (NTFA). Nuclear extracts, $5 \mu \mathrm{g}$ per sample, were analyzed by a Chemicon Non-Radioactive Transcription Factor Assay to determine NF-кB p65 DNA binding activity, as described by manufacturer (Chemicon Int., Temecula, CA). Briefly, nuclear extracts were incubated for $2 \mathrm{~h}$ with biotinylated NF- $\mathrm{KB}$ consensus DNA sequences in a transcription assay buffer containing sonicated salmon sperm DNA to allow the formation of protein/DNA complexes. Next, NF-kB protein in the nuclear extracts bound to biotinylated 
consensus sequences was immobilized to the streptavidin-coated plate, and any unbound material was washed away. NF-kB protein was detected with a specific rabbit anti-p65 antibody, followed by incubation with anti-rabbit HRP-conjugated antibody detected by TMB/E substrate. Absorbance of the samples was measured with a $\mu$ Quant Universal Microplate Spectrophotometer (Bio-Tek Instruments, Winooski, VT). The NTFA experimental results are reported as the ratio of the absorbance measured for a particular condition (i.e. time $>0$ ) relative to the absorbance prior to treatment (i.e. time $=0$ ).

NF- $\kappa$ B Model Development. The stimulation of macrophages by LPS results in the activation of the TLR4 pathway (Poltorak et al., 1998). The transduction of signals via TLR4 results in the activation of a series of intermediate signaling proteins and ultimately in the activation of IKK. The activation of IKK leads to the liberation of NF- $\mathrm{KB}$ from protein

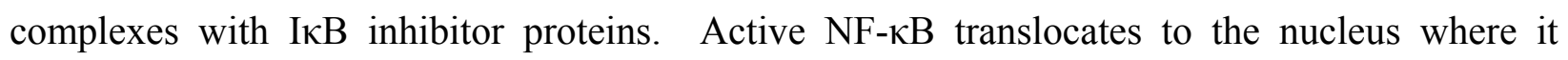
initiates the transcription of various genes, including the IкB proteins. Newly transcribed and

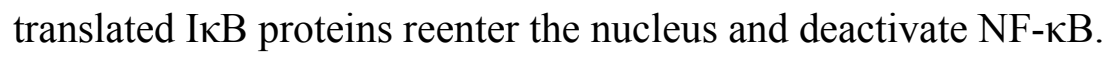




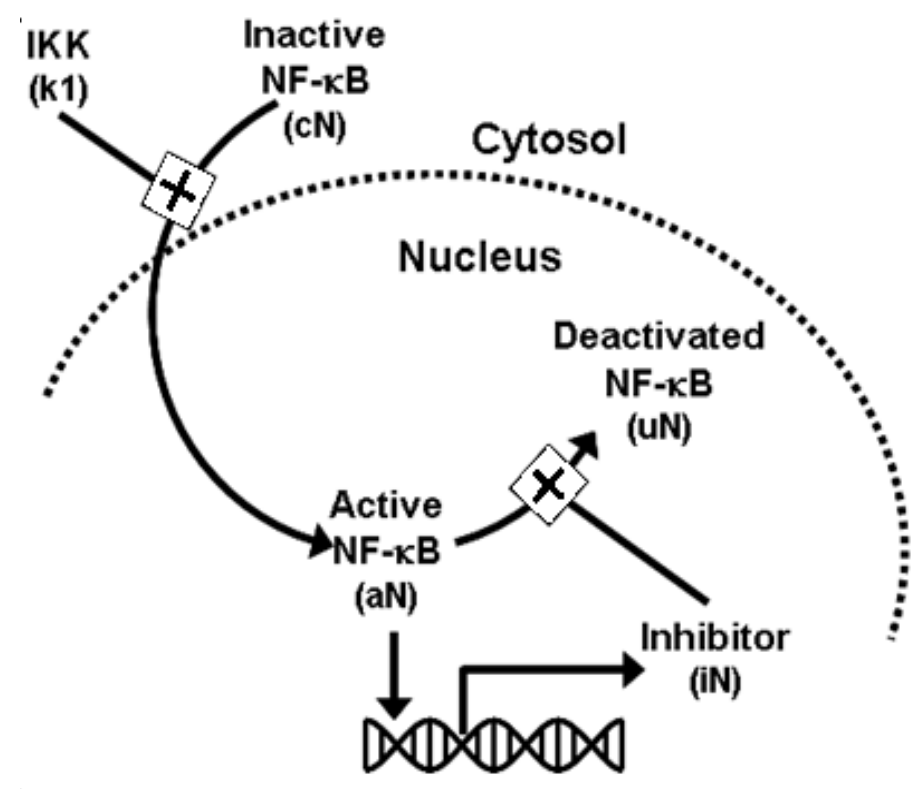

Figure 1. Schematic diagram of mathematical model developed to represent the initial activation of NF- $\mathrm{kB}$.

Shown schematically in Figure 1, the initial dynamics of NF-kB activation following LPS stimulation is represented by the following three chemical kinetic equations:

$$
\begin{aligned}
& \frac{d[c N]}{d t}=-k 1 \cdot\left(1+\frac{\alpha \cdot[D C P A]}{[D C P A]+K_{D C P A}}\right) \cdot[c N] \\
& \frac{d[a N]}{d t}=k 1 \cdot\left(1+\frac{\alpha \cdot[D C P A]}{[D C P A]+K_{D C P A}}\right) \cdot[c N]-k 2 \cdot[a N] \cdot[i N] \\
& \frac{d[i N]}{d t}=k 3 \cdot[a N]
\end{aligned}
$$

where $c N, a N, i N$, and $D C P A$ represent the concentrations of inactive NF-kB in the cytosol,

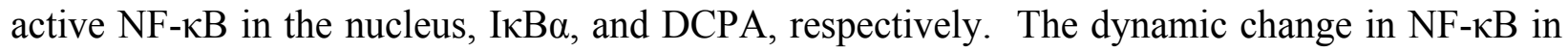
the cytosol is represented by equation 1, where the impact of IKK on liberating NF- $\mathrm{kB}$ and transport to the nucleus is represented by a single parameter $k 1$. DCPA modulates the activation of NF- $\kappa \mathrm{B}$ with the strength parameter $\alpha$. A negative value for $\alpha$ signifies that DCPA inhibits the 
activation of NF- $\mathrm{KB}$ while a positive value potentiates. The change in active NF- $\mathrm{KB}$ in the nucleus is represented by equation 2, where the second term represents the inactivation of

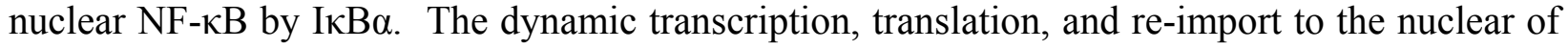
the NF- $\kappa \mathrm{B}$ inhibitor protein, $\mathrm{I} \kappa \mathrm{B} \alpha$, in response to active NF- $\kappa \mathrm{B}$ is represented by equation 3 . The initial normalized concentrations of $a N$ and $i N$ were set equal to 1 and 0 , respectively. The estimates for the initial concentration of $c N$ and parameters $k 1, \alpha$, and $k 3$ were determined using these three ordinary differential equations and experimental measurement of active NF- $\mathrm{kB}$ in the nucleus. The half-maximal inhibition constant, $K_{D C P A}$, was assumed to be $5 \mu \mathrm{M}$ based on the study by Xie et al. (1997a). The rate constant for the deactivation of active NF-kB in the nucleus, $k 2$, was assumed to be equal to $0.015 \mathrm{conc}^{-1} \mathrm{~min}^{-1}$. These three ordinary differential equations were evaluated within MatLab V7.1 (MathWorks, Natwick, MA). Summed squared error between experimentally measured and simulated values for active NF- $\mathrm{kB}$ in the nucleus were used to determine goodness-of-fit. Optimal values and confidence intervals for the parameters are detailed in the Table 1. 
Table 1. List of variables and parameters for NF-אB activation model. Optimal value for initial conditions and parameters were determined using a genetic algorithm. Separate values were determined from dose-escalation measurements obtained using EMSA or NTFA assays. Non-parametric bootstrapping using residual errors provided estimates of confidence intervals.

\begin{tabular}{|c|c|c|c|c|c|}
\hline Name & Definition & Assay & Value & $95 \% \mathrm{CI}$ & Units \\
\hline \multirow[t]{2}{*}{$k 1$} & $\mathrm{NF} \cdot \cdot \kappa \mathrm{B}$ activation rate & NTFA & 0.0624 & $(0.0033-0.111)$ & $\min ^{-1}$ \\
\hline & constant & EMSA & 0.102 & $(0.0005-0.164)$ & “ \\
\hline \multirow[t]{2}{*}{$k 2$} & NF- $\kappa \mathrm{B}$ inactivation rate & NTFA & 0.015 & assumed & Conc $^{-1} \times \min ^{-1}$ \\
\hline & constant & EMSA & “ & “ & “ \\
\hline \multirow[t]{2}{*}{$k 3$} & Synthesis of NF-kB inhibitor & NTFA & 0.0043 & $(0.0030-0.0144)$ & $\min ^{-1}$ \\
\hline & rate constant & EMSA & 0.0057 & $(0.0029-0.0288)$ & “ \\
\hline \multirow[t]{2}{*}{$\alpha$} & Effect of DCPA on NF-кB & NTFA & 0.465 & $(0.0625-0.999)$ & unitless \\
\hline & activation & EMSA & 0.0687 & $(-0.187-0.716)$ & \\
\hline \multirow[t]{2}{*}{$K_{D C P A}$} & Half-maximum DCPA & NTFA & 5 & Reference (14) & $\mu \mathrm{M}$ \\
\hline & concentration & EMSA & “ & “ & \\
\hline \multirow[t]{2}{*}{$c N$} & Initial concentration of NF- & NTFA & 56.1 & $(38.5-868)$ & Conc \\
\hline & $\kappa \mathrm{B}$ in cytosol & EMSA & 13.6 & $(10.8-1760)$ & “ \\
\hline \multirow[t]{2}{*}{$a N$} & Initial concentration of & NTFA & 1 & assumed & conc \\
\hline & active nuclear NF- $\mathrm{KB}$ & EMSA & “ & “ & “ \\
\hline \multirow[t]{2}{*}{$i N$} & Initial concentration of I $\mathrm{B} \alpha$ & NFTA & 0 & assumed & conc \\
\hline & & EMSA & ” & “ & “ \\
\hline \multirow[t]{2}{*}{$\overline{D C P A}$} & Concentration of DCPA & NTFA & $0-150$ & experimental conditions & $\mu \mathrm{M}$ \\
\hline & & EMSA & “ & “ & “ \\
\hline
\end{tabular}


Bootstrap Re-sampling - Confidence Interval Estimation. The bootstrap re-sampling is an effective method for the estimation of confidence intervals of model parameters (Efron and Tibshirani, 1986). Let's assume that the experimental measurement of a dynamic system can be described by the following equation

$$
y_{\text {exp }}\left(t_{i}\right)=y_{\text {mod }}\left(t_{i} ; \theta\right)+\varepsilon\left(t_{i}\right)
$$

where $y_{\exp }\left(t_{i}\right)$ is the measured value at time $t_{i}$ and $\theta$ is the vector of model parameters that are constant with respect to time. A mechanistic model of the dynamic system provides an estimate of the expected biological response, $y_{\bmod }\left(t_{i}, \theta\right)$, at time $t_{i}$, given the parameter vector $\theta$. The measurement error, or residual, is represented by $\varepsilon\left(t_{i}\right)$ and can be obtained at each time point, $t_{i}$. The population of $\varepsilon\left(t_{i}\right)$ determined from the data set is a representative sample of the variability in observing this phenomena experimentally. Analysis of the variance ensures that there are no systematic errors in the residual population.

Experimentally, replication is used to establish significance of an observation. Bootstrap resampling is a computational approach that creates synthetic replicates drawn from the population of residuals. The residuals are first normalized based on the appropriate error model of the experimental assay. Error models for each of the assays (NTFA and EMSA) were based upon an analysis of the residuals. Synthetic sets of experimental replicates were created using the following steps. First, optimal values for $k 1, k 3, \alpha$, and the initial value for $c N$ were determined based upon the DCPA dose-escalation experiments using either NTFA or EMSA.

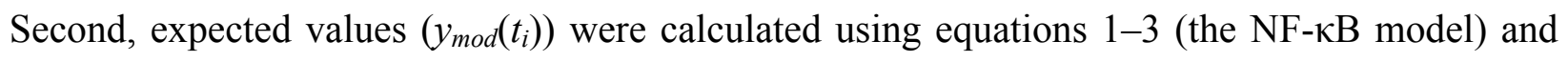
the set of optimal parameters for every measured experimental condition $\left(y_{\text {exp }}\left(t_{i}\right)\right)$ to yield the residuals, $\varepsilon\left(t_{i}\right)$. The residuals were normalized based upon the error model that corresponds to the particular assay. Finally, a large number $(\mathrm{N}=1000)$ of synthetic data sets (i.e. bootstrapped 
data sets) that replicate the original experimental protocol were created by sampling, with replacement, from the population of residuals. These sampled residuals are then recombined with the expected values $\left(y_{\bmod }\left(t_{i}\right)\right)$ to give new synthetic data sets. A new optimal set of parameter values were determined for the NF- $\kappa \mathrm{B}$ model that capture the synthetic DCPA doseescalation experiments. Each one of the bootstrap data sets yields a novel set of values for $k 1$, $k 3, \alpha$, and the initial value of $c N$. This collection of optimal values provides an estimate of the 95\% confidence intervals for $k 1, k 3, \alpha$, and $c N(t=0)$, shown in the Table 1 . The reported significance corresponds to the probability that the strength parameter $\alpha$ is positive.

\section{Results}

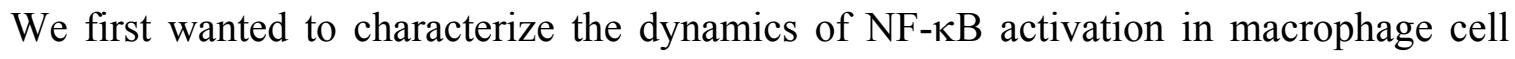
line. As shown in Figure 2, sustained LPS stimulation of a mouse peritoneal macrophage cell line, IC-21, resulted in damped oscillations in NF- $\kappa B$ DNA binding activity. Over a period of six hours, the dynamic activation of NF- $\kappa \mathrm{B}$ was quantified using an electromobility shift assay (EMSA) at the indicated time points (Figure 2a). IC-21 macrophages were treated with either

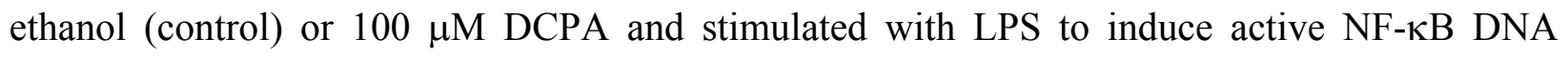
binding. Both treatments demonstrated similar damped oscillations graphically represented in Figure $2 \mathrm{~b}(\mathrm{EtOH}$ - solid line, open circles, $100 \mu \mathrm{M}$ DCPA - dashed line, plus sign). 
a
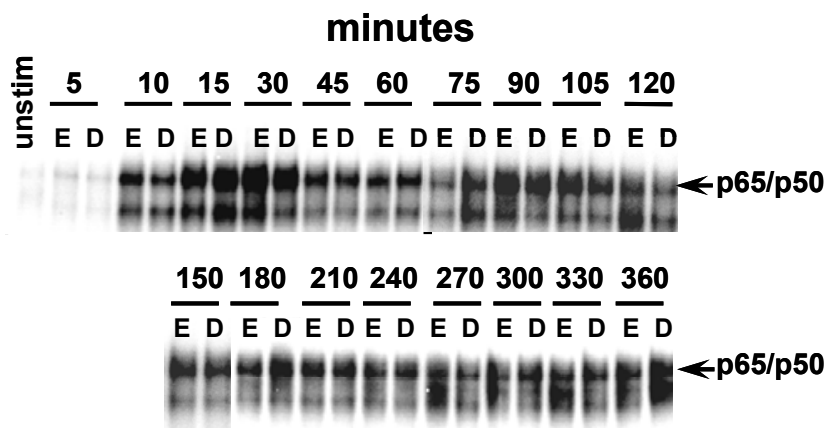

b

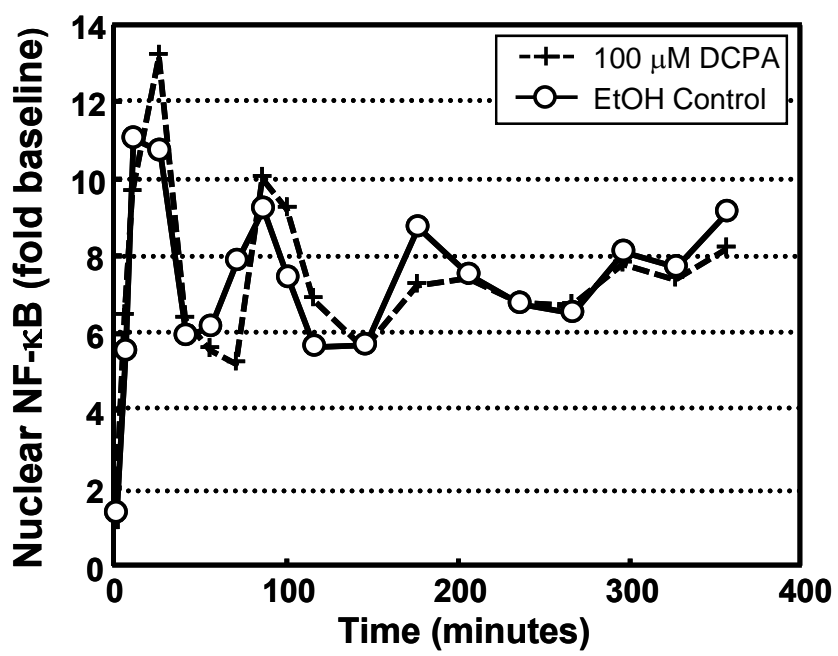

Figure 2. Biochemical measurement of oscillations in LPS-stimulated IC-21 macrophages persists following DCPA treatment.

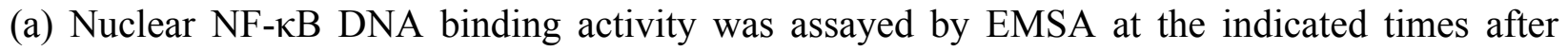
sustained stimulation with LPS $(1 \mu \mathrm{g} / \mathrm{ml})$. Macrophages were either treated with ethanol (E) or $100 \mu \mathrm{M}$ DCPA (D). (b) The specific NF- $\kappa$ B mobility shift phosphoimage was quantified using ImageQuant and normalized to basal levels. Both control (०) and DCPA pretreated $(+)$ macrophages exhibit similar damped oscillatory behavior. 
These damped oscillations observed in macrophages are in variance with the findings of Covert et al. (2005), who demonstrated sustained NF- $\kappa B$ activation following LPS stimulation in mouse embryonic fibroblasts. While the EMSA measurements shown in Figure 2 are representative of the dynamic response in IC-21 macrophages to LPS, significant variability was observed between replicates following the initial peak in NF-kB activation (data not shown). Moreover, observed variability in amplitude of response and frequency of response inhibited the ability to quantify the pharmacological effect of a particular mediator on the dynamics of NF-kB. Based on these findings, we focused subsequent efforts on quantifying the dynamics of NF- $\mathrm{BB}$ activation within the first 45 minutes following LPS stimulation.

Next, both EMSA and NTFA were used to replicate measurements of active NF- $\mathrm{kB}$ in the nucleus at multiple time points during initial peak of DNA binding activity (0-45 min) in response to LPS stimulation. Figure 3a demonstrates multiple replicates of this process using EMSA, for comparison, Figure $3 \mathrm{~b}$ represents the data obtain from NTFA. Both methods demonstrated that the initial peak of NF- $\mathrm{KB}$ activation reached maximum at $20 \mathrm{~min}$, which is caused by rapid degradation of $\mathrm{I} \mathrm{B} \mathrm{B} \alpha$ inhibitor and results in maximum DNA binding.

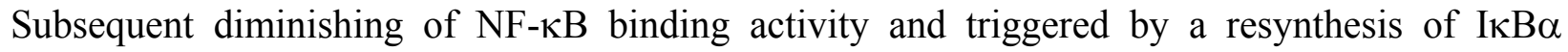
graphically displayed as a decline of the curve. A mathematical model, shown schematically in Figure 1, incorporating these biochemical steps was created to capture this dynamic behavior. Parameter values that correspond to a particular assay are shown in Table 1. The EMSA measurements obtained from LPS-induced macrophage cell line are compared against the mathematically-simulated EMSA response in Figure 3a represented by solid (ethanol) and dashed (150 $\mu \mathrm{M}$ DCPA) lines. For comparison, data from NTFA is compared against mathematically-simulated NF- $\mathrm{kB}$ activation dynamics in Figure $3 \mathrm{~b}$. 

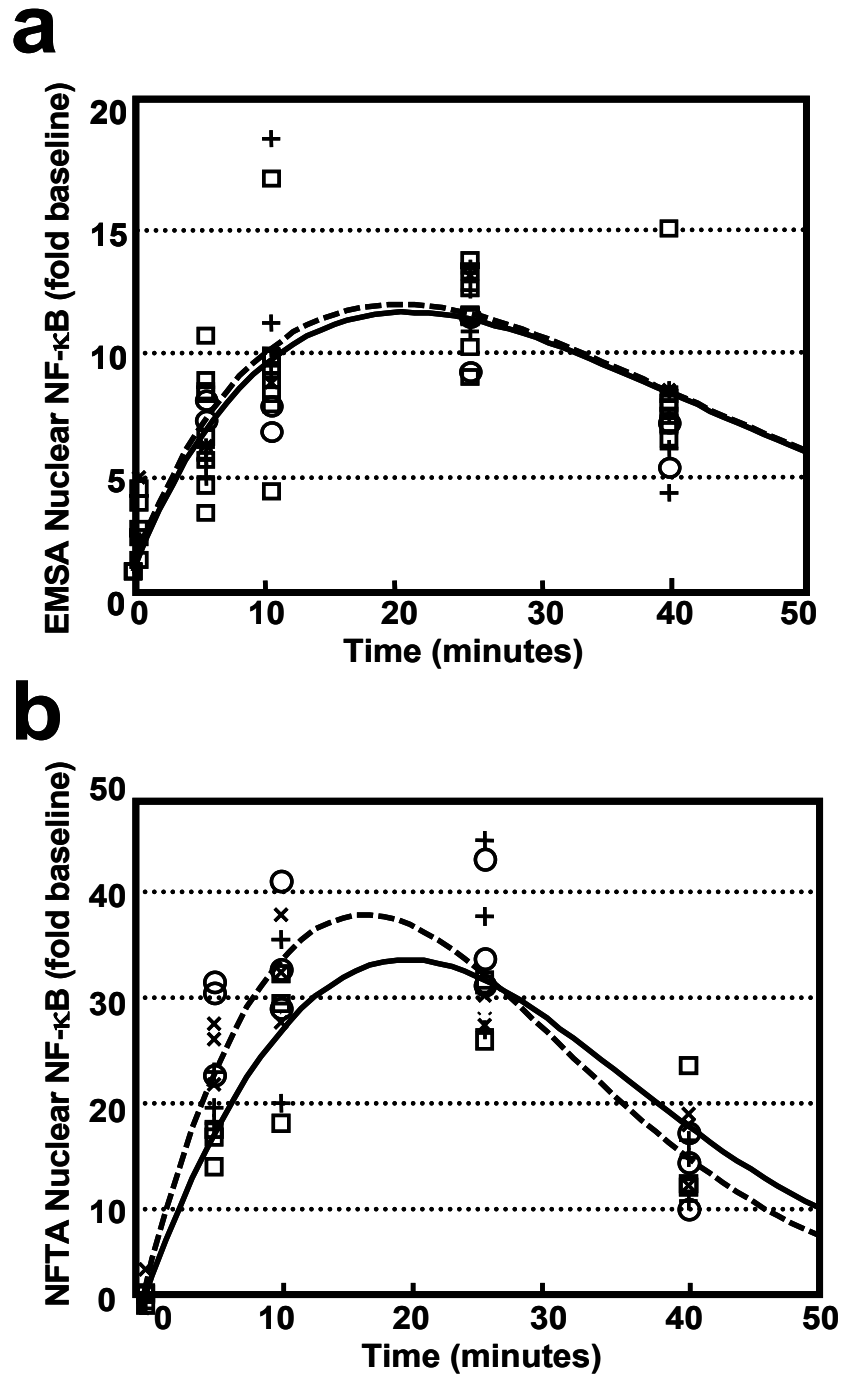

Figure 3. Modeling the potentiation by DCPA of the early activation of NF- $\mathrm{B}$ in IC-21 macrophages following LPS stimulation.

The dynamic response in nuclear NF- $\mathrm{B}$ was measured using (a) EMSA and (b) NTFA. The active NF- $\kappa$ B in the nucleus as measured following LPS stimulation and treatment with $0 \mu \mathrm{M}(\square$, EMSA $n=8$, NTFA $n=3), 25 \mu \mathrm{M}(\circ$, EMSA $n=2$, NTFA $n=3), 100 \mu \mathrm{M}(+$, EMSA $n=4$, NTFA $\mathrm{n}=3)$, and $150 \mu \mathrm{M}(\times$, EMSA $\mathrm{n}=1$, NTFA $\mathrm{n}=3)$ DCPA. The simulated time courses of active $\mathrm{NF}-\kappa \mathrm{B}$ in the absence and pretreated with $150 \mu \mathrm{M}$ DCPA are shown as the solid curves and dashed curves, respectively. 
The overall kinetics of the underlying biological mechanism observed using the NTFA and EMSA assays are in agreement. The results of comparison between the two assays revealed that NTFA exhibits greater sensitivity and reproducibility in measuring active $\mathrm{NF}-\kappa \mathrm{B}$ relative to the EMSA as shown by the differences in dynamic ranges observed during the control experiments.

To manipulate the dynamics of NF- $\kappa \mathrm{B}$ oscillatory behavior, a known immunosuppressant, DCPA, was introduced into the experimental system. IC-21 macrophages were treated with three different concentrations of DCPA: 25, 100, and $150 \mu \mathrm{M}$ DCPA and simultaneously stimulated with LPS. In order to quantify the effect of DCPA on dynamics of binding activity, we focused on the initial peak of NF-kB activation following LPS stimulation. Both assays were used to characterize alterations in $\mathrm{NF}-\kappa \mathrm{B}$ binding activity by DCPA in response to LPS stimulation, and experimental results from EMSA and NTFA are show in Figures $3 \mathrm{a}$ and $3 \mathrm{~b}$, respectively. All concentrations of DCPA are graphically represented by a separate sign $(25 \mu \mathrm{M}$-“○”, $100 \mu \mathrm{M}$-“+”; $150 \mu \mathrm{M}$-“×”). The effect of DCPA on the dynamic activation of NF- $\kappa \mathrm{B}$ was represented in the mathematical model by modulating the activation rate of NF- $\kappa \mathrm{B}$ in the cytosol, $k 1$. The pharmacologic effect of DCPA on the initial activation of $\mathrm{NF}-\kappa \mathrm{B}$ was quantified by the strength parameter $\alpha$. Using the EMSA parameter values shown in Table 1, the simulated NF- $\kappa$ B response to LPS following treatment with $150 \mu \mathrm{M}$ DCPA was compared against the EMSA results in Figure 3a. Similarly, the simulated NTFA measurements following DCPA treatment were compared against the NTFA results in Figure 3b. Overall, the simulated responses for both NTFA and EMSA showed agreement with the experimentally measured values. In comparison, the simulated NTFA results showed greater discrimination between macrophages treated with DCPA and controls compared to the EMSA results. These 
differences were a reflection of the values of $\alpha$ estimated using NTFA versus EMSA. The results from both assays suggest that DCPA potentiates the activation of NF- $\mathrm{kB}$ at the early time points (0-45 min). Quantitatively, the NTFA results suggest that DCPA increases the activation rate of NF- $\kappa \mathrm{B}$ by $46.5 \%(\alpha=0.465)$. In contrast, the EMSA results suggest that DCPA increases the activation rate by $6.9 \%(\alpha=0.069)$. These results seem counter-intuitive as we have previously reported that $66 \mu \mathrm{M}$ DCPA resulted in an $80 \%$ reduction in IL-6 mRNA and a $50 \%$ reduction in TNF- $\alpha$ mRNA following stimulation with $10 \mu \mathrm{g} / \mathrm{ml}$ LPS (Xie et al., 1997a). This suppression in mRNA resulted in an inhibition of IL- 6 production by $60 \%$ and TNF- $\alpha$ production by $50 \%$. However, the stabilities of IL- 6 and TNF- $\alpha$ mRNA were not affected by DCPA suggesting that DCPA modulates cytokine production specifically at the pre-transcriptional level as inhibition of

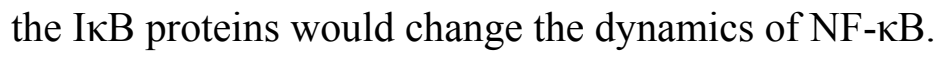

One of the most important aspects of data analysis is the determination of confidence intervals for model parameters that represent the data. A bootstrap resampling approach applied to the residuals $\left(\varepsilon\left(t_{i}\right)\right)$ between the predicted $\left(y_{\bmod }\left(t_{i}, \theta\right)\right)$ and measured $\left(y_{\exp }\left(t_{i}\right)\right)$ values was used to estimate the confidence intervals of the model parameters. Prior to applying the bootstrap algorithm, we analyzed the population of residuals for underlying structure. The residuals are assumed to have a Gaussian distribution with a zero mean (i.e. $\varepsilon\left(t_{i}\right) \in N\left(0, \sigma^{2}\left(t_{i}, \theta, \lambda\right)\right)$. Generally, the variance of residuals, $\sigma^{2}\left(t_{i}, \theta, \lambda\right)$, is a function of time, the model parameters, and a parameter vector that is unique to the variance, $\lambda$. The underlying structure in the variance of the residuals is sometimes referred to as the error model. Separate error models were created for the EMSA and NTFA measurements. In this study, we assume that the error model is a linear function of the predicted value:

$$
\sigma^{2}\left(t_{i}, \theta, \lambda\right)=\lambda_{1} \cdot y_{\text {mod }}\left(t_{i}, \theta\right)+\lambda_{2}
$$


The parameter, $\lambda_{l}$, quantifies the variance that is proportional to the underlying signal that is being measured. The $\lambda_{2}$ parameter quantifies the contribution of a random noise distribution to the error model. Values for $\lambda_{1}$ and $\lambda_{2}$ can be estimated by combining the error model with the equation for the residuals $\left(\varepsilon\left(t_{i}\right)=y_{\exp }\left(t_{i}\right)-y_{\bmod }\left(t_{i}, \theta\right)\right)$ and rearranging terms to yield:

$$
\frac{y_{\text {exp }}\left(t_{i}\right)-y_{\text {mod }}\left(t_{i}, \theta\right)}{y_{\text {mod }}\left(t_{i}, \theta\right)}=\Lambda 1_{i}+\Lambda 2_{i} \cdot \frac{1}{y_{\text {mod }}\left(t_{i}, \theta\right)}
$$

where $\Lambda 1_{i}$ and $\Lambda 2_{i}$ provide estimates of variance parameters $\lambda_{1}$ and $\lambda_{2}$. The left hand side of equation 6 represents the normalized error values and is plotted against $y_{\text {mod }}^{-1}$ in Figure 4 . As identified in Figure 4, the normalized error values were grouped into two groups based on their respective values of $y_{\text {mod }}^{-1}$. The variances of the two groups for each assay are labeled in Figure 4. The variance compared between the high and low NTFA groups was not statistically significant while the difference between the EMSA groups was significant $(\mathrm{p}<0.05)$. These results suggest that $\lambda_{2}$ is equal to zero for the NTFA error model and that the residuals are proportional only to the underlying signal $\left(y_{m o d}\right)$. In contrast, the variance in the EMSA measurements is proportional to the underlying signal and contains contributions from random noise. 


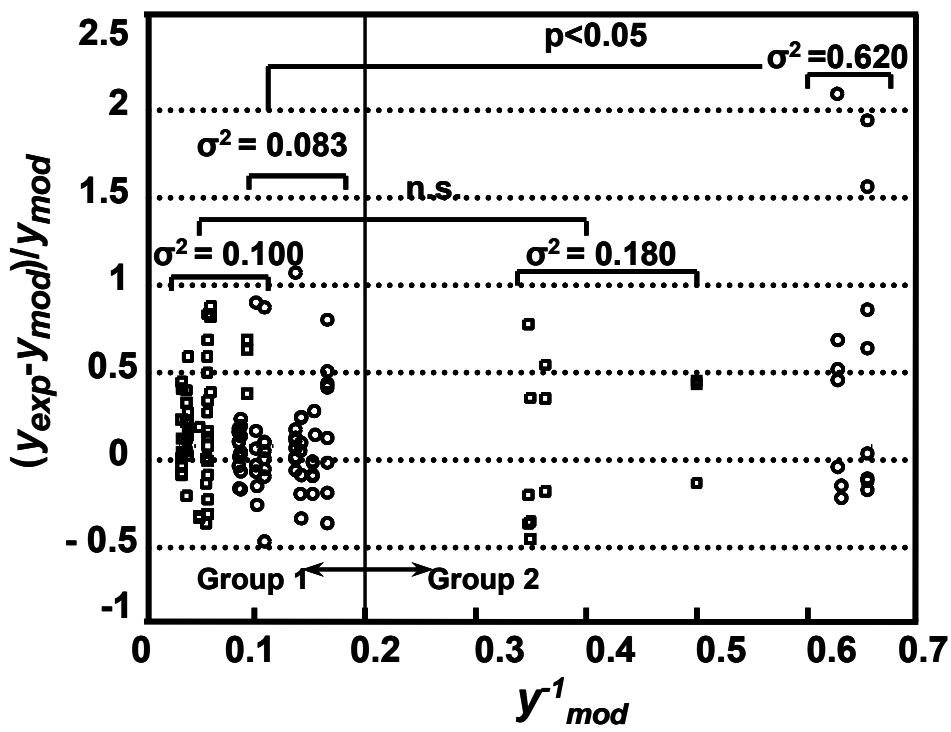

Figure 4. Analysis of the NTFA and EMSA residuals to construct appropriate error models.

The difference between experimental measurement $\left(y_{\exp }\right)$ and simulated response $\left(y_{\text {mod }}\right)$ of active nuclear NF- $\mathrm{kB}$ (residual error) following LPS stimulation in IC-21 macrophages is shown as a function of $y_{\text {mod }}^{-1}$. The EMSA measurements are shown as circles and the NTFA measurements are shown as squares. The residual errors are normalized by the simulated response. EMSA residuals with $y_{\text {mod }}^{-1}>0.2$ were assigned to EMSA Group 2 while remaining residuals were assigned to EMSA Group 1. Similar grouping was applied to NTFA residuals. Variances for each group are shown in the figure. The difference in variance between NTFA groups was not significant while the EMSA groups exhibited significant differences in variance $(p<0.05)$. 
Given this analysis of the residuals for the NTFA and EMSA measurements, we constructed a bootstrap sample population using the following error models:

$$
\begin{aligned}
& \varepsilon_{\text {NTFA }}\left(t_{i}\right)=\frac{y_{\text {exp }}\left(t_{i}\right)-y_{\text {mod }}\left(t_{i}, \theta_{\text {NTFA }}\right)}{y_{\text {mod }}\left(t_{i}, \theta_{\text {NTFA }}\right)} \\
& \varepsilon_{\text {EMSA }}\left(t_{i}\right)=y_{\text {exp }}\left(t_{i}\right)-y_{\text {mod }}\left(t_{i}, \theta_{\text {EMSA }}\right)
\end{aligned}
$$

The bootstrapped sample populations were used to provide estimates of the confidence intervals associated with the model parameters. The 95\% confidence intervals for the model parameters are shown in the Table 1. We are particularly interested in the confidence intervals associated with the strength parameter $\alpha$. Based upon bootstrapping of the EMSA residuals, the 95\% confidence interval for the strength parameter $\alpha$ spans the range -0.187 to $0.716(p<0.2)$. In contrast, the $95 \%$ confidence interval for the strength parameter $\alpha$ based on the NTFA residuals spans 0.0625 to $0.999(\mathrm{p}<0.01)$. The distributions in estimates of the strength parameter $\alpha$ provided by bootstrapped replicates of the EMSA and NTFA residuals are shown in the Supporting Information (Figures S1 and S2). In summary, the higher signal-to-noise ratio observed using the NTFA provides a superior platform for observing biologically significant phenomena.

\section{Discussion}

$\mathrm{NF}-\kappa \mathrm{B}$ regulates the inducible expression of a wide range of immune and inflammatory response genes (Kopp and Ghosh, 1995). As a result, NF- $\kappa \mathrm{B}$ is one of the most studied molecules in the area of signal transduction. Due to the complex nature of biological system, the study of NF- $\kappa \mathrm{B}$ is important for two reasons. First, the objective of biomedical research is to infer biochemical mechanisms that underpin biological response to stimuli. Second, biomedical 
research aims to develop strategies that modulate aberrant biochemical mechanisms to revert a pathogenic state. In both cases, biological assays provide avenues for observing cellular response following biochemical interrogation.

One of the most important aspects in the design of a biological assay is selecting a physiologically relevant context. We first observed damped oscillations in active NF- $\mathrm{kB}$ in macrophages following LPS stimulation. This observation is in contrast to other published studies examining the dynamic activation of NF- $\mathrm{KB}$ following LPS stimulation. In particular, Werner et al. (2005) observed in fibroblasts that the initial activation of NF- $\mathrm{kB}$ by $0.1 \mu \mathrm{g} / \mathrm{ml} \mathrm{LPS}$ was not rapid but dependent on autocrine feedback via the TNF- $\alpha$ pathway. Covert et al. (2005) observed that $0.5 \mu \mathrm{g} / \mathrm{ml}$ LPS induced stable NF- $\mathrm{kB}$ activation through a combination of MyD88dependent and MyD88-independent pathways. In Figure 5, the NF- $\kappa \mathrm{B}$ activation in macrophages obtained from IC-21 cells was compared to LPS-stimulated fibroblasts activation profile obtained by Werner et al. (2005) and Covert et al. (2005). The data from all three studies were combined and graphically presented in Figure 5. 


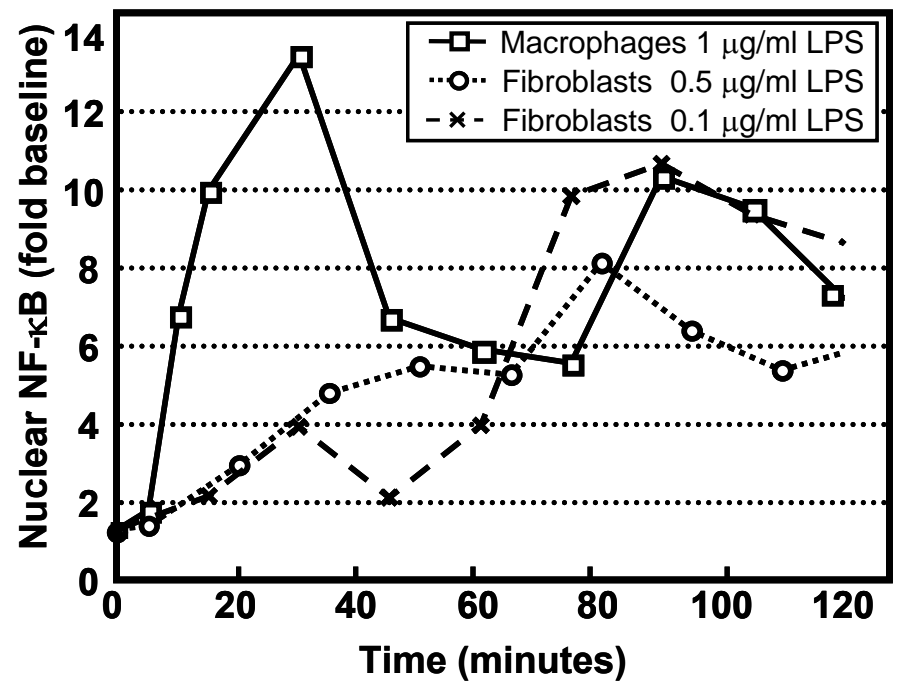

Figure 5. The dynamic activation of NF-KB in macrophages compared against prior studies using fibroblasts.

Nuclear NF- $\mathrm{kB}$ was assayed by EMSA at the indicated times after persistent stimulation with 1 $\mu \mathrm{g} / \mathrm{ml}$ LPS in macrophages ( $\square$, this study), $0.5 \mu \mathrm{g} / \mathrm{ml}$ LPS in fibroblasts demonstrated by Covert et al. (2005) (०), and $0.1 \mu \mathrm{g} / \mathrm{ml}$ LPS in fibroblasts demonstrated by Werner et al. (2005) ( $\times$ ). 
The initial rates of $\mathrm{NF}-\kappa \mathrm{B}$ activation are similar in both previous studies using mouse embryonic fibroblasts. We observed a much higher initial rate of activation using $1.0 \mu \mathrm{g} / \mathrm{ml}$ LPS. This higher activation rate may be attributed to the increased expression of CD14 in macrophages compared to fibroblasts and/or increased stimulant. Cellular response to LPS is mediated by the TLR4 pathway (Poltorak et al., 1998). CD14, an accessory cell surface protein, interacts with TLR4 to increase the sensitivity to LPS a thousand-fold (Wright et al., 1990) and facilitates the robust response to LPS. Thus, the cellular context plays an important role in determining the contribution of a particular signaling pathway on the dynamic behavior of NF$\kappa \mathrm{B}$ activation.

Chemical manipulation of NF- $\mathrm{BB}$ binding activity with immunosuppressant DCPA resulted in the earlier activation of the initial peak observed during first 45 minutes after LPS stimulation. This earlier activation might result in altered frequency of the oscillations that, in turn, will change the transcriptional regulation of some genes. Changes in number, period and amplitude of oscillations were observed by Nelson at al. (2004) in HeLa cell line continuously stimulated with TNF- $\alpha$. Furthermore, the transcription of NF- $\kappa \mathrm{B}$ target genes was dependent on persistence of oscillations. Nelson et al. (2004) also suggest that changes in oscillations could have functional consequences on NF- $\mathrm{B}$ signaling in response to different stimuli. Therefore,

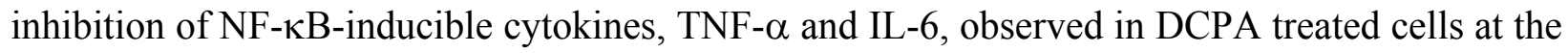
later time points (12 and $24 \mathrm{~h}$ after sustained LPS stimulation) may be a result of the early potentiation of NF- $\mathrm{NB}$ activation caused by a shift in oscillatory behavior. Alternatively, treating cells with DCPA may shift the dynamic equilibrium of active NF- $\kappa \mathrm{B}$ among the corresponding DNA binding sites within the nucleus, resulting in a change in the profile of NF-kB-inducible genes. 
An additional consideration in the design of a biological assay is how to observe a cellular response. Observed variability in measured data is due to technical variation (e.g. error in measurement) or biological variation (e.g. cellular heterogeneity, asynchrony, or stochasticity). Implicitly, design of the experimental protocol is intended to limit the contributions of biological variation by selecting cellular systems that exhibit favorable characteristics. In contrast, the contribution of technical variation has received little attention. Moreover, the experimental tools of molecular biology have been criticized due to their qualitative nature (Maddox, 1992; Maddox, 1994). Over the years, biochemical assays have been developed with improved sensitivity (Renard et al., 2001). Yet, as we have shown herein, technical variation can be attributed to multiple sources. Improved sensitivity alone is an insufficient criteria to improve the information context of an assay. If the technical variation is associated solely with the magnitude of the signal, there will be no difference in extracting meaningful information regarding cellular response using either assay. However, when an assay, such as the EMSA assay discussed here, exhibits a higher contribution of random noise, pharmacologically significant modulation of cellular response and insight into underlying biological mechanisms can be masked. Thus, assays, such as NTFA, that provide a greater signal-to-noise ratio contribute to a clearer window into fundamental cellular behavior. The importance of developing biological assays that exhibit improved signal-to-noise ratios is highlighted by our study of the potentiation of NF- $\kappa \mathrm{B}$ activation by DCPA.

While much effort has focused on identifying the dynamic phenomena associated with the activation of NF-kB, we focused our efforts on understanding how this dynamic phenomena can be modulated for therapeutic aims. Following our investigations into the impact of DCPA on the dynamic modulation of NF- $\mathrm{B}$ activation within a mouse peritoneal macrophage cell line, 
we come to the following three conclusions. First, the dynamic behavior of NF-kB in response to stimuli is dependent on cell type and developmental stage. Second, DCPA potentiates early activation of NF-kB yet suppresses inflammatory gene expression. Extraction of this counterintuitive behavior could only be achieved through the use of a mechanistic model that encoded the relevant biochemical events. Finally, non-radioactive transcription factor assays provide superior signal-to-noise ratios over electromobility shift assays for observing cellular response. 


\section{Acknowledgements}

J.B.B. and D.J.K. conceived the study, I.V.U. performed the experiments, and D.J.K. performed the analysis and wrote the paper. The author would like to thank Prof. N. Charon (Microbiology, Immunology, \& Cell Biology WVU) for his critical reading of this manuscript. This work was supported by the National Institutes of Health grant ES011311 (J.B.B.).

Competing Interests: The authors declare that they have no competing financial interests. 


\section{References}

Adams, D. O., and Hamilton, T. A. (1984). The cell biology of macrophage activation. Annu. Rev. Immunol. 2, 283-318.

Baldwin, A. S., Jr. (1996). The NF-kappa B and I kappa B proteins: new discoveries and insights. Annu. Rev. Immunol. 14, 649-683.

Benotmane, A. M., Hoylaerts, M. F., Collen, D., and Belayew, A. (1997). Nonisotopic quantitative analysis of protein-DNA interactions at equilibrium. Anal. Biochem. $250: 181-185$.

Covert, M. W., Leung, T. H., Gaston, J. E., and Baltimore, D. (2005). Achieving stability of lipopolysaccharide-induced NF-kappaB activation. Science 309(5742), 1854-1857.

Efron, B., and Tibshirani, R. (1986). [Bootstrap Methods for Standard Errors, Confidence Intervals, and Other Measures of Statistical Accuracy]: Rejoinder. Statistical Science $1(1), 77$.

Fried, M., and Crothers, D. M. (1981). Equilibria and kinetics of lac repressor-operator interactions by polyacrylamide gel electrophoresis. Nucleic Acids Res. 9(23):6505-6525.

Frost, L. L., Neeley, Y. X., Schafer, R., Gibson, L. F., and Barnett, J. B. (2001). Propanil inhibits tumor necrosis factor-alpha production by reducing nuclear levels of the transcription factor nuclear factor-kappab in the macrophage cell line ic-21. Toxicol. Appl. Pharmacol. 172(3), 186-193.

Garner, M. M, and Revzin, A. (1981). A gel electrophoresis method for quantifying the binding of proteins to specific DNA regions: application to components of the Escherichia coli lactose operon regulatory system. Nucleic Acids Res. 9(13):3047-3060.

Ghosh, S., May, M. J., and Kopp, E. B. (1998). NF-kappa B and Rel proteins: evolutionarily conserved mediators of immune responses. Annu. Rev. Immunol. 16, 225-260. 
Gilmore, T. D., and Herscovitch, M. (2006). Inhibitors of NF-kappaB signaling: 785 and counting. Oncogene 25(51), 6887-6899.

Hayden, M. S., and Ghosh, S. (2004). Signaling to NF-kappaB. Genes Dev 18(18), 2195-2224.

Hendrickson, W. (1985). Protein-DNA Interactions Studied By The Gel Electrophoresis-DNA Binding Assay. BioTechniques 3(3),198-207

Hoffmann, A., Levchenko, A., Scott, M. L., and Baltimore, D. (2002). The IkappaB-NF-kappaB signaling module: temporal control and selective gene activation. Science 298(5596), 1241-1245.

Hoffmann, A., and Baltimore, D. (2006). Circuitry of nuclear factor kappaB signaling. Immunol. Rev. 210, 171-186.

Kopp, E. B., and Ghosh, S. (1995). NF-kappa B and rel proteins in innate immunity. Adv. Immunol. 58, 1-27.

Maddox, J. (1992). Is molecular biology yet a science? Nature 355(6357), 201.

Maddox, J. (1994). Towards more measurement in biology. Nature 368(6467), 95.

McKay, I. A., Kirby L., Volyanik, E. V., Kumar, V., Wong P. W. Y.; and Bustin, S.A. (1998). An enzyme-linked immunosorbent assay for the detection of agents which interf e re with DNA binding activities of transcription factors - exemplified by NF-IL6. Anal. Biochem. 265(1),28-34.

Miller, R. A., and Britigan, B. E. (1997). Role of oxidants in microbial pathophysiology. Clin. Microbiol. Rev. 10(1), 1-18.

Nathan, C. F., and Hibbs, J. B., Jr. (1991). Role of nitric oxide synthesis in macrophage antimicrobial activity. Curr. Opin. Immunol. 3(1), 65-70. 
Nelson, D. E., Ihekwaba, A. E., Elliott, M., Johnson, J. R., Gibney, C. A., Foreman, B. E., Nelson, G., See, V., Horton, C. A., Spiller, D. G., Edwards, S. W., McDowell, H. P., Unitt, J. F., Sullivan, E., Grimley, R., Benson, N., Broomhead, D., Kell, D. B., and White, M. R. (2004). Oscillations in NF-kappaB signaling control the dynamics of gene expression. Science 306(5696), 704-708.

Poltorak, A., He, X., Smirnova, I., Liu, M. Y., Van, H. C., Du, X., Birdwell, D., Alejos, E., Silva, M., Galanos, C., Freudenberg, M., Ricciardi-Castagnoli, P., Layton, B., and Beutler, B. (1998). Defective LPS signaling in C3H/HeJ and C57BL/10ScCr mice: mutations in Tlr4 gene. Science 282(5396), 2085-2088.

Renard, P., Ernest, I., Houbion, A., Art, M., Le, C. H., Raes, M., and Remacle, J. (2001). Development of a sensitive multi-well colorimetric assay for active NFkappaB. Nucleic Acids Res. 29(4), E21.

Revzin, A. (1989) Gel Electrophoresis Assays for DNA-Protein Interactions. BioTechniques 7(4),346-355.

Unanue, E. R. (1981). The regulatory role of macrophages in antigenic stimulation. Part Two: symbiotic relationship between lymphocytes and macrophages. Adv. Immunol. 31, 1136.

Unanue, E. R. (1984). Antigen-presenting function of the macrophage. Annu. Rev. Immunol. 2, 395-428.

Ustyugova, I. V., Frost, L. L., Vandyke, K., Brundage, K. M., Schafer, R., and Barnett, J. B. (2007). 3,4-Dichloropropionaniline Suppresses Normal Macrophage Function. Toxicol. Sci. 97(2), 364-374. 
Wallach, D., Varfolomeev, E. E., Malinin, N. L., Goltsev, Y. V., Kovalenko, A. V., and Boldin, M. P. (1999). Tumor necrosis factor receptor and Fas signaling mechanisms. Annu. Rev. Immunol. 17, 331-367.

Werner, S. L., Barken, D., and Hoffmann, A. (2005). Stimulus specificity of gene expression programs determined by temporal control of IKK activity. Science 309(5742), 18571861.

Wright, S. D., Ramos, R. A., Tobias, P. S., Ulevitch, R. J., and Mathison, J. C. (1990). CD14, a receptor for complexes of lipopolysaccharide (LPS) and LPS binding protein. Science 249(4975), 1431-1433.

Xie, Y. C., Schafer, R., and Barnett, J. B. (1997a). Inhibitory effect of 3,4-dichloropropionaniline on cytokine production by macrophages is associated with LPS-mediated signal transduction. J. Leukoc. Biol. 61(6), 745-752.

Xie, Y. C., Schafer, R., and Barnett, J. B. (1997b). The immunomodulatory effects of the herbicide propanil on murine macrophage interleukin-6 and tumor necrosis factor-alpha production. Toxicol. Appl. Pharmacol. 145(1), 184-191. 


\section{Supporting Information}

\section{Parameter Identification.}

An important aspect of sensitivity analysis is to identify model parameters that can be uniquely determined from the available data. A priori identifiability is one approach to select identifiable parameters given unlimited information about the modeled system (Jacquez and Perry, 1990; Audoly et al., 2001). This assessment of parameter identifiability is intimately linked to the sensitivity of the model results to changes in parameter values. Local sensitivity analysis is defined as the relative change in model variables $\left(y_{j}\right)$ in response to a perturbation of the model parameters $\left(k_{i}\right)$ around a local optimum (Turanyi et al., 2001). The resulting sensitivity function is defined as,

$$
S_{i j}(t)=\frac{k_{i}}{\operatorname{MAX}\left(y_{j},(t)\right)} \cdot \frac{\partial y_{j}(t)}{\partial k_{i}}
$$

where the partial derivative values are scaled by the parameter value and the maximum value of the model variable during the simulation. In practice, the sensitivity function is approximated by obtaining the sensitivity measure $S_{i j}$ at a set of discrete time points, $t_{k}$, and experimental conditions, $[\mathrm{Cn}]_{n}$. In addition, measurements of only a subset the model variables may be obtained experimentally. A reduced sensitivity matrix $(M)$ is then constructed using a subset of the sensitivity measures $\left(S_{i \hat{j}}\left(t_{k}, C n_{n}\right)\right)$ such that

$$
M=\left[S_{\hat{i}}\left(t_{1}, C n_{0}\right), \ldots, S_{\hat{i}}\left(t_{k}, C n_{0}\right), S_{\hat{i j}}\left(t_{1}, C n_{n}\right), \ldots, S_{\hat{i}}\left(t_{k}, C n_{n}\right)\right]^{T}
$$

A set of correlation coefficients between model parameters is calculated from $M$. Parameters that are locally identifiable have correlations with all other parameters between -1 and +1 . Parameters that are not locally identifiable, termed a priori unidentifiable, have correlations of exactly +1 or -1 with at least one other parameter. We are particularly interested in the 
confidence intervals associated with the strength parameter $\alpha$. The correlation coefficients listed in the Supporting Information (Table S1) demonstrate that estimates of the strength parameter $\alpha$ are unique if $K_{D C P A}$ is specified to be $5 \mu \mathrm{M}$, as determined previously (Xie et al., 1997a). 
Table S1: Correlation coefficients of model parameters and initial concentrationof NF- $\kappa B$ in cytosol.

Significantly correlated parameters $(\mathrm{p}<0.05)$ are highlighted in bold.

\begin{tabular}{lcccccc}
\hline Correlation & & & & & & \\
Coefficient & $k 1$ & $k 2$ & $k 3$ & $\alpha$ & $K_{D C P A}$ & $c N(t=0)$ \\
\hline$k 1$ & 1 & 0.422 & 0.422 & 0.671 & -0.667 & 0.664 \\
$k 2$ & 0.422 & 1 & $\mathbf{1}$ & 0.352 & -0.341 & -0.283 \\
$k 3$ & 0.422 & $\mathbf{1}$ & 1 & 0.352 & -0.341 & -0.283 \\
$\alpha$ & 0.671 & 0.352 & 0.352 & 1 & $\mathbf{- 0 . 9 9 9}$ & 0.492 \\
$K_{D C P A}$ & -0.667 & -0.341 & -0.341 & $\mathbf{- 0 . 9 9 9}$ & 1 & -0.514 \\
$c N(t=0)$ & 0.664 & -0.283 & -0.283 & 0.492 & -0.514 & 1 \\
\hline
\end{tabular}




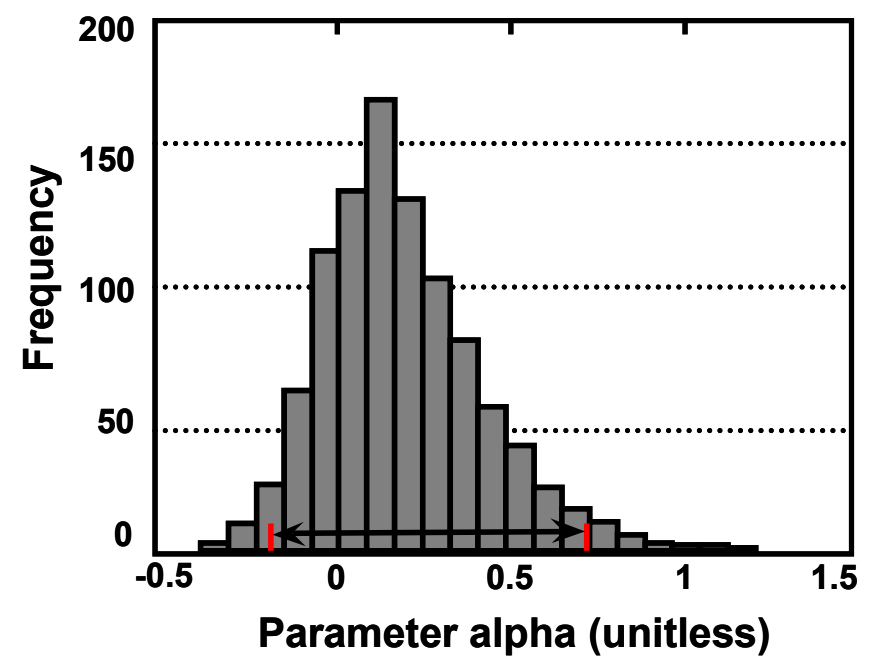

Figure S1: Frequency of parameter values for the strength parameter $\alpha$ determined via bootstrap resampling of the EMSA residuals.

The confidence interval corresponding to $95 \%$ of population of bootstrapped parameter values is highlighted in the figure. 


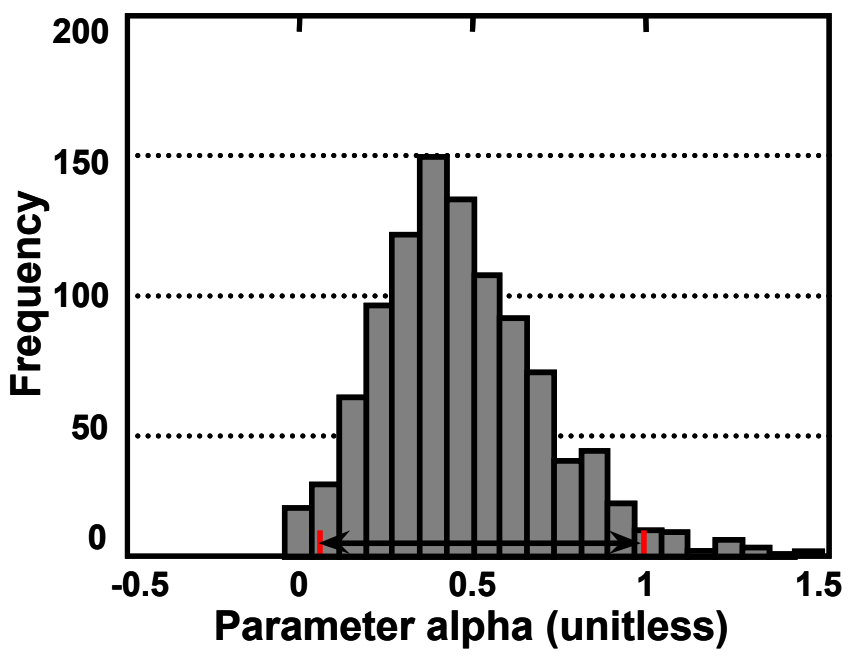

Figure S2: Frequency of parameter values for the strength parameter $\alpha$ determined via bootstrap resampling of the NTFA residuals.

The confidence interval corresponding to $95 \%$ of population of bootstrapped parameter values is highlighted by the double arrow in the figure. 


\section{References}

Jacquez, J. A., and Perry, T. (1990). Parameter estimation: local identifiability of parameters. Am. J Physiol 258(4 Pt 1), E727-E736.

Audoly, S., Bellu, G., D'Angio, L., Saccomani, M. P., and Cobelli, C. (2001). Global identifiability of nonlinear models of biological systems. IEEE Trans. Biomed. Eng $48(1), 55-65$.

Turanyi, T., Rabitz, H., in Sensitivity Analysis, eds Saltelli A, Chan K, \& Scott, E. M. (John Wiley, New York), pp 81-100 (2000).

Xie, Y. C., Schafer, R., and Barnett, J. B. (1997a). Inhibitory effect of 3,4-dichloropropionaniline on cytokine production by macrophages is associated with LPS-mediated signal transduction. J. Leukoc. Biol. 61(6), 745-752. 


\section{CHAPTER 5.}

\section{GENERAL DISCUSSION}

The immunotoxic effects of propanil on different components of the immune system have been demonstrated in numerous studies. The current dissertation focuses on one of the major components of the innate immune system, macrophages. The first section discusses the ability of macrophages to initiate the immune response by recognizing and phagocytosing bacteria in the presence of propanil. It is followed by an examination of inflammatory mediators, such as cytokines, prostaglandins, ROS and RNS, produced in response to bacterial challenge. The second section focuses on alterations in NF-kB signaling, specifically, on oscillatory behavior of the activated transcription factor and modulation of its binding activity by propanil.

\section{Propanil suppresses normal macrophage function.}

The production of a number of chemokines and cytokines by macrophages are important immune mediators in both innate and adaptive immune responses. Two of the important cytokines produced by macrophages are IL- 6 and TNF- $\alpha$. Ex vivo and in vitro studies have previously demonstrated the inhibitory effects of propanil on the production of both cytokines by mouse macrophages after 24 hr LPS stimulation (Xie et al., 1997a; Xie et al., 1997b; Frost et al., 2002). The current study demonstrated similar inhibition of TNF- $\alpha$ production by the human monocytic cell line, THP-1 (Ustyugova et al., 2007).

TNF- $\alpha$ is mainly produced by activated macrophages and T lymphocytes (Jadus et al., 1986; Cuturi et al., 1987). It stimulates endothelial cells to produce IL-1, hematopoeitic growth factor, arachidonic acid metabolites, thus promoting an inflammatory response (Libby et al., 1986; Pober et al., 1986). It also induces the expression of adhesion molecules, such as ICAMs and VCAMs, which makes endothelial cells adhesive and leads to accumulation of leukocytes at 
local sites of inflammation (Bevilacqua, 1993). TNF- $\alpha$ also directly affects neutrophils, causing degranulation of their preformed granules, stimulating phagocytic activity and generating ROS (Figari et al., 1987; Shalaby et al., 1987; Sayers et al., 1988). TNF- $\alpha$ is known to stimulate the production of other inflammatory cytokines, such as IL-1, IL-6, GM-CSF and even activates its own transcription by leukocytes at the site of immune reaction (Broudy et al., 1986; Libby et al., 1986; Cicco et al., 1990). During the development of an adaptive immune response, TNF- $\alpha$ may act as a co-stimulator for $\mathrm{T}$ cell activation. By stimulating other macrophages in the inflamed area to produce IL-1 and IL- 6 cytokines, TNF- $\alpha$ indirectly stimulates antibody production by B cells, thus mediating humoral response (Ghiara et al., 1987).

TNF- $\alpha$ synthesis is dependent on the transcription factor NF-kB (Collart et al., 1990). Upon LPS stimulation, NF- $\mathrm{kB}$ translocates into the nucleus where it binds the promoter regions of genes responsible for cytokine production. A series of studies were performed using the mouse peritoneal macrophage cell line, IC-21 to determine if the reduction in cytokine production after exposure to propanil was due to effects on NF- $\mathrm{B}$ activation. Propanil was demonstrated to reduce TNF- $\alpha$ promoter activity in regions that contain NF- $\mathrm{kB}$ binding sites (Frost et al., 2001). In addition, nuclear levels of the p65 subunit of NF- $\mathrm{BB}$ were reduced, as well as DNA binding of both the p65/p50 heterodimer and p50/p50 homodimers of NF- $\mathrm{kB}$ was inhibited after exposure to propanil (Frost et al., 2001). Overall, these results suggest that propanil may reduce cytokine production through effects on NF- $\mathrm{\kappa B}$ activation.

The ability of macrophages to phagocytose fluorescent beads and the pathogenic bacteria, Listeria monocytogenes was decreased. This process can be interrupted at several levels, starting with receptor recognition and binding, followed by bacterial engulfment and final destruction of the microorganism. Two types of receptors are involved in recognition and binding: complement 
receptor 3 (CR3) and Fc gamma receptors (FcyRs). CR3 binds C3bi on complement-opsonized targets, whereas Fc $\gamma$ Rs bind to immunoglobulin G (IgG)-coated targets. First, Fc $\gamma$ R-mediated uptake is accompanied by pseudopod extension and membrane ruffling, whereas complementopsonized targets sink into the cell, producing little protrusive activity (Kaplan, 1977). Second, Fc $\gamma \mathrm{R}$ ligation is accompanied by the activation of the respiratory burst, and by the production of arachidonic acid metabolites and cytokines, such as TNF- $\alpha$. C3bi-dependent uptake occurs in the absence of any of these proinflammatory signals (Aderem et al., 1985; Wright and Silverstein, 1983; Yamamoto and Johnston, 1984; Scholl et al., 1992; Stein and Gordon, 1991).

The Rho family of small guanosine triphosphatases (GTPases) is involved in the reorganization of filamentous actin structures in response to extracellular stimuli (Hall, 1998). Rho induces the assembly of contractile actomyosin filaments, whereas Rac and Cdc 42 control actin polymerization into lamellipodial and filopodial membrane protrusions, respectively (Ridley and Hall, 1992; Ridley et al., 1995; Nobes and Hall., 1995). In addition, these GTPases

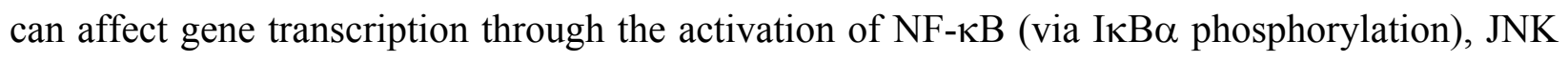
and p38 mitogen-activated protein kinase (MAPK) (Perona et al., 1997; Coso et al., 1995; Minden et al., 1996; Teramoto et al., 1996). Rac regulates the reduced form of NADPH oxidase, an enzyme responsible for the respiratory burst, specifically through assembly of the p47 and p67 oxidase components on the cytosolic face of plasma membrane via cytoskeletal reorganization (Gabig et al., 1995).

Propanil-treated cells were able to phagocytose a smaller number of fluorescent beads, which indicates the disruption of receptor binding or inability of macrophages to reorganize their actin filaments in response to stimuli. Previous studies have demonstrated that propanil abrogates the initial IP3-mediated calcium release (Xie et al., 1997b). However, binding of LPS 
to macrophages (Xie et al., 1997b) as well as mobility of plasma membrane lipid hydrocarbon chains were not affected by propanil (Brundage et al, 2003).

The transient increase in intracellular calcium has been demonstrated in both macrophages and neutophils (Geiszt et al., 2001; Larsen et al., 2000). Calcium is also important in the activation of the NADPH oxidase (Dusi et al., 1993; Foyouzi-Youssefi et al., 1997; Geiszt et al., 1999; Granfeldt et al., 2002; Zhou et al., 1997). Translocation of the phox proteins, p47 and p67 is triggered by an increase in intracellular calcium (Dusi et al., 1993; Zhou et al., 1997). Supporting data on $\mathrm{Ca}^{2+}$-inlux inhibition was obtained from in vitro studies in human Jurkat $\mathrm{T}$ cell line. Fluorescent measurement of intracellular $\mathrm{Ca}^{2+}$ in anti-CD3 stimulated Jurkat and primary mouse cells revealed a concentration-dependent reduction in $\mathrm{Ca}^{2+}$ levels after propanil exposure (Lewis et al, unpublished data).

Reduced bactericidal activity of propanil-treated macrophages was partially explained by their decreased ability to produce a respiratory burst. Listeria monocytogenes clearance is a result of NADPH oxidase activity (Dinauer et al., 1997; Shiloh et al., 1999), and is accompanied by endogenous TNF- $\alpha$ production (Havell et al., 1989; Kato et al., 1989; Leenen et al., 1994). Active NADPH oxidase produces hydrogen peroxide and hydroxyl radicals $\left(\mathrm{OH}^{-}\right)$which are detectable intracellulary by confocal microscopy. The decreased amount of ROS observed in propanil-treated macrophages may partially explain their reduced listericidal activity.

Another component of the respiratory burst examined in Chapter 2 was RNS, produced by inducible nitric oxide synthase (iNOS) as a result of LPS stimulation or a combination of treatment with cytokines, such as, TNF- $\alpha$ and IL-1 $\beta$ (Lowenstein et al., 1993; Xie et al., 1993). Short-lived NO reacts with ROS giving rise to a number of toxic nitrogen compounds, such as peroxynitrite (ONOO-) which in turn decompose into additional nitrates and nitrites. Decreased 
levels of nitrites, which are partially generated from the reaction with ROS, demonstrated an inhibition of RNS generation in propanil-treated macrophages. Another cause of low RNS production is the level of iNOS gene expression. In macrophages, it is regulated mainly at the transcriptional level, particularly by NF- $\mathrm{BB}$, which binds to multiple sites on the iNOS gene promoter (Xie et al., 1993). Decreased levels of iNOS protein were detected in propanil-treated cells, which can be explained by a low NF-kB transcriptional activity in macrophages (Frost $e t$ al., 2002). Interestingly, NF-kB activity can be also upregulated in response to ROS, suggesting a novel positive feedback loop in which NO might activate transcription factors, which in turn could increase NO synthesis by causing additional iNOS expression (Schreck et al., 1991).

The last inflammatory mediator discussed in Chapter 3 is $\mathrm{PGE}_{2}$. Its production is also dependent on calcium influx which causes translocation of cytosolic $\mathrm{PLA}_{2}$ enzyme to the membrane resulting in its activation. Another signal for $\mathrm{CPLA}_{2}$ activation is PKC-dependant phosphorylation which triggers the production of free arachidonic acid (AA) (Kramer and Sharp, 1997). Phosphorylation of $\mathrm{cPLA}_{2}$ protein studied in activated macrophages was not affected by propanil exposure. Next, the release of AA into the media was evaluated, but no effects of propanil were observed. The last enzymatic step in prostaglandins production is the conversion of AA to $\mathrm{PGH}_{2}$ by cyclooxygenase-1, -2 enzymes (William and Shakter, 1997). COX-2 is rapidly induced by inflammatory and mitogenic stimuli, and its transcription is activated by several transcription factors, such as AP-1, NF-IL6, NF-kB and NF-AT (reviewed in Williams et al., 1999). However, neither the levels of COX-2 nor its enzymatic activity were affected by propanil treatment. Phosphorylation of $\mathrm{CPLA}_{2}$ protein was not changed as well. So far, the mechanism by which propanil dramatically decreases $\mathrm{PGE}_{2}$ production is still unknown. 
Among possible mechanisms is the decreased availability of membrane phospholipids for $\mathrm{cPLA}_{2}$ and reduced secretion of prostaglandins into the extracellular space due to the impaired function of prostaglandins transporter (PGT) (Schuster, 1998). PGs have low intrinsic plasma membrane permeabilities, they cross it twice: first upon release from the cytosol into the blood, and again upon cellular uptake prior to oxidation. PGT catalyzes the rapid, specific, and highaffinity uptake of PGE2, PGF2 alpha, PGD2, 8-iso-PGF2 alpha, and thromboxane B2 (Schuster, 1998). Therefore, the decreased levels of $\mathrm{PGE}_{2}$ secreted into the media are hypothesized to be due an inhibition of this transporter.

\section{Propanil affects LPS-induced NF-kB activation in macrophages}

Propanil has been previously shown to decrease TNF- $\alpha$ in murine macrophages and a human monocytic cell line. The reduction of protein levels corresponded to reduced mRNA levels of this cytokine (Xiet et al., 1997b). In activated macrophages, TNF- $\alpha$ is produced in response to a variety of stimuli and is strongly dependent on NF- $\mathrm{KB}$ transcription factor (Trede et al., 1995; Frost et al., 2002). However, other transcription factors, such as AP-1, EGR, Elk and Ets have been implicated in cooperative binding to the TNF- $\alpha$ promoter (Tsai et al., 1996; Sheppard et al., 1999; Zagariya et al., 1998). Mutation studies of $\kappa \mathrm{B}$ binding sites within the TNF- $\alpha$ promoter demonstrated drastic effects on its transcriptional activity (Collart et al., 1990; Kuprash et al., 1999; Shakhov et al., 1990). Examination of nuclear levels of the p65 subunit of NF- $\kappa \mathrm{B}$ in LPS-stimulated macrophages revealed reduced levels of this transcription factor after exposure to propanil. In addition, it was demonstrated that there was decreased DNA binding of both the p65/p50 heterodimer and p50/p50 homodimers of NF- $\mathrm{kB}$ after exposure to propanil

(Frost et al., 2001). Overall, these results suggested that propanil may reduce cytokine production through effects on NF- $\mathrm{KB}$ binding activity. 
The ability of NF- $\mathrm{kB}$ to regulate gene expression is controlled by interactions with other

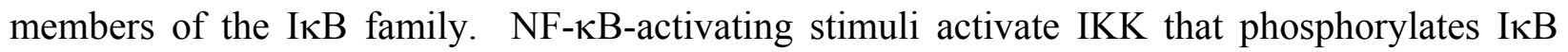
isoforms on Ser32 and Ser36 and NF-kB on Ser536 and Ser276 (DiDonato et al., 1997; Sakurai et al., 1999). Phosphorylated IкBs are then ubiquitinated and degraded by the $26 \mathrm{~S}$ proteosome, freeing NF- $\mathrm{kB}$ dimers to translocate to the nucleus and bind to DNA.

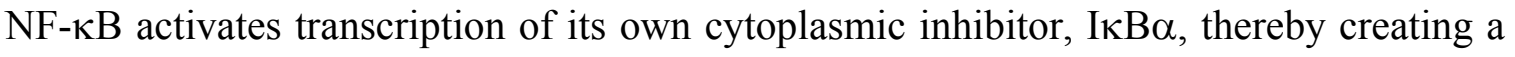
negative feedback loop for its own activity. IкB $\alpha$ contains both nuclear localization and export

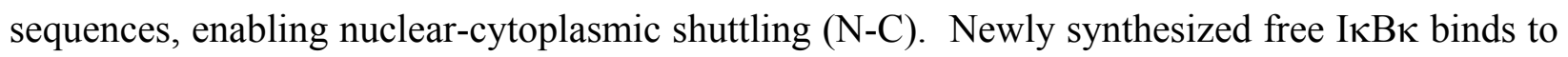
nuclear NF-kB, causing exportation of the complex to the cytoplasm (Arenzana-Seisdedos et al.,

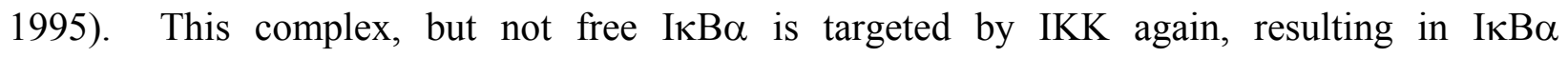
phosphorylation and degradation (Nelson et al., 2002; Zandi et al., 1998). This N-C shuttling results in oscillatory behavior of activated NF-kB (Hoffmann et al., 2002). These oscillations are asynchronous and decrease (damp) in frequency with increased IKB $\alpha$ transcription (Nelson et al., 2004).

To characterize NF-kB binding activity, macrophages were stimulated with LPS and exposed to propanil in study three (Chapter 4). Two independent assays were used to detect damped oscillatory behavior of NF- $\mathrm{KB}$ with a different degree of sensitivity and reproducibility. Based on experimental data, a kinetic model simulating NF- $\mathrm{KB}$ activation process was developed to capture the dynamic of its regulation. Propanil treatment resulted in a potentiation of early NF- $\kappa B$ activation by LPS. This earlier activation might result in altered frequency of the oscillations that, in turn, will change the transcriptional regulation of some genes. 
Nelson et al. (2004) demonstrated that transcription of target genes was also dependent on oscillation persistence, which was not only triggered by cycles of IкB $\alpha$ degradation and resynthesis, but by cycles of p65 phosphorylation and dephosphorylation. Changes in number, period and amplitude of oscillations were observed by Nelson at al. (2004) in HeLa cell line continuously stimulated with TNF- $\alpha$. Nelson and colleagues (2004) also suggested that changes in oscillations could have functional consequences on NF- $\mathrm{KB}$ signaling in response to different stimuli. Therefore, inhibition of NF-kB-inducible cytokines, TNF- $\alpha$ and IL-6, observed in propanil-treated cells at the later time points (12 and $24 \mathrm{~h}$ after sustained LPS stimulation) may be a result of the early potentiation of NF- $\mathrm{kB}$ activation caused by a shift in oscillatory behavior. Therefore, treating cells with propanil may shift the dynamic equilibrium of active NF- $\mathrm{KB}$ among the corresponding DNA binding sites within the nucleus, causing imbalance between

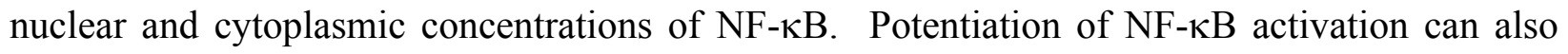
result in asynchronized binding of other transcription factors which normally bind cooperatively to the promoters of certain genes. All these alterations may result in a change in the profile of NF-кB-inducible genes.

In summary, our work has demonstrated that propanil exposure significantly inhibits a number of pro-inflammatory mediators, such as TNF- $\alpha$ and prostaglandins in activated macrophages. Propanil also suppressed the ability of these cells to perform phagocytosis and generate bactericidal ROS and RNS. Evaluation of NF- $\mathrm{kB}$ binding activity demonstrated damped oscillatory behavior following LPS stimulation which was altered by propanil suggesting a molecular mechanism of its immunotoxic effects. The changes described in the dissertation examine the effects of propanil at the molecular and cellular levels; however, these changes can be translated into the organ and systemic effects. For instance, exposure to propanil 
could possibly inhibit a person's ability to initiate an innate immune response by suppressing normal macrophage functions, such as phagocytosis and respiratory burst. The development of an adaptive immune response is also helped by macrophage's $\mathrm{Ag}$ presentation to $\mathrm{CD} 4^{+} \mathrm{T}$ helper cells and cytokine production, which attracts other cell types to the area of inflammation and creates a favorable environment for the bacterial clearance as well as proliferation of the immune response. Thus, applicators and propanil's manufacturers exposed to propanil are potentially vulnerable to bacterial and viral infections, and their tumor-surveillance abilities could be compromised.

The ability of macrophages to phagocytose apoptotic cells is another important function for normal homeostasis as well as resolution of inflammatory conditions. Macrophages remove dying cells which allows for the fast "clean up" of the infected area, e.g. phagocytosis of dying neutrophils', and this also accelerates the healing processes. Propanil exposure, which inhibits phagocytosis of pathogenic bacteria, might also suppress the removal of apoptotic cells resulting in prolongation of inflammatory condition.

The studies of an anti-inflammatory potential of propanil yield very promising results, demonstrating an inhibition of $\mathrm{PGE}_{2}$ production by $1-5 \mu \mathrm{M}$ concentrations of propanil. This low micromolar concentration of propanil does not affect cell viability and did not appear to be toxic during the time-points observed (up to $48 \mathrm{hr}$ ); however, there are no data available yet on a longterm toxicity of propanil.

Changes in $\mathrm{NF}-\kappa \mathrm{B}$ activation profile could lead to a large number of effects. NF- $\mathrm{B}$ is one of the most ubiquitous transcription factors responsible for the transcription of 150 genes in many cell types. Almost all inflammatory mediators discussed in the dissertation are NF- $\kappa$ inducible, e.g. iNOS, COX-2, TNF- $\alpha$, IL-6. Macrophages have to be fully activated in order to 
fulfill their bactericidal potential; therefore, NF- $\mathrm{BB}$ activation enables them to express inflammatory cytokines and upregulates respiratory burst molecules.

The oscillatory behavior of NF- $\mathrm{kB}$ is an important part of the activation process. More studies are needed to describe this novel process in order to learn how NF-kB activation can be altered or adjusted through the modification of the oscillations. These fine adjustments of the NF- $\kappa B$ may help to manage many inflammatory and autoimmune conditions because the complete inhibition of this transcription factor may affect other normal biological functions.

An important part of any toxicological study would be an investigation of the effects of metabolites of the toxic compound. Most of the studies were done in vitro, where propanil was applied directly to macrophages. Upon entry into the human body, propanil is rapidly metabolized by the liver; therefore, macrophages would probably encounter propanil's metabolite, DCA. Future studies need to examine the effects of DCA on macrophages and other cell types of immune system. 


\section{References}

Aderem, A. A., Wright, S. D., Silverstein, S. C., and Cohn, Z. A. (1985). Ligated complement receptors do not activate the arachidonic acid cascade in resident peritoneal macrophages. J.Exp.Med. 161(3), 617-622.

Arenzana-Seisdedos, F., Turpin, P., Rodriguez, M., Thomas, D., Hay, R. T., Virelizier, J. L., and Dargemont, C. (1997). Nuclear localization of I kappa B alpha promotes active transport of NF-kappa B from the nucleus to the cytoplasm. J. Cell Sci. 110 ( Pt 3), 369-378.

Bevilacqua, M .P. (1993). Endothelial-leukocyte adhesion molecules. Annu. Rev. Immunol. 11:767-804.

Cicco, N. A., Lindemann, A., Content, J., Vandenbussche, P., Lubbert, M., Gauss, J., Mertelsmann, R., and Herrmann, F. (1990). Inducible production of interleukin-6 by human polymorphonuclear neutrophils: role of granulocyte-macrophage colonystimulating factor and tumor necrosis factor-alpha. Blood 75(10), 2049-2052.

Collart, M. A., Baeuerle, P., and Vassalli, P. (1990). Regulation of tumor necrosis factor alpha transcription in macrophages: involvement of four kappa B-like motifs and of constitutive and inducible forms of NF-kappa B. Mol. Cell Biol. 10(4), 1498-1506.

Coso, O. A., Chiariello, M., Yu, J. C., Teramoto, H., Crespo, P., Xu, N., Miki, T., and Gutkind, J. S. (1995). The small GTP-binding proteins Rac1 and Cdc42 regulate the activity of the JNK/SAPK signaling pathway. Cell 81(7), 1137-1146.

Cuturi, M. C., Murphy, M., Costa-Giomi, M. P., Weinmann, R., Perussia, B., and Trinchieri, G. (1987). Independent regulation of tumor necrosis factor and lymphotoxin production by human peripheral blood lymphocytes. J.Exp.Med. 165(6), 1581-1594. 
DiDonato, J. A., Hayakawa, M., Rothwarf, D. M., Zandi, E., and Karin, M. (1997). A cytokineresponsive IkappaB kinase that activates the transcription factor NF-kappaB. Nature 388(6642), 548-554.

Dinauer, M. C., Deck, M. B., and Unanue, E. R. (1997). Mice lacking reduced nicotinamide adenine dinucleotide phosphate oxidase activity show increased susceptibility to early infection with Listeria monocytogenes. J Immunol. 158(12), 5581-5583.

Dusi, S., Della, B., V, Grzeskowiak, M., and Rossi, F. (1993). Relationship between phosphorylation and translocation to the plasma membrane of p47phox and p67phox and activation of the NADPH oxidase in normal and $\mathrm{Ca}(2+)$-depleted human neutrophils. Biochem. J 290 ( Pt 1), 173-178.

Figari, I. S., Mori, N. A., and Palladino, M. A., Jr. (1987). Regulation of neutrophil migration and superoxide production by recombinant tumor necrosis factors-alpha and -beta: comparison to recombinant interferon-gamma and interleukin-1 alpha. Blood 70(4), 979984.

Foyouzi-Youssefi, R., Petersson, F., Lew, D. P., Krause, K. H., and Nusse, O. (1997). Chemoattractant-induced respiratory burst: increases in cytosolic $\mathrm{Ca} 2+$ concentrations are essential and synergize with a kinetically distinct second signal. Biochem. J 322 ( Pt 3), 709-718.

Frost, L. L., Neeley, Y. X., Schafer, R., Gibson, L. F., and Barnett, J. B. (2001). Propanil inhibits tumor necrosis factor-alpha production by reducing nuclear levels of the transcription factor nuclear factor-kappab in the macrophage cell line ic-21. Toxicol. Appl. Pharmacol. 172(3), 186-193. 
Gabig, T. G., Crean, C. D., Mantel, P. L., and Rosli, R. (1995). Function of wild-type or mutant Rac2 and Rap1a GTPases in differentiated HL60 cell NADPH oxidase activation. Blood 85(3), 804-811.

Geiszt, M., Szeberenyi, J. B., Kaldi, K., and Ligeti, E. (1999). Role of different Ca2+ sources in the superoxide production of human neutrophil granulocytes. Free Radic. Biol. Med. 26(9-10), 1092-1099.

Geiszt, M., Dagher, M. C., Molnar, G., Havasi, A., Faure, J., Paclet, M. H., Morel, F., and Ligeti, E. (2001). Characterization of membrane-localized and cytosolic Rac-GTPase-activating proteins in human neutrophil granulocytes: contribution to the regulation of NADPH oxidase. Biochem. J 355(Pt 3), 851-858.

Ghiara, P., Boraschi, D., Nencioni, L., Ghezzi, P., and Tagliabue, A. (1987). Enhancement of in vivo immune response by tumor necrosis factor. J.Immunol. 139(11), 3676-3679.

Granfeldt, D., Samuelsson, M., and Karlsson, A. (2002). Capacitative Ca2+ influx and activation of the neutrophil respiratory burst. Different regulation of plasma membrane- and granule-localized NADPH-oxidase. J Leukoc. Biol. 71(4), 611-617.

Hall, A. (1998). Rho GTPases and the actin cytoskeleton. Science 279(5350), 509-514.

Havell, E. A. (1989). Evidence that tumor necrosis factor has an important role in antibacterial resistance. J Immunol. 143(9), 2894-2899.

Jadus, M. R., and Peck, A. B. (1986). Naturally occurring, spleen-associated suppressor activity of the newborn mouse. Biochemical and functional identification of three monokines secreted by newborn suppressor-inducer monocytes. Scand.J.Immunol. 23(1), 35-44.

Kaplan, G. (1977). Differences in the mode of phagocytosis with Fc and C3 receptors in macrophages. Scand.J.Immunol. 6(8), 797-807. 
Kato, K., Nakane, A., Minagawa, T., Kasai, N., Yamamoto, K., Sato, N., and Tsuruoka, N. (1989). Human tumor necrosis factor increases the resistance against Listeria infection in mice. Med.Microbiol.Immunol. 178(6), 337-346.

Kramer, R. M., and Sharp, J. D. (1997). Structure, function and regulation of Ca2+-sensitive cytosolic phospholipase A2 (cPLA2). FEBS Lett. 410(1), 49-53.

Kuprash, D. V., Udalova, I. A., Turetskaya, R. L., Kwiatkowski, D., Rice, N. R., and Nedospasov, S. A. (1999). Similarities and differences between human and murine TNF promoters in their response to lipopolysaccharide. J.Immunol. 162(7), 4045-4052.

Leenen, P. J., Canono, B. P., Drevets, D. A., Voerman, J. S., and Campbell, P. A. (1994). TNFalpha and IFN-gamma stimulate a macrophage precursor cell line to kill Listeria monocytogenes in a nitric oxide-independent manner. J.Immunol. 153(11), 5141-5147.

Libby, P., Ordovas, J. M., Auger, K. R., Robbins, A. H., Birinyi, L. K., and Dinarello, C. A. (1986). Endotoxin and tumor necrosis factor induce interleukin-1 gene expression in adult human vascular endothelial cells. Am.J.Pathol. 124(2), 179-185.

Lowenstein, C. J., Alley, E. W., Raval, P., Snowman, A. M., Snyder, S. H., Russell, S. W., and Murphy, W. J. (1993). Macrophage nitric oxide synthase gene: two upstream regions mediate induction by interferon gamma and lipopolysaccharide. Proc.Natl.Acad.Sci.U.S.A 90(20), 9730-9734.

Minden, A., Lin, A., Claret, F. X., Abo, A., and Karin, M. (1995). Selective activation of the JNK signaling cascade and c-Jun transcriptional activity by the small GTPases Rac and Cdc42Hs. Cell 81(7), 1147-1157.

Nelson, D. E., Ihekwaba, A. E., Elliott, M., Johnson, J. R., Gibney, C. A., Foreman, B. E., Nelson, G., See, V., Horton, C. A., Spiller, D. G., Edwards, S. W., McDowell, H. P., 
Unitt, J. F., Sullivan, E., Grimley, R., Benson, N., Broomhead, D., Kell, D. B., and White, M. R. (2004). Oscillations in NF-kappaB signaling control the dynamics of gene expression. Science 306(5696), 704-708.

Nelson, G., Paraoan, L., Spiller, D. G., Wilde, G. J., Browne, M. A., Djali, P. K., Unitt, J. F., Sullivan, E., Floettmann, E., and White, M. R. (2002). Multi-parameter analysis of the kinetics of NF-kappaB signalling and transcription in single living cells. J.Cell Sci. 115(Pt 6), 1137-1148.

Nobes, C. D., and Hall, A. (1995). Rho, rac, and cdc42 GTPases regulate the assembly of multimolecular focal complexes associated with actin stress fibers, lamellipodia, and filopodia. Cell 81(1), 53-62.

Perona, R., Montaner, S., Saniger, L., Sanchez-Perez, I., Bravo, R., and Lacal, J. C. (1997). Activation of the nuclear factor-kappaB by Rho, CDC42, and Rac-1 proteins. Genes Dev. 11(4), 463-475.

Pober, J. S., Gimbrone, M. A., Jr., Lapierre, L. A., Mendrick, D. L., Fiers, W., Rothlein, R., and Springer, T. A. (1986). Overlapping patterns of activation of human endothelial cells by interleukin 1, tumor necrosis factor, and immune interferon. J.Immunol. 137(6), 18931896.

Ridley, A. J., and Hall, A. (1992). The small GTP-binding protein rho regulates the assembly of focal adhesions and actin stress fibers in response to growth factors. Cell 70(3), 389-399.

Ridley, A. J., Paterson, H. F., Johnston, C. L., Diekmann, D., and Hall, A. (1992). The small GTP-binding protein rac regulates growth factor-induced membrane ruffling. Cell 70(3), 401-410. 
Sakurai, H., Chiba, H., Miyoshi, H., Sugita, T., and Toriumi, W. (1999). IkappaB kinases phosphorylate NF-kappaB p65 subunit on serine 536 in the transactivation domain. J. Biol. Chem. 274(43), 30353-30356.

Sayers, T. J., Wiltrout, T. A., Bull, C. A., Denn, A. C., III, Pilaro, A. M., and Lokesh, B. (1988). Effect of cytokines on polymorphonuclear neutrophil infiltration in the mouse. Prostaglandin- and leukotriene-independent induction of infiltration by IL-1 and tumor necrosis factor. J.Immunol. 141(5), 1670-1677.

Scholl, P. R., Ahern, D., and Geha, R. S. (1992). Protein tyrosine phosphorylation induced via the IgG receptors Fe gamma Ri and Fe gamma RII in the human monocytic cell line THP-1. J.Immunol. 149(5), 1751-1757.

Schreck, R., Rieber, P., and Baeuerle, P. A. (1991). Reactive oxygen intermediates as apparently widely used messengers in the activation of the NF-kappa B transcription factor and HIV-1. EMBO J. 10(8), 2247-2258.

Schuster, V. L. (1998). Molecular mechanisms of prostaglandin transport. Annu.Rev.Physiol 60, 221-242.

Shakhov, A. N., Collart, M. A., Vassalli, P., Nedospasov, S. A., and Jongeneel, C. V. (1990). Kappa B-type enhancers are involved in lipopolysaccharide-mediated transcriptional activation of the tumor necrosis factor alpha gene in primary macrophages. J.Exp.Med. 171(1), 35-47.

Shalaby, M. R., Palladino, M. A., Jr., Hirabayashi, S. E., Eessalu, T. E., Lewis, G. D., Shepard, H. M., and Aggarwal, B. B. (1987). Receptor binding and activation of polymorphonuclear neutrophils by tumor necrosis factor-alpha. J.Leukoc.Biol. 41(3), 196-204. 
Sheppard, K. A., Rose, D. W., Haque, Z. K., Kurokawa, R., McInerney, E., Westin, S., Thanos, D., Rosenfeld, M. G., Glass, C. K., and Collins, T. (1999) Transcriptional activation by NF-kappaB requires multiple coactivators. Mol.Cell Biol. 19(9), 6367-6378.

Shiloh, M. U., MacMicking, J. D., Nicholson, S., Brause, J. E., Potter, S., Marino, M., Fang, F., Dinauer, M., and Nathan, C. (1999). Phenotype of mice and macrophages deficient in both phagocyte oxidase and inducible nitric oxide synthase. Immunity. 10(1), 29-38.

Stein, M., and Gordon, S. (1991). Regulation of tumor necrosis factor (TNF) release by murine peritoneal macrophages: role of cell stimulation and specific phagocytic plasma membrane receptors. Eur.J.Immunol. 21(2), 431-437.

Teramoto, H., Crespo, P., Coso, O. A., Igishi, T., Xu, N., and Gutkind, J. S. (1996).The small GTP-binding protein rho activates c-Jun N-terminal kinases/stress-activated protein kinases in human kidney 293 T cells. Evidence for a Pak-independent signaling pathway. J.Biol.Chem. 271(42), 25731-25734.

Trede, N. S., Tsytsykova, A. V., Chatila, T., Goldfeld, A. E., and Geha, R. S. (1995). Transcriptional activation of the human TNF-alpha promoter by superantigen in human monocytic cells: role of NF-kappa B. J.Immunol. 155(2), 902-908.

Tsai, E. Y., Falvo, J. V., Tsytsykova, A. V., Barczak, A. K., Reimold, A. M., Glimcher, L. H., Fenton, M. J., Gordon, D. C., Dunn, I. F., and Goldfeld, A. E. (2000). A lipopolysaccharide-specific enhancer complex involving Ets, Elk-1, Sp1, and CREB binding protein and p300 is recruited to the tumor necrosis factor alpha promoter in vivo. Mol.Cell Biol. 20(16), 6084-6094.

Williams, C. S., Mann, M., and DuBois, R. N. (1999). The role of cyclooxygenases in inflammation, cancer, and development. Oncogene 18(55), 7908-7916. 
Williams, J. A., and Shacter, E. (1997). Regulation of macrophage cytokine production by prostaglandin E2. Distinct roles of cyclooxygenase-1 and -2. J Biol. Chem. 272(41), 25693-25699.

Wright, S. D., and Silverstein, S. C. (1983). Receptors for C3b and C3bi promote phagocytosis but not the release of toxic oxygen from human phagocytes. J.Exp.Med. 158(6), 20162023.

Xie, Q. W., Whisnant, R., and Nathan, C. (1993). Promoter of the mouse gene encoding calciumindependent nitric oxide synthase confers inducibility by interferon gamma and bacterial lipopolysaccharide. J Exp. Med. 177(6), 1779-1784.

Xie, Y. C., Schafer, R., and Barnett, J. B. (1997). Inhibitory effect of 3,4-dichloro-propionaniline on cytokine production by macrophages is associated with LPS-mediated signal transduction. J. Leukoc. Biol. 61(6), 745-752.

Xie, Y. C., Schafer, R., and Barnett, J. B. (1997). The immunomodulatory effects of the herbicide propanil on murine macrophage interleukin- 6 and tumor necrosis factor-alpha production. Toxicol. Appl. Pharmacol. 145(1), 184-191.

Yamamoto, K., and Johnston, R. B., Jr. (1984).Dissociation of phagocytosis from stimulation of the oxidative metabolic burst in macrophages. J.Exp.Med. 159(2), 405-416.

Zagariya, A., Mungre, S., Lovis, R., Birrer, M., Ness, S., Thimmapaya, B., and Pope, R. (1998) .Tumor necrosis factor alpha gene regulation: enhancement of C/EBPbeta-induced activation by c-Jun. Mol.Cell Biol. 18(5), 2815-2824.

Zandi, E., Chen, Y., and Karin, M. (1998). Direct phosphorylation of IkappaB by IKKalpha and IKKbeta: discrimination between free and NF-kappaB-bound substrate. Science 281(5381), 1360-1363. 
Zhao, W., Schafer, R., and Barnett, J. B. (1998). Cytokine production by C57BL/6 mouse spleen cells is selectively reduced by exposure to propanil. J. Toxicol. Environ. Health A 55(2), 107-120.

Zhou, H., Duncan, R. F., Robison, T. W., Gao, L., and Forman, H. J. (1997). Ca(2+)-dependent p47phox translocation in hydroperoxide modulation of the alveolar macrophage respiratory burst. Am. J Physiol 273(5 Pt 1), L1042-L1047. 